\title{
AVALIAÇÃO DA DENSIDADE ÓTICA E DAS DENSIDADES RADIOGRÁFICAS, UTILIZANDO FILMES RADIOGRÁFICOS AGFA DENTUS M2 “COMFORT" PROCESSADOS EM TRÊS SOLUÇÕES DE PROCESSAMENTO EM DIFERENTES TEMPERATURAS.
}

\section{Mariela Siqueira Gião Dezotti}

Dissertação apresentada à Faculdade de Odontologia de Bauru da Universidade de São Paulo, como parte dos requisitos para obtenção do título de Mestre em Odontologia, na área de Diagnóstico Bucal. 


\section{AVALIAÇÃO DA DENSIDADE ÓTICA E DAS DENSIDADES RADIOGRÁFICAS, UTILIZANDO FILMES RADIOGRÁFICOS AGFA DENTUS M2 “COMFORT" PROCESSADOS EM TRÊS SOLUÇÕES DE PROCESSAMENTO EM DIFERENTES TEMPERATURAS.}

Mariela Siqueira Gião Dezotti

Dissertação apresentada à Faculdade de Odontologia de Bauru da Universidade de São Paulo, como parte dos requisitos para obtenção do título de Mestre em Odontologia, na área de Diagnóstico Bucal. (Edição Revista)

Orientador: Professor Dr. Orivaldo Tavano 
Dezotti, Mariela Siqueira Gião

D535a Avaliação da Densidade Ótica e das Densidade Radiográficas, utilizando filmes radiográficos Agfa Dentus M2 "Comfort” processados em três soluções de processamento em diferentes temperaturas./ Mariela Siqueira Gião Dezotti Bauru, 2000.

$145 \mathrm{p}$; il. ; $30 \mathrm{~cm}$.

Tese, (Mestrado) - Faculdade de Odontologia de Bauru. USP.

Orientador: Prof. Dr. Orivaldo Tavano

Autorizo, exclusivamente para fins acadêmicos e científicos, a reprodução total ou parcial desta dissertação/tese, por processos fotocopiadores e/ou meios eletrônicos.

Assinatura do autor:

Data: 


\section{DADOS CURRICULARES}

\section{MARIELA SIQUEIRA GIÃO DEZOTTI}

01 de outubro de 1971

Nascimento

Bauru - SP

1992- 1995

Curso de Odontologia - Universidade do Sagrado Coração - Bauru -SP.

$1996-1997$

Curso de Aperfeiçoamento em Endodontia - Hospital de Reabilitação de Anomalias Craniofaciais da USP.

$1997-1998$

Curso de Especialização em Endodontia - Hospital de Reabilitação de Anomalias Craniofaciais da USP.

$1998-2000$

Curso de Pós-Graduação em Diagnóstico Bucal em nível de Mestrado - Faculdade de Odontologia de Bauru - USP.

Associações ABO - Associação Brasileira de Odontologia.

APCD - Associação Paulista de Cirurgiões-Dentistas do Estado de São Paulo. 


\section{Dedico este trabalho,}

Aos meus pais Marco e Diléa por me mostrarem sempre o melhor caminho com muito amor, carinho $e$ compreensão,

Aos meus irmãos João e Márcia pela amizade e companheirismo constantes,

À minha cunhada Cátia e minha sobrinha Thayana pelo carinho e amor,

À D. Neida pela inestimável colaboração e atenção sempre dispensadas.

E em especial ao Norberto e ao Cássio pela maravilhosa vida que me proporcionam e pela paciência $e$ compreensão sempre presentes. 
Ao Professor Dr. Orivaldo Tavano, agradeço sinceramente pela orientação neste trabalho, por todos os seus conhecimentos que me foram transmitidos com confiança, paciência e muita dedicação. 


\section{AGRADECIMENTOS}

À Faculdade de Odontologia de Bauru da Universidade de São Paulo, na pessoa de seu Diretor, Prof. Dr. Aymar Pavarini e do Coordenador da Pós - Graduação, Dr. Prof. Luiz Fernando Pegoraro.

À FAPESP, Fundação de Amparo à Pesquisa do Estado de São Paulo, meus sinceros agradecimentos pela oportunidade de poder freqüentar o curso de Pós-Graduação e por financiar este trabalho de pesquisa.

Aos Profs. do Departamento de Estomatologia e Cirurgia da FOBUSP, Dra Ana Lúcia Alvares Capelozza, Dr. José Humberto Damante, Dr. Luiz Eduardo Montenegro Chinellato, Dr. Eduardo Sant'Ana e Dr. Osny Ferreira Júnior, pela grande contribuição na minha formação profissional, pelo carinho $e$ incentivo sempre presentes.

Aos queridos amigos da Pós-Graduação, Lilian, Vanessa, Andréa, Christiano e Luciana pela amizade e agradável convivência durante este período.

Aos colegas da Pós-Graduação (Doutorado), Ângelo, Izabel e Osny pela colaboração sempre presente. 
Aos funcionários do Departamento de Estomatologia e Cirurgia da FOB-USP, Walderez, Fernanda, José Messias, Lígia, Priscila, Josi, Rose e Célio pela atenção que sempre me dispensaram.

Em especial, à Marília, que em nenhum momento poupou esforços para me auxiliar, incentivar e compreender.

À amiga Elizabeth, do Departamento de Dentística da FOB-USP, por todo o apoio que sempre me dispensou.

Ao Prof. José Roberto Pereira Lauris, do Departamento de Odontologia Social da FOB-USP, pela confecção da análise estatística deste trabalho.

À bibliotecária Valéria pela Revisão da Bibliografia.

Aos funcionários da Biblioteca que em todos os momentos auxiliaram na confecção de trabalhos científicos e levantamentos bibliográficos.

Ao amigo Gilberto pela amizade e solicitude sempre presentes $e$ pelo trabalho de formatação e imagens.

Ao Sr. Valdir pela correção ortográfica.

A todos os colegas, profissionais e funcionários da FOB-USP, que de uma forma ou de outra contribuíram para a confecção deste trabalho e para a minha formação profissional. 


\section{SUMÁRIO}

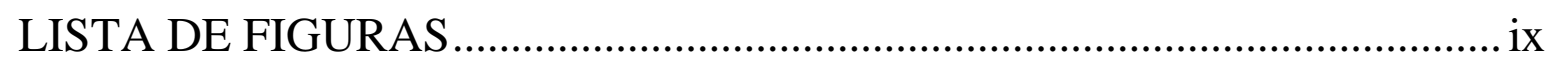

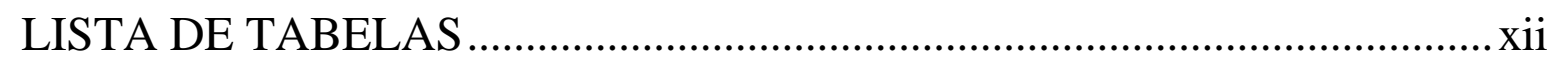

LISTA DE ABREVIATURAS E SÍMBOLOS............................................

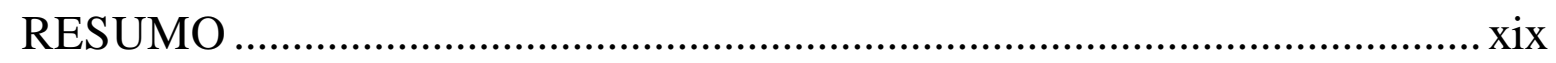

1. INTRODUÇÃ

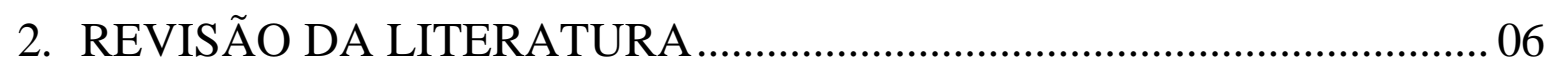

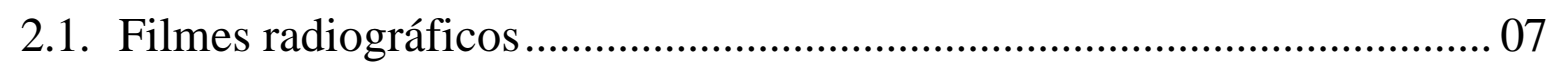

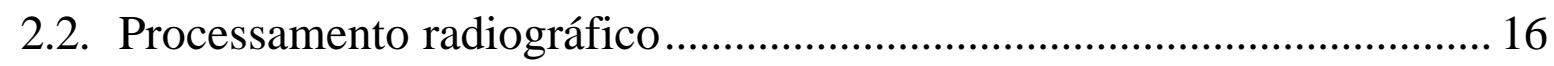

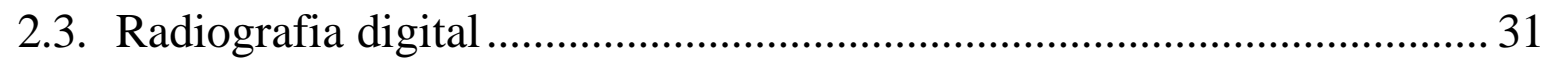

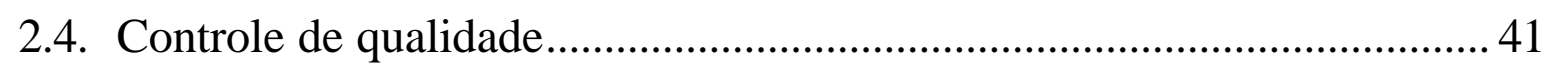

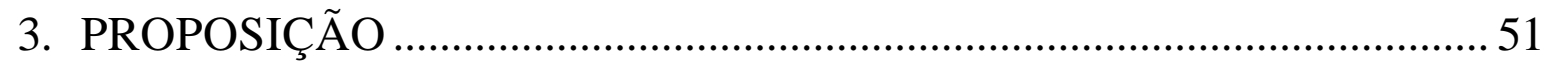

4. MATERIAL E MÉTODOS ...................................................................... 53

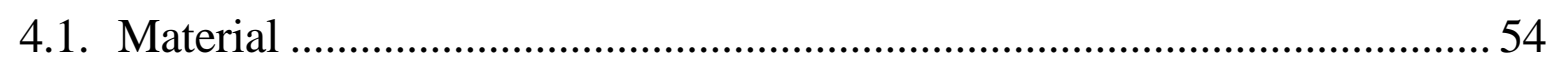

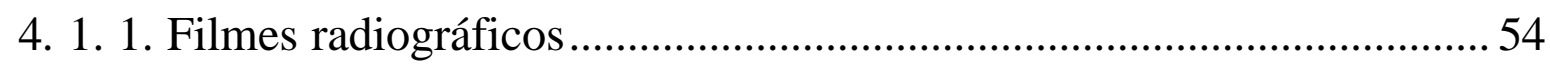

4. 1. 2. Soluções de processamento ……………….......................................... 54

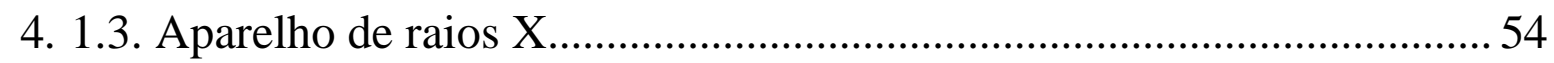

4. 1.4. Dispositivo utilizado para as exposições aos raios $X$.............................. 55

4. 1.5. Aparelho fotodensitômetro ………………………………………….... 55

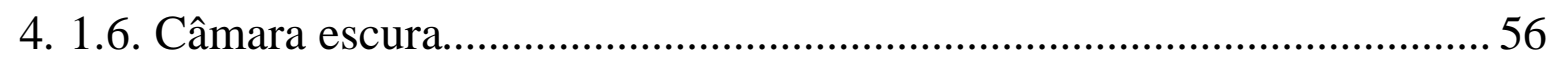

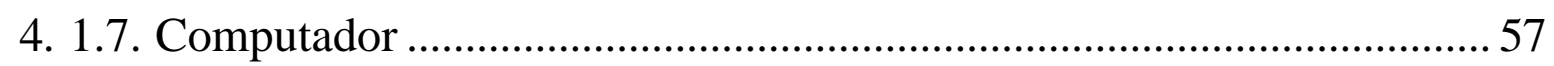

4. 1.8. Scanner de mesa e gravador de CD................................................... 57

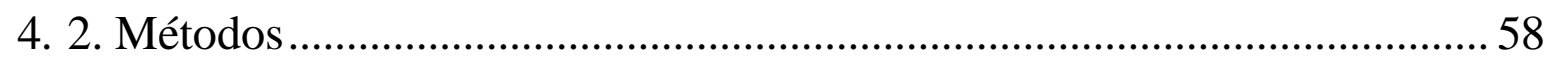

4. 2.1. Exposição dos filmes aos raios $\mathrm{X}$ no dispositivo de chumbo ................ 58

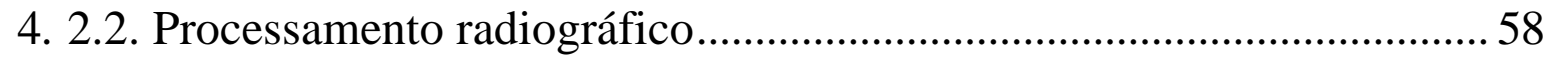

4. 2.3. Leitura da Densidade Ótica.................................................................... 60

4. 2.4. Construção das curvas características ..................................................... 61 


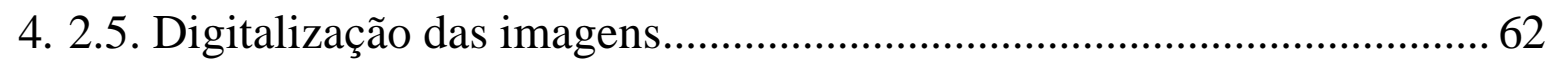

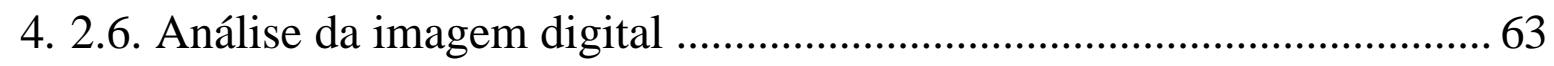

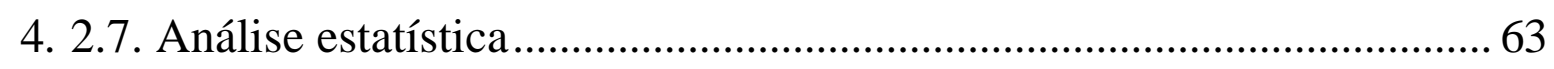

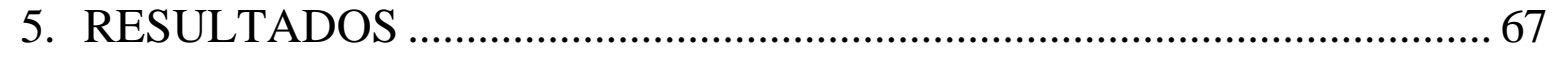

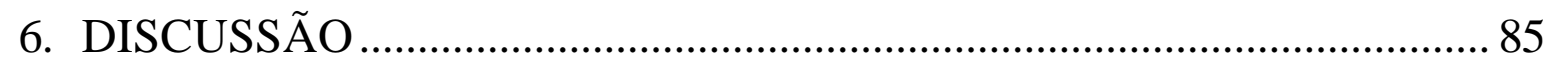

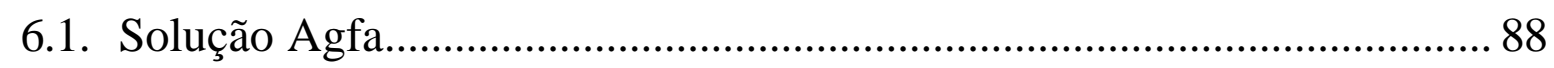

6.2. Solução Kodak...................................................................................... 92

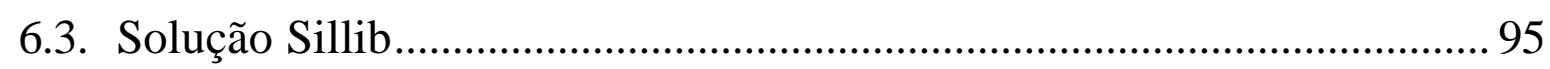

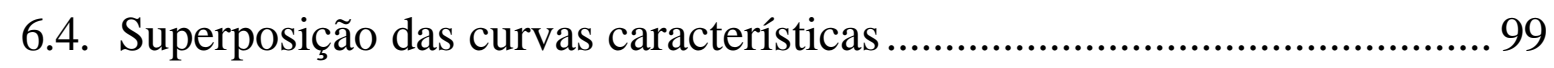

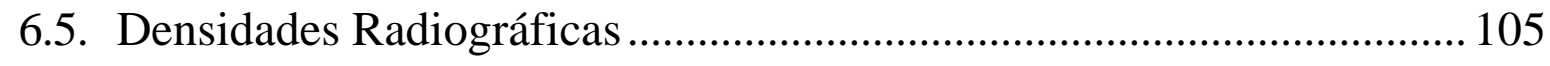

6.6. Densidades Óticas e Densidades Radiográficas ........................................ 113

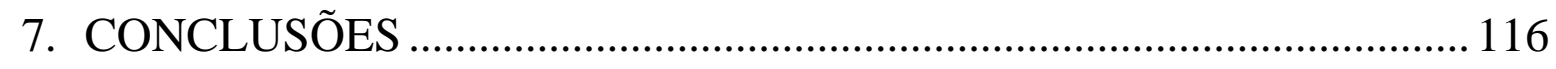

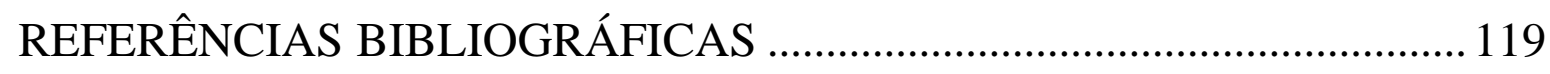

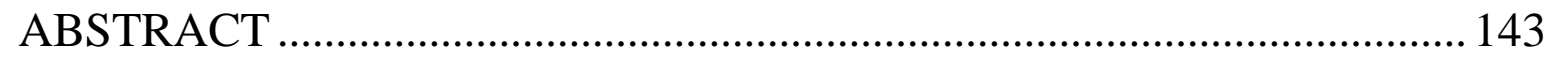

\section{ANEXOS}




\section{LISTA DE FIGURAS}

FIGURA 1 - Caixa de filme radiográfico intrabucal Agfa Dentus M2 "Comfort"

FIGURA 2 - Soluções para o processamento radiográfico manual - Agfa

Dentus, Kodak e Sillib.

FIGURA 3 - Aparelho fotodensitômetro com uma radiografia em posição, para realização da leitura da Densidade Ótica

FIGURA 4 - Demonstração da leitura de Densidade Ótica realizada no fotodensitômetro MRA

FIGURA 5 - Demonstração da tela do monitor com uma radiografia no Programa Adobe Photoshop 5.0, que mostra a Densidade Radiográfica da área, a mediana e o desvio padrão.

FIGURA 6 - Demonstração da tela do monitor com uma radiografia no Programa Adobe Photoshop 5.0, que mostra a Densidade Radiográfica invertida da área, a mediana e o desvio padrão 65

FIGURA 7 - Radiografias obtidas após a exposição e processamento com as soluções Agfa Dentus, Kodak e Sillib nas temperaturas de $20^{\circ} \mathrm{C}, 25^{\circ} \mathrm{C}$ e $30^{\circ} \mathrm{C}$ 66

FIGURA 8 - Curva característica obtida com o valor médio das leituras de Densidades Óticas no fotodensitômetro MRA nas quatro radiografias estudadas, utilizando o filme Agfa Dentus M2 "Comfort", processado na solução Agfa Dentus a $20^{\circ} \mathrm{C} / 5$ minutos (grupo 1 ) 
FIGURA 9 - Curva característica obtida com o valor médio das leituras de Densidades Óticas no fotodensitômetro MRA nas quatro radiografias estudadas, utilizando o filme Agfa Dentus M2 "Comfort", processado na solução Agfa Dentus a $25^{\circ} \mathrm{C} / 2,5$ minutos (grupo 2 )

FIGURA 10 - Curva característica obtida com o valor médio das leituras de Densidades Óticas no fotodensitômetro MRA nas quatro radiografias estudadas, utilizando o filme Agfa Dentus M2 "Comfort", processado na solução Agfa Dentus a $30^{\circ} \mathrm{C} / 1,25$ minuto (grupo 3 )

FIGURA 11 - Curva característica obtida com o valor médio das leituras de Densidades Óticas no fotodensitômetro MRA nas quatro radiografias estudadas, utilizando o filme Agfa Dentus M2 "Comfort", processado na solução Kodak a $20^{\circ} \mathrm{C} / 5$ minutos (grupo 4 )

FIGURA 12 - Curva característica obtida com o valor médio das leituras de Densidades Óticas no fotodensitômetro MRA nas quatro radiografias estudadas, utilizando o filme Agfa Dentus M2 "Comfort", processado na solução Kodak a $25^{\circ} \mathrm{C} / 2,5$ minutos (grupo 5)

FIGURA 13 - Curva característica obtida com o valor médio das leituras de Densidades Óticas no fotodensitômetro MRA nas quatro radiografias estudadas, utilizando o filme Agfa Dentus M2 "Comfort", processado na solução Kodak a $30^{\circ} \mathrm{C} / 1,25$ minuto (grupo 6 ) 
FIGURA 14 - Curva característica obtida com o valor médio das leituras de Densidades Óticas no fotodensitômetro MRA nas quatro radiografias estudadas, utilizando o filme Agfa Dentus M2 "Comfort", processado na solução Sillib a $20^{\circ} \mathrm{C} / 2$ minutos (grupo 7 )

FIGURA 15 - Curva característica obtida com o valor médio das leituras de Densidades Óticas no fotodensitômetro MRA nas quatro radiografias estudadas, utilizando o filme Agfa Dentus M2 "Comfort", processado na solução Sillib a $25^{\circ} \mathrm{C} / 1$ minuto (grupo 8) .76

FIGURA 16 - Curva característica obtida com o valor médio das leituras de Densidades Óticas no fotodensitômetro MRA nas quatro radiografias estudadas, utilizando o filme Agfa Dentus M2 "Comfort", processado na solução Sillib a $30^{\circ} \mathrm{C} / 0,5$ minuto (grupo 9)

FIGURA 17 - Superposição das nove curvas características construídas a partir das médias das Densidades Óticas das quatro radiografias estudadas, obtidas com fotodensitômetro MRA, utilizando o filme Agfa Dentus M2 "Comfort", processado nas diferentes soluções, temperaturas e tempos de acordo com o grupo analisado 78 


\section{LISTA DE TABELAS}

TABELA 1 - Tabela com o valor médio das dez leituras das Densidades Óticas, realizadas com o fotodensitômetro MRA em cada uma das cinco faixas nas quatro radiografias obtidas com filmes radiográficos Agfa Dentus M2 "Comfort", processados na solução Agfa Dentus, na temperatura de $20^{\circ} \mathrm{C}$, por cinco minutos - Grupo 1

TABELA 2 - Tabela com o valor médio das dez leituras das Densidades Óticas, realizadas com o fotodensitômetro MRA em cada uma das cinco faixas nas quatro radiografias obtidas com filmes radiográficos Agfa Dentus M2 "Comfort", processados na solução Agfa Dentus, na temperatura de $25^{\circ} \mathrm{C}$, por 2,5 minutos - Grupo 2

TABELA 3 - Tabela com o valor médio das dez leituras das Densidades Óticas, realizadas com o fotodensitômetro MRA em cada uma das cinco faixas nas quatro radiografias obtidas com filmes radiográficos Agfa Dentus M2 "Comfort", processados na solução Agfa Dentus, na temperatura de $30^{\circ} \mathrm{C}$, por 1,25 minutos - Grupo 3

TABELA 4 - Tabela com o valor médio das dez leituras das Densidades Óticas, realizadas com o fotodensitômetro MRA em cada uma das cinco faixas nas quatro radiografias obtidas com filmes radiográficos Agfa Dentus M2 "Comfort", processados na solução Kodak, na temperatura de $20^{\circ} \mathrm{C}$, por cinco minutos - Grupo 4 
TABELA 5 - Tabela com o valor médio das dez leituras das Densidades Óticas, realizadas com o fotodensitômetro MRA em cada uma das cinco faixas nas quatro radiografias obtidas com filmes radiográficos Agfa Dentus M2 "Comfort", processados na solução Kodak, na temperatura de $25^{\circ} \mathrm{C}$, por 2,5 minutos - Grupo 5

TABELA 6 - Tabela com o valor médio das dez leituras das Densidades Óticas, realizadas com o fotodensitômetro MRA em cada uma das cinco faixas nas quatro radiografias obtidas com filmes radiográficos Agfa Dentus M2 "Comfort", processados na solução Kodak, na temperatura de $30^{\circ} \mathrm{C}$, por 1,25 minuto - Grupo 6

TABELA 7 - Tabela com o valor médio das dez leituras das Densidades Óticas, realizadas com o fotodensitômetro MRA em cada uma das cinco faixas nas quatro radiografias obtidas com filmes radiográficos Agfa Dentus M2 "Comfort", processados na solução Sillib, na temperatura de $20^{\circ} \mathrm{C}$, por dois minutos - Grupo 7

TABELA 8 - Tabela com o valor médio das dez leituras das Densidades Óticas, realizadas com o fotodensitômetro MRA em cada uma das cinco faixas nas quatro radiografias obtidas com filmes radiográficos Agfa Dentus M2 "Comfort", processados na solução Sillib, na temperatura de $25^{\circ} \mathrm{C}$, por um minuto - Grupo 8 .76 
TABELA 9 - Tabela com o valor médio das dez leituras das Densidades Óticas, realizadas com o fotodensitômetro MRA em cada uma das cinco faixas nas quatro radiografias obtidas com filmes radiográficos Agfa Dentus M2 "Comfort", processados na solução Sillib, na temperatura de $30^{\circ} \mathrm{C}$, por 0,5 minuto - Grupo 9

TABELA 10 - Média das Densidades Óticas do filme Agfa Dentus M2 "Comfort", obtidas no fotodensitômetro MRA nas cinco faixas de exposição (impulsos) nas diferentes combinações de solução/ temperatura $\left({ }^{\circ} \mathrm{C}\right) /$ tempo (min.) nove grupos 78

TABELA 11 - Valores de densidade máxima, sensibilidade (mAs e R*), contraste, latitude e DBV do filme Agfa Dentus M2 "Comfort", processados nas diferentes combinações solução/temperatura $\left({ }^{\circ} \mathrm{C}\right) /$ tempo (min.), obtidos a partir do traçado das curvas características

TABELA 12 - Tabela com o valor das leituras das Densidades Radiográfica e Radiográfica invertida, realizadas em cada uma das cinco faixas nas quatro radiografias, utilizando-se o programa de imagem Adobe Photoshop 5.0, em filmes radiográficos Agfa Dentus M2 "Comfort", processados na solução Agfa Dentus, na temperatura de $20^{\circ} \mathrm{C}$, por cinco minutos - Grupo 1

TABELA 13 - Tabela com o valor das leituras das Densidades Radiográfica e Radiográfica invertida, realizadas em cada uma das cinco faixas nas quatro radiografias, utilizando-se o programa de imagem Adobe Photoshop 5.0, em filmes radiográficos Agfa Dentus M2 "Comfort", processados na solução Agfa Dentus, na temperatura de $25^{\circ} \mathrm{C}$, por 2,5 minutos - Grupo 2 
TABELA 14 - Tabela com o valor das leituras das Densidades Radiográfica e Radiográfica invertida, realizadas em cada uma das cinco faixas nas quatro radiografias, utilizando-se o programa de imagem Adobe Photoshop 5.0, em filmes radiográficos Agfa Dentus M2 "Comfort", processados na solução Agfa Dentus, na temperatura de $30^{\circ} \mathrm{C}$, por 1,25 minuto - Grupo 3

TABELA 15 - Tabela com o valor das leituras das Densidades Radiográfica e Radiográfica invertida, realizadas em cada uma das cinco faixas nas quatro radiografias, utilizando-se o programa de imagem Adobe Photoshop 5.0, em filmes radiográficos Agfa Dentus M2 "Comfort", processados na solução Kodak, na temperatura de $20^{\circ} \mathrm{C}$, por cinco minutos - Grupo 4 .

TABELA 16 - Tabela com o valor das leituras das Densidades Radiográfica e Radiográfica invertida, realizadas em cada uma das cinco faixas nas quatro radiografias, utilizando-se o programa de imagem Adobe Photoshop 5.0, em filmes radiográficos Agfa Dentus M2 "Comfort", processados na solução Kodak, na temperatura de $25^{\circ} \mathrm{C}$, por 2,5 minutos - Grupo 5

TABELA 17 - Tabela com o valor das leituras das Densidades Radiográfica e Radiográfica invertida, realizadas em cada uma das cinco faixas nas quatro radiografias, utilizando-se o programa de imagem Adobe Photoshop 5.0, em filmes radiográficos Agfa Dentus M2 "Comfort", processados na solução Kodak, na temperatura de $30^{\circ} \mathrm{C}$, por 1,25 minuto - Grupo 6 . 
TABELA 18 - Tabelas com o valor das leituras das Densidades Radiográfica e Radiográfica invertida, realizadas em cada uma das cinco faixas nas quatro radiografias, utilizando-se o programa de imagem Adobe Photoshop 5.0, em filmes radiográficos Agfa Dentus M2 "Comfort", processados na solução Sillib, na temperatura de $20^{\circ} \mathrm{C}$, por dois minutos - Grupo 7 .

TABELA 19 - Tabela com o valor das leituras das Densidades Radiográfica e Radiográfica invertida, realizadas em cada uma das cinco faixas nas quatro radiografias, utilizando-se o programa de imagem Adobe Photoshop 5.0, em filmes radiográficos Agfa Dentus M2 "Comfort", processados na solução Sillib, na temperatura de $25^{\circ} \mathrm{C}$, por um minuto - Grupo 8

TABELA 20 - Tabela com o valor das leituras das Densidades Radiográfica e Radiográfica invertida, realizadas em cada uma das cinco faixas nas quatro radiografias, utilizando-se o programa de imagem Adobe Photoshop 5.0, em filmes radiográficos Agfa Dentus M2 "Comfort", processados na solução Sillib, na temperatura de $30^{\circ} \mathrm{C}$, por 0,5 minuto - Grupo 9 
TABELA 21 - Média das Densidades Óticas e Densidades Radiográficas do filme Agfa Dentus M2 "Comfort", nas cinco faixas de exposição (impulsos), nas quatro radiografias, das diferentes combinações solução/temperatura/tempo (nove grupos)

TABELA 22 - Coeficiente de Correlação de Pearson entre Densidade Ótica (D. O.) e Densidade Radiográfica (D. R.), Densidade Ótica (D. O.) e Densidade Radiográfica invertida (D.R.i) e Densidade Radiográfica (D. R.) e Densidade Radiográfica invertida (D.R.i), com nível de confiança de 95\%. 84 


\section{LISTA DE ABREVIATURAS E SÍMBOLOS}

CCD - Charge Coupled Device (Dispositivo Acoplado de Carga)

$\mathrm{CD}$ - compact disc

$\mathrm{cm}$ - centímetros

D.O. - Densidade Ótica

D.R. - Densidade Radiográfica

D.Ri - Densidade Radiográfica invertida

GB - gigabytes (capacidade de armazenamento)

${ }^{\circ} \mathrm{C}$ - graus Celsius

HD - disco rígido

$\mathrm{kVp}$ - quilovoltagem pico

$\mathrm{mA}$ - miliamperagem

$\mathrm{mAs}$ - miliamperagem segundo

MB - megabites (capacidade de armazenamento)

min - minutos

mm - milímetro

Pixel - picture element (elemento de figura)

RAM - Memória de acesso aleatório

$\mathrm{R}^{*}$ - Röntgen recíproco 
RESUMo 


\section{RESUMO}

O controle de qualidade radiográfica é essencial dentro da Radiologia Odontológica. Justifica-se o seu uso na avaliação dos filmes radiográficos e atividade das soluções de processamento para alcançar, cada vez mais, este controle na clínica diária. Este estudo teve por objetivo avaliar as propriedades sensitométricas do filme radiográfico Agfa Dentus M2 "Comfort" (sensibilidade, contraste e latitude) quando processado nas soluções de processamento Agfa Dentus, Kodak e Sillib em diferentes combinações: $20^{\circ} \mathrm{C} / 5$ minutos, $25^{\circ} \mathrm{C} / 2,5$ minutos e $30^{\circ} \mathrm{C} / 1,25$ minuto para as duas primeiras e $20^{\circ} \mathrm{C} / 2$ minutos, $25^{\circ} \mathrm{C} / 1$ minuto e $30^{\circ} \mathrm{C} / 0,5$ minuto para a solução Sillib. Para obtenção destas propriedades sensitométricas, foram traçadas curvas características a partir das médias de Densidades Óticas obtidas em quatro radiografias expostas e processadas para cada grupo. Os resultados mostraram que o filme Agfa Dentus M2 "Comfort" alcançou sensibilidade do grupo F quando se utilizou a solução Agfa Dentus nas três diferentes combinações, o que foi observado analisando-se as curvas características derivadas dos grupos 1, 2 e 3 (solução Agfa Dentus). Notou-se uma tendência da curva para esquerda em relação aos outros seis grupos (soluções Kodak e Sillib). Nas soluções Kodak e Sillib, nas diferentes combinações, o filme alcançou sensibilidade do grupo E. O filme apresentou, em todas as soluções e combinações utilizadas, contraste dentro de uma faixa de normalidade, variando de 1,72 (Kodak $30^{\circ} \mathrm{C} / 1,25$ minuto) a 2,21 (Sillib $25^{\circ} \mathrm{C} / 1$ minuto). A maior latitude foi observada quando se utilizou a solução Kodak na temperatura de $30^{\circ} \mathrm{C}$ com um tempo de revelação de 1,25 minuto e a menor latitude foi observada utilizando-se a solução Kodak a $25^{\circ} \mathrm{C}$ com um 2,5 minutos de revelação. Concluiu-se que o filme Agfa Dentus M2 "Comfort" alcançou propriedades sensitométricas adequadas quando processado nas três soluções e nas diferentes combinações de 
temperatura/tempo. Um segundo propósito para esta pesquisa foi confirmar a observação de que a obtenção das Densidades Óticas pode ser substituída pelo método digital, utilizando-se um programa de imagem. Concluiu-se que Densidade Ótica e Densidades Radiográficas podem ser usadas na clínica Odontológica, no controle de qualidade radiográfica para verificação da atividade de soluções processadoras, visto que, sob as condições utilizadas no presente experimento, houve grande correlação estatística entre os valores das mesmas, com um nível de confiança de 95\% para todos os grupos. 


\section{INTRODUÇÃO}




\section{INTRODUÇÃO}

A Radiologia dentro da Odontologia, foi iniciada com a tomada da primeira radiografia dentária realizada por Otto Walkhoff, logo após a sua descoberta por Wilhelm Conrad Röntgen em 1895. A aplicação das propriedades desta ciência com o intuito de descobrir, confirmar, definir, localizar uma lesão e possibilitar um diagnóstico precoce no campo da Odontologia e da Medicina, principalmente em relação ao estudo de alterações ósseas, tornou o exame radiográfico um método auxiliar para o diagnóstico muito utilizado ${ }^{19,42,43,67}$. Por outro lado, sabe-se que as radiações $\mathrm{X}$ podem produzir efeitos biológicos deletérios ao organismo. Assim, justifica-se a preocupação dos pesquisadores em reduzir ao máximo a radiação que o paciente recebe durante os exames radiográficos utilizados em Odontologia para diagnóstico ${ }^{8,45,68,76,127}$.

O exame radiográfico, para que cumpra o seu objetivo, deve trazer informações de excelente qualidade e os princípios de ótimo detalhe, mínima distorção, densidade e contraste médios, devem sempre ser preservados. Os fatores que interferem na imagem radiográfica final são: equipamento, filme, exposição e processamento e devem ser controlados e sempre estudados, de maneira que permitam cada vez mais uma evolução na área da Radiologia e uma redução das doses de radiações ionizantes aos pacientes ${ }^{19,45,67,70,76,127}$.

Ressalta-se que para a obtenção de uma radiografia de alta qualidade, vários fatores se integram, não devendo ser apenas considerado o conhecimento dos filmes radiográficos ou dos equipamentos necessários para a produção de raios X. Segundo TAVANO; RAYMUNDO JÚNIOR ${ }^{115}$, em 1982, HAVUKAINEN; SERVOMAA ${ }^{48}$, em 1986, FLETCHER ${ }^{32}$, em 1987 e BRÜCKER; TAVANO ${ }^{14}$, em 1990, inclui-se aos fatores técnicos do aparelho, o seu potencial, suas limitações e sua conservação; a adequada 
escolha do filme radiográfico de acordo com suas normas técnicas e sua utilização segundo instruções do fabricante, e também a opção pelo tipo de solução processadora que deverá ser utilizada.

Com o decorrer do tempo foram surgindo várias pesquisas, as quais têm trazido grandes avanços em relação à fabricação dos aparelhos e à sensibilidade dos filmes radiográficos ${ }^{24,98,99,106,111,122,126}$.

A preocupação com vários métodos utilizados para reduzir a dose de radiação ao paciente, durante o exame radiográfico, tais como filtragem e colimação adequados, aumento da quilovoltagem e conscientização dos operadores quanto aos efeitos biológicos foi demonstrada por ETTER ${ }^{27}$, em 1956, RICHARDS ${ }^{91}$ em 1958, e RICHARDS; COLQUITS ${ }^{92}$, em 1981. Busca-se o desenvolvimento de um equipamento confiável e relativamente seguro para a produção de radiação. Cronômetros eletrônicos são regulados e calibrados para garantir a correta exposição do filme radiográfico ${ }^{4,13,36}$.

O filme radiográfico é o maior responsável pela redução da dose de radiação que o paciente recebe durante uma tomada radiográfica. Utilizando filmes mais sensíveis, conseqüentemente o profissional reduzirá o tempo de exposição e a quantidade de radiação produzida pelo aparelho, diminuindo na mesma proporção os efeitos biológicos nocivos ao paciente ou a si mesmo $^{3,4,42 .}$

Aproximadamente 20 anos atrás, a Kodak introduziu no mercado o filme Ektaspeed, de sensibilidade E, o qual resultava em uma redução de 40 a $50 \%$ na dose de radiação emitida ao paciente em comparação ao Ultraspeed, do grupo D de sensibilidade. Apesar de muitos afirmarem que o Ektaspeed era similar ao Ultraspeed quanto à capacidade de diagnóstico, a maioria dos dentistas não o adotou. O Ektaspeed apresentava alta sensibilidade às variações de condições ideais de processamento, tais como flutuação de temperatura, concentração e exaustão da solução de processamento utilizada. 
A falta de cuidado no processamento é comum na prática diária, pois os dentistas não operam rotineiramente com um programa de controle de qualidade. Em 1994, a Kodak introduziu no mercado o Ektaspeed Plus, que é um filme mais consistente em relação às variações de condições de processamento. Em 1997, foi lançado no mercado, o Agfa Dentus M2 "Comfort", com características similares ao Ektaspeed Plus em condições de processamento ideal. Este filme apresenta sensibilidade E, diferindo do antigo que apresentava uma sensibilidade entre os grupos D/E. Assim, tornam-se necessários estudos utilizando este novo filme sob condições variadas de processamento $^{108}$. Fazem-se necessárias, alterações no tipo de solução, na temperatura da mesma e no tempo de revelação, alcançando desta maneira as combinações ideais para utilização com este novo tipo de filme.

As dificuldades verificadas na obtenção de uma radiografia, que segundo alguns autores chegam a 90\%, são encontradas na câmara escura, devido à falta de instalações adequadas, utilização do método visual de processamento, descuido com as etapas do processamento e, finalmente, desconhecimento da atividade e características das soluções depois de colocadas em uso ${ }^{13,73}$.

Existe um grande número de estudos, no qual as soluções processadoras foram avaliadas $1,15,16,17,30,41,55,56,61,74,75,77,78,79,84$. Estuda-se, entre outros fatores, o uso da elevação da temperatura dos banhos ${ }^{33,34,80,109,117}$, a exaustão química das soluções processadoras $9,90,110,118$, sua degradação $^{13,81,89,115}$ e a utilização de processadoras automáticas ${ }^{32,47,93,94}$, provando que é fundamental o seu estudo, visando cada vez mais um rígido controle de qualidade.

Os filmes radiográficos e as soluções para processamento são estudados utilizando-se o método sensitométrico. Este método consiste na confecção de curvas características de onde se obtêm as propriedades 
sensitométricas dos filmes (contraste, latitude e sensibilidade). Estas curvas são construídas a partir da densidade ótica do filme radiográfico e dos tempos de exposição utilizados para sensibilizarmos os filmes. A densidade ótica é alcançada utilizando-se leituras a partir de um fotodensitômetro. Este é o método convencional, onde se requerem várias leituras em cada faixa do filme radiográfico, obtendo-se uma média para posterior confecção das curvas características.

Recentemente, com o advento da informática e de programas de imagem, é possível avaliar as áreas do filme radiográfico em toda sua extensão, desde que sejam reproduzidas digitalmente, transformando os dados numéricos da imagem original analógica em pequenos quadrados ou retângulos que denominamos pixel, e associar a cada um deles um número que represente uma cor da imagem formando um conjunto de números que são avaliados e armazenados na memória de um computador ${ }^{21,57,83,100}$.

Assim, a utilização de um programa de imagem para avaliar as Densidades Radiográficas, isto é, a quantificação dos níveis de cinza de um filme radiográfico, vem contribuir também na evolução da Radiologia Odontológica, no que se refere ao controle de qualidade. Este novo método traz agilidade, rapidez, facilidade e capacidade de armazenagem de dados para o estudo de filmes radiográficos e soluções de processamento. 
2. REVISÃO DA LITERATURA 


\section{REVISÃO DA LITERATURA}

\subsection{Filmes radiográficos}

Um feixe de fótons de raios $\mathrm{X}$, partindo de um aparelho, ao interagir com um objeto, terá reduzida a sua intensidade, o que se chama de atenuação, pela absorção e espalhamento de fótons do feixe primário. Este feixe atenuado que deixa o objeto conduz uma informação relacionada com a estrutura e composição do mesmo, e para que esta informação seja aproveitada para diagnóstico há a necessidade de um receptor de imagens.

Quando Röntgen descobriu os raios X, este receptor era o filme fotográfico, daí a primeira radiografia dentária realizada utilizando um filme fotográfico recortado e recoberto por um lençol de borracha. Inicialmente a base do filme era constituída de vidro, e mais tarde, foi substituída por nitrato de celulose (celulóide). Em 1920, esta base foi substituída por acetato de celulose, visto que o nitrato de celulose apresentava a característica de ser inflamável. Por volta de 1960, nova substituição foi realizada e a base utilizada, então, é derivada do petróleo, o poliéster ${ }^{35}$.

A partir da introdução no comércio de filmes radiográficos odontológicos, foi dada ênfase à redução da quantidade de radiação necessária para produzir radiografias, mantendo a qualidade para diagnóstico. Quando foram lançados os filmes Radiatized, eram necessários 4,5 segundos para a exposição da área de molares superiores. Em 1955, surgiu no mercado o filme Ultraspeed, com sensibilidade 5 a 6 vezes maior do que o Radiatized. Em 1981, foi lançado no mercado o filme Ektaspeed, duas vezes mais sensível que qualquer outro do grupo D (Ultraspeed e Agfa Dentus M2) ${ }^{85}$. Por apresentar menor contraste, velamento acentuado, irregularidade na granulação e menor latitude, o filme Ektaspeed foi substituído pelo Ektaspeed Plus, lançado pela Kodak em 1994. O filme Ektaspeed Plus usa, em sua 
emulsão, a tecnologia T-Mat, com grânulos tabulares, diferente da emulsão anterior. Esta tecnologia além de melhorar a resolução da imagem, aumenta a sensibilidade do filme ${ }^{121}$.

Atualmente, os filmes radiográficos apresentam uma padronização para a sua produção. Possuem em ambos os lados de uma base de poliéster, a emulsão, que se constitui de gelatina onde estão contidos os cristais de halogenetos de prata (brometo de prata e iodetos de prata). A emulsão tem por finalidade absorver radiação durante a exposição aos raios $\mathrm{X}$ e produzir imagem latente, a qual se transforma em imagem radiográfica visível após o uso das soluções para o processamento.

Os filmes mais sensíveis necessitam de menor quantidade de radiação para produzirem imagens com valor para diagnóstico e por isto representam o mais eficiente fator na redução da radiação ao paciente durante a tomada radiográfica. Este ganho na sensibilidade pode implicar em perda de nitidez. O tamanho dos cristais de halogenetos de prata contidos na emulsão dos filmes radiográficos, é um dos fatores que determina uma maior ou menor sensibilidade dos mesmos, sendo assim, filmes mais sensíveis possuem cristais maiores e vice-versa. Desta maneira, quando estes cristais são maiores, aumenta-se também a área de sensibilização do filme, causando perda da nitidez do mesmo. Hoje em dia estão disponíveis no mercado filmes dos grupos D, E e F de sensibilidade. A sensibilidade dos filmes radiográficos é expressa em Röntgen recíproco $\left(\mathrm{R}^{*}\right)$, assim, filmes do grupo $\mathrm{D}$ necessitam de 12 a $24 \mathrm{R}^{*}$, filmes do grupo E, 24 a $48 \mathrm{R}^{*}$ e do grupo $\mathrm{F}, 48$ a $96 \mathrm{R}^{*}$ de exposição para alcançar uma densidade específica. Quanto maior o $\mathrm{R}^{*}$, menor é a quantidade de radiação necessária para alcançar a densidade ótica de 1 acima da densidade base e velamento.

Surgiram com o tempo, um grande número de experimentos utilizando filmes radiográficos, realizados de diferentes formas e que 
trouxeram grandes benefícios no que diz respeito ao avanço da Radiologia, redução da exposição aos raios $\mathrm{X}$ e melhoria na qualidade da imagem radiográfica.

$\mathrm{SMITH}^{101}$, em 1970, analisou dez tipos de filmes radiográficos utilizando as propriedades sensitométricas (sensibilidade e contraste). Os filmes utilizados foram: Adox, Agfa Gevaert, Ilford (padrão e rápido), Kodak (rápido e Defilux), Minimax, Phil, Rinn e Typon. A solução utilizada foi o revelador Ilford Phenisol a $20^{\circ} \mathrm{C} / 4$ minutos. Os resultados mostraram que houve pequena correlação entre a sensibilidade indicada pelo fabricante e a descoberta no experimento. O filme mais sensível foi o Ilford (rápido). O filme com contraste mais baixo foi o Phil quando revelado de acordo com as instruções do fabricante, um contraste maior foi observado nos filmes Adox e Rinn.

HORTON $^{51}$, em 1984, com o objetivo de avaliar a capacidade de diagnóstico do filme Ektaspeed, utilizou 70 e $90 \mathrm{kVp}$ para saber se a qualidade da imagem era afetada pelo aumento da quilovoltagem e concluiu que o filme do grupo E apresentou imagem ligeiramente melhor com $90 \mathrm{kVp}$ do que com $70 \mathrm{kVp}$.

KAFFE; LITTNER; KUSPET ${ }^{61}$, em 1984, realizaram um estudo comparando os filmes radiográficos Kodak Ultraspeed e Ektaspeed, dos grupos D e E de sensibilidade, respectivamente. Concluíram que não houve deterioração da imagem com $50 \%$ de redução na exposição quando o filme Ektaspeed foi usado, sendo este recomendado para radiografias de rotina. A densidade base e velamento para os dois filmes foi similar e a resolução e contraste foram idênticos para ambos.

KLEIER; BENNER; AVERBACH ${ }^{64}$, em 1985, compararam dois filmes radiográficos, o Kodak Ultraspeed e o Ektaspeed. Foram selecionados quatro grupos de pacientes em diferentes fases do tratamento endodôntico e 
duas radiografias foram tomadas com os respectivos filmes. As radiografias foram montadas lado a lado e submetidas a avaliações por 30 examinadores quanto à preferência do ponto de vista endodôntico. O filme Ultraspeed mostrou-se superior ao Ektaspeed do ponto de vista do contraste e qualidade de imagem.

ALVARES; ALVARES; TAVANO ${ }^{3}$, em 1986, realizaram um experimento no qual compararam os filmes radiográficos Agfa-Gevart, Kodak Ultraspeed e Kodak Ektaspeed, processados na solução Kodak pronta para uso. Os filmes foram expostos em um fantoma sob condições padronizadas de exposição e processamento. Foi realizada uma análise subjetiva por profissionais e técnicos especialistas das imagens obtidas, além da obtenção das propriedades sensitométricas. Concluíram que o filme mais sensível foi Ektaspeed da Kodak (grupo E de sensibilidade), seguido pelo Agfa-Gevaert, do grupo D e por último o Ultraspeed da Kodak (grupo D). O filme AgfaGevaert apresentou melhor qualidade de imagem, enquanto o filme Ektaspeed não deixa de ter suas vantagens, devido à sua maior sensibilidade.

FROMMER; JAIN ${ }^{37}$, em 1987, realizaram um estudo onde questionaram dentistas que trabalhavam em condições clínicas se saberiam ou não distinguir diferenças entre os filmes dos grupos D e E de sensibilidade. Os dentistas não sabiam qual filme estavam analisando e foram questionados quanto à melhor definição da imagem. Os resultados indicaram que o filme do grupo E de sensibilidade produziram imagens aceitáveis para diagnóstico, com a vantagem de reduzir a exposição ao paciente em 50\% quando comparado com o filme do grupo D.

GHILARDI $\mathrm{NETO}^{42}$ et al, em 1988, construíram curvas características com o intuito de analisar as propriedades sensitométricas dos filmes radiográficos Kodak Ektaspeed, Kodak Ultraspeed, Agfa Gevaert e Rinn. Pelas características apresentadas, concluiu-se que o filme Kodak 
Ektaspeed foi o que ofereceu melhores condições de proteção ao paciente em Radiologia Odontológica. Verificou-se que houve uma necessidade de 55, 77 e $84 \%$ a mais de exposição aos raios X, respectivamente para os filmes Agfa Gevaert, Rinn e Kodak Ultraspeed, quando comparados ao Kodak Ektaspeed. Em termos de resolução, ou seja, para análise de detalhes de estruturas mais finas, o filme Agfa Gevaert foi o que apresentou melhores resultados, seguido do Kodak Ultraspeed.

Com a finalidade de comparar os filmes do grupo $\mathrm{E}$ de sensibilidade, $\mathrm{KAFFE}^{59}$, em 1990, usou o filme Agfa Dentus M4 e o Kodak Ektaspeed. Analisou o contraste, sensibilidade, densidade base e velamento e resolução. Concluiu que a sensibilidade e o contraste foram ligeiramente maiores no Agfa Dentus M4, porém a densidade base e velamento foi ligeiramente menor. Não foram encontradas diferenças quanto à resolução.

SVENSON; LINDVALL; GRÖNDAHL ${ }^{106}$, em 1993, compararam a capacidade de diagnóstico para cáries proximais e as propriedades sensitométricas do filme Agfa Dentus M4 com as dos filmes Kodak Ultraspeed e Ektaspeed. As avaliações foram realizadas por sete clínicos gerais e seis especialistas em Radiologia, que registraram cáries incipientes e manifestações de cáries proximais em radiografias de dentes pré-molares. Utilizou-se a curva característica para analisar os resultados. Foi descoberta uma diferença significante na capacidade de diagnóstico para cáries incipientes e superfícies cavitadas entre os filmes Ektaspeed e Agfa Dentus M4, mas não entre o Ektaspeed e o Ultraspeed ou entre o Ultraspeed e o Agfa Dentus M4. O filme Ektaspeed apresentou maior capacidade de diagnóstico, enquanto o Agfa Dentus M4, a menor. O Agfa Dentus M4 mostrou-se 1,8 vezes mais rápido que o Ektaspeed e 2,8 vezes mais rápido que o Ultraspeed e apresentou um contraste mais baixo do que o Ultraspeed e Ektaspeed. 
Concluíram que o filme Agfa Dentus M4 tem um valor limitado no diagnóstico de cáries incipientes.

SVENSON; PETERSSON ${ }^{105}$, em 1993, por meio de curvas de perceptibilidade compararam filmes Flow dos grupos D e E de sensibilidade com os filmes mais comumente usados, o Kodak Ultraspeed e o Ektaspeed. Não encontraram grandes diferenças entre os filmes quanto ao contraste. Quando avaliados subjetivamente notou-se pequena diferença de contraste entre os filmes. Para obter a mesma densidade, o filme Flow do grupo $\mathrm{E}$ recebeu $66 \%$ menos radiação e o Ektaspeed, 39\%, quando comparados com o Ultraspeed. O filme Flow do grupo D e o Ultraspeed apresentaram a mesma sensibilidade.

CONOVER; HILDEBOLT; ANTHONY ${ }^{22}$, em 1995, compararam objetiva e subjetivamente filmes radiográficos intrabucais. Os filmes utilizados foram: Ektaspeed Plus, Agfa Dentus M2, Ideal MX58, Ultraspeed, Minimax TRX-S e Schein DX58. Foram realizadas medidas objetivas, tais como a sensibilidade, contraste e densidade base e velamento. Avaliações subjetivas como facilidade de uso, granulação do filme e aparência geral, também foram realizadas. O filme Ektaspeed Plus foi o mais sensível, seguido pelo Agfa Dentus M2 e do Ultraspeed. O Agfa Dentus M2, Schein e Minimax apresentaram baixo contraste. O Ultraspeed e o Ideal MX58 mostraram alto contraste, seguido pelo Ektaspeed Plus.

CONOVER; HILDEBOLT; ANTHONY ${ }^{23}$, em 1995, compararam o filme Ektaspeed Plus com o Ektaspeed e o Ultraspeed. A comparação foi realizada utilizando medidas objetivas (sensibilidade, contraste e densidade base e velamento) e por uma avaliação subjetiva (granulação do filme e aparência). O Ektaspeed Plus apresentou maior contraste que o Ektaspeed e foi similar ao Ultraspeed, além disso o Ektaspeed Plus apresentou maior sensibilidade que o Ektaspeed. Os filmes foram estocados em diferentes 
locais e determinada a densidade base e velamento em diferentes dias. O Ektaspeed Plus e o Ultraspeed apresentaram estabilidade de resultados durante este teste e não houve diferença significante na formação da densidade base e velamento. O Ektaspeed Plus apresentou a densidade base e velamento mais baixa e o Ektaspeed apresentou a mais alta. Imagens radiográficas foram realizadas da região de molares de um simulador e as radiografias avaliadas subjetivamente por três observadores. O filme Ektaspeed Plus apresentou a menor granulação. Com base nas avaliações realizadas, concluíram que o Ektaspeed Plus foi superior ao Ektaspeed e superior ou equivalente ao Ultraspeed.

Em 1995, WAKOH ${ }^{128}$ et al descreveram um estudo que comparou as propriedades sensitométricas e a quantidade de informações de quatro filmes radiográficos: Ultraspeed DF-57, Ektaspeed EP-21, Flow DV-58 e o Agfa Dentus M2 "Comfort". Os resultados mostraram que o filme Agfa Dentus M2 "Comfort" apresentou melhor contraste, uma sensibilidade intermediária entre os grupos D/E e uma latitude de exposição maior que o Ultraspeed DF-57 e menor que o Flow DV-58. Diferenças estatisticamente significantes ocorreram em relação à nitidez, quando baixas exposições foram empregadas. O filme Agfa Dentus M2 "Comfort" e o Ektaspeed EP-21, apresentaram nitidez superior aos filmes Ultraspeed DF-57 e Flow DV-58.

THUNTHY, WEINBERG ${ }^{120}$, em 1995, avaliaram as propriedades sensitométricas da emulsão do filme intrabucal Kodak Ektaspeed Plus e as compararam com as dos filmes Ultraspeed e Ektaspeed, processados em solução Kodak Readymatic a $20^{\circ} \mathrm{C}$ por 5,5 minutos, considerada padrão. Concluíram que o filme Ektaspeed Plus apresentou a vantagem de um alto contraste, semelhante ao filme Ultraspeed, e a alta sensibilidade do filme Ektaspeed. O filme Ektaspeed Plus apresentou alta sensibilidade aliada à ótima densidade. 
Em 1995, LUDLOW; PLATIN; HILL ${ }^{74}$ compararam filmes radiográficos Ultraspeed, Ektaspeed e Ektaspeed Plus quanto à sensibilidade, latitude de exposição e resolução. Foram confeccionadas curvas características para cada tipo de filme sob condições padronizadas de processamento. O filme Ektaspeed Plus apresentou maior sensibilidade, sendo duas vezes mais rápido que o Ultraspeed. O Ektaspeed exibiu uma latitude de exposição relativamente grande, seguido do Ektaspeed Plus e Ultraspeed. Todos os filmes foram capazes para resolver mais que 16,6 pares de linhas por milímetro.

PRICE $^{87}$, em 1995, comparou o filme Ektaspeed Plus com os filmes Ultraspeed e Ektaspeed, utilizando para isto a análise da curva característica. O Ektaspeed Plus foi duas vezes mais rápido do que o Ultraspeed. O contraste do filme Ektaspeed Plus foi similar a do Ultraspeed e muito maior do que do filme Ektaspeed. O Ektaspeed Plus mostrou boa resolução assim como o Ektaspeed, porém ambas emulsões foram inferiores a do Ultraspeed. O autor concluiu que o Ektaspeed Plus pode ser uma alternativa aceitável ao filme Ultraspeed.

Em 1996, HINTZE, CHRISTOFFERSEN; WENZEL ${ }^{49}$ realizaram um estudo com o objetivo de comparar a capacidade de detecção de cáries de dois novos filmes radiográficos, o Ektaspeed Plus e o Agfa Dentus M2 "Comfort", com a de filmes mais comumente usados, o Kodak Ultraspeed e o Ektaspeed. Três observadores analisaram superfícies oclusais (103) e proximais (224). Foi realizada uma avaliação microscópica após os dentes serem seccionados para uma validação deste método. A análise foi realizada com curvas características. Não foram descobertas diferenças estatisticamente significantes entre os diferentes filmes quanto à capacidade em detectar cáries proximais e oclusais. 
SYRIOPOULOS $^{108}$ et al, em 1999, avaliou as propriedades sensitométricas dos filmes Ektaspeed Plus, Ultraspeed, Agfa Dentus M2 "Comfort" antigo e recente, utilizando cinco soluções para processamento. O filme Ektaspeed Plus apresentou a maior densidade base e velamento e o Ultraspeed, a mais baixa, independentemente da solução utilizada. O Ektaspeed Plus apresentou sensibilidade mais alta em quatro das cinco soluções utilizadas. O Agfa Dentus M2 "Comfort", lançado recentemente, foi mais sensível que o Ektaspeed Plus quando se utilizou a solução para processamento automático. Todos os filmes processados nas soluções automáticas foram mais sensíveis do que quando processados manualmente. O filme Agfa Dentus M2 "Comfort" recente, é um filme de sensibilidade E e pode ser considerado uma alternativa ao Ektaspeed Plus. Ambos podem ser recomendados para uso na prática Odontológica e contribuem para a redução da dose de radiação ao paciente.

FARMAN; FARMAN ${ }^{29}$, em 2000, compararam as propriedades de um novo filme intrabucal de sensibilidade do grupo F com as obtidas por outros quatro filmes mais antigos dos grupos D e E, e avaliaram o uso de seis soluções de processamento. Utilizaram os filmes Flow, de sensibilidade do grupo F, o Ektaspeed Plus, o Agfa Dentus M2 "Comfort" e o Ultraspeed. Foram calculados a densidade base e velamento, densidade ótica do filme, sensibilidade, contraste, latitude e resolução. Os resultados mostraram que a escolha da solução processadora pode afetar as propriedades do filme incluindo a sensibilidade. O novo filme do grupo F foi o mais sensível, o Agfa Dentus M2 "Comfort" pôde alcançar a sensibilidade do grupo F e o Ultraspeed, a sensibilidade do grupo E, quando se utilizou a solução Automat XR. O contraste dos filmes foi similar independente da solução utilizada. O novo filme $\mathrm{F}$ reduz pela metade a exposição de radiação ao paciente quando comparado com o filme E, sem detrimento da qualidade da imagem. 


\subsection{Processamento radiográfico}

Há uma preocupação constante para se desenvolver novas técnicas que reduzam o tempo de processamento dos filmes radiográficos utilizados em Odontologia. Esta preocupação é em função da urgência na obtenção de radiografias em tempo relativamente curto para procedimentos em Endodontia e Cirurgia, dispensando assim, pequenos detalhes de diagnóstico que na maioria das vezes podem ser desprezados por estas Especialidades.

Os fabricantes de filmes e soluções processadoras sugerem tempos de exposição e revelação, com os quais, admite-se, possa o profissional obter os melhores resultados. Porém não raro, encontram-se profissionais ou alunos que alteram alguns destes fatores com a inaceitável justificativa de ganho de tempo ${ }^{96}$.

A revelação dos filmes radiográficos é, em última análise, um processo químico no qual agentes redutores agem sobre o sal de prata sensibilizado e provocam a precipitação do metal sob a forma de grãos emulsionados em gelatina. Esta reação química é afetada pela temperatura em que o processo ocorre, sendo acelerada ou retardada nos aumentos ou diminuições da mesma, respectivamente ${ }^{38}$.

O processamento de um filme radiográfico envolve um tempo não produtivo em termos de aproveitamento no tratamento dentário do paciente ${ }^{1}$. Quando existem boas razões para reduzir o tempo de revelação, métodos de processamento rápido ou o uso de processadoras automáticas devem ser considerados. Outras medidas para reduzir o tempo de revelação, compreendem o aumento da temperatura da solução reveladora, o uso de soluções concentradas e solução monobanho.

$\mathrm{O}$ uso de exposições maiores que as recomendadas resulta em aumento de exposição à radiação para o paciente e profissional e não contribuem significativamente para a redução do tempo de processamento, 
desta forma os autores e pesquisadores foram buscando outras formas para se alcançar os resultados desejados no que diz respeito ao tempo de processamento.

PESTRITTO; ANDERSON; BRASELTON ${ }^{84}$, em 1974, compararam a qualidade de diagnóstico de filmes radiográficos intrabucais utilizando cinco técnicas para processamento rápido. $\mathrm{O}$ filme utilizado foi o Ultraspeed da Kodak. Expuseram-se 260 filmes que foram divididos em cinco grupos de 52. As soluções utilizadas foram: revelador Collits para raios X, soluções auto misturáveis (adaptada de Gecker), revelador convencional com temperatura elevada, revelador ADP-60 e solução Uni-Chem (monobanho). As radiografias foram analisadas por 35 examinadores. As soluções Collits e as auto misturáveis produziram radiografias com ótima qualidade para diagnóstico. Os métodos Uni-Chem e ADP-60 mostraram radiografias de pior qualidade. A técnica na qual se aumentou a temperatura da solução reveladora produziu radiografias com qualidades inaceitáveis.

Com o objetivo de verificar possíveis alterações nas densidades óticas de filmes radiográficos Ultraspeed da Kodak, MANSON-HING; MONNIER $^{78}$, em 1975, analisaram sete tipos de soluções processadoras, a saber: revelador e fixador Kodak (usadas como padrão), solução Insta, revelador rápido Collits, solução Uni-Chem (monobanho), revelador Edwal, líquido Kodak concentrado e Kodak DX 80R (concentrado). Os resultados mostraram que as soluções Collits, Insta e Uni-Chem produziram radiografias com densidades menores do que as soluções convencionais. O líquido Kodak concentrado e o Kodak DX 80R podem ser usados como soluções para processamento rápido, produzindo radiografias com pequena perda de densidade da imagem. O revelador Edwal, quando misturado em concentrações maiores que o normal, produziu um leve aumento do contraste radiográfico. 
Utilizando filmes radiográficos Ultraspeed da Kodak e as soluções para processamento reforçador Kodak em três concentrações, revelador DryX-Sol e revelador Clayton em duas concentrações, MANSON-HING; PATEL $^{79}$, em 1977, tentaram determinar se o revelador Kodak concentrado poderia ser efetivamente usado como solução de processamento rápido. Os resultados mostraram que a diluição de $1: 2$ foi a mais eficaz quando o reforçador do revelador Kodak foi utilizado como solução de processamento rápido. A solução Clayton utilizada na concentração recomendada pelo fabricante de 1:4, com tempos de processamento rápido, produziu radiografias com densidades maiores do que o reforçador do revelador Kodak e o Dry-XSol. Os reveladores Clayton, Dry-X-Sol e o reforçador da Kodak utilizados como reveladores rápidos produziram radiografias com menor densidade de imagem do que a solução reveladora padrão da Kodak utilizada nos tempos de processamento convencional. $\mathrm{O}$ contraste radiográfico foi levemente menor quando o processamento rápido foi utilizado.

ACHUTTI; TAVANO; ALVARES ${ }^{1}$, em 1977, compararam um método de revelação rápida com um método de revelação convencional, utilizando filmes DF-57 da Kodak. Utilizaram a solução Kodak a $20^{\circ} \mathrm{C}$ por 4,5 minutos e a solução Gecker a $20^{\circ} \mathrm{C}$, variando o tempo de revelação em 15 , 30, 45 e 60 segundos. Foi aplicada a curva característica para obtenção das propriedades sensitométricas. A combinação solução Gecker a $20^{\circ} \mathrm{C} / 30$ segundos foi a que mais se aproximou da combinação Kodak a $20^{\circ} \mathrm{C} / 4,5$ minutos, quanto ao contraste, latitude e sensibilidade. Esta combinação apresentou alto valor de densidade base e velamento.

Com a finalidade de comparar os resultados alcançados pelas soluções reveladoras rápidas (Gecker e Tiplimatic) com os obtidos com o revelador convencional (Kodak), TAVANO; ALVARES ${ }^{112}$, em 1978, estudaram as propriedades sensitométricas de filmes radiográficos DF-57 da 
Kodak, utilizando estas soluções, obtidas a partir do traçado de suas curvas características. As combinações temperatura/tempo de processamento utilizadas foram as seguintes: Kodak a $20^{\circ} \mathrm{C} / 4,5$ minutos, Gecker a $20^{\circ} \mathrm{C} / 30$ segundos e Tiplimatic a $30^{\circ} \mathrm{C} / 30$ segundos e a $25^{\circ} \mathrm{C} / 37,5$ segundos. Concluíram que as soluções reveladoras testadas apresentaram praticamente as mesmas respostas quando as curvas características foram analisadas no que diz respeito ao contraste, latitude e sensibilidade, sendo que a curva que mais se aproximou da padrão foi a do Tiplimatic a $30^{\circ} \mathrm{C} / 30$ segundos. A densidade base e velamento dos filmes processados nos reveladores rápidos foram ligeiramente maiores do que os revelados no revelador padrão.

HUNT $^{53}$, em 1981, avaliando o processamento automático afirmou que, além do mesmo reduzir o tempo de revelação sem perda na qualidade da imagem, permite um melhor controle de qualidade por apresentar alta padronização.

CARVALHO; TAVANO ${ }^{16}$, em 1982, estudaram, utilizando a curva característica, o contraste, a sensibilidade e a latitude dos filmes radiográficos Kodak DF-57, quando revelados na solução convencional Kodak, durante 4,5 minutos a $20^{\circ} \mathrm{C}$ e no reforçador Kodak (usado como revelador rápido), na temperatura de $25^{\circ} \mathrm{C} / 30$ segundos. $\mathrm{O}$ reforçador Kodak foi utilizado em diferentes diluições, a saber: 1:1, 1:2 e 1:3. A análise dos resultados permitiu as seguintes conclusões: o reforçador Kodak, utilizado como revelador rápido (solução pura a $25^{\circ} \mathrm{C} / 30$ segundos), produziu radiografias de qualidades aceitáveis; em termos de contraste, sensibilidade e latitude, os filmes processados no reforçador Kodak, nas condições acima descritas, apresentaram resultados semelhantes àqueles obtidos com o uso do revelador convencional a $20^{\circ} \mathrm{C} / 4,5$ minutos, possuindo, entretanto, densidade base e velamento ligeiramente maiores. 
Utilizando a curva característica para obtenção das propriedades sensitométricas (latitude, contraste e sensibilidade), CASTELO; TAVANO; LOPES $^{17}$, em 1983, analisaram filmes radiográficos Ultraspeed da Kodak, processados no revelador Kodak a $20^{\circ} \mathrm{C} / 4,5$ minutos (usado como padrão) ou na solução rápida Rayonal, nas combinações de temperatura/tempo: $18^{\circ} \mathrm{C} / 2$ minutos, $20^{\circ} \mathrm{C} / 1,5$ minuto, $22^{\circ} \mathrm{C} / 1,25$ minuto e a $25^{\circ} \mathrm{C} / 1$ minuto. Concluíram que em termos de contraste radiográfico, latitude e sensibilidade, os filmes processados no revelador Rayonal apresentaram resultados aceitáveis quando utilizadas as combinações de temperatura/tempo recomendadas pelo fabricante. Os filmes revelados na solução Rayonal a $22^{\circ} \mathrm{C} / 1,25$ minuto, apresentaram propriedades sensitométricas semelhantes às dos filmes processados no revelador Kodak a $20^{\circ} \mathrm{C}$ durante 4,5 minutos, mostrando, inclusive, os mesmos valores de densidade base e velamento.

SPOSTO; TAVANO; LOPES ${ }^{103}$, em 1983, avaliaram o comportamento de dois reveladores (Kodak e Sillib) para o processamento de filmes radiográficos periapicais, utilizando a curva característica. Utilizaramse filmes Ultraspeed DF-58 da Kodak. O revelador Kodak (padrão) foi utilizado na combinação de $20^{\circ} \mathrm{C} / 5$ minutos e o Sillib, a $20^{\circ} \mathrm{C} / 2$ minutos, $22^{\circ} \mathrm{C} / 1,5$ minuto e $25^{\circ} \mathrm{C} / 1$ minuto. As propriedades sensitométricas dos filmes processados no revelador Sillib a $25^{\circ} \mathrm{C} / 1$ minuto, forneceram resultados semelhantes àqueles obtidos pelo uso do revelador Kodak a $20^{\circ} \mathrm{C} / 5$ minutos, considerado padrão.

TAVANO; SILVEIRA ${ }^{116}$, em 1984, tiveram como objetivo estudar o comportamento e a degradação da solução Kodak para raios X (líquido concentrado), quando utilizada como revelador rápido $\left(30^{\circ} \mathrm{C} / 1\right.$ minuto $)$ e comparar estes resultados quando se utiliza a solução Kodak na combinação convencional $\left(20^{\circ} \mathrm{C} / 5\right.$ minutos). O estudo da degradação foi realizado tomando como norma a revelação a $30^{\circ} \mathrm{C} / 1$ minuto, durante o período de 62 
dias. Os resultados mostraram que a melhor combinação temperatura/tempo para trabalhar com o revelador Kodak para raios X (líquido concentrado), usado como solução rápida foi $30^{\circ} \mathrm{C} / 1$ minuto, mostrando resultados semelhantes ao processamento convencional $\left(20^{\circ} \mathrm{C} / 5\right.$ minutos $)$, no que diz respeito à densidade ótica e propriedades sensitométricas. O período de degradação da solução foi um pouco mais curto, 56 dias, quando comparado com o uso da mesma solução a $20^{\circ} \mathrm{C} / 5$ minutos, que foi de 75 dias.

KAFFE; LITTNER; TAMSE ${ }^{62}$, em 1984, estudaram três filmes radiográficos intrabucais de sensibilidade do grupo $D$ de diferentes fabricantes, processados em cinco soluções para processamento em condições padronizadas, com o intuito de verificar qual a melhor combinação solução/filme em relação à densidade ótica, contraste, densidade base e velamento e sensibilidade. Os filmes utilizados foram Kodak Ultraspeed DF58, Agfa Dentus M2, e Rinn Auto 58 e as soluções, Adefo, Agfa Gevaert, Kerr, Kodak e Durr Periomat. De acordo com os resultados, a melhor combinação foi obtida utilizando-se o filme Kodak Ultraspeed e a solução Adefo, produzindo uma densidade base e velamento e contraste aceitáveis e alta sensibilidade. O filme Rinn, em todas as soluções de processamento, apresentou bom contraste e alta sensibilidade, porém, mostrou uma densidade base e velamento inaceitável, resultando em deterioração da qualidade de imagem.

Para verificar os efeitos de variáveis de processamento, tais como processamento manual e automático e variação na temperatura das soluções de processamento, KOGON ${ }^{65}$ et al, em 1985, utilizaram filmes Ultraspeed e Ektaspeed. A solução GBX da Kodak foi utilizada para processamento manual, e a RP X-Omat da Kodak para o processamento automático. O tempo de processamento manual foi mantido em quatro minutos, quando a temperatura da solução variava. Quando o tempo variava, a temperatura era 
mantida em $22^{\circ} \mathrm{C}$. Durante o processamento automático, quando a temperatura variava, o tempo era mantido em 4,5 minutos e quando o tempo variava, a temperatura era de $28,3^{\circ} \mathrm{C}$. Seis temperaturas $\left(\right.$ de $18,3^{\circ} \mathrm{C}$ a $26,7^{\circ} \mathrm{C}$ ) e seis tempos (variando de 2,5 - 6,0 minutos) foram utilizados para o processamento manual. Para o processamento automático utilizaram-se sete níveis de temperatura (variando de $23,3^{\circ} \mathrm{C}$ a $32,2^{\circ} \mathrm{C}$ ) e sete variações de tempo (de 1,2 a 6,0 minutos). Concluíram que quando se utilizou a solução GBX da Kodak durante o processamento manual, o filme Ektaspeed mostrou grande perda de contraste nas temperaturas acima de $22,2^{\circ} \mathrm{C}$. $\mathrm{O}$ filme $\mathrm{D}$ não foi afetado por altas temperaturas. No processamento automático, as temperaturas acima do recomendável, $28,3^{\circ} \mathrm{C}$, mostraram pouco efeito no contraste de ambos os filmes. Durante o processamento manual, quando a temperatura foi constante, não houve diferença significativa no contraste dos filmes. No tempo abaixo de três minutos para o processamento automático, ambos os filmes foram incompletamente revelados.

Com o intuito de descobrir o tempo ótimo de revelação para o filme Ektaspeed, da Kodak, FEJLLSTRÖM ${ }^{30}$ et al em 1986, utilizaram cinco soluções de processamento com diferentes tempos de revelação na temperatura de $21^{\circ} \mathrm{C}$. Os melhores tempos de revelação a $21^{\circ} \mathrm{C}$, para as diferentes soluções foram: Kodak Dental (1:1)/1,5 minuto; Elfwing Rapid (1:3)/1 minuto; Scanfors Dental (1:2)/1,5 minuto; Kodak Dental (1:3)/3 minutos e Gevaert G 150 (1:5)/3 minutos. Quando se aumentou o tempo de revelação, nenhuma melhora na qualidade da imagem pôde ser observada visualmente.

TAVANO; BARATIERI ${ }^{113}$, em 1986, desenvolveram uma solução monobanho para o processamento de filmes radiográficos. Para a análise desta solução utilizaram filmes radiográficos Kodak EP-21 e Agfa Gevaert DOS-1. As soluções processadoras convencional (Kodak) e rápida (Ray) 
foram tomadas como padrões para comparações. Os resultados permitiram as seguintes conclusões: o tempo de processamento ideal do monobanho, mantida a temperatura próxima de $20^{\circ} \mathrm{C}$, é de três minutos, quando se utiliza filmes radiográficos Kodak EP-21 ou Agfa Gevaert DOS-1; na utilização de filmes Agfa Gevaert, o resultado foi satisfatório a partir de um minuto de processamento; tempos de processamento maiores (até cinco minutos) não interferiram no resultado apresentado; a técnica que utiliza a solução monobanho é simplificada e é um procedimento viável quando se trata da obtenção rápida de radiografias.

PINHO; TAVANO; LOPES $^{85}$, em 1987, analisaram as variações que ocorriam em filmes periapicais Kodak Ektaspeed e Agfa Gevaert (Dentus M2) quando se variavam os tempos de exposição e de revelação. Os tempos de exposição utilizados para o filme Ektaspeed foram: 4, 8, 15, 24 e 30 impulsos e para o Dentus M2, 5, 8, 15, 30 e 48 impulsos. Utilizou-se o revelador para raios X Dental da Kodak. A temperatura desta solução foi mantida em $20^{\circ} \mathrm{C}$ e sempre controlada por um termômetro de imersão. Para o processamento dos filmes Ektaspeed, o tempo de revelação foi de 2,5, 5, 10, 15 e 20 minutos e para o Dentus M2 foram de 1,7, 2,5, 5, 10 e 15 minutos. As radiografias foram submetidas a uma análise subjetiva por 30 examinadores (cirurgiões-dentistas e técnicos em Radiologia). Verificou-se que o maior número de radiografias consideradas satisfatórias foi do filme Agfa Gevaert. Os dois tipos de filmes, quando expostos corretamente, produziram radiografias de boa qualidade. Os filmes superexpostos e sub-revelados produziram imagens radiográficas aceitáveis, o que foi também observado, porém com menos intensidade, nos filmes subexpostos e super-revelados.

FLETCHER $^{32}$, em 1987, comparou a qualidade dos filmes D e E de sensibilidade processados com duas técnicas de processamento manual e duas de processamento automático. A qualidade dos filmes foi determinada por 
avaliação sensitométrica para estudar o contraste, incluindo a densidade base e velamento, resolução, para estabelecer o número de linhas por milímetro visível, observação através de lentes de magnificação de 3,5 vezes para determinar a granulação do filme e uma comparação para observar os efeitos do processamento manual e automático. Os resultados mostraram que o filme do grupo E mostrou alto contraste quando processado com o processamento manual. $\mathrm{O}$ filme do grupo $\mathrm{E}$ apresentou grande variação na densidade ótica quando processado automaticamente. A redução na granulação ocorreu quando o filme E foi processado manualmente. A resolução foi idêntica para os filmes $\mathrm{D}$ e $\mathrm{E}$ processados tanto manualmente como automaticamente. $\mathrm{O}$ filme Kodak Ektaspeed processado manualmente ou automaticamente produziu radiografias de qualidade aceitável para diagnóstico.

A qualidade da imagem de filmes radiográficos do grupo $\mathrm{E}$ de sensibilidade, processados em quatro soluções, foi avaliada e comparada com a do grupo D de sensibilidade nos estudos de KAFFE; GRATT ${ }^{60}$, em 1987. Utilizou-se um fantoma para as exposições de 120 filmes (60 de sensibilidade E e 60 de sensibilidade D). Foram usadas quatro diferentes soluções para processamento rápido. Os filmes foram avaliados quanto à sensibilidade, contraste, resolução, granulação e densidade base e velamento. Os filmes processados exibiram imagens de qualidade igual. A densidade base e velamento do filme de sensibilidade $\mathrm{E}$ foi maior que aquela do filme de sensibilidade D. A resolução e a granulação das imagens foram iguais e julgadas adequadas em ambos os tipos de filmes. $\mathrm{O}$ processamento do filme $\mathrm{E}$ em química rápida é recomendado apenas em casos de emergências e em endodontia.

FREDHOLM; JULIN ${ }^{34}$, em 1987, estudaram três soluções para processamento rápido e uma solução padrão para analisar o contraste e a densidade ótica do filme radiográfico Ektaspeed. A temperatura das soluções 
variaram de $15^{\circ} \mathrm{C}$ a $30^{\circ} \mathrm{C}$. Temperaturas abaixo de $18^{\circ} \mathrm{C}$ apresentaram um longo tempo de revelação, mais do que três minutos com os reveladores rápidos e não são recomendadas. Nas temperaturas entre $21^{\circ} \mathrm{C}$ e $24^{\circ} \mathrm{C}$, a solução padrão necessitou de 3,5 - 2,5 minutos para resultar em ótimo contraste. Duas soluções rápidas necessitaram de 1,5 minutos de revelação para resultar em contraste satisfatório nestas temperaturas. Concluíram que a relação entre temperatura/tempo para soluções de processamento rápido, não é linear; um grande aumento do tempo de processamento é requerido quando a solução se encontra nas temperaturas abaixo de $20^{\circ} \mathrm{C}$ e acima de $24^{\circ} \mathrm{C}$, a redução do tempo de revelação é muito pequena.

Com o intuito de analisar os efeitos das variações da temperatura de uma solução reveladora sobre a densidade ótica e o contraste radiográfico, TAMBURÚS ${ }^{109}$, em 1987, utilizou o filme radiográfico Kodak Ektaspeed, do grupo E de sensibilidade. A solução utilizada neste experimento foi a Sillib pronta para uso nas temperaturas de $20^{\circ} \mathrm{C}, 22^{\circ} \mathrm{C}, 24^{\circ} \mathrm{C}$ e $26^{\circ} \mathrm{C}$. O tempo de revelação foi de dois minutos. Utilizou-se um penetrômetro de alumínio puro, escalonado em nove degraus, com espessuras variando de 0 a $16 \mathrm{~mm}$. As alterações de temperatura do revelador foram obtidas com o emprego de gelo e ou água aquecida, colocado no tanque de água em relação direta com os tanques das soluções reveladora e fixadora. Os resultados permitiram concluir que as densidades óticas, nas espessuras 0 e $2 \mathrm{~mm}$, foram significativamente diferentes nas temperaturas de $20^{\circ} \mathrm{C}, 22^{\circ} \mathrm{C}$ e $26^{\circ} \mathrm{C}$ e nas espessuras 4,6 e $8 \mathrm{~mm}$, nas temperaturas de $20^{\circ} \mathrm{C}$. Nas espessuras de 4,6 e $8 \mathrm{~mm}$, as densidades óticas não foram significativamente diferentes nas temperaturas de $22^{\circ} \mathrm{C}$ e $24^{\circ} \mathrm{C}$. Nas espessuras de 10,12, 14 e $16 \mathrm{~mm}$, as densidades óticas não diferiram significativamente nas temperaturas de $20^{\circ} \mathrm{C}, 22^{\circ} \mathrm{C}$ e $24^{\circ} \mathrm{C}$. Para uma mesma temperatura, as densidades óticas diferiram significativamente para todas as espessuras utilizadas. O contraste radiográfico nas quatro 
temperaturas do revelador e nas diferentes espessuras do penetrômetro foi de boa qualidade.

MADDALOZZO; KNOEPPEL; SCHOENFELD ${ }^{77}$, em 1990, realizaram um experimento para avaliar o desempenho de sete soluções de processamento rápido. A qualidade da imagem radiográfica foi observada em relação ao contraste, latitude e resolução. Os resultados indicaram que o processamento manual rápido compromete a qualidade da imagem bem como a sensibilidade e um aumento da exposição de radiação ao paciente. Não há uma motivação para o uso destas solução a menos que haja uma razão racional em termos de tempo ou conveniência.

Com o objetivo de determinar os efeitos no aumento da temperatura de filmes processados em seis diferentes soluções para processamento manual e identificar qual a combinação de filme, solução e temperatura produziria melhores resultados em termos de contraste radiográfico e sensibilidade do filme, MATTHEE; BECKER, SEELIGER ${ }^{80}$, em 1990, realizaram um experimento utilizando os filmes Agfa Dentus M2, Flow e Kodak Ultraspeed. As soluções usadas foram: Agfa, Dürr, EBX, Kolchem, MEMS e Pro-tech. Os filmes foram expostos em um penetrômetro de alumínio em condições padronizadas. $\mathrm{O}$ processamento foi realizado em uma processadora automática com temperaturas que variavam de $25^{\circ} \mathrm{C}$ a $35^{\circ} \mathrm{C}$. Concluíram que quando a temperatura da solução de processamento aumentava de $25^{\circ} \mathrm{C}$ para $35^{\circ} \mathrm{C}$, tanto o contraste radiográfico como a sensibilidade dos filmes também aumentavam. O maior contraste radiográfico foi obtido quando se utilizou o filme Agfa na solução Kolchem a $35^{\circ} \mathrm{C}$, enquanto o filme Kodak Ultraspeed na solução MEMS a $35^{\circ} \mathrm{C}$ apresentou a maior sensibilidade. Uma densidade base e velamento aceitável de 0,25 foi alcançada utilizando-se o filme Agfa em combinação com as soluções Agfa, Dürr, e Pro-tech e com o filme Flow 
na solução Dürr. Todas as outras combinações produziram uma densidade base e velamento maior que 0,25 .

Em 1991, HASHIMOTO; THUNTHY; WEINBERG ${ }^{47}$ estudaram os efeitos das alterações na temperatura da solução processadora e no tempo de processamento automático utilizando filmes intrabucais Kodak Ultraspeed e Ektaspeed. Este estudo mostrou que quando se aumenta a temperatura da solução e o tempo de processamento automático, há um aumento da sensibilidade e do contraste tanto para o Ultraspeed como para o Ektaspeed. Alterações na temperatura da solução têm maior influência na sensibilidade e no contraste do que as alterações realizadas no tempo do processamento automático. As alterações ocorreram mais nos filmes Ektaspeed do que no Ultraspeed e portanto maiores cuidados devem ser tomados durante o processamento dos filmes Ektaspeed.

IUCIF; TAVANO ${ }^{56}$, em 1995, realizaram um estudo com o objetivo de conhecer as características da solução Agfa Dentus no processamento manual de filmes radiográficos Agfa Dentus M2 "Comfort". Após as exposições e processamentos padronizados, com quatro repetições, as radiografias foram analisadas quanto à densidade ótica e curvas características, de onde foram obtidas as propriedades sensitométricas. Os resultados mostraram que a solução é de excelente qualidade, promovendo no filme testado características de alto padrão para o diagnóstico radiográfico.

GEIST; GLEASON ${ }^{41}$, em 1995, avaliaram as diferenças nas propriedades sensitométricas e na resolução entre o processamento rápido abreviado e o processamento rápido completo, utilizando-se filmes radiográficos intrabucais de sensibilidade dos grupos D e E. Quando comparados com filmes processados pelo método convencional em uma processadora automática, os filmes processados em soluções processadoras pelo método manual, apresentaram maior densidade ótica e níveis mais baixos 
de sensibilidade e contraste. $\mathrm{O}$ processamento rápido abreviado apresentou filmes excessivamente manchados, a menos que fossem lavados por 60 segundos após a fixação. A mais severa depreciação com o processamento rápido abreviado na qualidade do filme se desenvolveu quando o tempo de revelação foi reduzido em 50\%. O filme Ektaspeed produziu radiografias com propriedades sensitométricas e resolução comparáveis ao filme do grupo $\mathrm{D}$, utilizando o processamento rápido abreviado e o processamento rápido completo, aliado à redução em $40 \%$ da dose de radiação ao paciente.

Em 1994, a Kodak substituiu o filme Ektaspeed pelo Ektaspeed Plus. Os fabricantes chamavam a atenção para o fato de que este filme não era fortemente afetado pela exaustão das soluções processadoras. Em 1995, THUNTHY; WEINBERG ${ }^{120}$ testaram filmes radiográficos intrabucais Ektaspeed Plus, Ektaspeed e Ultraspeed, processados em processadora automática e com soluções Kodak. Concluíram que a solução apresentou suas melhores propriedades sensitométricas em um período de duas semanas e que devido à exaustão, seus efeitos diminuíram na terceira semana. O filme Ektaspeed Plus foi o que apresentou maior estabilidade em relação a esta exaustão progressiva no que diz respeito a valores médios de contraste e latitude.

A fim de estudar as densidade óticas, curvas características e as variações das propriedades sensitométricas induzidas no filme periapical radiográfico DF-58, TAVANO; CAPELOZZA; FONTÃO ${ }^{117}$, em 1996, utilizaram tempos de revelação que variaram entre 60, 30 e 15 segundos em soluções processadoras na temperatura de $35^{\circ} \mathrm{C}$. Utilizaram a solução Kodak Dental para Raios X, prontas para uso. Os resultados foram comparados com a combinação padrão de $20^{\circ} \mathrm{C} / 5$ minutos. $\mathrm{O}$ experimento foi repetido quatro vezes com o objetivo de buscar resultados mais exatos. Após as exposições e processamentos padronizados, as radiografias foram analisadas quanto à 
densidade ótica e curvas características, de onde se obtiveram as propriedades sensitométricas. Os resultados alcançados mostraram que a combinação temperatura/tempo de $35^{\circ} \mathrm{C} / 60$ segundos foi a que resultou em radiografias de melhor qualidade, sendo a que mais se aproximou do processamento padrão. O tempo de 30 segundos produziu radiografias com valores de sensibilidade e latitude próximos aos do processamento padrão. A combinação de $35^{\circ} \mathrm{C} / 15$ segundos produziu radiografias de qualidade precária e com propriedades sensitométricas inadequadas, sendo portanto, seu uso pouco indicado para diagnóstico radiográfico em Odontologia.

Em um estudo realizado por ROUT ${ }^{94}$ et al, em 1996, comparou-se o processamento radiográfico manual e automático, utilizando-se para isto um questionário enviado para alguns clínicos juntamente com radiografias padronizadas e pré-expostas para o processamento de rotina. A análise de variância dos resultados obtidos mostrou diferenças significantes entre $\mathrm{o}$ processamento manual e automático. Os filmes processados manualmente, apresentaram menor densidade ótica do que aqueles processados automaticamente.

Utilizando o filme radiográfico DF-58, processado em diferentes tempos de revelação (20, 15 e 10 segundos), FONTÃO ${ }^{33}$ et al, em 1997, estudaram as densidades óticas, curvas características e as variações das propriedades sensitométricas induzidas quando a temperatura da solução processadora era de $40^{\circ} \mathrm{C}$. Os resultados foram comparados com a combinação padrão de $20^{\circ} \mathrm{C} / 5$ minutos. A solução utilizada foi a Kodak Dental para Raios X. Os autores concluíram que: a combinação $40^{\circ} \mathrm{C} / 20$ segundos de revelação resultou em radiografias de melhor qualidade, sendo a que mais se aproximou do processamento padrão; as combinações de $40^{\circ} \mathrm{C} / 15$ segundos e $40^{\circ} \mathrm{C} / 10$ segundos, produziram radiografias de qualidade precária e com propriedades sensitométricas inadequadas, sendo, portanto, seu uso 
pouco indicado em Radiologia Odontológica. Acreditam que o tempo de revelação a $40^{\circ} \mathrm{C}$ deve sempre estar acima de 20 segundos.

Para determinar a atividade de quatro soluções de processamento, AKDENIZ; LOMÇALI ${ }^{2}$, em 1999, utilizaram o filme Minimax, do grupo D de sensibilidade e uma processadora automática para o processamento radiográfico. As soluções utilizadas foram Megasan, Hacettepe, Fuji, RPXOmat em três diferentes temperaturas: $25^{\circ} \mathrm{C}, 28^{\circ} \mathrm{C}$ e $30^{\circ} \mathrm{C}$. A processadora utilizada foi a Dürr XR 24, e o tempo de revelação foi de 4,5 minutos para todas as combinações. Avaliou-se o contraste, a sensibilidade e a densidade base e velamento. Todas as soluções produziram valores aceitáveis de densidade base e velamento que não variou significantemente com alterações da temperatura nas quatro soluções utilizadas. O contraste obtido com as soluções RP X-Omat e Fuji foram menores do que com as soluções Megasan e Hacettepe. A sensibilidade mais alta foi alcançada utilizando-se a solução Megasan.

SYRIOPOULOS ${ }^{108}$ et al, em 1999, avaliaram cinco soluções para processamento radiográfico, a saber: para processamento manual - Agfa Dentus, Kodak (1:3) e Demat e para processamento automático - Dürr XR e Periomat Intra. As soluções para processamento manual apresentaram temperatura de $20^{\circ} \mathrm{C}$ e o tempo de revelação foi de cinco minutos. A solução Dürr foi utilizada na temperatura de $28^{\circ} \mathrm{C}$ por um minuto e a Periomat a $25^{\circ} \mathrm{C}$ por um minuto. A densidade base e velamento e a sensibilidade foram mais altas quando se utilizaram as soluções para processamento automático. Das três soluções utilizadas para processamento manual, a Agfa Dentus produziu a maior sensibilidade. A solução Dürr XR a $28^{\circ} \mathrm{C}$ por um minuto produziu maior sensibilidade nos filmes do que a solução Periomat a $25^{\circ} \mathrm{C}$ por um minuto. 


\subsection{Radiografia digital}

A imagem digital está sofrendo sensíveis alterações dentro da Odontologia, novos dispositivos e sistemas de computadores têm sido introduzidos para registrar a imagem produzida pelos raios $\mathrm{X}$ e para sua manipulação, substituindo, desta forma, o filme radiográfico. Este desenvolvimento tem gerado interesse, expectativa, bem como pretensões de superioridade sobre o filme radiográfico ${ }^{25}$.

O exame radiográfico intrabucal, no qual a imagem se forma dos sais de prata da emulsão do filme, tem o seu reconhecido valor e importância, sendo um método extensamente utilizado em Odontologia. Ele oferece uma imagem de qualidade com um preço relativamente baixo. Porém, apresenta algumas desvantagens como: ineficiência como fóton-receptor, pois absorve apenas pequeno percentual da totalidade de fótons que colidem sobre ele, fornece uma imagem estática e que não pode ser alterada, requer um processamento que deve ser realizado sob condições ideais, para que não haja perda de informações, utiliza-se de soluções químicas que podem provocar alergias e causar danos ao meio ambiente, requer uma dose de radiação relativamente alta e é muito sensível às variações nos tempos de exposições aos raios $\mathrm{X}^{10}$.

Digitalizar uma imagem, tornando-a uma matriz contínua, significa transformá-la em dados numéricos e colocá-los na memória de um computador. Isto é feito por um processo chamado amostragem. A amostragem consiste em dividir a imagem original em pequenos quadrados e retângulos (amostras) e associar a cada um deles um número que representa a cor daquele pedaço da imagem. Isso faz com que se represente a imagem como um conjunto de números que pode ser armazenado na memória de um computador. A cada quadrado, que pode ser considerado um ponto da imagem devido ao seu tamanho reduzido, damos o nome de pixel. Uma 
imagem digital de boa qualidade é formada de centenas de milhares de pixels, cada um deles contendo um número com a informação da cor daquele ponto na imagem. Deste modo, o número de tons de cinza disponíveis no sistema digital determina a densidade da imagem e, em geral, o padrão para a radiografia intrabucal, é a digitalização da imagem em 256 tons de cinza, onde o valor 0 (zero) representa o preto e o valor 255, representa o branco. Os demais tons de cinza estão entre os dois valores, a esta escala de cinza denominamos Densidade Radiográfica (D.R.)*

Hoje em dia, podemos obter imagens digitalizadas por meio de dois métodos, o indireto e o direto ${ }^{12,18,28,31,39,40,50,52,97,102,123,124,125,129,130,133}$.

Pelo método indireto, a imagem pode ser capturada de uma radiografia convencional por meio de scanners de alta definição composto de um leitor de transparência que faz o papel de um negatoscópio, incidindo uma luz através da imagem permitindo assim a digitalização e em seguida esta imagem é enviada a um computador onde é visualizada em um monitor e analisada ou modificada por programas apropriados.

O método direto usa um sensor intrabucal para capturar a imagem, podendo-se utilizar dois métodos para esta finalidade. Um destes métodos é o Charge-Coupled-Device (CCD) - dispositivo acoplado de carga, que por um cabo, envia o sinal elétrico produzido pelos raios $\mathrm{X}$ ao microcomputador. $\mathrm{O}$ sinal obtido do $\mathrm{CCD}$, após a exposição à radiação, é armazenado e convertido pixel por pixel em 256 níveis de cinza. A possibilidade de analisar, modificar, medir e quantificar a densidade da imagem radiográfica diretamente no monitor do microcomputador é possível pela tecnologia da radiografia digital. O sensor intrabucal, o hardware e o software associados substituem o filme e o processamento radiográfico ${ }^{10,82}$.

\footnotetext{
*TAVANO, O. - Comunicação pessoal
} 
O efeito de variar a resolução de profundidade da escala de cinza e filtragem da imagem de radiografias periapicais para detectar lesões ósseas, foi discutido por WENZEL ${ }^{132}$, em 1987 e WENZEL ${ }^{131}$, em 1988, que utilizou alterações de contraste e filtros de suavização. As radiografias foram digitalizadas por câmera CCD gerando uma matriz de 512x512 pixels e resolução da escala de cinza variável de 256 a 32 tons de cinza. Concluiu que quando se utilizou a resolução de 256 tons, o diagnóstico foi equivalente ou até melhor em algumas regiões do que o obtido com a radiografia convencional. Quando se utilizaram 128 e 64 tons de cinza o diagnóstico foi equivalente à radiografia original. Com 32 tons, o diagnóstico foi menos preciso do que com a radiografia original. Para testar o efeito de filtros, utilizaram-se três tipos de tratamento: filtros, alteração de contraste e pseudocolorização. O estudo deixou evidente que a detecção de lesões ósseas na mandíbula pode ser melhorada pelo tratamento de imagem.

FUJITA $^{39}$ et al, em 1987, examinaram a melhora na qualidade da imagem de radiografias dentomaxilofaciais com o uso de um sistema de processamento digital indireto da imagem. A qualidade das imagens processadas foi melhor do que as radiografias originais. A visibilidade de detalhes das radiografias processadas, especialmente em áreas de baixa densidade, foi superior às radiografias originais. As radiografias processadas apresentaram mais artefatos e ruídos. Concluíram que o diagnóstico pode ser melhorado com o uso deste sistema.

FUJITA $^{40}$ et al, em 1988, após estudarem radiografias periapicais, que foram escaneadas e transmitidas para a memória de um computador, concluíram que quando comparadas às imagens originais, as imagens digitalizadas apresentaram mais ruídos e artefatos, prejudicando muitas vezes a interpretação radiográfica. Uma melhora do contraste radiográfico foi obtido 
e, segundo estes autores, esta tecnologia pode ser empregada em casos de radiografias com baixo contraste.

BROOKS; MILES ${ }^{12}$, em 1993, discutiram as novas modalidades de captura de imagens utilizadas em Odontologia. A radiografia digital, a ressonância magnética e a tomografia computadorizada foram explicadas. A imagem radiográfica de um filme convencional pode ser convertida para um sinal digital, utilizando-se para isto, um scanner. Uma vez a imagem armazenada em um computador, um grande número de operações pode ser realizada. Uma das mais úteis operações é a comparação de imagens, chamada de subtração digital. O computador pode comparar as duas imagens, pixel por pixel, e jogar a diferença de densidade para uma nova imagem. Alguns usos para este tipo de informação incluem a progressão da doença durante o período de avaliação do tratamento periodontal e terapia endodôntica. Além destas indicações, imagens digitais obtidas por CCD têm como vantagens uma diminuição da dose de radiação em aproximadamente 80\%; eliminação do processamento químico; possibilidade de reconstrução da imagem (2D, 3D) e capacidade de armazenamento no computador.

Foi considerado por DUNN; KANTOR ${ }^{25}$, em 1993, os fatos e ficções sobre a radiografia digital. Segundo estes autores, o processamento da imagem não aumenta o conteúdo da informação. A atual tecnologia limita o conteúdo das informações nos sensores digitais, que não são iguais aos filmes convencionais. Os sensores podem capturar e mostrar uma imagem muito mais rápido que o filme, e num futuro próximo poderão apresentar uma capacidade para diagnóstico equivalente ao filme radiográfico. A habilidade do observador para enxergar detalhes na imagem radiográfica é limitada pelas propriedades da imagem e pelo sistema visual do observador. A apresentação da imagem, as condições em que estas são observadas e o desempenho visual do operador afetam a recuperação da imagem. Os autores concluíram que a 
imagem digital ainda se encontra em fase de desenvolvimento e avaliação, tendo muitos benefícios em potencial a serem explorados.

ZUBERY; DOVE; EBERSOLE ${ }^{137}$, em 1993, propuseram o sistema de avaliação radiográfica auxiliada por computador (CARE) que se baseia na variação logarítmica para detectar pequenas mudanças na densidade ótica. Os autores sugerem que os sistemas para análise quantitativa das mudanças de densidade sejam avaliados baseados em estudos clínicos, incluindo reprodutibilidade, validade e variação ótima da densidade ótica de cada sistema de trabalho individual.

Em 1996, KERBAUY; MORAES ${ }^{63}$ avaliaram se imagens digitalizadas obtidas de radiografias periapicais tomadas com tempo de exposição reduzido poderiam ser melhoradas com o auxílio de um programa de computador para tratamento digital da imagem. Utilizaram-se radiografias de áreas de molares e pré-molares de mandíbulas secas, tomadas em série e padronizadas. Um total de 57 imagens equivalentes às radiografias com tempo de exposição reduzido (60\% a $80 \%$ do tempo considerado normal), digitalizadas e tratadas, foram submetidas à avaliação de sete examinadores que as compararam com as imagens não tratadas. Verificaram que cerca de $80 \%$ das imagens equivalentes às radiografias tomadas com redução de $60 \%$ da dose habitual foram consideradas de qualidade para elaboração de diagnóstico. Quanto às imagens radiográficas tomadas com $80 \%$ de redução do tempo de exposição, cerca de 50\% foram consideradas adequadas para o mesmo propósito.

Em 1997, LAURIS ${ }^{69}$, desenvolveu o SPIRO - Sistema para Processamento de Imagem Radiográfica Odontológica que permite o processamento de imagens previamente digitalizadas ou digitalizadas com o auxílio de um scanner. Os processamentos disponíveis compreendem a ampliação e redução, aumento do contraste e brilho, produção de imagem negativa, pseudocolorização e equalização de histograma. $\mathrm{O}$ programa foi 
testado por 14 Radiologistas e mostrou ter atingido seus objetivos por se tratar de um sistema que auxilia no diagnóstico, é de fácil manuseio e pode ser executado em equipamentos de baixo custo.

Com o intuito de comparar a mais apurada técnica convencional de uso radiográfico, como auxiliar no diagnóstico de doença periodontal, aos resultados obtidos com os sistemas de imagens digitalizadas, de maneira que estes recursos sejam usados de forma segura e generalizada, ZENÓBIO; FERREIRA $^{136}$, em 1997, realizaram uma radiografia obtida pela técnica periapical do paralelismo, que, após sua obtenção foi submetida à digitalização, utilizando-se para isto, um scanner. Determinou-se a área de interesse para análise e o recolorimento da região para determinar as áreas de maior radiolucidez e radiopacidade, utilizando o seguinte esquema de cores: vermelho - radiolúcido; amarelo - radiopacidade parcial e verde - radiopaco. Concluiu-se que o processo de digitalização de imagens possibilita a identificação mais precisa da perda óssea, sendo o mesmo mais uma opção como auxiliar de diagnóstico. Apesar do desenvolvimento e aperfeiçoamento desta tecnologia, a aproximação da relação custo/benefício do uso deste sistema, sua viabilidade e praticidade comparados com o sistema convencional, ainda dificultam sua utilização na clínica Odontológica.

Com o propósito de comparar a capacidade de observação da radiografia digital direta, com e sem processamento de imagem, com radiografias convencionais, para a detecção de lesões periapicais, KULLENDORFF; PETERSSON; ROHLIN ${ }^{66}$, em 1997, utilizaram 50 pacientes apresentando 59 lesões periapicais. Foram realizadas tomadas radiográficas com filme de sensibilidade $\mathrm{E}$ das áreas de interesse e em seguida realizaram-se radiografias digitais diretas das mesmas áreas. Concluiu-se que as radiografias convencionais apresentaram capacidade levemente superior para detecção de lesões periapicais do que radiografias digitais diretas e que o 
processamento da imagem, isto é, o tratamento da imagem utilizando uma escala de cinza para brilho e contraste, não melhoraram a capacidade do observador.

CHEN; CHIANG ${ }^{18}$, em 1997, avaliaram o desempenho físico de um scanner tipo roller. Utilizaram um scanner tipo roller VXR-12 para digitalizar imagens do filme Kodak T-Mat G. As radiografias foram submetidas a leituras com um fotodensitômetro. Em seguida foram escaneadas e também submetidas a leituras da densidade ótica no computador. Os valores de pixel da imagem foram avaliados. Os resultados mostraram que as imagens digitalizadas apresentaram valores de pixels distribuídos em uma variação dinâmica similar àquela do fotodensitômetro.

COCLETE $^{21}$, em 1999, realizou um trabalho no qual verificou a possibilidade de substituição do método convencional para obtenção da Densidade Ótica, utilizando-se um fotodensitômetro, por um método digital, no qual se realiza a leitura das Densidades Radiográfica e Radiográfica invertida utilizando um programa de imagem, a fim de estudar as propriedades do filme radiográfico e a atividade das soluções de processamento. Utilizou tiras de filmes radiográficos extrabucais XK-1 da Kodak, processados na processadora automática DUPONT T4 em diferentes temperaturas, a $27^{\circ} \mathrm{C}, 29^{\circ} \mathrm{C}, 31^{\circ} \mathrm{C}$ e $34^{\circ} \mathrm{C}$. Após a leitura da Densidade Ótica em um fotodensitômetro MRA, as tiras foram escaneadas e transferidas para um computador. A análise das Densidades Radiográficas foi realizada pelo programa Digora for Windows 1.51. A avaliação das Densidades Radiográficas mostrou que em todas as temperaturas utilizadas, os processamentos apresentaram um equilíbrio de resultados. $\mathrm{Na}$ análise estatística, obtida pela Correlação de Pearson, observou-se alta correlação entre a Densidade Ótica quando comparada com as Densidades Radiográfica e Radiográfica invertida, principalmente nas temperaturas de $31^{\circ} \mathrm{C}$ e $34^{\circ} \mathrm{C}$. 
Concluiu que as leituras das tiras sensitométricas realizadas com um fotodensitômetro podem ser substituídas pelas leituras digitalizadas, obtendose desta forma, dados de Densidades Radiográficas de forma objetiva, rápida e de comparação direta com bancos de dados em função da facilidade de arquivo informatizado.

Com o objetivo de analisar a utilização das Densidades Radiográfica e Radiográfica invertida obtidas com o programa de imagem Adobe Photoshop 4.0 para substituir a Densidade Ótica obtida com fotodensitômetros, SILVA ${ }^{100}$, em 1999, utilizou tiras de filmes extrabucais TMS-1. Os filmes foram expostos no sensitômetro MRA por 0,5 segundo e processados em processadora automática em diferentes temperaturas, $27^{\circ} \mathrm{C}$, $29^{\circ} \mathrm{C}, 31^{\circ} \mathrm{C}$ e $34^{\circ} \mathrm{C}$. Estes dados serviram para avaliar a solução de processamento radiográfico, quanto à sua atividade, degradação e uso em diferentes temperaturas. Os resultados mostraram que os processamentos foram mais eficientes nas temperaturas de $31^{\circ} \mathrm{C}$ e $34^{\circ} \mathrm{C}$. A análise estatística, obtida com a Correlação de Pearson, mostrou alta significância de resultados em todas as temperaturas avaliadas quanto às Densidades Radiográficas e Densidade Ótica. O autor concluiu que é viável a substituição do método convencional pelo método digital quando utiliza-se o programa de imagem Adobe Photoshop 4.0, com a vantagem deste método em ser mais objetivo e apresentar ganho de tempo.

$\mathrm{PAVAN}^{83}$, em 1999, realizou um estudo no qual verificou o uso do programa Digora for Windows 1.51 como recurso de controle de qualidade, dada a sua aplicação prática para filmes odontológicos. Verificou, também, se o aumento de temperatura das soluções processadoras modificaria a qualidade da imagem. Concluiu que o uso de imagens digitalizadas pode substituir a avaliação das imagens radiográficas realizadas com um fotodensitômetro em filmes periapicais processados manualmente. As combinações $25^{\circ} \mathrm{C} / 3$ minutos 
e $35^{\circ} \mathrm{C} / 1$ minuto, quando comparadas com a padrão $\left(20^{\circ} \mathrm{C} / 5\right.$ minutos $)$ apresentaram maiores valores de Densidade Ótica, Densidade Radiográfica e Densidade Radiográfica invertida em função de permanecerem tempo maior do que o necessário sob a ação dos agentes reveladores. As combinações $35^{\circ} \mathrm{C} / 15 \mathrm{~s}, 40^{\circ} \mathrm{C} / 15 \mathrm{~s}$ e $40^{\circ} \mathrm{C} / 10 \mathrm{~s}$ apresentaram valores inferiores de Densidade Ótica, Densidade Radiográfica e Densidade Radiográfica invertida e baixa qualidade de imagem, por permanecerem por menor tempo sob a ação da solução reveladora.

IWAKI $^{57}$, em 2000, teve por objetivo comparar a Densidade Ótica obtida no fotodensitômetro com as médias da Densidade Radiográfica e Radiográfica invertida fornecidas pelo sistema Digora for Windows 2.0, a fim de verificar uma possível substituição do método convencional pelo método digital para avaliar o comportamento de tiras sensitométricas obtidas com filmes radiográficos TMS-1, sensibilizados pelo sensitômetro IDIM e processados pela solução RP X-Omat em uma processadora automática. Comparou também a média da Densidade Radiográfica e Radiográfica invertida obtidas após medidas individualizadas em cada faixa produzida pelo sensitômetro IDIM na tira sensitométrica (19 faixas) com a média da medida total de todas as faixas tomadas conjuntamente. Após o estudo comparativo entre Densidade Ótica e Densidades Radiográficas, os resultados mostraram, pela Correlação de Pearson, alta significância estatística, comprovando-se a validade e eficácia deste método de análise do comportamento de filmes radiográficos e soluções de processamento. As Densidades Radiográficas assim como a Densidade Ótica detectaram na mesma proporção a perda da atividade das soluções de processamento. Houve uma grande concordância dos valores quando a solução era nova e uma pequena oscilação quando a solução se apresentava exaurida e/ou degradada, podendo-se utilizar este programa para avaliar a atividade química das soluções. 
A imagem digitalizada tem ampla aplicabilidade nas diferentes especialidades Odontológicas, tendo ainda maiores perspectivas à medida que novas técnicas vão sendo desenvolvidas e dificuldades inerentes ao método, resolvidas. A utilização da imagem digital para estudo das propriedades do filme radiográfico e atividade das soluções processadoras, vem, mais uma vez, contribuir para o avanço da Radiologia Odontológica, também na área de pesquisa de filmes e soluções para processamento. Assim, este estudo visou a aplicabilidade desta tecnologia para avaliar o filme radiográfico recentemente lançado no mercado, Agfa Dentus M2 "Comfort", em diferentes soluções para processamento, utilizando variações nas temperaturas e tempos de revelação. Esta avaliação foi feita por meio da obtenção das Densidades Radiográficas por um programa de imagem e comparada com os resultados obtidos utilizando o método convencional, onde se realizaram leituras a partir de um fotodensitômetro e obtiveram-se as Densidades Óticas, visando a comprovação da substituição do método convencional pelo digital. 


\subsection{Controle de qualidade}

O controle de qualidade é justificado em qualquer parte da realização do exame radiográfico. $\mathrm{O}$ seu uso pode diminuir o tempo de atendimento aos pacientes e conseqüentemente os custos dos exames, pois além de evitar as repetições desnecessárias, praticamos a proteção radiográfica $^{15}$.

GOULD; GRATT ${ }^{44}$, em 1983, realizaram um estudo onde citam que para a obtenção de imagens com qualidade há a necessidade de controlarse a exposição de radiação ao paciente, as condições de processamento do filme radiográfico e o adequado funcionamento dos aparelhos de raios $\mathrm{X}$.

BRIDGMAN; CAMPBELL ${ }^{11}$, em 1995, recomendam os procedimentos que devem ser seguidos para a obtenção de uma radiografia de ótima qualidade. Eles afirmam que os erros podem ocorrer em qualquer etapa da produção radiográfica, porém um defeito em particular pode ser causado por diferentes fatores. $\mathrm{O}$ entendimento de cada uma das fases da produção radiográfica e a observação dos procedimentos são necessários para conseguir radiografias de alta qualidade. Fatores como o equipamento utilizado para emissão dos raios $\mathrm{X}$, a técnica escolhida, estocagem e uso do filme, processamento, acompanhamento de todos os procedimentos, resolução dos problemas encontrados, radiação ao paciente e infecção cruzada, foram discutidos neste trabalho.

As recomendações da AMERICAN STANDARS ASSOCIATION ${ }^{7}$, de 1964, em relação ao controle de qualidade, vão desde o controle com os aparelhos de raios $\mathrm{X}$, processamento radiográfico, escolha adequada do filme radiográfico, uso de sensitômetros e fotodensitômetros para confecção de curvas características e estudo das propriedades sensitométricas dos filmes. Desta forma, analisa-se em qual das fases poderiam ocorrer alterações. 
O controle de qualidade compreende além de outras medidas, a correta observação dos equipamentos da câmara escura, verificação do bom funcionamento dos aparelhos de raios $\mathrm{X}$ e avaliações sensitométricas dos filmes radiográficos. Qualquer negligência das regras de exposição e processamento radiográfico, mesmo que mais simples, poderá levar muitas vezes ao erro na obtenção de uma radiografia ${ }^{45}$.

Segundo LANGLAND; SIPPY; LANGLAIS ${ }^{68}$, em 1984, sensitometria é o estudo da relação quantitativa entre exposição e densidade ótica.

De acordo com THOROGOOD; HORNER; SMITH ${ }^{118}$, em 1988, sensitometria é a resposta do filme à radiação eletromagnética (luz ou raios $\mathrm{X}$ ), verificada após o processamento radiográfico pela obtenção das densidades óticas. A tira sensitométrica, que é uma radiografia padronizada com diferentes faixas de densidades óticas em escala crescente, pode ser produzida utilizando-se dispositivos como penetrômetros de alumínio (para filmes sensíveis aos raios X) ou sensitômetros (para filmes sensíveis à luz). A avaliação das diferentes faixas da tira sensitométrica é realizada utilizando-se um fotodensitômetro, que tem a capacidade de medir a intensidade de luz transmitida pelo filme.

Vários autores dedicam-se aos estudos das propriedades sensitométricas dos filmes radiográficos e soluções processadoras. Eles se utilizam de penetrômetros, simuladores de mandíbula (fantoma), sensitômetros, fotodensitômetros, construção das curvas características e obtenção das propriedades sensitométricas, avaliando, desta forma, as possíveis variações sobre o contraste, a sensibilidade, latitude e densidade ótica dos filmes radiográficos $1,9,14,46,71,72,86,88,95,127$.

Em um manual de sensitometria para filmes radiográficos, publicado em 1974 pela EASTMAN KODAK COMPANY ${ }^{26}$, foi descrita a 
padronização dos métodos para obtenção das curvas características e das propriedades sensitométricas. Neste manual, observou-se ainda, que a curva característica tem sua confecção a partir da aplicação de uma série de exposições à luz ou raios $\mathrm{X}$ em um filme que, após o processamento, permitirá a obtenção das densidades óticas. Os valores das densidades óticas devem ser transferidos para um gráfico, no eixo das ordenadas (eixo Y), enquanto os valores de exposição devem ser transferidos para o eixo das abscissas (eixo X).

Sensitometria é o estudo das relações entre exposição e condições de processamento e a resposta do filme a estes fatores. Estas relações são regidas pelas propriedades sensitométricas, e quando apenas as densidades óticas são utilizadas como parâmetro para comparações entre exposições e condições de processamento, este método é chamado de densitometria.

A curva característica determina as propriedades sensitométricas: contraste, latitude e sensibilidade. Contraste é a diferença entre os diversos graus de preto, branco e cinza do filme radiográfico, e quanto maior o número de tons intermediários de cinza, menor é o contraste. A forma da curva característica indica o contraste, quanto maior for sua inclinação, menor é o contraste $^{114}$.

A sensibilidade é a capacidade que um filme tem de gravar as imagens durante a exposição aos raios X. Esta eficácia pode ser também chamada de velocidade, uma vez que se refere à capacidade de produzir imagens com um maior ou menor tempo de exposição, ou maior ou menor quantidade de radiação ${ }^{43}$.

A sensibilidade é determinada pelo posicionamento da curva característica sobre o eixo da abscissa (eixo X) e não pela sua forma. Pode ser definida como a recíproca de exposição em Röntgens requeridos para produzir a densidade 1 acima da densidade base e velamento sob condições 
padronizadas de exposição e processamento. Assim é expressa em Röntgen recíproco $\left(\mathrm{R}^{*}\right)$. A densidade base e velamento (DBV) é a densidade intrínseca da própria base do filme e que pode ser resultante da qualidade da emulsão e sua interação com as soluções de processamento, radiação secundária e luz de segurança $^{20}$.

A latitude é a maior ou menor capacidade de um filme de ser subexposto ou superexposto, e ainda assim, produzir imagens qualitativas para o diagnóstico. Também é medida no eixo das exposições $(\mathrm{X})^{19}$.

A latitude tem sua variação de forma inversamente proporcional à variação do contraste. Assim, quando um filme radiográfico apresenta alto contraste, ele apresenta, na maioria das vezes, baixa latitude. Os filmes menos sensíveis permitem uma maior facilidade no manuseio por apresentarem maior latitude ${ }^{68}$.

Recomenda-se que o controle de qualidade se aplique também à análise das soluções processadoras, no que diz respeito às temperaturas e tempos ideais para a revelação e fixação da radiografia, à sua exaustão e degradação, ao modo como estas soluções estão sendo armazenadas e preparadas, entre outros cuidados ${ }^{6}$.

É reconhecida a importância da atividade da solução reveladora na qualidade das radiografias produzidas. A atividade do revelador inicia-se após a mistura de seus componentes. A partir desse momento, começam a ocorrer duas modificações distintas: a exaustão e a degradação. À medida que as soluções são gradualmente utilizadas, podem ser constatadas alterações na densidade da radiografia, tornando necessário o aumento do tempo de revelação. Quando esses detalhes são notados, o revelador está perdendo sua atividade química, sendo, portanto, recomendável a troca das soluções ${ }^{81}$.

Em 1981, TAVANO ${ }^{110}$ avaliou o comportamento de vários filmes radiográficos processados em diferentes soluções de processamento, a saber: 
Continental, Hexa, Sillib e Kodak, com várias finalidades, entre elas a de verificar a atividade química das soluções, usando a quantidade de filmes processados como parâmetro, sem a interferência de fatores como oxidação, tempo de uso e luz de segurança, definindo o processo como exaustão química da solução, o que difere de degradação, que é decorrente além da oxidação, do tempo de uso da solução e quantidade de filmes processados.

Com o intuito de verificar o processo de exaustão do revelador e fixador rápido da Kodak para raios X, BARATIERI; TAVANO; NAGEM FILHO $^{9}$, em 1984, estudaram as modificações nas propriedades sensitométricas dos filmes periapicais DF-58. Avaliaram análises subjetivas da qualidade radiográfica realizadas por 12 examinadores. As modificações de $\mathrm{pH}$ e cor da solução durante o experimento foram também observadas. Os resultados apresentados pelos autores, mostraram que a solução em teste não apresentou um comportamento uniforme, pois sua atividade aumentou, atingindo o ponto máximo no $11^{\circ}$ processamento, quando então, passou a decrescer, sem que ocorresse até o final do experimento, a sua exaustão e o prejuízo da qualidade radiográfica. $\mathrm{O}$ pH da solução sofreu pequena redução do primeiro para o último processamento. A cor, que inicialmente era clara, tornou-se mais densa, chegando a acinzentada no final do experimento.

SÁ; ALVARES; TAVANO ${ }^{96}$, em 1986, traçaram curvas características para estudar o comportamento de filmes radiográficos periapicais DF-58 quando processados na solução Kodak a $20^{\circ} \mathrm{C}$, sob diferentes condições de exposição e processamento. $\mathrm{O}$ intuito deste trabalho foi verificar até que ponto alterações nos tempos de exposição, compensando com os tempos de processamento, e vice-versa, alterariam a qualidade final das radiografias obtidas. Os resultados mostraram que os filmes radiográficos que receberam as quantidades de exposição recomendadas pelo fabricante responderam melhor às variáveis de revelação, pois o fator preponderante no 
grau de escurecimento do filme é a quantidade de radiação que ele recebe. Os filmes radiográficos que foram subexpostos aos raios $\mathrm{X}$ apresentaram qualidade de imagem aceitável quando foram super-revelados. A subrevelação é necessária para obtenção de uma radiografia aceitável para diagnóstico quando o filme é superexposto.

Para avaliar o comportamento de soluções processadoras desde a abertura dos galões até o seu término, 105 dias após, BRÜCKER; TAVANO; $\operatorname{COSTA}^{15}$, em 1992, utilizaram soluções RP X-Omat da Kodak para a revelação de filmes extrabucais, tipo "screen" da Kodak. Os filmes foram processados em processadora automática. Foram analisadas as propriedades sensitométricas dos filmes e de acordo com os resultados obtidos, concluíram que estas soluções, quando submetidas à armazenagem adequada, mantém um comportamento semelhante desde sua abertura até o final do uso.

RIBEIRO; TAVANO ${ }^{90}$, em 1993, analisaram a exaustão da solução reveladora Ray, logo após a abertura do frasco. Utilizaram-se 40 filmes periapicais Ektaspeed EP-21 da Kodak. O processamento foi realizado em câmara portátil. Foi realizada a curva característica e analisadas as alterações de $\mathrm{pH}$, cor e perda de volume da solução. Os resultados mostraram que a solução Ray sofreu uma rápida exaustão quando os filmes foram revelados sem interrupção. Quanto às propriedades sensitométricas determinadas, observou-se redução do contraste e aumento da sensibilidade do início para o final dos processamentos. As alterações de $\mathrm{pH}$ foram insignificantes, enquanto a cor tornou-se mais densa. Pequena depleção foi verificada (mais ou menos $0,2 \mathrm{ml}$ por filme).

IUCIF $^{55}$, em 1994, verificou as características da solução de processamento manual Agfa Dentus, com o uso de filmes radiográficos periapicais Kodak DF-58, Agfa Dentus M2 "Comfort", Kodak EP-21 e Minimax TRX-S. Utilizaram-se dois aparelhos fotodensitômetros com a 
finalidade de medir as densidades óticas dos filmes para confecção de curvas características, o Mac Beth TD-504 e o MRA. Os resultados mostraram que o filme que apresentou melhor comportamento frente à solução estudada, foi o Agfa Dentus M2 "Comfort". Este filme apresentou a melhor densidade base e velamento e contraste mais alto, ficando em segundo colocado apenas no que diz respeito à sensibilidade. Os outros filmes apresentaram equivalência de resultados, sendo que o filme Kodak EP-21, apresentou maior sensibilidade, e o filme Kodak DF-58, a maior latitude. A solução testada foi de excelente qualidade, promovendo em todos os filmes utilizados características de alta qualidade para o diagnóstico radiográfico.

RODRIGUES; TAVANO ${ }^{93}$, em 1994, realizaram um estudo no qual utilizaram tiras sensitométricas de filmes radiográficos extrabucais, XK1 e TMS, ambos da Kodak, expostas no sensitômetro IDIM e MRA. Realizaram o teste sensitométrico e avaliaram a densidade ótica. As tiras sensitométricas foram processadas na processadora automática Dupont Cronex $\mathrm{T} 4$ nas temperaturas de $27^{\circ} \mathrm{C}, 29^{\circ} \mathrm{C}, 31^{\circ} \mathrm{C}$ e $34^{\circ} \mathrm{C}$. A leitura das densidades óticas foi realizada com o fotodensitômetro IDIM. Os resultados mostraram que a temperatura de $34^{\circ} \mathrm{C}$ foi mais eficiente para este tipo de processadora quando se utilizou a solução RP X-Omat da Kodak. Nos dois sensitômetros utilizados, a temperatura de $34^{\circ} \mathrm{C}$ proporcionou melhores resultados quanto à densidade ótica.

Para RIBEIRO; TAVANO; PEREIRA ${ }^{89}$, em 1994, a obtenção de uma radiografia com requisitos necessários a uma boa interpretação, funcionando como eficiente meio auxiliar de diagnóstico, tem seu êxito final baseado no processamento radiográfico. Nesta etapa é preciso avaliar não somente a qualidade, mas também o estado das soluções processadoras a serem empregadas, para que o resultado final do processamento radiográfico seja o melhor possível. Assim, muitos se pesquisa sobre processamento 
radiográfico, visando a redução do tempo utilizado, sem o comprometimento final da radiografia. Estes autores avaliaram o comportamento da solução Hexa diluída 1:1 em comparação à solução Kodak padrão, utilizando para isto, o estudo das propriedades sensitométricas (contraste, latitude e sensibilidade) obtidas utilizando-se a curva característica idealizada por HURTTER \& DRIFFIELD ${ }^{54}$, em 1890.

YACOVENCO $^{134}$ et al, em 1995 e YACOVENCO ${ }^{135}$ et al, em 1997, elaboraram uma programa de garantia de qualidade (PGC), com o objetivo de maximizar a obtenção de radiografias de boa qualidade para diagnóstico e com isto elevar o nível de desempenho. As metas fixadas para alcançar este objetivo foram: melhorar a qualificação dos profissionais, a atenção aos pacientes, a qualidade das radiografias, otimizar a dose por exame e reduzir os custos. O procedimento empregado na detecção de falhas no sistema baseou-se em uma análise dos filmes perdidos, procurando-se identificar se a causa foi devido ao aparelho, filme, paciente ou revelação. Os resultados obtidos mostraram uma redução de $70 \%$ na taxa de filmes perdidos com uma efetiva melhora na qualidade da imagem. Concluiu-se que a aplicação destes programas de qualidade proporciona aos pacientes, serviços e produtos que atendam as expectativas, demonstrando uma efetiva melhoria na qualidade das imagens radiográficas.

Com o intuito de examinar os efeitos da exaustão em cinco diferentes soluções de processamento por meio de suas propriedades sensitométricas, SYRIOPOULOS ${ }^{107}$ et al em 1999, utilizaram os filmes radiográficos intrabucais Ektaspeed Plus e Ultraspeed e o Agfa Dentus M2 "Comfort" antigo e o novo. Utilizaram as soluções para processamento manual, Agfa Dentus, Kodak e Demat e para processamento automático, Dürr XR e Periomat. Os resultados mostraram que o Ektaspeed Plus foi mais sensível nas soluções para processamento manual. O Agfa Dentus M2 
"Comfort", recentemente lançado, e o Ektaspeed Plus, apresentaram sensibilidade similar quando se utilizaram as soluções para processamento automático. O filme Ultraspeed apresentou a menor sensibilidade em todas as soluções estudadas. A exaustão do revelador causou comparável decréscimo na sensibilidade do filme Ektaspeed Plus e nos dois filmes Agfa Dentus M2 "Comfort". A solução Agfa Dentus foi a solução de processamento manual mais duradoura, porém apresentou alta proporção de exaustão. A combinação do filme e solução processadora é um importante fator para se alcançar as propriedades sensitométricas constantes. O Ektaspeed Plus e o recente Agfa Dentus M2 "Comfort" podem ser utilizados na prática Odontológica e requerem menor quantidade de radiação. Apresentam propriedades equivalentes ou superiores quando comparados com o filme Ultraspeed.

Em 1999, SULEIMAN ${ }^{104}$ et al, publicaram um artigo onde relataram um levantamento realizado em clínicas Odontológicas particulares que realizavam radiografia dentais, realizado em 1993, e compararam com os resultados obtidos de um levantamento realizado em Faculdades de Odontologia entre 1995 e 1996. Uma amostra representativa de clínicas Odontológicas particulares de cada estado participante foi estudada. Foram coletados dados como: exposição de radiação ao paciente, técnica radiográfica, qualidade da imagem radiográfica, qualidade do processamento radiográfico e velamento. Os autores descobriram que em Faculdades de Odontologia são utilizados filmes radiográficos do grupo E de sensibilidade com mais frequiência do que em clínicas particulares. O uso de filme $\mathrm{E}$ e melhores condições de processamento radiográfico nas Faculdades de Odontologia, resultam em baixas doses de radiação ao paciente sem perda de qualidade da imagem. Descobriram, também, que o velamento radiográfico ocorre mais nas clínicas Odontológicas do que em Faculdades. 
Em virtude da importância de todos estes fatores aqui discutidos, torna-se fundamental o estudo das soluções de processamento e do comportamento de filmes radiográficos quando submetidos à ação das mesmas. Assim, busca-se um controle de qualidade que possa ser utilizado por todos os profissionais que utilizam radiografias como auxiliar de diagnóstico. 
3. Proposição 


\section{PROPOSIÇÃO}

Utilizaram-se filmes radiográficos Agfa Dentus M2 "Comfort" processados nas soluções Agfa, Kodak e Sillib com o propósito de:

1) Verificar qual a melhor combinação temperatura/tempo de revelação quanto às Densidades Óticas, curvas características e propriedades sensitométricas (latitude, sensibilidade e contraste). Utilizaram-se as soluções Agfa Dentus e Kodak a $20^{\circ} \mathrm{C} / 5$ minutos, $25^{\circ} \mathrm{C} / 2,5$ minutos e $30^{\circ} \mathrm{C} / 1,25$ minuto e a solução Sillib a $20^{\circ} \mathrm{C} / 2$ minutos, $25^{\circ} \mathrm{C} / 1$ minuto e $30^{\circ} \mathrm{C} / 0,5$ minuto;

2) Confirmar a observação de que a obtenção das Densidades Óticas por meio de leituras com o uso de um fotodensitômetro, pode ser substituída pelo método digital, utilizando-se o programa de imagem Adobe Photoshop 5.0 para realizar a leitura das Densidades Radiográficas com o intuito de avaliar filmes radiográficos periapicais e soluções processadoras. 
4. Material e Métodos 


\section{MATERIAL E MÉTODOS}

\subsection{Material}

\subsubsection{Filmes radiográficos}

Utilizaram-se 36 filmes radiográficos Agfa Dentus M2 "Comfort", (Fabricado pela Gevaert-Agfa N. U., Amberes, Bélgica), do grupo E de sensibilidade (Figura 1).

A fim de se obter um padrão de qualidade neste experimento, todos os filmes foram retirados de uma mesma caixa com o mesmo prazo de validade que era de um ano após o término do experimento.

\subsubsection{Soluções de processamento}

Utilizaram-se as soluções de processamento radiográfico, compostas de revelador e fixador Agfa Dentus (Fabricada pela Gevaert-Agfa N. U., Amberes, Bélgica), Kodak (Fabricada pela Kodak do Brasil Comércio e Indústria Ltda., São José dos Campos - BR) e Sillib (Fabricada pela Polidental Indústria e Comércio Ltda., São Paulo - BR), seguindo as instruções dos fabricantes para seus respectivos preparos (Figura 2).

\subsubsection{Aparelho de raios $X$}

Utilizou-se um General Eletric, modelo 100, operando com $40 \mathrm{kVp}$ e $15 \mathrm{~mA}$, tendo uma filtragem total equivalente a 2,5 milímetros de alumínio, da Faculdade de Odontologia de Bauru - USP.

A norma PH 2.9 - 1964 da AMERICAN STANDARDS ASSOCIATION $^{7}$, recomenda que quando há variação da quilovoltagem no 
aparelho de raios $\mathrm{X}$, deve-se utilizar aquela que permita uma redução da dose pela metade, quando se acrescentam dois milímetros de alumínio à filtragem inerente ao aparelho.

A precisão do marcador do tempo de exposição foi confirmada utilizando-se um cronômetro de raios $\mathrm{X}$, da marca MRA fabricado pela Indústria e Comércio de Eletrônica - Ribeirão Preto - BR, que tem a função de medir o tempo de exposição em função da radiação real emanada pela área focal do aparelho.

\subsubsection{Dispositivo utilizado para as exposições aos raios $X$}

Utilizou-se um dispositivo para a exposição padronizada dos filmes radiográficos aos raios $\mathrm{X}$, também utilizado por TAVANO; RAYMUNDO JÚNIOR $^{115}$, em 1982, IUCIF; TAVANO ${ }^{56}$, em 1994 e TAVANO; CAPELOZZA; FONTÃO ${ }^{117}$, em 1996. Este dispositivo é composto de uma lâmina de chumbo de $17 \times 23 \mathrm{~cm}$ e $2 \mathrm{~mm}$ de espessura, onde foram realizadas aberturas, de maneira que apenas 1/5 de cada filme fosse exposto (cerca de $9 \mathrm{~mm}$ ). Esta placa de chumbo foi fixada em uma moldura de madeira de modo a centralizá-la com o feixe de raios $\mathrm{X}$ durante a exposição. Os filmes foram presos com uma fita adesiva na parte posterior da placa de chumbo, com a superfície a ser exposta, uma de cada vez, voltada para o aparelho de raios X. Este dispositivo apresenta em sua outra extremidade um suporte de madeira com um apoio para o cabeçote do aparelho de raios $\mathrm{X}$, que manteve a distância foco-filme fixa em $50 \mathrm{~cm}$.

\subsubsection{Aparelho fotodensitômetro}

As leituras das Densidades Óticas foram realizadas em um fotodensitômetro da marca MRA (Figuras 3 e 4), (Fabricado pela Indústria e 
Comércio de Eletrônica - Ribeirão Preto - BR), calibrado de acordo com as instruções do fabricante. Este aparelho apresenta as seguintes características:

- Estabilizador eletrônico de voltagem incorporado contra variações da tensão de alimentação;

- Abertura luminosa de 1mm de diâmetro;

- Mostrador digital com "leds"de 12,3mm;

- Filtro seletor rotativo;

- Leitura logarítmica direta da Densidade Ótica;

- Controle de zeragem;

- Precisão de 0,02 e

- Dimensões de 31 x 26 x $21 \mathrm{~cm}$.

\subsubsection{Câmara escura}

O processamento dos filmes radiográficos foi realizado na câmara escura do Departamento de Radiologia da Faculdade de Odontologia de Bauru - USP, equipada com os seguintes acessórios:

- Cronômetro Gra-Lab;

- Aquecedor de imersão;

- Termômetro de imersão Premium;

- Tanques com capacidade de 20 litros para lavagem final;

- cinco recipientes de vidro com capacidade de $200 \mathrm{ml}$ cada um;

- um recipiente contendo água com capacidade para 1000ml.

Para a revelação, banho intermediário e fixação, foram utilizadas colgaduras individuais. Colgaduras com 14 grampos foram utilizadas para a lavagem final no tanque de água corrente e secagem dos filmes radiográficos. 


\subsubsection{Computador}

Utilizou-se um computador Pentium II 266, 64 MB de RAM, 6 GB de HD, CD ROM 24X, com placa de vídeo de 2 MB e monitor Sony, gerenciado pelo programa Windows 98, para o processamento dos dados obtidos com o fotodensitômetro (Densidade Ótica), e com o programa Adobe Photoshop 5.0 (Adobe Systems Incorporated, San José, Ca 95110-2704 USA) para leitura das Densidades Radiográficas.

\subsubsection{Scanner de mesa e gravador de CD}

Utilizou-se um scanner de mesa Scanjet HP 4C/T da Hewllet Packard, made in USA, tendo como acessório, um leitor de transparência que permitiu a varredura da imagem e a digitalização do filme radiográfico. Estas imagens foram, então, transmitidas para a memória do computador, onde pudemos realizar a leitura das Densidades Radiográficas.

Para cópia de segurança dos arquivos de imagens obtidos utilizouse um gravador de CD da Hewllet Packard e um compact disc de 650 MB. 


\subsection{Métodos}

\subsubsection{Exposição dos filmes aos raios $X$ no dispositivo de chumbo}

Foram expostos 36 filmes radiográficos (12 para cada solução, sendo quatro para cada temperatura), pois o experimento foi repetido quatro vezes a fim de se obter resultados mais precisos.

Os filmes foram expostos no dispositivo de chumbo que permitiu a exposição de apenas uma parte de cada filme (1/5). Eles foram fixados na parte posterior do dispositivo com uma fita adesiva. Os tempos de exposição utilizados foram 1, 10, 60 e 300 impulsos. Foram expostos quatro filmes de cada vez e as exposições foram realizadas em seqüência, começando da maior (300 impulsos - faixa 4), para a menor (1 impulso - faixa - 1), ficando a última faixa sem ser exposta, representando a densidade base e velamento (DBV faixa 0), na qual foram observadas as alterações produzidas no filme radiográfico pela atuação apenas das soluções processadoras. Entre as diferentes exposições de cada faixa houve um intervalo de cinco minutos. Entre a exposição dos filmes e o processamento houve um intervalo de no mínimo duas horas e no máximo 24 horas, permitindo desta maneira, que as ionizações causadas nos halogenados de prata da emulsão se estabilizem, formando uma imagem latente, de acordo com a norma PH 2.9 de 1964 da AMERICAN STANDARDS ASSOCIATION ${ }^{7}$. Após este período, o esvaecimento da imagem se inicia.

\subsubsection{Processamento radiográfico}

Os filmes foram identificadas previamente às exposições com números de chumbo fixados em sua parte superior, correspondentes à solução processadora e à temperatura utilizada, na seguinte ordem: 
(1) Solução reveladora Agfa Dentus na temperatura de $20^{\circ} \mathrm{C} / 5$ minutos;

(2) Solução reveladora Agfa Dentus na temperatura de $25^{\circ} \mathrm{C} / 2,5$ minutos;

(3) Solução reveladora Agfa Dentus na temperatura de $30^{\circ} \mathrm{C} / 1,25$ minuto;

(4) Solução reveladora Kodak na temperatura de $20^{\circ} \mathrm{C} / 5$ minutos;

(5) Solução reveladora Kodak na temperatura de $25^{\circ} \mathrm{C} / 2,5$ minutos;

(6) Solução reveladora Kodak na temperatura de $30^{\circ} \mathrm{C} / 1,25$ minuto;

(7) Solução reveladora Sillib na temperatura de $20^{\circ} \mathrm{C} / 2$ minuto;

(8) Solução reveladora Sillib na temperatura de $25^{\circ} \mathrm{C} / 1$ minuto;

(9) Solução reveladora Sillib na temperatura de $30^{\circ} \mathrm{C} / 0,5$ minuto.

O processamento radiográfico foi realizado em câmara escura utilizando-se o método temperatura/tempo, garantindo sua precisão com um cronômetro elétrico. Durante o processamento manual dos filmes radiográficos, na câmara escura, não foram ligadas luzes de segurança. O processamento radiográfico foi realizado em uma só etapa, procurando desta maneira, máxima padronização.

Os filmes foram processados em etapas de acordo com a solução e as temperaturas utilizadas. Inicialmente foram processadas as quatro primeiras radiografias expostas. A solução utilizada foi a Agfa Dentus na temperatura de $20^{\circ} \mathrm{C}$. As radiografias foram dispostas na bancada da câmara escura e então presas em grampos individuais e levadas, duas a duas, aos recipientes de vidro com capacidade para $200 \mathrm{ml}$ contendo a solução 
reveladora a $20^{\circ} \mathrm{C}$. O tempo de revelação foi de cinco minutos para esta temperatura. $\mathrm{O}$ mesmo procedimento foi repetido para as outras soluções e temperaturas, alterando-se apenas o tempo de revelação. Os recipientes contendo as soluções foram colocados dentro de um outro recipiente de vidro com capacidade para $1000 \mathrm{ml}$ contendo água. Dentro deste recipiente maior foi colocado um aquecedor de imersão que, ligado à eletricidade, promovia o aquecimento da água, mantendo as soluções em banho-maria na temperatura desejada para a realização do experimento.

Após a revelação todas as películas foram processadas da seguinte maneira:

- banho intermediário - as películas foram transferidas para um recipiente contendo água corrente, onde foram submetidas à lavagem intermediária por 20 segundos.

- a solução fixadora foi dividida em dois recipientes de vidro com capacidade para $200 \mathrm{ml}$, onde as radiografias foram fixadas duas a duas por um tempo de dez minutos.

- as películas foram removidas dos grampos individuais e transferidas para uma colgadura Kodak para 14 películas e então levadas à lavagem final em água corrente durante 20 minutos. Após secas, as radiografias foram acondicionadas em envelopes individuais para cada um dos nove grupos utilizados.

Após as exposições e o processamento padronizado dos filmes, obtivemos radiografias com cinco diferentes faixas de densidade, para as três soluções, nas temperaturas de $20^{\circ} \mathrm{C}, 25^{\circ} \mathrm{C}$ e $30^{\circ} \mathrm{C}$ (Figura 7).

\subsubsection{Leitura da Densidade Ótica}

Após o processamento radiográfico obtivemos películas com vários graus de escurecimento em cinco faixas. Para realizarmos as medidas da 
Densidade Ótica, escolhemos dez áreas em cada faixa, onde então aplicamos a área ativa do fotodensitômetro (Figuras 3 e 4). Estas medidas foram anotadas em tabelas próprias e posteriormente realizaram-se as médias destas 10 leituras. Foram confeccionadas curvas características para a obtenção das propriedades sensitométricas.

\subsubsection{Construção das curvas características}

Os dados obtidos das leituras das Densidades Óticas, com o fotodensitômetro, depois de anotados em tabelas próprias, foram transferidos para um gráfico, para a confecção das curvas características e obtenção das propriedades sensitométricas.

Foram construídas nove curvas características, uma para cada combinação solução/temperatura/tempo.

A curva característica foi construída da seguinte maneira: os valores de exposição foram plotados no eixo $\mathrm{X}$ (abscissa), enquanto que no eixo $\mathrm{Y}$ (ordenada), foram marcadas as Densidades Óticas obtidas das radiografias em estudo. Os valores de exposição em impulsos emitidos à cada faixa, foram transformados em valores de uma escala logarítmica de maneira a facilitar a construção das curvas, tornando o gráfico mais compacto. As Densidades Óticas correspondem a números absolutos e são funções logarítmicas da quantidade de luz que atravessa a radiografia. Uma radiografia tem Densidade Ótica igual a um quando ela deixa passar 1/10 da luz que incide sobre ela. As exposições relativas foram marcadas de acordo com os impulsos dados em cada faixa de exposições dos filmes: $300,60,10,1$ e 0.

O contraste radiográfico é representado por um valor numérico chamado gradiente médio, que é a tangente do ângulo formado por uma reta que liga dois pontos de densidades específicas de uma curva característica. Traçam-se duas retas paralelas ao eixo X a partir da Densidade Ótica 0,25 e 2 
acima da densidade base e velamento, até encontrar a curva característica. Em seguida, traça-se uma reta que liga estes dois pontos. A tangente do ângulo formado por esta reta e o eixo $\mathrm{X}$, refere-se ao valor de contraste.

A sensibilidade refere-se ao posicionamento da curva ao longo do eixo $\mathrm{X}$ e pode ser definida como exposição requerida para produzir a densidade de 1,0 acima da DBV. Traçou-se uma paralela ao eixo $\mathrm{X}$, a partir da Densidade Ótica 1,0 mais DBV do eixo Y, até encontrar a curva. Deste cruzamento, traçou-se uma paralela ao eixo $\mathrm{Y}$, até encontrar o eixo $\mathrm{X}$, ponto correspondente à sensibilidade do filme.

Para a obtenção da latitude, traçaram-se duas linhas paralelas ao eixo das exposições (eixo $\mathrm{X}$ ), as quais partem de dois pontos específicos de densidade 1,0 e 2,0 acima da DBV. Na intersecção da curva, traçaram-se perpendicularmente a este mesmo eixo duas retas, cuja faixa de exposição delimitada foi a latitude do filme. Segundo a EASTMAN KODAK COMPANY ${ }^{26}$, em 1974, a latitude de um filme radiográfico é definida como a maior ou menor capacidade do mesmo em ser tanto subexposto como superexposto, e ainda produzir imagens de qualidade aceitável para interpretação.

Após a confecção das curvas características e a obtenção das propriedades sensitométricas, buscamos uma melhor combinação solução/temperatura/tempo dentro dos padrões aplicados nesta pesquisa.

\subsubsection{Digitalização das imagens}

Depois de obtidas as curvas características, realizou-se a captura de imagens dos mesmos filmes radiográficos e sua transmissão à memória do computador utilizando-se um scanner de mesa Scanjet 4C/T e um gravador de CD da Smart Friendly para obtenção de cópias de segurança dos arquivos de imagens gravadas em um compact disc. Realizou-se, então, a leitura da 
Densidade Radiográfica (níveis de cinza), com o programa Adobe Photoshop 5.0.

\subsubsection{Análise da imagem digital}

As imagens dos filmes radiográficos foram avaliadas utilizando-se o programa Adobe Photoshop, versão 5.0, compatível com o Windows, da seguinte maneira: abriu-se o programa e clicou-se na imagem que se desejava examinar; após o aparecimento da imagem clicou-se no item ferramenta para escolha da forma retangular. Em seguida, em opções, colocamos forma fixa, com largura de 94 pixels e altura de 28 pixels. Depois, arrastamos a forma sobre a primeira faixa de densidade, clicamos em imagem e em seguida em histograma, que nos mostrou como resultado a Densidade Radiográfica (níveis de cinza), a mediana e o desvio padrão. Repetimos o mesmo procedimento para todas as faixas de diferentes exposições (impulsos) em todos os grupos. Para se obter a Densidade Radiográfica invertida, clicamos em imagem e logo após em inverter. A imagem tornou-se invertida e então repetimos o mesmo procedimento para alcançar a Densidade Radiográfica invertida em todas as faixas de exposição (Figuras 5 e 6). Estes dados foram anotados em fichas próprias para serem, então, submetidos à análise estatística e comparados com os valores de Densidades Óticas obtidos.

\subsubsection{Análise estatística}

Os dados obtidos após a leitura das Densidades Radiográficas e das Densidades Óticas foram submetidos à análise estatística por meio do Coeficiente de Correlação de Pearson. O nível de confiança foi estabelecido em $95 \%$. Observou-se correlação estatística quando $\mathrm{p}<0,05$. 


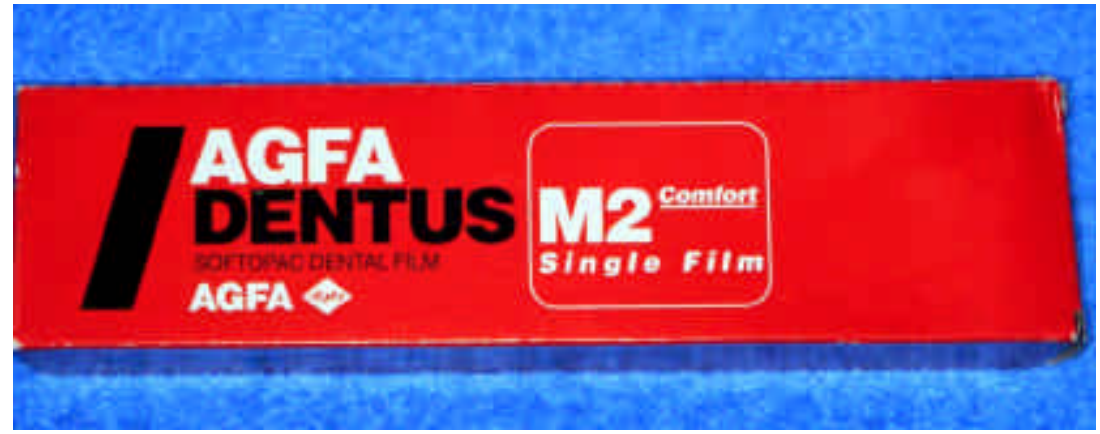

FIGURA 1 - Caixa de filme radiográfico intrabucal Agfa Dentus M2 "Comfort"

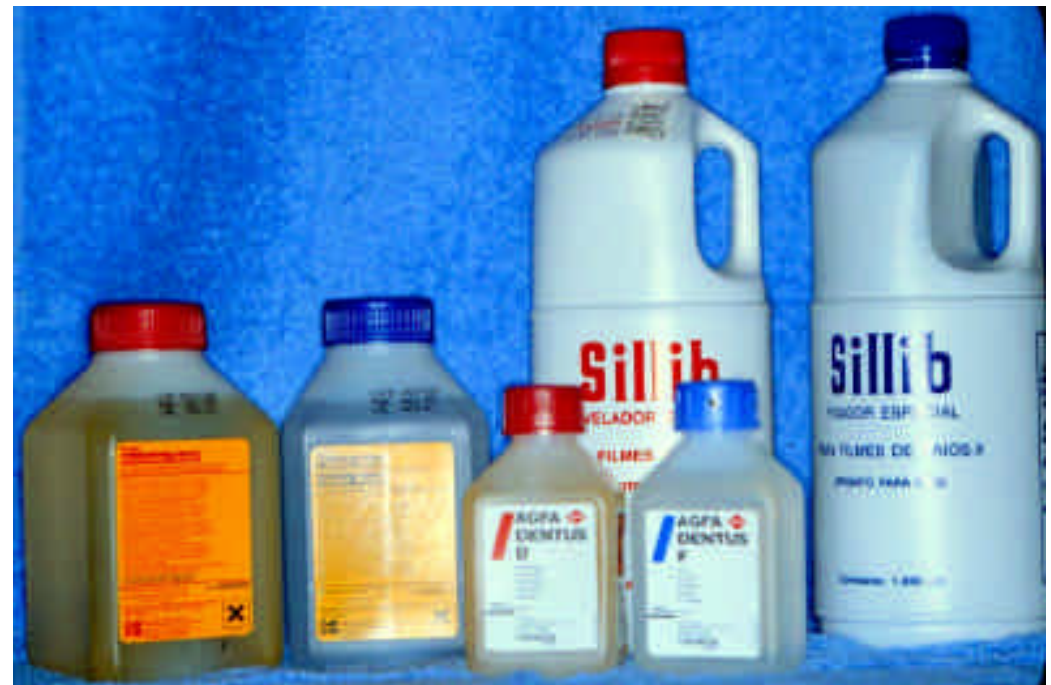

FIGURA 2 - Soluções para o processamento radiográfico manual - Agfa Dentus, Kodak e Sillib

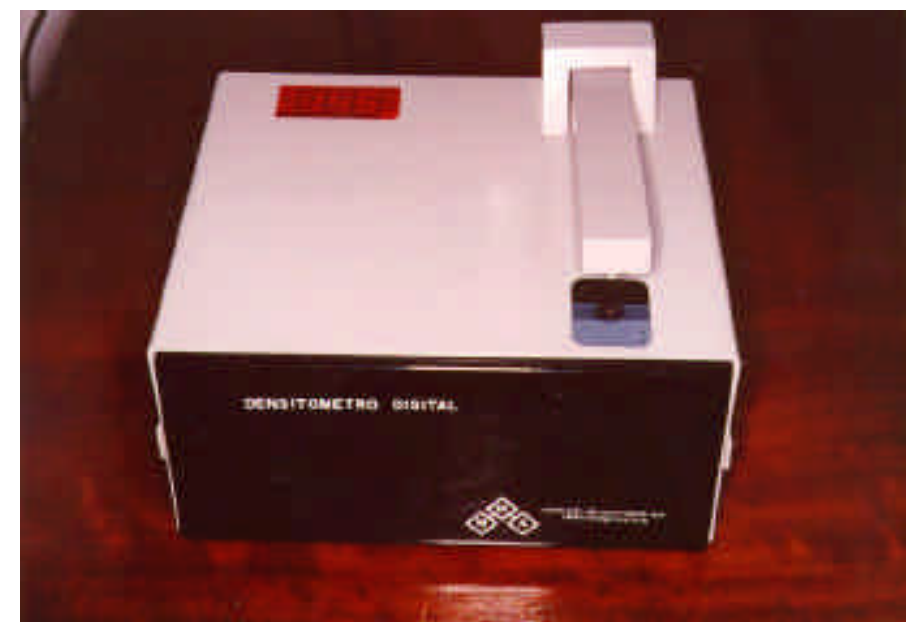

FIGURA 3 - Aparelho fotodensitômetro com uma radiografia em posição, para realização da leitura da Densidade Ótica

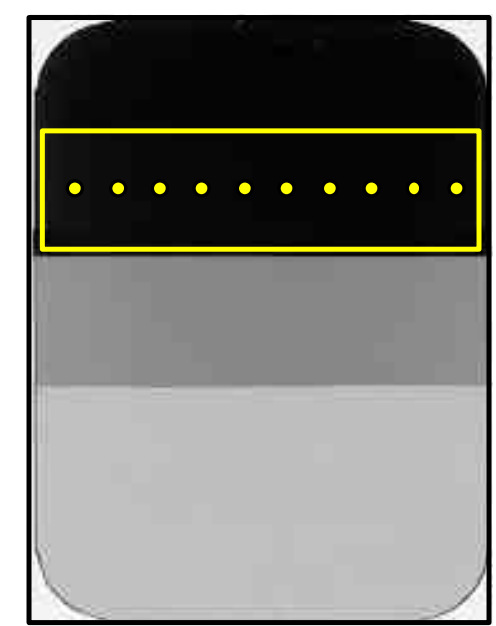

FIGURA 4 - Demonstração da leitura de Densidade Ótica realizada no fotodensitômetro MRA 


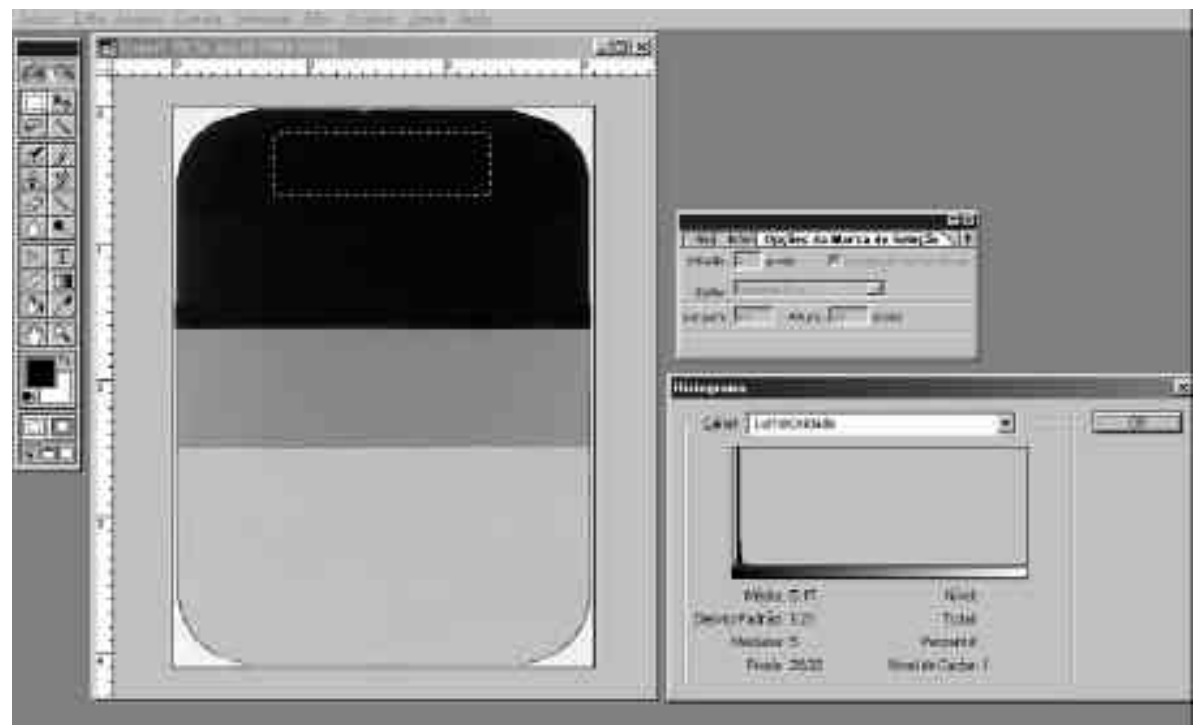

FIGURA 5 - Demonstração da tela do monitor com uma radiografia no Programa Adobe Photoshop 5.0, que mostra a Densidade Radiográfica da área, a mediana e o desvio padrão

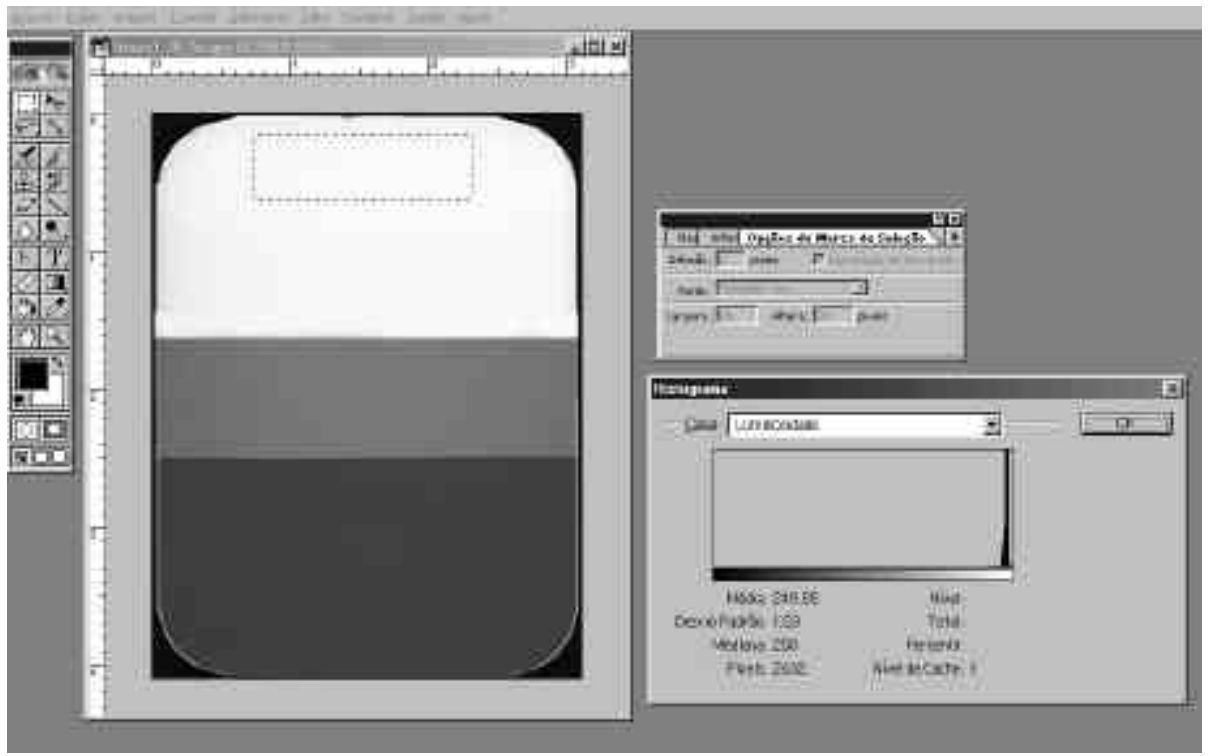

FIGURA 6 - Demonstração da tela do monitor com uma radiografia no Programa Adobe Photoshop 5.0, que mostra a Densidade Radiográfica invertida da área, a mediana e o desvio padrão 
AGFA DENTUS

KODAK
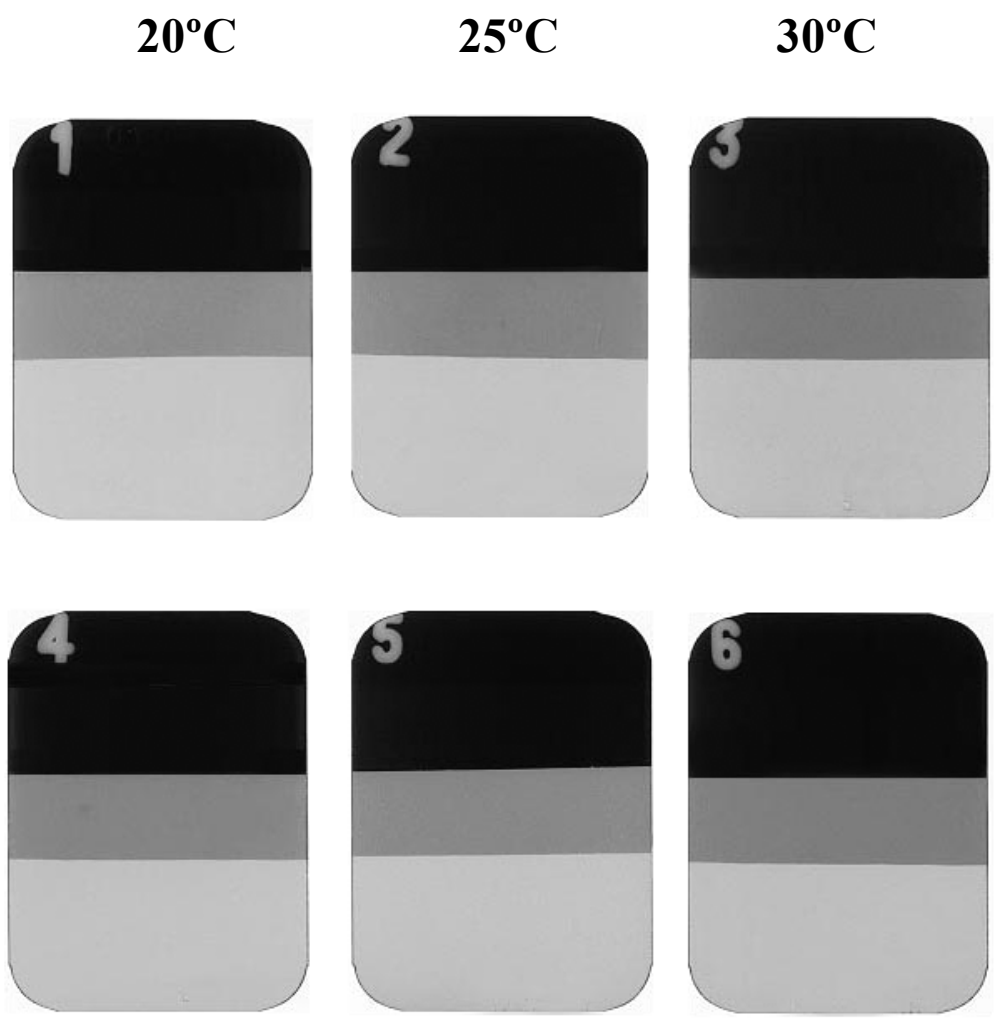

SILLIB
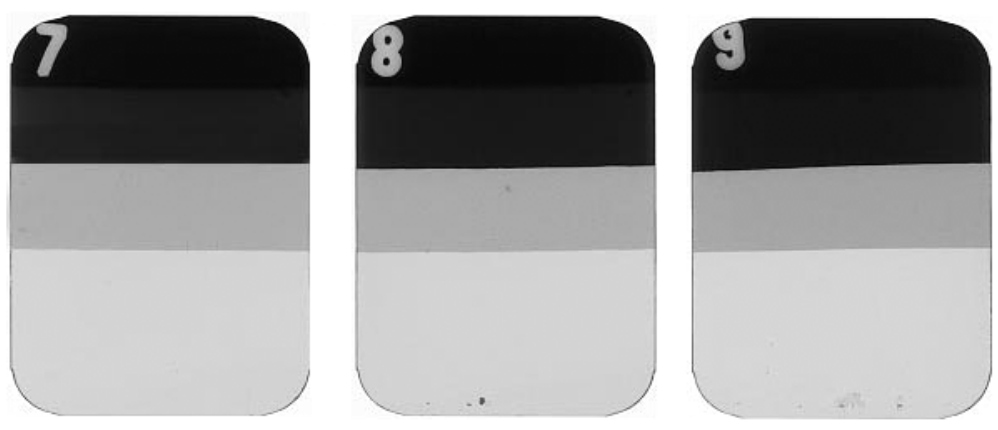

FIGURA 7 - Radiografias obtidas após a exposição e processamento com as soluções Agfa Dentus, Kodak e Sillib nas temperaturas de $20^{\circ} \mathrm{C}, 25^{\circ} \mathrm{C}$ e $30^{\circ} \mathrm{C}$ 
5. RESUltados 


\section{RESULTADOS}

Os resultados de Densidade Ótica alcançados com a utilização do fotodensitômetro MRA, nas quatro radiografias em estudo, estão mostrados nas tabelas de 1 a 9. As Figuras de 8 a 16 mostram as curvas características que foram traçadas a partir dos valores médios encontrados nas quatro radiografias utilizadas para o experimento. 
TABELA 1 - Tabela com o valor médio das dez leituras das Densidades Óticas, realizadas com o fotodensitômetro MRA em cada uma das cinco faixas nas quatro radiografias obtidas com filmes radiográficos Agfa Dentus M2 "Comfort", processados na solução Agfa Dentus, na temperatura de $20^{\circ} \mathrm{C}$, por cinco minutos - Grupo 1

\begin{tabular}{c|c|c|c|c|c}
\hline \hline & R1 & R2 & R3 & R4 & MÉDIA \\
\hline \hline $\mathbf{3 0 0}-4$ & $\mathbf{4 , 6 9}$ & $\mathbf{4 , 6 7}$ & $\mathbf{4 , 9 3}$ & $\mathbf{4 , 7 1}$ & $\mathbf{4 , 7 5}$ \\
\hline $\mathbf{6 0}-\mathbf{3}$ & $\mathbf{2 , 5 7}$ & $\mathbf{2 , 6 8}$ & $\mathbf{2 , 5 6}$ & $\mathbf{2 , 6 5}$ & $\mathbf{2 , 6 1}$ \\
\hline $10-2$ & $\mathbf{0 , 4 1}$ & $\mathbf{0 , 4 5}$ & $\mathbf{0 , 4 3}$ & $\mathbf{0 , 4 5}$ & $\mathbf{0 , 4 3}$ \\
\hline $1-1$ & $\mathbf{0 , 0 7}$ & $\mathbf{0 , 0 7}$ & $\mathbf{0 , 0 8}$ & $\mathbf{0 , 0 9}$ & $\mathbf{0 , 0 8}$ \\
\hline DBV - 0 & $\mathbf{0 , 0 6}$ & $\mathbf{0 , 0 7}$ & $\mathbf{0 , 0 8}$ & $\mathbf{0 , 0 8}$ & $\mathbf{0 , 0 7}$ \\
\hline
\end{tabular}

Filme: Agfa Dentus M2 "Comfort"

Fotodensitômetro: MRA

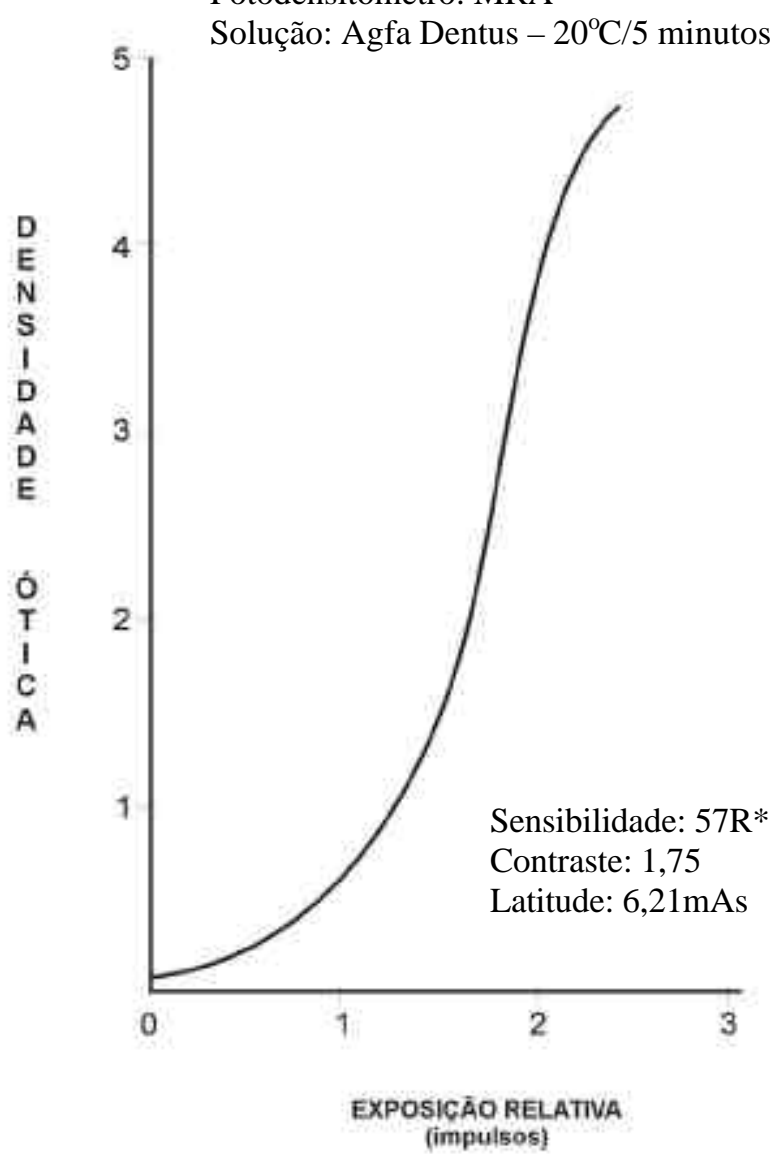

FIGURA 8 - Curva característica obtida com o valor médio das leituras de Densidades Óticas no fotodensitômetro MRA das quatro radiografias estudadas, utilizando o filme Agfa Dentus M2 "Comfort", processado na solução Agfa Dentus a $20^{\circ} \mathrm{C} / 5$ minutos (grupo 1 ) 
TABELA 2 - Tabela com o valor médio das dez leituras das Densidades Óticas, realizadas com o fotodensitômetro MRA em cada uma das cinco faixas nas quatro radiografias obtidas com filmes radiográficos Agfa Dentus M2 "Comfort", processados na solução Agfa Dentus, na temperatura de $25^{\circ} \mathrm{C}$, por 2,5 minutos - Grupo 2

\begin{tabular}{c|c|c|c|c|c}
\hline \hline & R1 & R2 & R3 & R4 & MÉDIA \\
\hline \hline $\mathbf{3 0 0}-4$ & $\mathbf{4 , 7 0}$ & $\mathbf{4 , 5 1}$ & $\mathbf{4 , 5 3}$ & 4,54 & $\mathbf{4 , 5 7}$ \\
\hline $\mathbf{6 0}-\mathbf{3}$ & $\mathbf{3 , 0 7}$ & $\mathbf{3 , 0 0}$ & $\mathbf{3 , 1 6}$ & $\mathbf{3 , 2 5}$ & $\mathbf{3 , 1 2}$ \\
\hline $10-2$ & $\mathbf{0 , 5 9}$ & $\mathbf{0 , 5 4}$ & $\mathbf{0 , 5 9}$ & $\mathbf{0 , 6 3}$ & $\mathbf{0 , 5 9}$ \\
\hline $1-1$ & $\mathbf{0 , 1 4}$ & $\mathbf{0 , 1 1}$ & $\mathbf{0 , 1 2}$ & $\mathbf{0 , 1 4}$ & $\mathbf{0 , 1 3}$ \\
\hline DBV - 0 & $\mathbf{0 , 1 3}$ & $\mathbf{0 , 1 2}$ & $\mathbf{0 , 1 2}$ & $\mathbf{0 , 1 3}$ & $\mathbf{0 , 1 2}$ \\
\hline
\end{tabular}

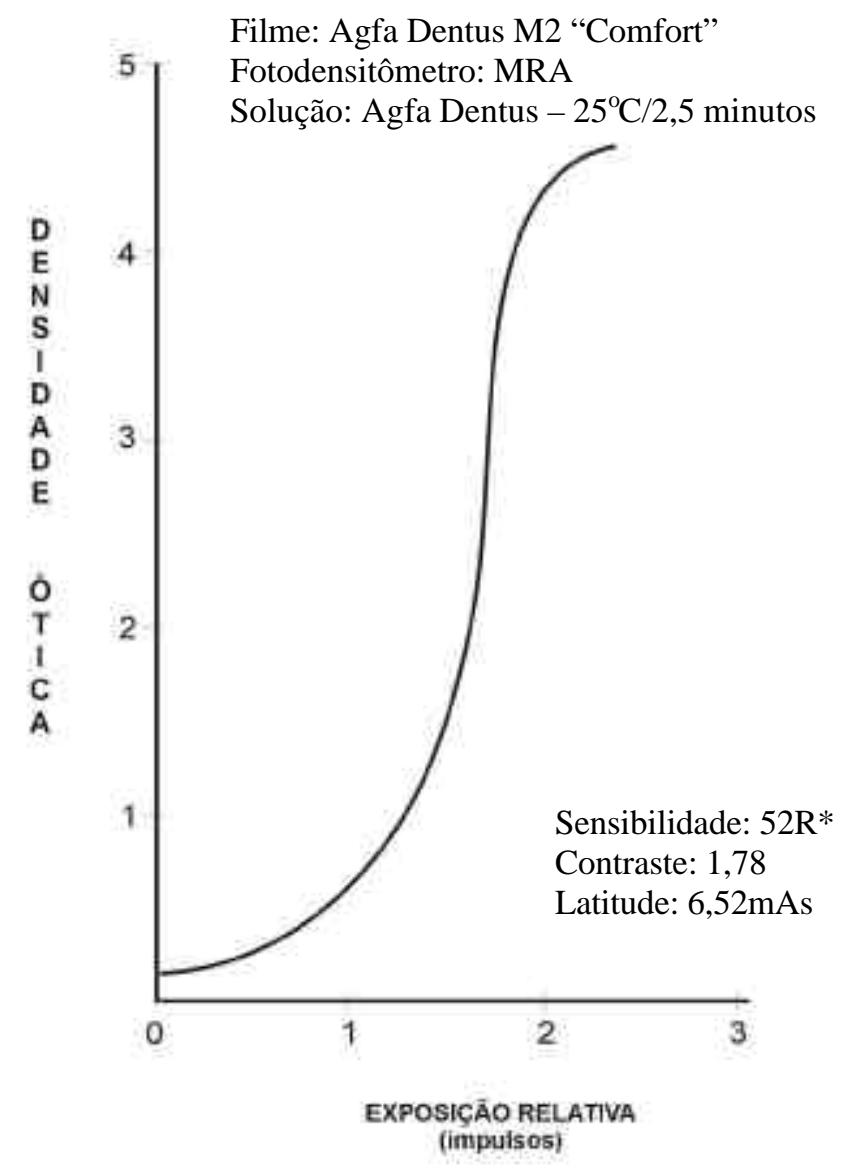

FIGURA 9 - Curva característica obtida com o valor médio das leituras de Densidades Óticas no fotodensitômetro MRA das quatro radiografias estudadas, utilizando o filme Agfa Dentus M2 "Comfort", processado na solução Agfa Dentus a $25^{\circ} \mathrm{C} / 2,5$ minutos (grupo 2) 
TABELA 3 - Tabela com o valor médio das dez leituras das Densidades Óticas, realizadas com o fotodensitômetro MRA em cada uma das cinco faixas nas quatro radiografias obtidas com filmes radiográficos Agfa Dentus M2 "Comfort", processados na solução Agfa Dentus, na temperatura de $30^{\circ} \mathrm{C}$, por 1,25 minuto - Grupo 3

\begin{tabular}{c|c|c|c|c|c}
\hline \hline & R1 & R2 & R3 & R4 & MÉDIA \\
\hline $300-4$ & 4,21 & 4,29 & 4,27 & $\mathbf{3 , 9 0}$ & $\mathbf{4 , 1 8}$ \\
\hline $60-3$ & $\mathbf{3 , 0 1}$ & $\mathbf{3 , 1 5}$ & $\mathbf{3 , 0 4}$ & $\mathbf{2 , 9 0}$ & $\mathbf{3 , 0 2}$ \\
\hline $10-2$ & $\mathbf{0 , 6 1}$ & $\mathbf{0 , 6 6}$ & $\mathbf{0 , 5 9}$ & $\mathbf{0 , 5 7}$ & $\mathbf{0 , 6 1}$ \\
\hline $1-1$ & $\mathbf{0 , 1 5}$ & $\mathbf{0 , 1 7}$ & $\mathbf{0 , 1 2}$ & $\mathbf{0 , 1 3}$ & $\mathbf{0 , 1 4}$ \\
\hline DBV -0 & $\mathbf{0 , 1 4}$ & $\mathbf{0 , 1 7}$ & $\mathbf{0 , 1 3}$ & $\mathbf{0 , 1 4}$ & $\mathbf{0 , 1 4}$ \\
\hline
\end{tabular}

Filme: Agfa Dentus M2 "Comfort”

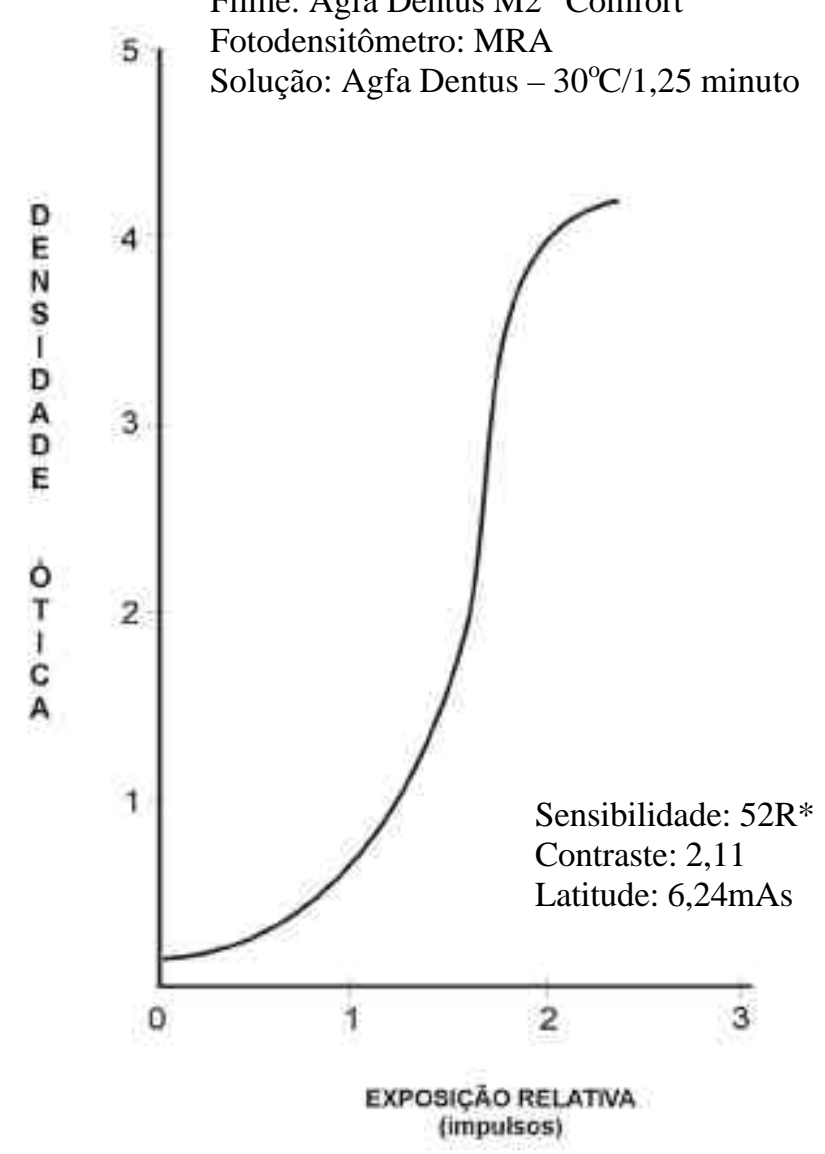

FIGURA 10 - Curva característica obtida com o valor médio das leituras de Densidades Óticas no fotodensitômetro MRA das quatro radiografias estudadas, utilizando o filme Agfa Dentus M2 "Comfort", processado na solução Agfa Dentus a $30^{\circ} \mathrm{C} / 1,25$ minuto (grupo 3) 
TABELA 4 - Tabela com o valor médio das dez leituras das Densidades Óticas, realizadas com o fotodensitômetro MRA em cada uma das cinco faixas nas quatro radiografias obtidas com filmes radiográficos Agfa Dentus M2 "Comfort", processados na solução Kodak, na temperatura de $20^{\circ} \mathrm{C}$, por cinco minutos Grupo 4

\begin{tabular}{c|c|c|c|c|c}
\hline \hline & R1 & R2 & R3 & R4 & MÉDIA \\
\hline \hline $300-4$ & $\mathbf{4 , 1 1}$ & $\mathbf{4 , 1 3}$ & $\mathbf{4 , 2 8}$ & 4,14 & 4,16 \\
\hline $60-3$ & $\mathbf{2 , 7 4}$ & $\mathbf{2 , 6 6}$ & $\mathbf{2 , 6 6}$ & $\mathbf{2 , 5 7}$ & $\mathbf{2 , 6 6}$ \\
\hline $10-2$ & $\mathbf{0 , 5 3}$ & $\mathbf{0 , 5 2}$ & $\mathbf{0 , 5 3}$ & $\mathbf{0 , 5 0}$ & $\mathbf{0 , 5 2}$ \\
\hline $1-1$ & $\mathbf{0 , 1 2}$ & $\mathbf{0 , 1 2}$ & $\mathbf{0 , 1 3}$ & $\mathbf{0 , 1 3}$ & $\mathbf{0 , 1 2}$ \\
\hline DBV $-\mathbf{0}$ & $\mathbf{0 , 1 3}$ & $\mathbf{0 , 1 2}$ & $\mathbf{0 , 1 3}$ & $\mathbf{0 , 1 2}$ & $\mathbf{0 , 1 2}$ \\
\hline
\end{tabular}

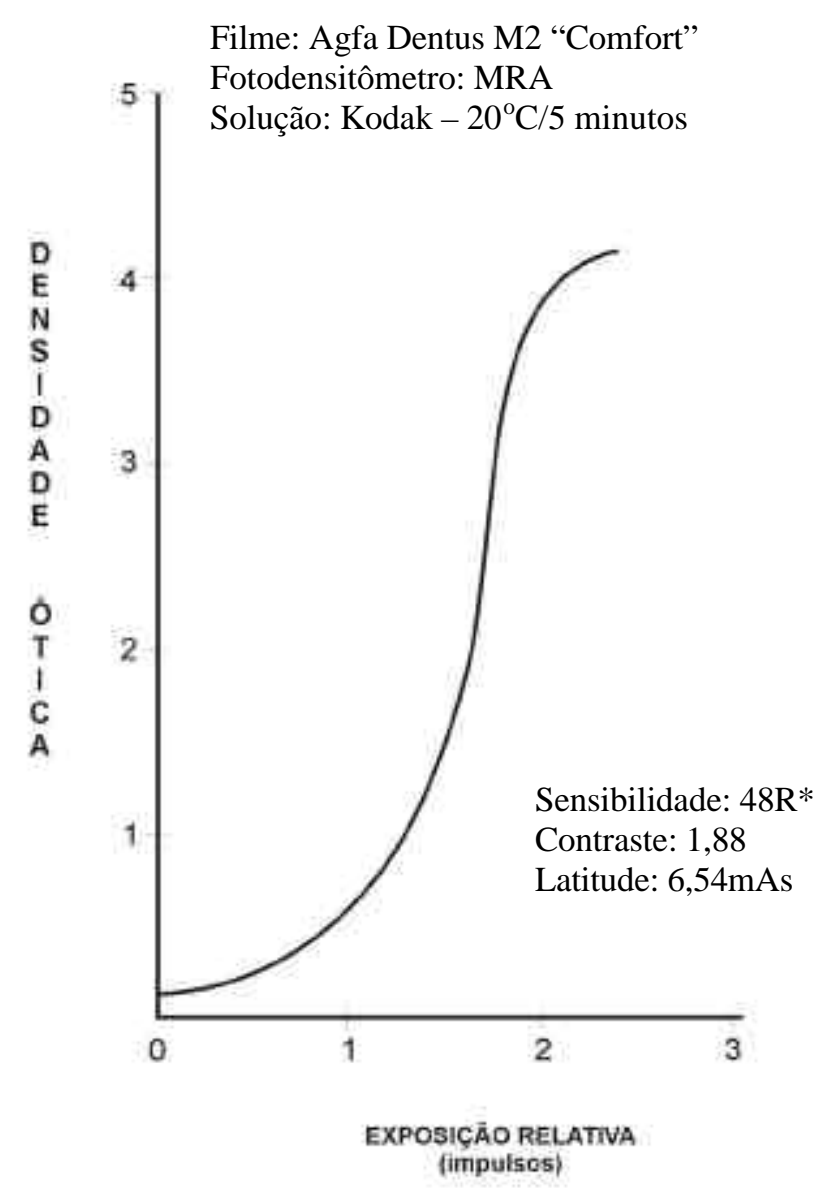

FIGURA 11 - Curva característica obtida com o valor médio das leituras de Densidades Óticas no fotodensitômetro MRA das quatro radiografias estudadas, utilizando o filme Agfa Dentus M2 "Comfort", processado na solução Kodak a $20^{\circ} \mathrm{C} / 5$ minutos (grupo 4 ) 
TABELA 5 - Tabela com o valor médio das dez leituras das Densidades Óticas, realizadas com o fotodensitômetro MRA em cada uma das cinco faixas nas quatro radiografias obtidas com filmes radiográficos Agfa Dentus M2 "Comfort", processados na solução Kodak, na temperatura de $25^{\circ} \mathrm{C}$, por 2,5 minutos Grupo 5

\begin{tabular}{c|c|c|c|c|c}
\hline \hline & R1 & R2 & R3 & R4 & MÉDIA \\
\hline $300-4$ & 4,67 & 4,73 & 4,67 & 4,68 & 4,69 \\
\hline $60-3$ & 2,59 & 2,53 & 2,65 & 2,67 & 2,61 \\
\hline $10-2$ & $\mathbf{0 , 4 9}$ & $\mathbf{0 , 4 7}$ & $\mathbf{0 , 5 1}$ & $\mathbf{0 , 5 1}$ & $\mathbf{0 , 4 9}$ \\
\hline $1-1$ & $\mathbf{0 , 1 0}$ & $\mathbf{0 , 0 8}$ & $\mathbf{0 , 1 1}$ & $\mathbf{0 , 1 0}$ & $\mathbf{0 , 1 0}$ \\
\hline DBV - 0 & $\mathbf{0 , 1 0}$ & $\mathbf{0 , 0 9}$ & $\mathbf{0 , 1 1}$ & $\mathbf{0 , 0 9}$ & $\mathbf{0 , 1 0}$ \\
\hline
\end{tabular}

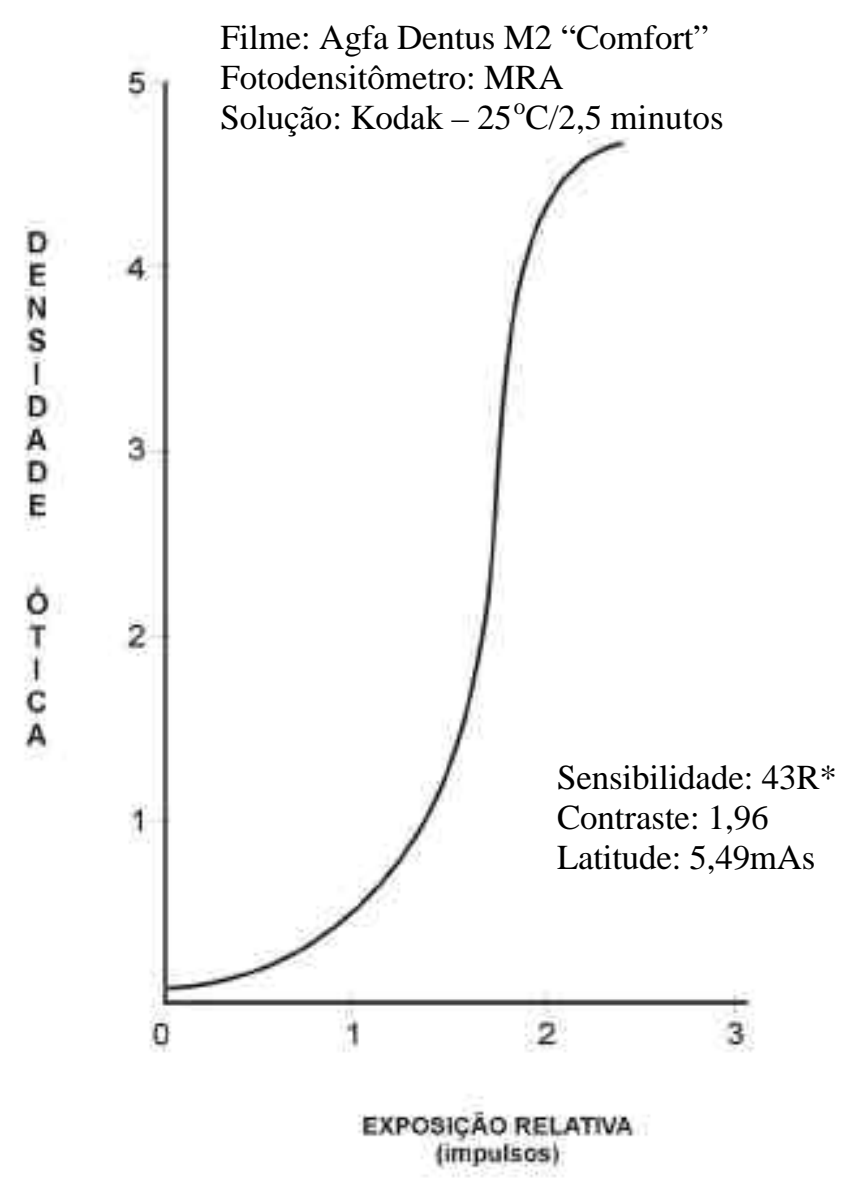

FIGURA 12 - Curva característica obtida com o valor médio das leituras de Densidades Óticas no fotodensitômetro MRA das quatro radiografias estudadas, utilizando o filme Agfa Dentus M2 "Comfort", processado na solução Kodak a $25^{\circ} \mathrm{C} / 2,5$ minutos (grupo 5) 
TABELA 6 - Tabela com o valor médio das dez leituras das Densidades Óticas, realizadas com o fotodensitômetro MRA em cada uma das cinco faixas nas quatro radiografias obtidas com filmes radiográficos Agfa Dentus M2 "Comfort", processados na solução Kodak, na temperatura de $30^{\circ} \mathrm{C}$, por 1,25 minuto Grupo 6

\begin{tabular}{c|c|c|c|c|c}
\hline \hline & R1 & R2 & R3 & R4 & MÉDIA \\
\hline \hline $300-4$ & 4,59 & 4.65 & 4,50 & 4,66 & 4,60 \\
\hline $60-3$ & $\mathbf{2 , 9 0}$ & $\mathbf{2 , 7 4}$ & $\mathbf{2 , 8 9}$ & $\mathbf{3 , 0 4}$ & $\mathbf{2 , 9 0}$ \\
\hline $10-2$ & $\mathbf{0 , 5 8}$ & $\mathbf{0 , 5 5}$ & $\mathbf{0 , 5 7}$ & $\mathbf{0 , 6 0}$ & $\mathbf{0 , 5 7}$ \\
\hline $1-1$ & $\mathbf{0 , 1 4}$ & $\mathbf{0 , 1 3}$ & $\mathbf{0 , 1 4}$ & $\mathbf{0 , 1 3}$ & $\mathbf{0 , 1 3}$ \\
\hline DBV - 0 & $\mathbf{0 , 1 3}$ & $\mathbf{0 , 1 3}$ & $\mathbf{0 , 1 3}$ & $\mathbf{0 , 1 3}$ & $\mathbf{0 , 1 3}$ \\
\hline
\end{tabular}

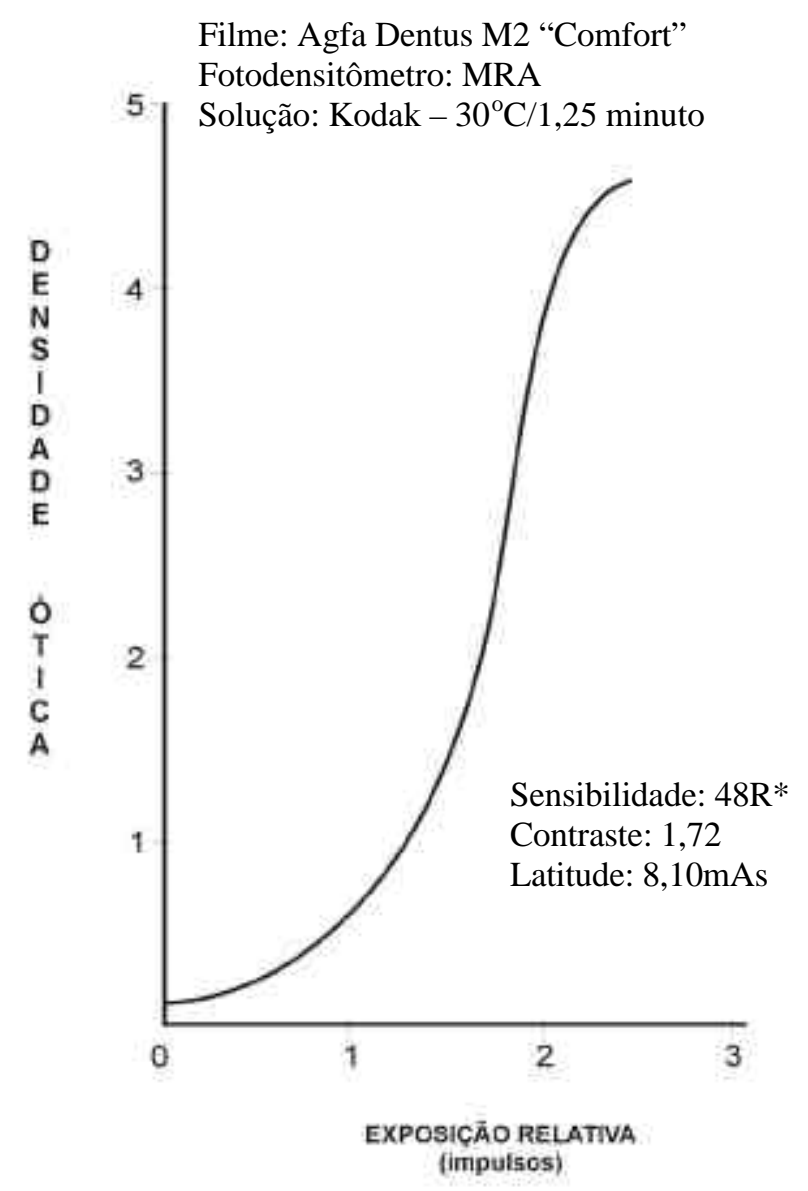

FIGURA 13 - Curva característica obtida com o valor médio das leituras de Densidades Óticas no fotodensitômetro MRA das quatro radiografias estudadas, utilizando o filme Agfa Dentus M2 "Comfort", processado na solução Kodak a $30^{\circ} \mathrm{C} / 1,25$ minuto (grupo 6) 
TABELA 7 - Tabela com o valor médio das dez leituras das Densidades Óticas, realizadas com o fotodensitômetro MRA em cada uma das cinco faixas nas quatro radiografias obtidas com filmes radiográficos Agfa Dentus M2 "Comfort", processados na solução Sillib, na temperatura de $20^{\circ} \mathrm{C}$, por dois minutos Grupo 7

\begin{tabular}{c|c|c|c|c|c}
\hline \hline & R1 & R2 & R3 & R4 & MÉDIA \\
\hline \hline $\mathbf{3 0 0}-4$ & $\mathbf{4 , 5 3}$ & $\mathbf{4 , 7 5}$ & $\mathbf{3 , 3 4}$ & $\mathbf{4 , 5 1}$ & $\mathbf{4 , 2 8}$ \\
\hline $\mathbf{6 0}-\mathbf{3}$ & $\mathbf{1 , 7 3}$ & $\mathbf{1 , 6 4}$ & $\mathbf{1 , 7 0}$ & $\mathbf{1 , 6 7}$ & $\mathbf{1 , 6 8}$ \\
\hline $10-2$ & $\mathbf{0 , 2 5}$ & $\mathbf{0 , 2 5}$ & $\mathbf{0 , 2 6}$ & $\mathbf{0 , 2 6}$ & $\mathbf{0 , 2 5}$ \\
\hline $1-1$ & $\mathbf{0 , 0 3}$ & $\mathbf{0 , 0 3}$ & $\mathbf{0 , 0 3}$ & $\mathbf{0 , 0 4}$ & $\mathbf{0 , 0 3}$ \\
\hline DBV $-\mathbf{0}$ & $\mathbf{0 , 0 2}$ & $\mathbf{0 , 0 2}$ & $\mathbf{0 , 0 2}$ & $\mathbf{0 , 0 3}$ & $\mathbf{0 , 0 2}$ \\
\hline
\end{tabular}

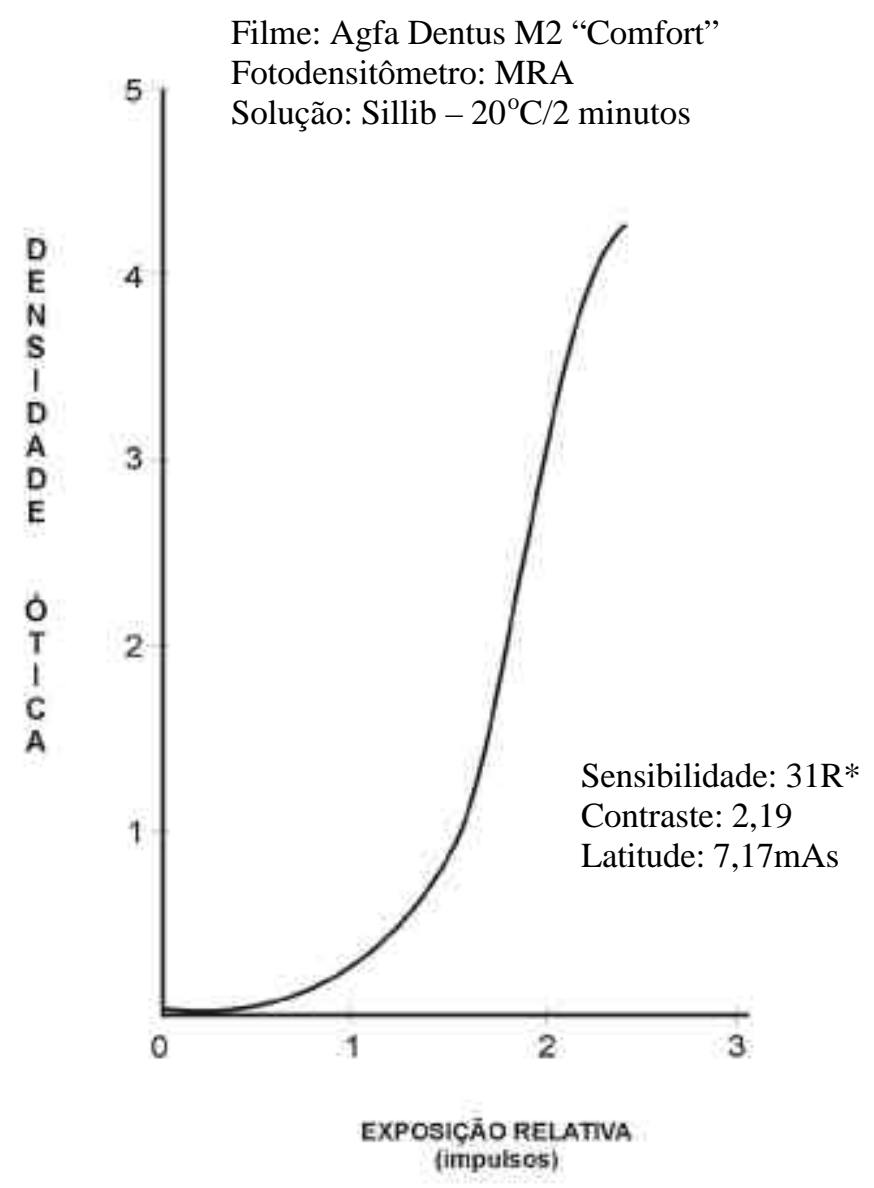

FIGURA 14 - Curva característica obtida com o valor médio das leituras de Densidades Óticas no fotodensitômetro MRA das quatro radiografias estudadas, utilizando o filme Agfa Dentus M2 "Comfort", processado na solução Sillib a $20^{\circ} \mathrm{C} / 2$ minutos (grupo 7 ) 
TABELA 8 - Tabela com o valor médio das dez leituras das Densidades Óticas, realizadas com o fotodensitômetro MRA em cada uma das cinco faixas nas quatro radiografias obtidas com filmes radiográficos Agfa Dentus M2 "Comfort", processados na solução Sillib, na temperatura de $25^{\circ} \mathrm{C}$, por um minuto Grupo 8

\begin{tabular}{c|c|c|c|c|c}
\hline \hline & R1 & R2 & R3 & R4 & MÉDIA \\
\hline \hline $\mathbf{3 0 0}-4$ & $\mathbf{4 , 5 2}$ & $\mathbf{4 , 5 0}$ & $\mathbf{4 , 5 8}$ & $\mathbf{4 , 5 0}$ & $\mathbf{4 , 5 2}$ \\
\hline $\mathbf{6 0}-\mathbf{3}$ & $\mathbf{1 , 8 3}$ & $\mathbf{1 , 7 4}$ & $\mathbf{1 , 8 3}$ & $\mathbf{1 , 7 5}$ & $\mathbf{1 , 7 9}$ \\
\hline $\mathbf{1 0}-\mathbf{2}$ & $\mathbf{0 , 2 8}$ & $\mathbf{0 , 2 7}$ & $\mathbf{0 , 2 8}$ & $\mathbf{0 , 2 8}$ & $\mathbf{0 , 2 8}$ \\
\hline $1-1$ & $\mathbf{0 , 0 4}$ & $\mathbf{0 , 0 4}$ & $\mathbf{0 , 0 4}$ & $\mathbf{0 , 0 4}$ & $\mathbf{0 , 0 4}$ \\
\hline DBV - 0 & $\mathbf{0 , 0 3}$ & $\mathbf{0 , 0 4}$ & $\mathbf{0 , 0 5}$ & $\mathbf{0 , 0 4}$ & $\mathbf{0 , 0 4}$ \\
\hline
\end{tabular}

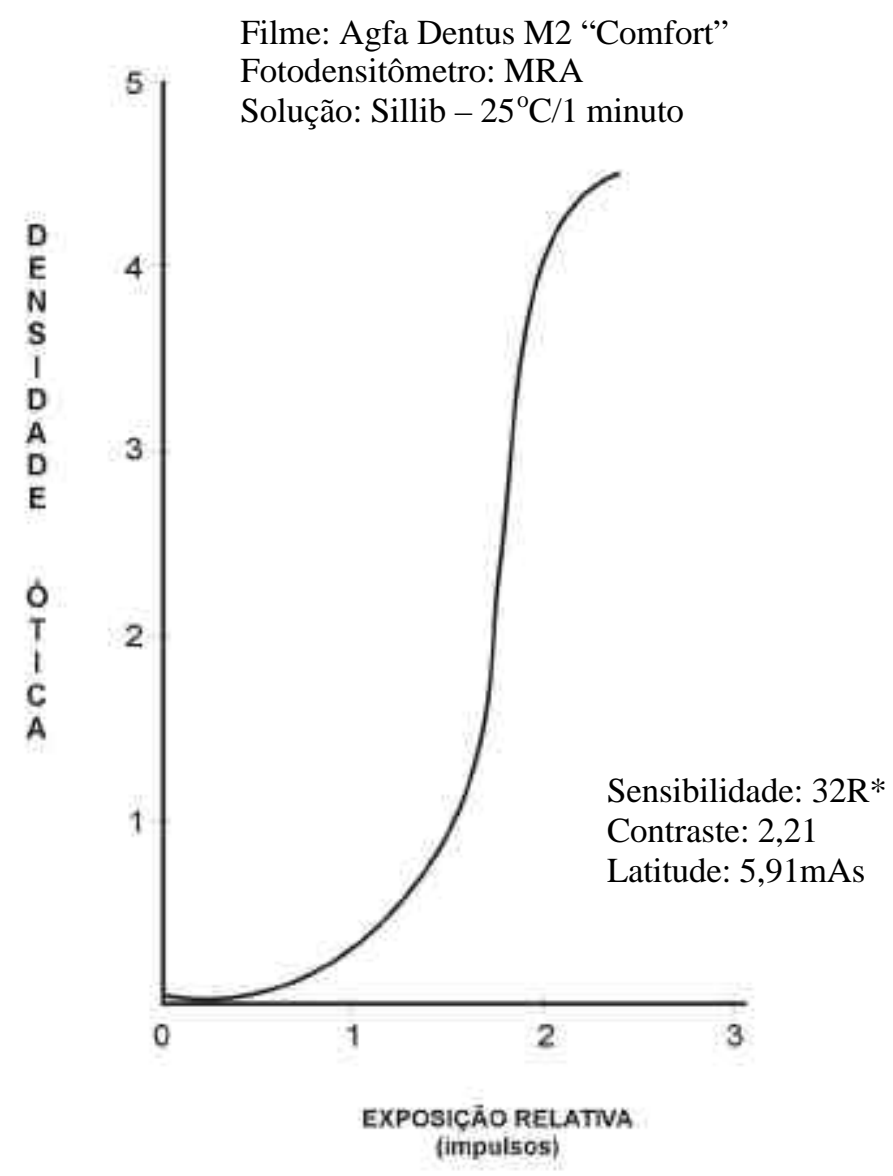

FIGURA 15 - Curva característica obtida com o valor médio das leituras de Densidades Óticas no fotodensitômetro MRA das quatro radiografias estudadas, utilizando o filme Agfa Dentus M2 "Comfort", processado na solução Sillib a $25^{\circ} \mathrm{C} / 1$ minuto (grupo 8 ) 
TABELA 9 - Tabela com o valor médio das dez leituras das Densidades Óticas, realizadas com o fotodensitômetro MRA em cada uma das cinco faixas nas quatro radiografias obtidas com filmes radiográficos Agfa Dentus M2 "Comfort", processados na solução Sillib, na temperatura de $30^{\circ} \mathrm{C}$, por 0,5 minuto Grupo 9

\begin{tabular}{c|c|c|c|c|c}
\hline \hline & R1 & R2 & R3 & R4 & MÉDIA \\
\hline \hline $\mathbf{3 0 0}-4$ & $\mathbf{4 , 5 9}$ & $\mathbf{4 , 5 0}$ & $\mathbf{4 , 2 2}$ & $\mathbf{4 , 3 5}$ & $\mathbf{4 , 4 1}$ \\
\hline $\mathbf{6 0}-\mathbf{3}$ & $\mathbf{2 , 1 5}$ & $\mathbf{2 , 0 6}$ & $\mathbf{1 , 9 7}$ & $\mathbf{2 , 1 0}$ & $\mathbf{2 , 0 7}$ \\
\hline $10-2$ & $\mathbf{0 , 3 3}$ & $\mathbf{0 , 3 2}$ & $\mathbf{0 , 3 1}$ & $\mathbf{0 , 3 2}$ & $\mathbf{0 , 3 2}$ \\
\hline $1-1$ & $\mathbf{0 , 0 4}$ & $\mathbf{0 , 0 5}$ & $\mathbf{0 , 0 5}$ & $\mathbf{0 , 0 5}$ & $\mathbf{0 , 0 5}$ \\
\hline DBV $-\mathbf{0}$ & $\mathbf{0 , 0 4}$ & $\mathbf{0 , 0 5}$ & $\mathbf{0 , 0 4}$ & $\mathbf{0 , 0 5}$ & $\mathbf{0 , 0 4}$ \\
\hline
\end{tabular}

Filme: Agfa Dentus M2 "Comfort"

Fotodensitômetro: MRA

Solução: Sillib $-30^{\circ} \mathrm{C} / 0,5$ minutos

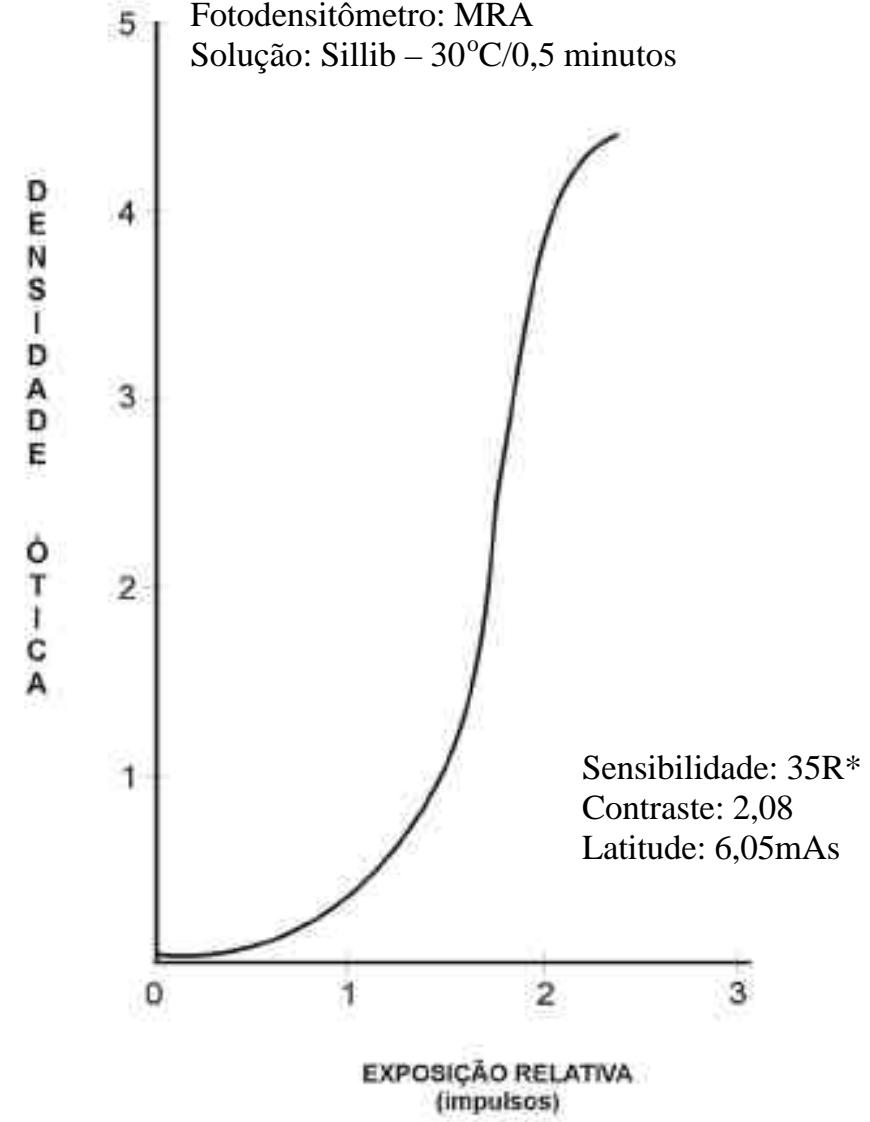

FIGURA 16 - Curva característica obtida com o valor médio das leituras de Densidades Óticas no fotodensitômetro MRA das quatro radiografias estudadas, utilizando o filme Agfa Dentus M2 "Comfort", processado na solução Sillib a $30^{\circ} \mathrm{C} / 0,5$ minuto (grupo 9) 
A tabela 10 mostra as médias das Densidades Óticas em todos os grupos. A partir destas médias foram construídas as curvas características para a obtenção das propriedades sensitométricas.

TABELA 10 - Média das Densidades Óticas das quatro radiografias estudadas (filme Agfa Dentus M2 "Comfort"), obtidas no fotodensitômetro MRA nas cinco faixas de exposição (impulsos) nas diferentes combinações de solução/temperatura $\left({ }^{\circ} \mathrm{C}\right) /$ tempo (min.) - nove grupos

\begin{tabular}{c|c|c|c|c|c|c|c|c|c}
\hline & $\begin{array}{c}\text { Agfa } \\
20 / 5\end{array}$ & $\begin{array}{c}\text { Agfa } \\
25 / 2,5\end{array}$ & $\begin{array}{c}\text { Agfa } \\
\mathbf{3 0} / \mathbf{1 , 2 5}\end{array}$ & $\begin{array}{c}\text { Kodak } \\
\mathbf{2 0} / \mathbf{5}\end{array}$ & $\begin{array}{c}\text { Kodak } \\
25 / 2,5\end{array}$ & $\begin{array}{c}\text { Kodak } \\
\mathbf{3 0} / \mathbf{1 , 2 5}\end{array}$ & $\begin{array}{c}\text { Sillib } \\
20 / 2\end{array}$ & $\begin{array}{c}\text { Sillib } \\
\mathbf{2 5} / \mathbf{1}\end{array}$ & $\begin{array}{c}\text { Sillib } \\
\mathbf{3 0} / \mathbf{0 , 5}\end{array}$ \\
\hline \hline $\mathbf{3 0 0}-\mathbf{4}$ & $\mathbf{4 , 7 5}$ & $\mathbf{4 , 5 7}$ & $\mathbf{4 , 1 8}$ & $\mathbf{4 , 1 6}$ & $\mathbf{4 , 6 9}$ & $\mathbf{4 , 6 0}$ & $\mathbf{4 , 2 8}$ & $\mathbf{4 , 5 2}$ & $\mathbf{4 , 4 1}$ \\
\hline $\mathbf{6 0}-\mathbf{3}$ & $\mathbf{2 , 6 1}$ & $\mathbf{3 , 1 2}$ & $\mathbf{3 , 0 2}$ & $\mathbf{2 , 6 6}$ & $\mathbf{2 , 6 1}$ & $\mathbf{2 , 9 0}$ & $\mathbf{1 , 6 8}$ & $\mathbf{1 , 7 9}$ & $\mathbf{2 , 0 7}$ \\
\hline $\mathbf{1 0}-\mathbf{2}$ & $\mathbf{0 , 4 3}$ & $\mathbf{0 , 5 9}$ & $\mathbf{0 , 6 1}$ & $\mathbf{0 , 5 2}$ & $\mathbf{0 , 4 9}$ & $\mathbf{0 , 5 7}$ & $\mathbf{0 , 2 5}$ & $\mathbf{0 , 2 8}$ & $\mathbf{0 , 3 2}$ \\
\hline $1-1$ & $\mathbf{0 , 0 8}$ & $\mathbf{0 , 1 3}$ & $\mathbf{0 , 1 4}$ & $\mathbf{0 , 1 2}$ & $\mathbf{0 , 1 0}$ & $\mathbf{0 , 1 3}$ & $\mathbf{0 , 0 3}$ & $\mathbf{0 , 0 4}$ & $\mathbf{0 , 0 5}$ \\
\hline DBV -0 & $\mathbf{0 , 0 7}$ & $\mathbf{0 , 1 2}$ & $\mathbf{0 , 1 4}$ & $\mathbf{0 , 1 2}$ & $\mathbf{0 , 1 0}$ & $\mathbf{0 , 1 3}$ & $\mathbf{0 , 0 2}$ & $\mathbf{0 , 0 4}$ & $\mathbf{0 , 0 4}$ \\
\hline
\end{tabular}

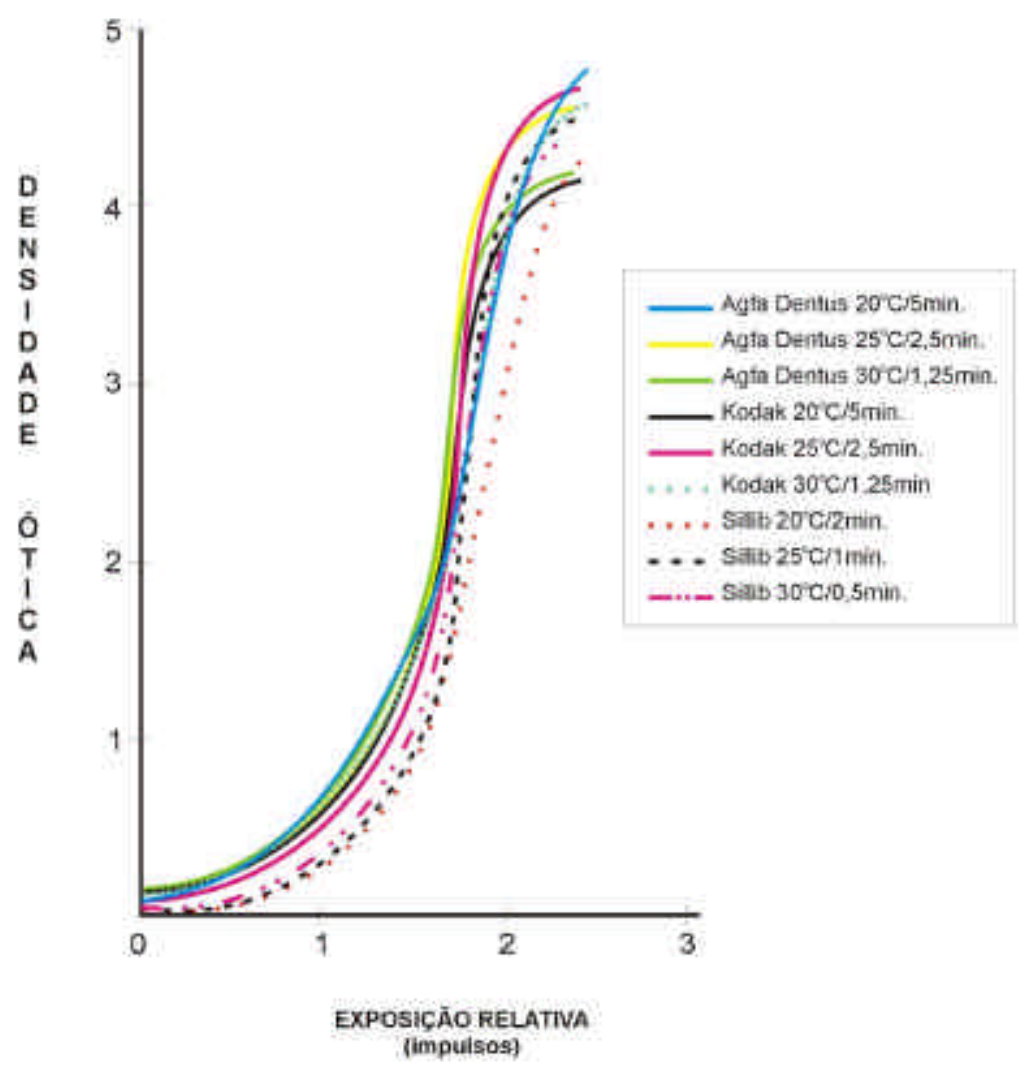

FIGURA 17 - Superposição das nove curvas características construídas a partir das médias das Densidades Óticas das quatro radiografias estudadas, obtidas com fotodensitômetro MRA, utilizando o filme Agfa Dentus M2 "Comfort", processado nas diferentes soluções, temperaturas e tempos de acordo com o grupo analisado 
A tabela 11 mostra as propriedades sensitométricas obtidas por meio da confecção das curvas características (sensibilidade, contraste e latitude).

TABELA 11 - Valores de densidade máxima, sensibilidade (mAs e R*), contraste, latitude e DBV do filme Agfa Dentus M2 "Comfort", processados nas diferentes combinações solução/temperatura $\left({ }^{\circ} \mathrm{C}\right) /$ tempo (min.), obtidos a partir do traçado das curvas características

\begin{tabular}{l|c|c|c|c|c|c|c|c|c}
\hline \hline & $\begin{array}{c}\text { Agfa } \\
\mathbf{2 0 / 5}\end{array}$ & $\begin{array}{c}\text { Agfa } \\
\mathbf{2 5 / 2 , 5}\end{array}$ & $\begin{array}{c}\text { Agfa } \\
\mathbf{3 0 / 1 , 2 5}\end{array}$ & $\begin{array}{c}\text { Kodak } \\
\mathbf{2 0 / 5}\end{array}$ & $\begin{array}{c}\text { Kodak } \\
\mathbf{2 5 / 2 , 5}\end{array}$ & $\begin{array}{c}\text { Kodak } \\
\mathbf{3 0 / 1 , 2 5}\end{array}$ & $\begin{array}{c}\text { Sillib } \\
\mathbf{2 0 / 2}\end{array}$ & $\begin{array}{c}\text { Sillib } \\
\mathbf{2 5 / 1}\end{array}$ & $\begin{array}{c}\text { Sillib } \\
\mathbf{3 0 / 0 , 5}\end{array}$ \\
\hline \hline $\begin{array}{l}\text { Densidade } \\
\text { Máxima }\end{array}$ & 4,75 & 4,57 & 4,18 & 4,16 & 4,69 & 4,60 & 4,28 & 4,52 & 4,41 \\
\hline $\begin{array}{l}\text { Sensibilidade } \\
(\mathbf{m A s})\end{array}$ & 5,22 & 5,72 & 5,72 & 6,28 & 7,04 & 6,28 & 9,73 & 9,50 & 8,67 \\
\hline $\begin{array}{l}\text { Sensibilidade } \\
\left(\mathbf{R}^{*}\right)\end{array}$ & 57 & 52 & 52 & 48 & 43 & 48 & 31 & 32 & 35 \\
\hline \begin{tabular}{l} 
Contraste \\
\hline Latitude
\end{tabular} & 1,75 & 1,78 & 2,11 & 1,88 & 1,96 & 1,72 & 2,19 & 2,21 & 2,08 \\
& 6,21 & 6,52 & 6,24 & 6,54 & 5,49 & 8,10 & 7,17 & 5,91 & 6,05 \\
\hline DBV & 0,07 & 0,12 & 0,14 & 0,12 & 0,10 & 0,13 & 0,02 & 0,04 & 0,04 \\
& & & & & & & & & \\
\hline
\end{tabular}

As tabelas de 12 a 20 apresentam os resultados das Densidades Radiográficas nos nove grupos analisados. Na tabela 21 observa-se os valores da Densidade Ótica e Densidades Radiográficas obtidas nas quatro radiografias de todos os grupos. A tabela 22 mostra os resultados da análise estatística. 
TABELA 12 - Tabela com o valor das leituras das Densidades Radiográfica e Radiográfica invertida, realizadas em cada uma das cinco faixas nas quatro radiografias, utilizando-se o programa de imagem Adobe Photoshop 5.0, em filmes radiográficos Agfa Dentus M2 "Comfort", processados na solução Agfa Dentus, na temperatura de $20^{\circ} \mathrm{C}$, por cinco minutos - Grupo 1

\begin{tabular}{c|c|c|c|c|c|c|c|c|c|c}
\hline \hline & \multicolumn{2}{|c|}{ R1 } & \multicolumn{2}{c|}{ R2 } & \multicolumn{2}{c|}{ R3 } & \multicolumn{2}{c|}{ R4 } & \multicolumn{2}{c}{ MÉDIA } \\
\hline \hline & D.R. & D.R.i & D.R. & D.R.i & D.R. & D.R.i & D.R. & D.R.i & D.R. & D.R.i \\
\hline $300-4$ & 3 & 252 & 2 & 253 & 5 & 250 & 3 & 252 & 3 & 252 \\
\hline $60-3$ & 4 & 251 & 2 & 253 & 6 & 249 & 4 & 251 & 4 & 251 \\
\hline $10-2$ & 135 & 120 & 130 & 126 & 135 & 120 & 130 & 125 & 132 & 123 \\
\hline $1-1$ & 190 & 65 & 188 & 67 & 191 & 64 & 188 & 67 & 189 & 66 \\
\hline DBV-0 & 191 & 64 & 188 & 67 & 192 & 63 & 189 & 66 & 190 & 65 \\
\hline
\end{tabular}

TABELA 13 - Tabela com o valor das leituras das Densidades Radiográfica e Radiográfica invertida, realizadas em cada uma das cinco faixas nas quatro radiografias, utilizando-se o programa de imagem Adobe Photoshop 5.0, em filmes radiográficos Agfa Dentus M2 "Comfort", processados na solução Agfa Dentus, na temperatura de $25^{\circ} \mathrm{C}$, por 2,5 minutos - Grupo 2

\begin{tabular}{c|c|c|c|c|c|c|c|c|c|c}
\hline \hline & \multicolumn{2}{|c|}{ R1 } & \multicolumn{2}{c|}{ R2 } & \multicolumn{2}{c|}{ R3 } & \multicolumn{2}{c}{ R4 } & \multicolumn{2}{c}{ MÉDIA } \\
\hline & D.R. & D.R.i & D.R. & D.R.i & D.R. & D.R.i & D.R. & D.R.i & D.R. & D.R.i \\
\hline $\mathbf{3 0 0}-\mathbf{4}$ & $\mathbf{5}$ & $\mathbf{2 5 0}$ & $\mathbf{3}$ & $\mathbf{2 5 2}$ & $\mathbf{8}$ & $\mathbf{2 4 7}$ & $\mathbf{6}$ & $\mathbf{2 4 9}$ & $\mathbf{5}$ & $\mathbf{2 4 9}$ \\
\hline $\mathbf{6 0}-\mathbf{3}$ & $\mathbf{5}$ & $\mathbf{2 5 0}$ & $\mathbf{3}$ & $\mathbf{2 5 2}$ & $\mathbf{8}$ & $\mathbf{2 4 7}$ & $\mathbf{6}$ & $\mathbf{2 4 9}$ & $\mathbf{5}$ & $\mathbf{2 4 9}$ \\
\hline $\mathbf{1 0}-\mathbf{2}$ & $\mathbf{1 2 0}$ & $\mathbf{1 3 5}$ & $\mathbf{1 0 9}$ & $\mathbf{1 4 6}$ & $\mathbf{1 1 5}$ & $\mathbf{1 4 0}$ & $\mathbf{1 1 5}$ & $\mathbf{1 4 0}$ & $\mathbf{1 1 5}$ & $\mathbf{1 4 0}$ \\
\hline $1-\mathbf{1}$ & $\mathbf{1 8 5}$ & $\mathbf{7 0}$ & $\mathbf{1 7 9}$ & $\mathbf{7 6}$ & $\mathbf{1 8 2}$ & $\mathbf{7 3}$ & $\mathbf{1 8 4}$ & $\mathbf{7 1}$ & $\mathbf{1 8 2}$ & $\mathbf{7 3}$ \\
\hline DBV - 0 & $\mathbf{1 8 7}$ & $\mathbf{6 8}$ & $\mathbf{1 8 1}$ & $\mathbf{7 4}$ & $\mathbf{1 8 2}$ & $\mathbf{7 3}$ & $\mathbf{1 8 5}$ & $\mathbf{7 0}$ & $\mathbf{1 8 4}$ & $\mathbf{7 1}$ \\
\hline
\end{tabular}

TABELA 14 - Tabela com o valor das leituras das Densidades Radiográfica e Radiográfica invertida, realizadas em cada uma das cinco faixas nas quatro radiografias, utilizando-se o programa de imagem Adobe Photoshop 5.0, em filmes radiográficos Agfa Dentus M2 "Comfort", processados na solução Agfa Dentus, na temperatura de $30^{\circ} \mathrm{C}$, por 1,25 minuto - Grupo 3

\begin{tabular}{c|c|c|c|c|c|c|c|c|c|c}
\hline & \multicolumn{2}{|c|}{ R1 } & \multicolumn{2}{c|}{ R2 } & \multicolumn{2}{c|}{ R3 } & \multicolumn{3}{c}{ R4 } & \multicolumn{2}{c}{ MÉDIA } \\
\hline \hline & D.R. & D.R.i & D.R. & D.R.i & D.R. & D.R.i & D.R. & D.R.i & D.R. & D.R.i \\
\hline $300-4$ & 4 & $\mathbf{2 5 1}$ & $\mathbf{3}$ & $\mathbf{2 5 2}$ & 7 & $\mathbf{2 4 8}$ & $\mathbf{5}$ & $\mathbf{2 5 0}$ & $\mathbf{5}$ & $\mathbf{2 5 0}$ \\
\hline $60-3$ & 4 & $\mathbf{2 5 1}$ & $\mathbf{3}$ & $\mathbf{2 5 2}$ & $\mathbf{6}$ & $\mathbf{2 4 9}$ & $\mathbf{5}$ & $\mathbf{2 5 0}$ & $\mathbf{4}$ & $\mathbf{2 5 0}$ \\
\hline $10-2$ & $\mathbf{1 1 8}$ & 137 & 115 & $\mathbf{1 4 0}$ & $\mathbf{1 0 9}$ & $\mathbf{1 4 6}$ & $\mathbf{1 1 2}$ & $\mathbf{1 4 3}$ & $\mathbf{1 1 3}$ & $\mathbf{1 4 1}$ \\
\hline $1-1$ & $\mathbf{1 8 2}$ & $\mathbf{7 3}$ & $\mathbf{1 8 3}$ & $\mathbf{7 2}$ & $\mathbf{1 7 7}$ & $\mathbf{7 8}$ & $\mathbf{1 8 0}$ & $\mathbf{7 5}$ & $\mathbf{1 8 0}$ & $\mathbf{7 4}$ \\
\hline DBV-0 & $\mathbf{1 8 3}$ & $\mathbf{7 2}$ & $\mathbf{1 8 2}$ & $\mathbf{7 3}$ & $\mathbf{1 7 7}$ & $\mathbf{7 8}$ & $\mathbf{1 8 1}$ & $\mathbf{7 4}$ & $\mathbf{1 8 1}$ & $\mathbf{7 4}$ \\
\hline
\end{tabular}


TABELA 15 - Tabela com o valor das leituras das Densidades Radiográfica e Radiográfica invertida, realizadas em cada uma das cinco faixas nas quatro radiografias, utilizando-se o programa de imagem Adobe Photoshop 5.0, em filmes radiográficos Agfa Dentus M2 "Comfort", processados na solução Kodak, na temperatura de $20^{\circ} \mathrm{C}$, por cinco minutos - Grupo 4

\begin{tabular}{|c|c|c|c|c|c|c|c|c|c|c|}
\hline & \multicolumn{2}{|c|}{ R1 } & \multicolumn{2}{|c|}{$\mathbf{R 2}$} & \multicolumn{2}{|c|}{ R3 } & \multicolumn{2}{|c|}{ R4 } & \multicolumn{2}{|c|}{ MÉDIA } \\
\hline & D.R. & D.R.i & D.R. & D.R.i & D.R. & D.R.i & D.R. & D.R.i & D.R. & D.R.i \\
\hline $300-4$ & 5 & 250 & 4 & 251 & 8 & 247 & 6 & 249 & 6 & 249 \\
\hline $60-3$ & 6 & 249 & 4 & 251 & 10 & 245 & 8 & 247 & 7 & 248 \\
\hline $10-2$ & 125 & 130 & 122 & 133 & 127 & 129 & 128 & 127 & 125 & 130 \\
\hline $1-1$ & 185 & 70 & 183 & 72 & 186 & 69 & 186 & 69 & 185 & 70 \\
\hline DBV - 0 & 184 & 71 & 183 & 72 & 187 & 68 & 186 & 69 & 185 & 70 \\
\hline
\end{tabular}

TABELA 16 - Tabela com o valor das leituras das Densidades Radiográfica e Radiográfica invertida, realizadas em cada uma das cinco faixas nas quatro radiografias, utilizando-se o programa de imagem Adobe Photoshop 5.0, em filmes radiográficos Agfa Dentus M2 "Comfort", processados na solução Kodak, na temperatura de $25^{\circ} \mathrm{C}$, por 2,5 minutos - Grupo 5

\begin{tabular}{c|c|c|c|c|c|c|c|c|c|c}
\hline \hline & \multicolumn{2}{|c|}{ R1 } & \multicolumn{2}{c|}{ R2 } & \multicolumn{2}{c|}{ R3 } & \multicolumn{2}{c}{ R4 } & \multicolumn{2}{c}{ MÉDIA } \\
\hline & D.R. & D.R.i & D.R. & D.R.i & D.R. & D.R.i & D.R. & D.R.i & D.R. & D.R.i \\
\hline $300-4$ & 4 & $\mathbf{2 5 1}$ & $\mathbf{3}$ & $\mathbf{2 5 2}$ & $\mathbf{7}$ & $\mathbf{2 4 8}$ & $\mathbf{5}$ & $\mathbf{2 5 0}$ & $\mathbf{5}$ & $\mathbf{2 5 0}$ \\
\hline $\mathbf{6 0}-\mathbf{3}$ & $\mathbf{5}$ & $\mathbf{2 5 0}$ & $\mathbf{3}$ & $\mathbf{2 5 2}$ & $\mathbf{8}$ & $\mathbf{2 4 7}$ & $\mathbf{6}$ & $\mathbf{2 4 8}$ & $\mathbf{5}$ & $\mathbf{2 4 9}$ \\
\hline $\mathbf{1 0}-\mathbf{2}$ & $\mathbf{1 2 6}$ & $\mathbf{1 2 9}$ & $\mathbf{1 2 1}$ & $\mathbf{1 3 4}$ & $\mathbf{1 2 3}$ & $\mathbf{1 3 2}$ & $\mathbf{1 2 5}$ & $\mathbf{1 3 0}$ & $\mathbf{1 2 2}$ & $\mathbf{1 3 1}$ \\
\hline $1-1$ & $\mathbf{1 8 3}$ & $\mathbf{7 2}$ & $\mathbf{1 8 2}$ & $\mathbf{7 3}$ & $\mathbf{1 8 5}$ & $\mathbf{7 0}$ & $\mathbf{1 8 6}$ & $\mathbf{6 9}$ & $\mathbf{1 8 4}$ & $\mathbf{7 1}$ \\
\hline DBV - 0 & $\mathbf{1 8 1}$ & $\mathbf{7 4}$ & $\mathbf{1 7 8}$ & $\mathbf{7 5}$ & $\mathbf{1 8 3}$ & $\mathbf{7 1}$ & $\mathbf{1 8 5}$ & $\mathbf{7 0}$ & $\mathbf{1 8 2}$ & $\mathbf{7 2}$ \\
\hline
\end{tabular}

TABELA 17 - Tabela com o valor das leituras das Densidades Radiográfica e Radiográfica invertida, realizadas em cada uma das cinco faixas nas quatro radiografias, utilizando-se o programa de imagem Adobe Photoshop 5.0, em filmes radiográficos Agfa Dentus M2 "Comfort", processados na solução Kodak, na temperatura de $30^{\circ} \mathrm{C}$, por 1,25 minuto - Grupo 6

\begin{tabular}{c|c|c|c|c|c|c|c|c|c|c}
\hline & \multicolumn{2}{|c|}{ R1 } & \multicolumn{2}{c|}{ R2 } & \multicolumn{2}{c|}{ R3 } & \multicolumn{3}{c}{ R4 } & \multicolumn{2}{c}{ MÉDIA } \\
\hline \hline & D.R. & D.R.i & D.R. & D.R.i & D.R. & D.R.i & D.R. & D.R.i & D.R. & D.R.i \\
\hline $300-4$ & $\mathbf{3}$ & $\mathbf{2 5 2}$ & $\mathbf{2}$ & $\mathbf{2 5 3}$ & $\mathbf{6}$ & $\mathbf{2 4 9}$ & $\mathbf{5}$ & $\mathbf{2 5 0}$ & $\mathbf{4}$ & $\mathbf{2 5 1}$ \\
\hline $\mathbf{6 0}-\mathbf{3}$ & $\mathbf{3}$ & $\mathbf{2 5 2}$ & $\mathbf{2}$ & $\mathbf{2 5 3}$ & $\mathbf{6}$ & $\mathbf{2 4 9}$ & $\mathbf{5}$ & $\mathbf{2 5 0}$ & $\mathbf{4}$ & $\mathbf{2 5 1}$ \\
\hline $10-2$ & 115 & $\mathbf{1 4 0}$ & $\mathbf{1 1 2}$ & $\mathbf{1 4 3}$ & $\mathbf{1 2 1}$ & $\mathbf{1 3 4}$ & $\mathbf{1 1 7}$ & $\mathbf{1 3 8}$ & $\mathbf{1 1 6}$ & $\mathbf{1 3 9}$ \\
\hline $1-1$ & $\mathbf{1 7 9}$ & $\mathbf{7 6}$ & $\mathbf{1 7 9}$ & $\mathbf{7 6}$ & $\mathbf{1 8 3}$ & $\mathbf{7 2}$ & $\mathbf{1 8 2}$ & $\mathbf{7 3}$ & $\mathbf{1 8 0}$ & $\mathbf{7 4}$ \\
\hline DBV - 0 & $\mathbf{1 7 9}$ & $\mathbf{7 6}$ & $\mathbf{1 7 9}$ & $\mathbf{7 6}$ & $\mathbf{1 8 3}$ & $\mathbf{7 2}$ & $\mathbf{1 8 1}$ & $\mathbf{7 4}$ & $\mathbf{1 8 0}$ & $\mathbf{7 4}$ \\
\hline
\end{tabular}


TABELA 18 - Tabela com o valor das leituras das Densidades Radiográfica e Radiográfica invertida, realizadas em cada uma das cinco faixas nas quatro radiografias, utilizando-se o programa de imagem Adobe Photoshop 5.0, em filmes radiográficos Agfa Dentus M2 "Comfort", processados na solução Sillib, na temperatura de $20^{\circ} \mathrm{C}$, por dois minutos - Grupo 7

\begin{tabular}{c|c|c|c|c|c|c|c|c|c|c}
\hline \hline & \multicolumn{2}{|c|}{ R1 } & \multicolumn{2}{c|}{ R2 } & \multicolumn{2}{c|}{ R3 } & \multicolumn{2}{c}{ R4 } & \multicolumn{2}{c}{ MÉDIA } \\
\hline \hline & D.R. & D.R.i & D.R. & D.R.i & D.R. & D.R.i & D.R. & D.R.i & D.R. & D.R.i \\
\hline $\mathbf{3 0 0}-\mathbf{4}$ & $\mathbf{4}$ & $\mathbf{2 5 1}$ & $\mathbf{4}$ & $\mathbf{2 5 1}$ & $\mathbf{7}$ & $\mathbf{2 4 9}$ & $\mathbf{5}$ & $\mathbf{2 5 0}$ & $\mathbf{5}$ & $\mathbf{2 5 0}$ \\
\hline $\mathbf{6 0}-\mathbf{3}$ & $\mathbf{2 0}$ & $\mathbf{2 3 5}$ & $\mathbf{1 9}$ & $\mathbf{2 3 6}$ & $\mathbf{2 4}$ & $\mathbf{2 3 1}$ & $\mathbf{2 1}$ & $\mathbf{2 3 4}$ & $\mathbf{2 1}$ & $\mathbf{2 3 4}$ \\
\hline $\mathbf{1 0}-\mathbf{2}$ & $\mathbf{1 6 1}$ & $\mathbf{9 4}$ & $\mathbf{1 6 1}$ & $\mathbf{9 4}$ & $\mathbf{1 6 4}$ & $\mathbf{9 1}$ & $\mathbf{1 6 2}$ & $\mathbf{9 4}$ & $\mathbf{1 6 2}$ & $\mathbf{9 3}$ \\
\hline $1-\mathbf{1}$ & $\mathbf{2 0 0}$ & $\mathbf{5 5}$ & $\mathbf{2 0 1}$ & $\mathbf{5 4}$ & $\mathbf{2 0 3}$ & $\mathbf{5 2}$ & $\mathbf{2 0 2}$ & $\mathbf{5 3}$ & $\mathbf{2 0 1}$ & $\mathbf{5 3}$ \\
\hline DBV-0 & $\mathbf{2 0 0}$ & $\mathbf{5 4}$ & $\mathbf{2 0 1}$ & $\mathbf{5 4}$ & $\mathbf{2 0 3}$ & $\mathbf{5 2}$ & $\mathbf{2 0 3}$ & $\mathbf{5 2}$ & $\mathbf{2 0 2}$ & $\mathbf{5 3}$ \\
\hline
\end{tabular}

TABELA 19 - Tabela com o valor das leituras das Densidades Radiográfica e Radiográfica invertida, realizadas em cada uma das cinco faixas nas quatro radiografias, utilizando-se o programa de imagem Adobe Photoshop 5.0, em filmes radiográficos Agfa Dentus M2 "Comfort", processados na solução Sillib, na temperatura de $25^{\circ} \mathrm{C}$, por um minuto Grupo 8

\begin{tabular}{c|c|c|c|c|c|c|c|c|c|c}
\hline \hline & \multicolumn{2}{|c|}{ R1 } & \multicolumn{2}{c|}{ R2 } & \multicolumn{2}{c|}{ R3 } & \multicolumn{3}{c|}{ R4 } & \multicolumn{2}{c}{ MÉDIA } \\
\hline & D.R. & D.R.i & D.R. & D.R.i & D.R. & D.R.i & D.R. & D.R.i & D.R. & D.R.i \\
\hline $\mathbf{3 0 0}-\mathbf{4}$ & $\mathbf{4}$ & $\mathbf{2 5 1}$ & $\mathbf{2}$ & $\mathbf{2 5 2}$ & $\mathbf{8}$ & $\mathbf{2 4 7}$ & $\mathbf{5}$ & $\mathbf{2 5 0}$ & $\mathbf{5}$ & $\mathbf{2 5 0}$ \\
\hline $\mathbf{6 0}-\mathbf{3}$ & $\mathbf{1 6}$ & $\mathbf{2 3 9}$ & $\mathbf{1 6}$ & $\mathbf{2 3 9}$ & $\mathbf{2 2}$ & $\mathbf{2 3 3}$ & $\mathbf{1 7}$ & $\mathbf{2 3 8}$ & $\mathbf{1 8}$ & $\mathbf{2 3 7}$ \\
\hline $\mathbf{1 0}-\mathbf{2}$ & $\mathbf{1 5 9}$ & $\mathbf{9 6}$ & $\mathbf{1 5 9}$ & $\mathbf{9 5}$ & $\mathbf{1 6 2}$ & $\mathbf{9 4}$ & $\mathbf{1 5 9}$ & $\mathbf{9 6}$ & $\mathbf{1 6 0}$ & $\mathbf{9 5}$ \\
\hline $\mathbf{1 - 1}$ & $\mathbf{2 0 0}$ & $\mathbf{5 5}$ & $\mathbf{2 0 0}$ & $\mathbf{5 5}$ & $\mathbf{2 0 2}$ & $\mathbf{5 3}$ & $\mathbf{2 0 1}$ & $\mathbf{5 4}$ & $\mathbf{2 0 1}$ & $\mathbf{5 4}$ \\
\hline DBV-0 & $\mathbf{2 0 0}$ & $\mathbf{5 6}$ & $\mathbf{2 0 0}$ & $\mathbf{5 5}$ & $\mathbf{2 0 1}$ & $\mathbf{5 3}$ & $\mathbf{2 0 2}$ & $\mathbf{5 3}$ & $\mathbf{2 0 1}$ & $\mathbf{5 4}$ \\
\hline
\end{tabular}

TABELA 20 - Tabela com o valor das leituras das Densidades Radiográfica e Radiográfica invertida, realizadas em cada uma das cinco faixas nas quatro radiografias, utilizando-se o programa de imagem Adobe Photoshop 5.0, em filmes radiográficos Agfa Dentus M2 "Comfort", processados na solução Sillib, na temperatura de $30^{\circ} \mathrm{C}$, por 0,5 minuto Grupo 9

\begin{tabular}{c|c|c|c|c|c|c|c|c|c|c}
\hline \hline & \multicolumn{2}{|c|}{ R1 } & \multicolumn{2}{c|}{ R2 } & \multicolumn{2}{c|}{ R3 } & \multicolumn{2}{c}{ R4 } & \multicolumn{2}{c}{ MÉDIA } \\
\hline \hline & D.R. & D.R.i & D.R. & D.R.i & D.R. & D.R.i & D.R. & D.R.i & D.R. & D.R.i \\
\hline $\mathbf{3 0 0}-\mathbf{4}$ & $\mathbf{4}$ & $\mathbf{2 5 1}$ & $\mathbf{3}$ & $\mathbf{2 5 2}$ & $\mathbf{8}$ & $\mathbf{2 4 7}$ & $\mathbf{6}$ & $\mathbf{2 4 9}$ & $\mathbf{5}$ & $\mathbf{2 5 0}$ \\
\hline $\mathbf{6 0}-\mathbf{3}$ & $\mathbf{1 1}$ & $\mathbf{2 4 4}$ & $\mathbf{9}$ & $\mathbf{2 4 6}$ & $\mathbf{1 7}$ & $\mathbf{2 3 8}$ & $\mathbf{1 2}$ & $\mathbf{2 4 3}$ & $\mathbf{1 2}$ & $\mathbf{2 4 3}$ \\
\hline $\mathbf{1 0}-\mathbf{2}$ & $\mathbf{1 5 5}$ & $\mathbf{1 0 0}$ & $\mathbf{1 5 5}$ & $\mathbf{1 0 0}$ & $\mathbf{1 5 7}$ & $\mathbf{9 7}$ & $\mathbf{1 5 3}$ & $\mathbf{1 0 2}$ & $\mathbf{1 5 5}$ & $\mathbf{1 0 0}$ \\
\hline $1-\mathbf{1}$ & $\mathbf{2 0 0}$ & $\mathbf{5 5}$ & $\mathbf{2 0 0}$ & $\mathbf{5 5}$ & $\mathbf{2 0 2}$ & $\mathbf{5 3}$ & $\mathbf{2 0 2}$ & $\mathbf{5 3}$ & $\mathbf{2 0 1}$ & $\mathbf{5 4}$ \\
\hline DBV - 0 & $\mathbf{2 0 0}$ & $\mathbf{5 5}$ & $\mathbf{2 0 0}$ & $\mathbf{5 5}$ & $\mathbf{2 0 3}$ & $\mathbf{5 2}$ & $\mathbf{2 0 2}$ & $\mathbf{5 3}$ & $\mathbf{2 0 1}$ & $\mathbf{5 4}$ \\
\hline
\end{tabular}


TABELA 21 - Média das Densidades Óticas e Densidades Radiográficas do filme Agfa Dentus M2 “Comfort”, nas cinco faixas de exposição (impulsos), nas quatro radiografias, das diferentes combinações solução/temperatura/tempo (nove grupos)

\begin{tabular}{|c|c|c|c|c|c|c|c|c|c|c|c|c|c|c|c|c|c|c|c|c|c|c|c|c|c|c|c|}
\hline & \multicolumn{3}{|c|}{$\begin{array}{c}\text { Agfa } \\
20^{\circ} \mathrm{C} / 5 \mathrm{~min} .\end{array}$} & \multicolumn{3}{|c|}{$\begin{array}{c}\text { Agfa } \\
2^{\circ} \mathrm{C} / 2,5 \mathrm{~min}\end{array}$} & \multicolumn{3}{|c|}{$\begin{array}{c}\text { Agfa } \\
\mathbf{3 0}^{\circ} \mathrm{C} / \mathbf{1}, \mathbf{2 5} \mathrm{min}\end{array}$} & \multicolumn{3}{|c|}{$\begin{array}{c}\text { Kodak } \\
20^{\circ} \mathrm{C} / 5 \mathrm{~min} .\end{array}$} & \multicolumn{3}{|c|}{$\begin{array}{c}\text { Kodak } \\
25^{\circ} \mathrm{C} / 2,5 \mathrm{~min}\end{array}$} & \multicolumn{3}{|c|}{\begin{tabular}{c|} 
Kodak \\
$\mathbf{3 0}^{\circ} \mathrm{C} / \mathbf{1}, \mathbf{2 5 m i n}$.
\end{tabular}} & \multicolumn{3}{|c|}{$\begin{array}{c}\text { Sillib } \\
20^{\circ} \mathrm{C} / 2 \mathrm{~min} .\end{array}$} & \multicolumn{3}{|c|}{$\begin{array}{c}\text { Sillib } \\
25^{\circ} \mathrm{C} / 1 \mathrm{~min} .\end{array}$} & \multicolumn{3}{|c|}{$\begin{array}{c}\text { Sillib } \\
\mathbf{3 0}^{\circ} \mathrm{C} / \mathbf{0 , 5} \mathrm{min} .\end{array}$} \\
\hline & D.O. & D.R. & D.R.i & D.O. & D.R. & D.R.i & D.O. & D.R. & D.R.i & D.O. & D.R. & D.R.i & D.O. & D.R. & D.R.i & D.O. & D.R. & D.R.i & D.O. & D.R. & D.R.i & D.O. & D.R. & D.R.i & D.O. & D.R. & D.R.i \\
\hline $300-4$ & 69 & 3 & 252 & 4,70 & 5 & 250 & 4,21 & 4 & 251 & 11 & 5 & 250 & 4,67 & 4 & 251 & 4,59 & 5 & 252 & 4,53 & 4 & 251 & ,52 & 4 & 251 & 4,59 & 4 & 251 \\
\hline $60-3$ &, 57 & 4 & 251 & 3,07 & 5 & 250 & 3,01 & 4 & 251 & 2,74 & 6 & 249 & 2,59 & 5 & 250 & 2,90 & 3 & 252 & 1,73 & 20 & 235 & 1,83 & 16 & 239 & 2,15 & 11 & 244 \\
\hline $10-2$ & 41 & 135 & 120 & $\mathbf{0 , 5 9}$ & 120 & 135 & 0,61 & 118 & 137 & 0,53 & 125 & 130 & 0,49 & 126 & 129 & $\mathbf{0 , 5 8}$ & 115 & 140 & 0,25 & 161 & 94 & 0,28 & 159 & 96 & $\mathbf{0 , 3 3}$ & 155 & 100 \\
\hline $1-1$ & ,07 & 190 & 65 & 0,14 & 185 & 70 & 0,15 & 182 & 73 & 0,12 & 185 & 70 & 0,10 & 183 & 72 & 0,14 & 179 & 76 & 0,03 & 200 & 55 & 0,04 & 200 & 55 & 0,04 & 200 & 55 \\
\hline DBV - 0 & 0,06 & 191 & 64 & $\mathbf{0 , 1 3}$ & 187 & 68 & 0,14 & 183 & 72 & 13 & 184 & 71 & 0,10 & 181 & 74 & 0,13 & 179 & 76 & 0,02 & 200 & 54 & $\mathbf{0 , 0 3}$ & 200 & 56 & 0,04 & 200 & 55 \\
\hline & & & & & & & & & & & & & & & & & & & & & & & & & & & \\
\hline $300-4$ & 4,67 & 2 & 253 & 4,51 & 3 & 252 & 4,29 & 3 & 252 & 4,13 & 4 & 251 & 4,73 & J & 252 & 4,65 & 2 & 253 & 4,75 & 4 & 251 & $\mathbf{4 , 5 0}$ & 2 & 252 & 4,50 & 3 & 252 \\
\hline $60-3$ & 2,68 & 2 & 253 & $\mathbf{3 , 0 0}$ & 3 & 252 & 3,15 & 3 & 252 & 2,66 & 4 & 251 & 2,53 & 3 & 252 & 2,74 & 2 & 253 & 1,64 & 19 & 236 & 1,74 & 16 & 239 & 2,06 & 9 & 246 \\
\hline $10-2$ & 0,45 & 130 & 126 & 0,54 & 109 & 146 & 0,66 & 115 & 140 & 0,52 & 122 & 133 & 0,47 & 121 & 134 & $\mathbf{0 , 5 5}$ & 112 & 143 & 0,25 & 161 & 94 & 0,27 & 159 & 95 & 0,32 & 155 & 100 \\
\hline $1-1$ & 07 & 188 & 67 & 0,11 & 179 & 76 & 0,17 & 183 & 72 & 0,12 & 183 & 72 & 0,08 & 182 & 73 & 0,13 & 179 & 76 & 0,03 & 201 & 54 & 0,04 & 200 & 55 & 0,05 & 200 & 55 \\
\hline DBV - 0 & 0,07 & 188 & 67 & 0,12 & 181 & 74 & 0,17 & 182 & 73 & 0,12 & 183 & 72 & 0,09 & 178 & 75 & 0,13 & 179 & 76 & 0,02 & 201 & 54 & 0,04 & 200 & 55 & 0,05 & 200 & 55 \\
\hline & & & & & & & & & & & & & & & & & & & & & & & & & & & \\
\hline $300-4$ & 3 & 5 & 250 & 4,53 & 8 & 247 & \begin{tabular}{ll|}
4,27 \\
\end{tabular} & 7 & 248 & 4,28 & 8 & 247 & 4,67 & 7 & 248 & 4,50 & 0 & 249 & 3,34 & 7 & 249 & 4,58 & 8 & 247 & 4,22 & 8 & 247 \\
\hline $60-3$ & 2,56 & 6 & 249 & 3,16 & 8 & 247 & \begin{tabular}{|l|}
3,04 \\
\end{tabular} & 6 & 249 & 2,66 & 10 & 245 & 2,65 & 8 & 247 & 2,89 & 6 & 249 & 1,70 & 24 & 231 & 1,83 & 22 & 233 & 1,97 & 17 & 238 \\
\hline $10-2$ & 0,43 & 135 & 120 & 0,59 & 115 & 140 & 0,59 & 109 & 146 & 0,53 & 127 & 129 & 0,51 & 123 & 132 & 0,57 & 121 & 134 & 0,26 & 164 & 91 & 0,28 & 162 & 94 & 0,31 & 157 & 97 \\
\hline $1-1$ & $\mathbf{0 , 0 8}$ & 191 & 64 & 0,12 & 182 & 73 & 0,12 & 177 & 78 & 0,13 & 186 & 69 & 0,11 & 185 & 70 & $\mathbf{0 , 1 4}$ & 183 & 72 & $\mathbf{0 , 0 3}$ & 203 & 52 & $\mathbf{0 , 0 4}$ & 202 & 53 & 0,05 & 202 & 53 \\
\hline DBV - 0 & $\mathbf{0 , 0 8}$ & 192 & 63 & 0,12 & 182 & 73 & 0,13 & 177 & 78 & 0,13 & 187 & 68 & 0,11 & 183 & 71 & \begin{tabular}{l|l|}
0,13 \\
\end{tabular} & 183 & 72 & 0,02 & 203 & 52 & $\mathbf{0 , 0 5}$ & 201 & 53 & 0,04 & 203 & 52 \\
\hline & & & & & & & & & & & & & & & & & & & & & & & & & & & \\
\hline $300-4$ & 4,71 & 3 & 252 & 4,54 & 6 & 249 & 3,90 & 5 & 250 & 4,14 & 6 & 249 & 4,68 & 3 & 250 & 4,66 & J & 250 & 4,51 & 5 & 250 & 4,50 & 5 & 250 & 4,35 & 6 & 249 \\
\hline $60-3$ & 2,65 & 4 & 251 & 3,25 & 6 & 249 & 2,90 & 5 & 250 & 2,57 & 8 & 247 & 2,67 & 6 & 248 & |3,04 & 5 & 250 & 1,67 & 21 & 234 & 1,75 & 17 & 238 & 2,10 & 12 & 243 \\
\hline $10-2$ & 0,45 & 130 & 125 & 0,63 & 115 & 140 & $\mathbf{0 , 5 7}$ & 112 & 143 & $\mathbf{0 , 5 0}$ & 128 & 127 & 0,51 & 125 & 130 & $\mathbf{0 , 6 0}$ & 117 & 138 & 0,26 & 162 & 94 & $\mathbf{0 , 2 8}$ & 159 & 96 & $\mathbf{0 , 3 2}$ & 153 & 102 \\
\hline $1-1$ & 0,09 & 188 & 67 & 0,14 & 184 & 71 & 0,13 & 180 & 75 & 0,13 & 186 & 69 & 0,10 & 186 & 69 & 0,13 & 182 & 73 & 0,04 & 202 & 53 & 0,04 & 201 & 54 & 0,05 & 202 & 53 \\
\hline DBV - o & 0,08 & 189 & 66 & 0,13 & 185 & 70 & 0,14 & 181 & 74 & 0,12 & 186 & 69 & 0,09 & 185 & 70 & 0,13 & 181 & 74 & 0,03 & 203 & 52 & 0,04 & 202 & 53 & 0,05 & 202 & 53 \\
\hline
\end{tabular}


TABELA 22 - Coeficiente de Correlação de Pearson entre Densidade Ótica (D. O.) e Densidade Radiográfica (D. R.), Densidade Ótica (D. O.) e Densidade Radiográfica invertida (D.R.i) e Densidade Radiográfica (D. R.) e Densidade Radiográfica invertida (D.R.i), com nível de confiança de 95\%

\begin{tabular}{|c|c|c|c|}
\hline SOLUÇÕES & D.O. X D.R. & D.O. X D.R.i & D. R. X D.R.i \\
\hline Agfa $20^{\circ} \mathrm{C} / 5 \mathrm{~min}$. & $-0,917 *$ & $0,917 *$ & $-1,000 *$ \\
\hline Agfa $25^{\circ} \mathrm{C} / 2,5 \mathrm{~min}$. & $-0,942 *$ & $0,942 *$ & $-1,000 *$ \\
\hline Agfa $30^{\circ} \mathrm{C} / 1,25 \mathrm{~min}$. & $-0,953 *$ & 0,953* & $-1,000 *$ \\
\hline Kodak $20^{\circ} \mathrm{C} / 5 \mathrm{~min}$. & $-0,941 *$ & $0,941 *$ & $-1,000 *$ \\
\hline Kodak $25^{\circ} \mathrm{C} / 2,5 \mathrm{~min}$. & $-0,916 *$ & 0,916* & $-1,000 *$ \\
\hline Kodak $30^{\circ} \mathrm{C} / 1,25 \mathrm{~min}$. & $-0,932 *$ & $0,932 *$ & $-1,000 *$ \\
\hline Sillib $20^{\circ} \mathrm{C} / 2 \mathrm{~min}$. & $-0,878 *$ & $\mathbf{0 , 8 7 8 *}$ & $-1,000 *$ \\
\hline Sillib $25^{\circ} \mathrm{C} / 1 \mathrm{~min}$. & $-0,881 *$ & $0,881 *$ & $-1,000 *$ \\
\hline Sillib $30^{\circ} \mathrm{C} / 0,5 \mathrm{~min}$. & $-0,902 *$ & $0,902 *$ & $-1,000 *$ \\
\hline
\end{tabular}

*Correlação estatisticamente significante quando $\mathrm{p}<0,05$. 
6. Discussão 


\section{DISCUSSÃO}

Existe uma necessidade de um programa de controle de qualidade para ser utilizado na prática diária da Radiologia Odontológica. Em função disto, as pesquisas são direcionadas para métodos que alcancem este objetivo e que possam ser utilizados pelos profissionais de uma maneira geral.

Utilizamos no presente trabalho o filme radiográfico Agfa Dentus M2 "Comfort", processado em três soluções processadoras em diferentes temperaturas $\left(20^{\circ} \mathrm{C}, 25^{\circ} \mathrm{C}\right.$ e $\left.30^{\circ} \mathrm{C}\right)$ e tempos de revelação. O filme Agfa Dentus M2 "Comfort" utilizado, foi lançado no mercado em 1997, para substituir o antigo filme Agfa que pertencia ao grupo D/E de sensibilidade. Este novo filme, segundo o seu fabricante, pertence ao grupo E e é comparável ao Ektaspeed Plus, apresentando algumas características que o tornam estável sob diferentes condições de processamento, produzindo mínima densidade base e velamento, fina granulatura, brilho e contraste $\operatorname{adequados}^{108}$.

As soluções usadas para o processamento manual das películas radiográficas foram Agfa Dentus, Kodak e Sillib. A solução Agfa Dentus é uma solução de uso rotineiro na prática Odontológica nos países europeus e é recomendada por produzir no filme radiográfico os mais altos valores de sensibilidade $^{108}$. A solução Kodak é amplamente usada no Brasil e considerada uma solução padrão por muitos autores, quando utilizada na temperatura de $20^{\circ} \mathrm{C}$ por cinco minutos ${ }^{1,16,17,33,55,56,117}$. A solução Sillib é considerada uma solução para processamento rápido, requerendo-se um total de dois minutos de revelação na temperatura de $20^{\circ} \mathrm{C}$, segundo as recomendações do fabricante.

O ajuste do tempo de revelação, de acordo com a temperatura das soluções, representa uma importante etapa do processamento radiográfico, 
pois além de influenciar na qualidade da imagem final, impede que ocorram superexposição e sub-revelação dos filmes, impedindo que o paciente seja exposto à radiação desnecessária ${ }^{33}$.

Buscamos com este experimento as propriedades sensitométricas do filme radiográfico Agfa Dentus M2 "Comfort", sob diferentes condições de processamento. A análise das tabelas e curvas características permitiu-nos uma discussão sobre as propriedades do filme nas diferentes soluções e temperaturas utilizadas. Esta discussão foi organizada em tópicos sobre o comportamento do filme em cada solução de maneira a organizar os dados e facilitar a leitura. 


\subsection{Solução Agfa Dentus}

As tabelas de 1 a 3 mostram os resultados das Densidades Óticas obtidos com a média das dez leituras realizadas em cada radiografia nas cinco faixas de exposição nos grupos 1, 2 e 3 estudados com esta solução nas três temperaturas e tempos de revelação.

O processamento dos filmes radiográficos Agfa Dentus M2 "Comfort", nos nove grupos estudados, foi realizado sob rígidas condições de padronização e além disso o experimento foi repetido quatro vezes (radiografias 1, 2, 3 e 4) para que houvesse certeza dos resultados alcançados.

Para correlacionarmos os valores observados nestas tabelas quanto à eficácia da padronização do processamento radiográfico, estabelecemos uma faixa de variação, para mais ou para menos em relação à média para cada faixa de exposição. Na faixa de 300 impulsos, estabelecemos 0,20 acima ou abaixo da média para as respectivas radiografias. Na faixa de 60 impulsos, o valor foi de 0,15 e nas faixas subseqüentes foi de $0,10,0,5$ e 0,5 . Estes valores foram determinados de forma aleatória a partir da afirmação de que leituras do fotodensitômetro com variação de 0,5 de densidade ótica, para mais ou para menos são esperadas ${ }^{19,26}$.

Os resultados da tabela 1 mostram os valores das médias da Densidade Ótica obtidos das dez leituras nas quatro radiografias e nas cinco faixas de exposição, do grupo 1. Quando se relacionaram os valores obtidos na faixa de 300 impulsos, observou-se que a média foi 4,75 e o valor acima da média foi encontrado para a radiografia $3(4,93)$, as radiografias 1 , 2 e 4 apresentaram valores abaixo da média, 4,69, 4,67, e 4,71. Na faixa de 60 impulsos, onde a média foi 2,61, as radiografias 2 e 4 apresentaram valores acima da média, e as radiografias 1 e 3 , valores que ficaram abaixo, sendo respectivamente $2,68,2,65,2,57$ e 2,56. Na faixa de dez impulsos, a média foi 0,43 e os valores das radiografias $1,2,3$ e 4 foram, respectivamente, 0,41, 
$0,45,0,43$ e 0,45 , sendo que as radiografias 2 e 4 ficaram acima da média, a radiografia 3 permaneceu na média e a radiografia 1 ficou abaixo da média. $\mathrm{Na}$ faixa de um impulso, a média foi 0,08 e os valores das quatro radiografias foram, respectivamente, 0,06, 0,07, 0,08 e 0,08, sendo que as radiografias de 1 a 4 apresentaram valores muito próximos da média. Na faixa da DBV, notase que a média foi de 0,07 e os valores das 4 radiografias foram $0,06,0,07$, 0,08 e 0,08 , respectivamente, o que mostra que a radiografia 1 ficou abaixo da média, a 2 permaneceu na média e as radiografias 3 e 4 ficaram acima da média. Isto mostra que o processamento das radiografias utilizadas neste experimento, para este grupo, apresentou alta padronização.

Na tabela 2 observamos os valores médios obtidos das dez leituras em cada faixa de exposição nas quatro radiografias utilizadas para o grupo 2 . Notamos que a média na faixa de 300 impulsos, foi 4,57 e os valores das quatro radiografias, foram 4,70 (acima da média), 4,51 e 4,53 (abaixo da média) e 4,57 (na média), respectivamente. Na faixa de 60 impulsos, o valor médio obtido foi de 3,12 e os valores 3,16 e 3,25 ficaram acima da média e os valores 3,07 e 3 ficaram abaixo da média. Na faixa onde se utilizaram dez impulsos de exposição, o valor médio encontrado foi 0,59 , na radiografia $1 \mathrm{o}$ valor foi igual ao da média e na $2(0,54)$, abaixo da média. Na radiografia 3 , o valor foi igual a média e na radiografia 4 foi de 0,63 , acima da média. Quando se utilizou um impulso de exposição, a média foi 0,13 e os valores obtidos das radiografias 1, 2, 3 e 4, foram, respectivamente, 0,14, (acima da média), 0,11 e 0,12 (abaixo da média) e 0,14 (acima da média). A média da DBV foi 0,12, sendo que as radiografias 2 e 3 permaneceram na média e as radiografias 1 e 4 ficaram acima da média com o valor de 0,13. Novamente podemos observar que a padronização manteve-se neste grupo da mesma forma que no anterior.

Na tabela 3, onde observamos os resultados do grupo 3, notamos que o valor médio da faixa de 300 impulsos de exposição, foi de 4,18 e os 
valores das radiografias 1, 2, 3 e 4 foram 4,21, 4,29, 4,27 e 3,90, sendo que as radiografias 1, 2 e 3 ficaram acima da média e a radiografia 4, abaixo. $\mathrm{Na}$ faixa de 60 impulsos, a média foi de 3,02 sendo que a radiografia 1 e 4 ficaram abaixo, com valores de 3,01 e 2,90, respectivamente, as radiografias 2 e 3 ficaram acima da média $(3,15$ e 3,04), respectivamente. Na faixa onde se utilizaram dez impulsos, o valor médio encontrado foi de 0,61 , sendo que a radiografia 1, permaneceu na média, a radiografia 2 ficou acima da média, com o valor de 0,66 e as radiografias 3 e 4 apresentaram os valores de 0,59 e 0,57 , nesta ordem, ficando abaixo da média. Quando se utilizou um impulso, a média encontrada foi de 0,14 , as radiografias 1 e 2 , ficaram acima da média com valores de 0,15 e 0,17 e as radiografias 3 e 4 apresentaram os valores de 0,12 e 0,13 , nesta ordem, ficando abaixo da média. O valor médio na DBV, foi de 0,14 , nas radiografias 1 e 4 os valores foram iguais a média, para a radiografia 2 o valor ficou acima da média $(0,17)$ e na radiografia 3 , foi abaixo da média $(0,13)$. Novamente observamos a alta padronização nos resultados dos processamentos.

Analisando-se estas três tabelas observa-se que quando utilizamos a solução Agfa Dentus, o grupo que apresentou a Densidade Ótica mais alta foi o grupo $1(4,75)$, seguido pelos grupos $2(4,57)$ e $3(4,18)$. Em relação à DBV, o resultado mais baixo foi observado também no grupo $1(0,07)$, seguido pelos grupos $2(0,12)$ e $3(0,14)$.

Nas Figuras 8, 9 e 10 observamos as curvas características construídas a partir da média das quatro radiografias dos grupos 1, 2 e 3 $\left(20^{\circ} \mathrm{C} / 5\right.$ minutos, $25^{\circ} \mathrm{C} / 2,5$ minutos e $30^{\circ} \mathrm{C} / 1,25$ minuto). Observamos que a posição da curva característica da Figura 8 é mais para esquerda, o que forneceu ao grupo 1 a maior sensibilidade alcançada pelo filme (57R*). Os grupos 2 e 3 apresentaram sensibilidades iguais (52R*), sendo que as curvas características da Figura 9 e 10 se posicionaram um pouco mais à direita em 
relação ao grupo 1. Estes valores colocaram o filme Agfa Dentus M2 "Comfort" dentro do grupo F de sensibilidade, nesta solução de processamento.

Ainda em relação a esta solução, o contraste mais alto foi observado no grupo $3(2,11)$, quando pôde-se observar na curva característica da Figura 10, uma menor inclinação em relação às curvas características das Figuras 8 e 9 referentes aos grupos 1 e 2 . O grupo 2 forneceu contraste de 1,78 seguido pelo grupo $1(1,75)$, que apresentou uma inclinação maior da curva característica observada na Figura 8. Estes valores representam contraste dentro de uma variação de normalidade.

A latitude obtida no grupo 2 (6,52mAs) foi a mais alta, seguido pelos grupos $3(6,24 \mathrm{mAs})$ e 1 (6,21mAs), estando estes valores dentro de padrões de normalidade para latitude de filmes radiográficos. 


\subsection{Solução Kodak}

As tabelas de 4 a 6 mostram os resultados de Densidades Óticas alcançadas pelo filme na solução Kodak nas três diferentes temperaturas e tempos de revelação, grupos 4,5 e 6 .

Quando analisamos a tabela 4, notamos que a média na faixa de 300 impulsos de exposição, no grupo 4, foi de 4,16. Os valores encontrados abaixo da média foram observados nas radiografias 1,2 e 4, sendo os seguintes 4,11, 4,13 e 4,14. A radiografia 3 apresentou um valor acima da média, sendo 4,28. O valor médio na faixa de 60 impulsos foi de 2,66, sendo que os valores das radiografias 2 e 3 foram iguais à média e o valor da radiografia 1 foi acima da média $(2,74)$ e na radiografia 4 , abaixo da média $(2,57)$. A faixa com dez impulsos, apresentou média de 0,52 , e os valores de 0,53 para as radiografias 1 e 3 ficaram acima da média. Para a radiografia 4, o valor foi abaixo da média $(0,50)$, e a radiografia 2 permaneceu na média. Quando se utilizou um impulso de exposição, o valor médio foi de 0,12 e as radiografias 1 e 2, mantiveram-se na média. As radiografias 3 e 4, com valores de 0,13, permaneceram acima da média. Na faixa da DBV, a média foi de 0,12 sendo que as radiografias 1 e 3 apresentaram valores acima da média, 0,13 e as radiografias 2 e 4 ficaram na média. Observa-se também neste grupo, alta padronização dos processamentos.

A tabela 5 mostra os resultados obtidos do grupo 5, onde se utilizou a solução Kodak na temperatura de $25^{\circ} \mathrm{C}$ por 2,5 minutos. A média para a faixa de exposição de 300 impulsos, foi de 4,69, sendo que as radiografias 1, 2 e 4 ficaram abaixo da média, com os valores de 4,67, 4,67 e 4,68, respectivamente; a radiografia 3 apresentou valor de 4,73 (acima da média). $\mathrm{Na}$ faixa de 60 impulsos de exposição, a média foi de 2,61 e as radiografias 1 e 2, apresentaram valores mais baixos do que a média $(2,59$ e 2,53) e as radiografias 3 e 4, apresentaram valores de 2,65 e 2,67, permanecendo acima 
da média. Quando se utilizaram dez impulsos de exposição o valor médio encontrado foi de 0,49 e o valor encontrado para a radiografia 1 foi o mesmo, para a radiografia 2 o valor encontrado ficou abaixo da média $(0,47)$ e nas radiografias 3 e 4, os valores foram 0,51 para ambas, acima da média. $\mathrm{Na}$ faixa de um impulso, o valor médio encontrado foi de 0,10 ; o valor encontrado acima da média foi observado na radiografia $3(0,11)$. Para as radiografias 2 e 4 os valores encontrados foram abaixo da média $(0,09)$, e a radiografia 2 permaneceu na média. Quando não se utilizou nenhum tempo de exposição (faixa de DBV), a média encontrada foi de 0,10 sendo que a radiografia 1 permaneceu na média, a 2 e a 4 ficaram abaixo $(0,09)$ e a 3 , acima, com o valor de 0,11. Mais uma vez a padronização das etapas dos processamentos foi mantida neste grupo.

Os valores encontrados na tabela 6 são os resultados de Densidade Ótica obtidos no grupo 6. Na faixa de 300 impulsos, a média foi de 4,60; os valores de 4,59 e 4,50, apresentados pelas radiografias 1 e 3 ficaram abaixo da média; as radiografias 2 e 4 apresentaram-se acima da média com valores de 4,65 e 4,66. Quando se utilizaram 60 impulsos, o valor médio encontrado foi de 2,90 e a radiografia 1 permaneceu na média, as radiografias 2 e 3 ficaram abaixo da média com valores de 2,74 e 2,89 e a radiografia 4 , acima dela $(3,04)$. Com dez impulsos de exposição, a média foi de 0,57 e este valor se manteve na radiografia 3, nas radiografias 1 e 4 os valores foram acima da média (0,58 e 0,60, respectivamente) e a radiografia 2 apresentou valor abaixo da média, $(0,55)$. Na faixa de um impulso, os valores encontrados para as radiografias 2 e 4 permaneceram na média $(0,13)$; as radiografias 1 e 3 ficaram acima da média $(0,14)$. Para a faixa da DBV, os valores das quatro radiografias mantiveram-se dentro da média que foi de 0,13. Este grupo apresentou a mesma tendência de padronização do processamento dos grupos anteriores. 
Após analisarmos as tabelas 4, 5 e 6 , notamos que quando se utilizou esta solução, os maiores resultados de Densidade Ótica foram alcançados no grupo $5(4,69)$, seguido pelos grupos $6(4,60)$ e $4(4,16)$. Em relação à DBV, o resultado mais alto foi alcançado no grupo $6(0,13)$, seguido pelos grupos $4(0,12)$ e $5(0,10)$.

As curvas características referentes à solução Kodak, estão representadas nas Figuras 11, 12 e 13.

As sensibilidades derivadas da curvas características das Figuras 11 e 13 mostram que, dentro desta solução, a menor sensibilidade foi alcançada nos grupos 4 e 6 , que foram iguais (48R*), mostrando que estas duas curvas estão posicionadas mais à esquerda em relação à curva da Figura 12. Esta curva característica forneceu sensibilidade de $43 \mathrm{R}^{*}$ ao grupo 5. Estes valores colocam o filme Agfa Dentus M2 "Comfort", no grupo E de sensibilidade.

Em relação ao contraste, o resultado mais alto observado foi no grupo $5(1,96)$, seguido pelos grupos $4(1,88)$ e $6(1,72)$, resultado este adequado para um bom contraste radiográfico. Analisando as curvas características das Figuras 11, 12 e 13, nota-se que a inclinação da curva da Figura 13 (grupo 6) é levemente maior que as curvas características das Figuras 11 e 12 (grupos 4 e 5). A inclinação da curva da Figura 11 (grupo 5) é maior que a da curva da Figura 12 (grupo 4).

A latitude mais alta foi observada no grupo $6(8,10 \mathrm{mAs})$, seguido pelos grupos 4 (6,54mAs) e 5 (5,49mAs), estando estes valores dentro de uma faixa de normalidade no que se refere à latitude do filme radiográfico. 


\subsection{Solução Sillib}

As tabelas de 7 a 9 apresentam os resultados obtidos com o uso da solução Sillib nas três temperaturas utilizadas para determinar as Densidades Óticas no filme Agfa Dentus M2 “Comfort", grupos 7, 8 e 9.

A tabela 7 mostra os resultados obtidos quando se utilizou a solução Sillib com $20^{\circ} \mathrm{C}$ por dois minutos. Com 300 impulsos de exposição, o valor médio encontrado foi de 4,28 e os valores de 4,53, 4,75, e 4,51 ficaram acima da média e pertencem às radiografias 1,2 e 4 ; o valor de 3,34 foi observado para radiografia 3, estando abaixo da média. Observa-se nesta faixa de exposição uma alteração do padrão encontrado até aqui, sendo que as radiografias 1 e 4 apresentaram variação leve; a radiografia 2 mostra, nesta faixa de exposição, um aumento na Densidade Ótica em relação à média, isto pode ser explicado em função de leve aumento no tempo de exposição do aparelho. Esta alteração não foi observada nas faixas subseqüentes, não sendo possível, ser decorrente de uma alteração na emulsão do filme ou causada pela atuação desigual da solução reveladora. A radiografia 4, que mostra valor de 3,34, para esta faixa de exposição, de 300 impulsos, muito provavelmente recebeu uma menor dose de radiação emitida pelo aparelho, visto que as outras faixas da mesma radiografia apresentaram a mesma tendência que nos grupos anteriores. $\mathrm{Na}$ faixa de 60 impulsos, o valor médio encontrado foi de 1,68; as radiografias 1 e 3 ficaram acima da média (1,73 e 1,70); para as radiografias 2 e 4, os valores ficaram abaixo da média (1,64 e 1,67). Nota-se, novamente uma certa padronização dos resultados e que as alterações que ocorreram na faixa de 300 impulsos, muito provavelmente foram decorrentes do tempo de exposição do aparelho de raios X. A mesma tendência de padronização foi observada para as faixas subseqüentes, onde na faixa de dez impulsos de exposição, a média foi de 0,25, sendo que as radiografias 1 e 2 foram iguais a média; as radiografias 3 e 4 apresentaram-se acima da média 
com valor de 0,26 para ambas. Na faixa de um impulso, o valor médio encontrado foi de 0,03 sendo que as radiografias 1,2 e 3, permaneceram na média e a radiografia 4 apresentou valor de 0,04 , ficando pouco acima do valor médio. Na faixa de $\mathrm{DBV}$, a média foi de 0,02 sendo que somente a radiografia 4 apresentou valor acima da média $(0,03)$, as outras radiografias permaneceram dentro do valor médio.

Quando analisamos os resultados da tabela 8, referentes ao grupo 8, observamos que a média na faixa de 300 impulsos, foi de 4,52; a radiografia 1 manteve-se na média; as radiografias 1 e 4 permaneceram abaixo da média $(4,50)$, a radiografia 3 apresentou o valor de 4,58, acima da média. A faixa de 60 impulsos de exposição, mostrou média de 1,79, as radiografias 1 e 3, com valor de 1,83, ficaram acima da média, e as radiografias 2 e 4 ficaram abaixo da média com os valores: 1,74 e 1,75. Quando se utilizaram dez impulsos de exposição, as radiografias 1, 2, 3 e 4, apresentaram, respectivamente, os valores de $0,28,0,27,0,28$ e 0,28 , quando a média foi de 0,28 , portanto as radiografias 1, 3 e 4 mantiveram-se na média e a radiografia 2, abaixo. $\mathrm{Na}$ faixa de um impulso, a média encontrada foi de 0,04 e os valores das quatro radiografias mantiveram-se dentro da média. $\mathrm{Na} \mathrm{DBV}$, a média foi de 0,04; os valores para as radiografias 2 e 4 ficaram na média, a 1 ficou abaixo $(0,03)$ e a 3 ficou acima $(0,05)$. Os valores apresentados pelas quatro radiografias mostraram uma coerência com os valores das médias de cada faixa de exposição, denotando mais uma vez a padronização dos processamentos radiográficos.

A tabela 9 mostra os resultados obtidos do grupo 9 , onde se observa que na faixa de 300 impulsos, o valor médio encontrado foi de 4,41; as radiografias 1 e 2 ficaram acima da média (4,59 e 4,50) e as radiografias 3 e 4 apresentaram valores de 4,22 e 4,35, abaixo da média. O valor médio da faixa de 60 impulsos de exposição, foi de 2,07, sendo que os valores de 2,15 e 2,10, 
encontrados para as radiografias 1 e 4 , respectivamente, ficaram acima da média; os valores 2,06 e 1,97 apresentados pelas radiografias 2 e 3, ficaram abaixo da média. Quando se utilizaram dez impulsos de exposição, a média foi 0,32 e os valores obtidos para cada uma das quatro radiografias foram, respectivamente, $0,33,0,32,0,31$ e 0,32 , sendo que as radiografias 2 e 4 mantiveram-se na média, a radiografia 1 ficou acima da média e a 3, abaixo. $\mathrm{Na}$ faixa onde se utilizou um impulso, a média foi de 0,05 sendo que as radiografias 2,3 e 4 permaneceram na média e a radiografia 1 ficou abaixo da média $(0,04)$. Na faixa da DBV, a média encontrada foi de 0,04 , sendo que os valores para as radiografias 1 e 3 permaneceram na média; as radiografias 2 e 4 apresentaram valores acima da média $(0,05)$. Mais uma vez a alta padronização do processamento radiográfico foi a responsável pela semelhança dos valores neste grupo.

Analisando-se as tabelas 7, 8 e 9, podemos observar que a maior Densidade Ótica foi alcançada no grupo $8(4,52)$, seguido pelos grupos 9 $(4,41)$ e $7(4,28)$. Quanto à $\mathrm{DBV}$, resultados iguais e mais altos foram alcançados nos grupos 8 e $9(0,04)$, seguidos pelo grupo $7(0,02)$.

As Figuras 14, 15 e 16 representam as curvas características construídas a partir das médias das Densidades Óticas das quatro radiografias quando se utilizou a solução Sillib, nas diferentes combinações.

A curva característica observada na Figura 16, construída a partir dos valores médios de Densidade Ótica do grupo 9, proporcionou a maior sensibilidade $\left(35 R^{*}\right)$ ao filme quando se utilizou esta solução. A menor sensibilidade foi observada no grupo $7\left(31 R^{*}\right)$ seguido pelo grupo $8\left(32 R^{*}\right)$, onde observamos, pela análise das Figuras 14 e 15, o posicionamento mais à direita destas curvas em relação à curva característica da Figura 16. Estes valores proporcionaram ao filme Agfa Dentus M2 "Comfort", sensibilidade do grupo E. 
Quando analisamos os valores de contraste, notamos que o valor mais alto foi obtido no grupo $8(2,21)$, seguido pelos grupos $7(2,19)$ e 9 $(2,08)$, estando estes valores dentro dos padrões de normalidade para contraste radiográfico. A análise das Figuras 14, 15 e 16 mostra a maior inclinação da curva para o grupo 9 (Figura 16), sendo menos acentuada para o grupo 7 (Figura 14) e ainda menos para o grupo 8 (Figura 15).

Os valores de latitude mostram que o grupo 7 apresentou o mais alto valor (7,17mAs), seguido pelos grupos 9 (6,05mAs) e 8 (5,91mAs). Estes valores apresentam-se dentro de uma faixa de normalidade para latitude do filme radiográfico. 


\subsection{Superposição das curvas características}

O processamento de um filme radiográfico em diferentes soluções produz radiografias de diferentes qualidades em relação à densidade ótica, contraste, sensibilidade e densidade base e velamento ${ }^{58}$.

Analisando a tabela 10, que foi construída a partir das médias obtidas das quatro radiografias processadas, podemos observar que a Densidade Ótica mais alta foi a alcançada com a solução Agfa Dentus na temperatura de $20^{\circ} \mathrm{C}$ e com tempo de cinco minutos de revelação, na faixa de 300 impulsos de exposição. Esta combinação forneceu ao filme Agfa Dentus M2 "Comfort", a maior sensibilidade observada (tabela 11). As outras combinações forneceram altos valores de Densidade Ótica, sendo que a combinação que apresentou os valores mais baixos foi a solução Kodak a $20^{\circ} \mathrm{C}$ por cinco minutos, mas dentro de uma faixa aceitável de variação, visto que uma Densidade Ótica maior do que três, não é perceptível ao olho humano, sendo portanto impossível de se definir as diferenças presentes nestas áreas de alta densidade.

Uma densidade base e velamento maior que 0,25 , é normalmente inaceitável pela maioria dos autores ${ }^{58}$. No presente estudo todos os valores de densidade base e velamento foram inferiores a este valor, denotando baixos valores de densidade base e velamento em todas as combinações testadas. Uma variação quando se utilizou a solução Sillib, em todas as combinações de temperatura/tempo foi observada. Valores relativamente baixos de DBV foram encontrados quando se utilizou esta solução. Isto pode ser explicado pelo fato deste revelador ser menos enérgico do que os outros. Os valores de Densidade Ótica ficaram dentro da variação aceitável para todas as combinações, sendo que as pequenas diferenças encontradas entre os nove grupos não apresentam significado prático no uso rotineiro da clínica. 
De acordo com a tabela 11, podemos observar que a solução Agfa Dentus em todas as combinações, pôde produzir no filme Agfa Dentus M2 "Comfort", sensibilidade do grupo F, enquanto as outras soluções, nas diferentes combinações, produziram sensibilidade do grupo E. Isto concorda com os achados de FARMAN; FARMAN ${ }^{29}$, 2000, onde verificaram que a escolha da química de processamento afeta as características radiográficas, incluindo a sensibilidade do filme. Nos resultados encontrados por estes autores, o filme Agfa Dentus M2 “Comfort”, alcançou sensibilidade do grupo F e o filme Ultraspeed sensibilidade E quando se utilizou o revelador Automat $\mathrm{XR}$, para processamento automático. Em nossos estudos, o resultado de sensibilidade para a solução Agfa Dentus a $20^{\circ} \mathrm{C}$ por cinco minutos, foi de 5,22mAs, o que corresponde em Röntgen recíproco $\left(\mathrm{R}^{*}\right)$ a 57 , na combinação de $25^{\circ} \mathrm{C}$ por 2,5 minutos e $30^{\circ} \mathrm{C}$ por 1,25 minuto, o valor foi de $5,72 \mathrm{mAs}$ e em $\mathrm{R}^{*}, 52$, encontrando-se estes valores dentro do grupo $\mathrm{F}$ de sensibilidade.

Quando se utilizou a solução Kodak nas três diferentes temperaturas e tempos de revelação, encontramos os valores de 6,28, 7,04 e 6,28mAs, respectivamente. Estes valores, quando expressos em $\mathrm{R}^{*}$, correspondem a 48, 43 e 48, nesta ordem, denotando que com esta combinação, o filme Agfa Dentus M2 "Comfort", apresentou sensibilidade do grupo E.

Na solução Sillib, nas três temperaturas e tempos de revelação utilizados, os valores de sensibilidade encontrados foram de 9,73, 9,50 e 8,67mAs, o que corresponde em $\mathrm{R}^{*}$ a 31,32 e 35, estando estes valores enquadrados no grupo $\mathrm{E}$ de sensibilidade. Nos achados de IUCIF; TAVANO $^{56}$, em 1995, os valores de sensibilidade alcançados pelo filme Agfa Dentus M2 "Comfort”, classificado como grupo D/E, mostraram que o filme pertencia ao grupo D de sensibilidade. Este novo filme por nós testado, é descrito pelo fabricante como um filme de sensibilidade do grupo E, 
comparável ao Ektaspeed Plus. Ele substitui o Agfa Dentus anterior, considerado entre o grupo $\mathrm{D} / \mathrm{E}$ de sensibilidade. $\mathrm{O}$ fabricante chama a atenção para o fato deste filme ser estável sob uma variação de diferentes condições de processamento, produzindo mínima densidade base e velamento, fina granulação e alto contraste. Estes resultados foram confirmados por nós, visto que o filme, quando submetido a uma grande variação de condições de processamento, apresentou sensibilidade do grupo E e ainda conseguiu alcançar a sensibilidade do grupo F quando se utilizou a solução Agfa Dentus, provando uma relativa estabilidade dependendo da solução utilizada.

A Figura 17 representa a superposição das curvas obtidas dos nove grupos analisados, que foram construídas a partir dos valores de Densidade Ótica observados na tabela 10. Nesta Figura observamos as tendências de posicionamento das curvas, onde a curva referente ao grupo 1 (Agfa Dentus $30^{\circ} \mathrm{C} / 5$ minutos), representada por azul, que apresentou a maior sensibilidade, está posicionada mais à esquerda em relação às outras. As curvas referentes aos $2^{\text {os }}$ melhores resultados, que foram obtidas dos grupos 2 e 3 (Agfa Dentus $25^{\circ} \mathrm{C} / 2,5$ minutos e $30^{\circ} \mathrm{C} / 1,25$ minuto), estão representadas em amarelo e verde, respectivamente, e estão posicionadas um pouco mais à direita em relação ao grupo 1 e mais à esquerda em relação aos demais grupos. Os grupos 4 e 6 (Kodak $20^{\circ} \mathrm{C} / 5$ minutos e $30^{\circ} \mathrm{C} / 1,25$ minuto), apresentaram sensibilidades iguais e estão representados nesta Figura em preto e verde pontilhado. Estas curvas vêm logo depois que as anteriores, posicionadas um pouco mais à direita. A solução Kodak $25^{\circ} \mathrm{C} / 2,5$ minutos, grupo 5 apresentou menor sensibilidade que as anteriores e está representada nesta Figura na cor rosa. As curvas construídas a partir das combinações realizadas com a solução Sillib, estão representadas em vermelho pontilhado, preto pontilhado e rosa pontilhado, respectivamente, para $20^{\circ} \mathrm{C} / 2$ minutos, $25^{\circ} \mathrm{C} / 1$ minuto e $30^{\circ} \mathrm{C} / 0,5$ 
minuto. Estas curvas posicionam-se mais à direita em relação às anteriores por apresentarem as menores sensibilidades.

Os nossos resultados mostraram que o filme Agfa Dentus M2 "Comfort", apresentou uma grande variação quanto à sensibilidade, mostrando-se mais sensível quando se utilizou a solução Agfa Dentus em todas as combinações. Estes resultados concordam com os de SYRIOPOULOS ${ }^{108}$ et al, 1999, onde os resultados de sensibilidade foram mais altos quando se utilizou a solução Agfa Dentus a $20^{\circ} \mathrm{C} / 5$ minutos.

O contraste ideal está entre 1,5 a 2,5 , portanto os resultados observados na tabela 11, mostram coerência de nossos resultados com a literatura no que diz respeito ao contraste ideal. Dentro desta faixa de variação, observa-se que a solução Sillib nas três combinações $(2,19,2,21$ e 2,08) e a solução Agfa Dentus a $30^{\circ} \mathrm{C} / 1,25$ minuto $(2,11)$, apresentaram os mais altos contrastes. O contraste mais baixo foi observado com a solução Kodak $30^{\circ} \mathrm{C} / 1,25$ minuto $(1,72)$. Estes achados concordam com os observados por MATTHEE; BECKER; SEELIGER ${ }^{80}, 1990$, onde os melhores valores de contraste foram encontrados quando se utilizou um aumento de temperatura de $25^{\circ} \mathrm{C}$ até $35^{\circ} \mathrm{C}$. Verificou, este autor, que o melhor contraste foi obtido utilizando-se o filme Agfa Dentus processado a $35^{\circ} \mathrm{C}$. Nossos resultados concordam com os encontrados por TAMBURÚS ${ }^{109}$, 1987, quando afirma que todas as temperaturas avaliadas, $20^{\circ} \mathrm{C}, 22^{\circ} \mathrm{C}, 24^{\circ} \mathrm{C}$ e $26^{\circ} \mathrm{C}$, utilizando-se o filme Ektaspeed, não alteraram o contraste radiográfico substancialmente, mantendo-se dentro de uma faixa aceitável de variação. A variação da temperatura da solução para o processamento radiográfico, não produziu, em nossos estudos, diferenças significantes em relação ao contraste radiográfico, discordando dos achados de $\mathrm{KOGON}^{65}$, et al, 1985, que afirmaram que o aumento na temperatura acima de $22^{\circ} \mathrm{C}$, reduziu substancialmente o contraste quando se utilizou o filme Ektaspeed. De acordo com ALVARES; FREITAS; 
ESTEVAM $^{5}, 1969$, pequenas diferenças encontradas em relação ao contraste, não seriam notadas pelo profissional que examina uma radiografia ao negatoscópio.

Analisando a Figura 17, observamos a tendência das curvas em relação ao contraste radiográfico. A curva característica da combinação que apresentou o mais alto contraste (Sillib $25^{\circ} \mathrm{C} / 1$ minuto), está representada por preto pontilhado e apresenta a menor inclinação em relação às outras curvas. A curva característica da combinação que forneceu o menor valor de contraste radiográfico (Kodak $30^{\circ} \mathrm{C} / 1,25$ minuto), está representada por verde pontilhado e foi a curva característica que apresentou a maior inclinação em relação às outras.

A latitude foi semelhante para todos os grupos, sendo um pouco maior quando se utilizou a solução Kodak $30^{\circ} \mathrm{C} / 1,25$ minuto, mostrando que este filme, quando processado nesta solução, nesta temperatura e com este tempo de revelação, aceita maiores variações quanto à exposição.

As propriedades sensitométricas obtidas do filme radiográfico Agfa Dentus M2 "Comfort", processados nas diferentes combinações, foram consideradas dentro do padrão. O filme apresentou alta sensibilidade, contraste ideal e latitude aceitável em todas as combinações utilizadas. Quando processado nas soluções Kodak e Sillib, o filme apresentou sensibilidade do grupo E.

Quando analisamos a tabela 11, e observamos as propriedades sensitométricas dos grupos 7, 8 e 9 (solução Sillib), podemos notar que os valores de densidade base e velamento foram significantemente menores que nos outros grupos, concordando com SPOSTO; TAVANO; LOPES ${ }^{103}, 1983$.

A sensibilidade foi menor nestes três grupos, porém o filme permaneceu no grupo E de sensibilidade. O contraste mais alto foi também observado para esta solução, porém, permanecendo dentro da faixa normal de 
variação. Quanto à latitude os valores correspondem a uma faixa aceitável de variação. Desta forma, quando consideramos que o filme Agfa Dentus M2 "Comfort", alcançou propriedades sensitométricas aceitáveis utilizando-se a solução Sillib nas diferentes combinações, podemos dizer que esta apresenta uma certa vantagem em relação às outras, visto que, com o mesmo tempo de exposição e um menor tempo de revelação, podemos alcançar radiografias de qualidades aceitáveis. 


\subsection{Densidades Radiográficas}

Da mesma forma que para a Densidade Ótica, as Densidades Radiográficas foram medidas em quatro radiografias para cada um dos nove grupos, a fim de se obter uma maior precisão e fidelidade dos resultados.

Para correlacionar os valores encontrados nas tabelas de 12 a 20 , estabelecemos uma faixa de variação para mais ou para menos em relação à média para todas as faixas de exposições, que foi de cinco níveis de cinza, tanto para a Densidade Radiográfica como para a Densidade Radiográfica invertida, em todas as faixas de exposições analisadas. Como na Densidade Ótica estes valores foram aleatórios e servem apenas para facilitar a análise dos resultados quanto à padronização do método.

Na tabela 12 observam-se os resultados obtidos no grupo 1, quando utilizou-se a solução Agfa Dentus a $20^{\circ} \mathrm{C}$ por cinco minutos. Na faixa de 300 impulsos, as médias da D.R. e D.R.i foram, respectivamente, 3 e 252. Para a D.R., as radiografias 1 e 4 permaneceram dentro da média e as demais ficaram muito próximas ( 2 e 5), assim como na D.R.i. Na faixa de 60 impulsos, a média para D.R. e D.R.i foi 4 e 251, e os valores das quatro radiografias foram muito próximos para D.R. ( 4, 2 e 6) e para D.R.i (251, 253 e 249). Quando se utilizaram dez impulsos, as médias foram 132 e 123 para D.R. e D.R.i, respectivamente. As radiografias 2 e 4, para D.R., ficaram abaixo da média (130) e as radiografias 1 e 3 ficaram acima (135). Para D.R.i, as radiografias 1 e 3 ficaram abaixo (120) e as radiografias 2 e 4, acima (126 e 135). Na faixa de um impulso, a média para D.R. foi 189 e para a D.R.i, 66, sendo os valores das quatro radiografias muito próximos da média $(190,188$, 191 e 188), para D.R. e (65, 67, 64 e 67) para D.R.i. Na DBV, a média para a D.R. foi 190 e para a D.R.i foi 65, os valores para as radiografias 1, 2, 3 e 4 foram, respectivamente, 191 (acima da média), 188 (abaixo da média), 192 (acima da média) e 190 (na média), para a D.R. e para a D.R.i, foram 64 
(abaixo da média), 67 (acima da média), 63 (abaixo da média) e 66 (acima da média).

Os resultados das Densidades Radiográficas para o grupo 2, onde se utilizou a solução Agfa Dentus a $25^{\circ} \mathrm{C}$ por 2,5 minutos, encontram-se na tabela 13. Na faixa de 300 impulsos de exposição, as médias para D.R. e D.R.i, foram 5 e 249. Os valores das radiografias 1, 2, 3 e 4 ficaram muito próximos da média (5, 3, 8 e 6) para D.R. e (250, 252, 247 e 249), para D.R.i. Quando se utilizaram 60 impulsos observamos que foram encontrados os mesmo valores que na faixa anterior. Na faixa de dez impulsos, os valores 115 e 140 foram as médias das D.R. e D.R.i. Os valores encontrados para as radiografias 1, 2, 3 e 4, foram, para D.R. e D.R.i, respectivamente, 120 (acima da média), 109 (abaixo da média), 115 (na média) e 115 (na média), 135 (abaixo da média), 146 (acima da média), 140 (na média) e 140 (na média). $\mathrm{Na}$ faixa de um impulso, os valores médios encontrados para D.R. e D.R.i, foram de 182 e 73 . As radiografias 1 e 4, para D.R., ficaram acima da média (185 e 184); a 2, abaixo (179) e a 3 permaneceu na média. Na D.R.i as radiografias 1 e 4 apresentaram valores abaixo da média (70 e 71), a radiografia 2 ficou acima (76) e a 3 foi igual. $\mathrm{Na} \mathrm{DBV}$, as médias foram para D.R. e D.R.i, 184 e 71 e os valores encontrados para as quatro radiografias foram 187 (acima da média), 181 (abaixo da média), 182 (abaixo da média) e 185 (acima da média) para D.R. e 68 (abaixo da média), 74 (acima da média), 73 (acima da média) e 70 (abaixo da média) para D.R.i.

A tabela 14 também mostra os resultados encontrados no grupo 3, que utilizou a solução Agfa Dentus a $30^{\circ} \mathrm{C}$ por 1,25 minuto. A média na faixa de 300 impulsos, para D.R. e D.R.i, foram respectivamente 5 e 250. As radiografias 1 e 2, na D.R., ficaram abaixo da média (4 e 3); as radiografias 3 e 4 acima (7 e 5). As radiografias 1 e 2, na D.R.i, ficaram acima da média (251 e 252); a radiografia 3, ficou abaixo (248) e a 4 ficou na média. Na faixa 
de 60 impulsos de exposição, a média para D.R. foi 4 e para D.R.i, foi 250 e os valores para as quatro radiografias foram, respectivamente, 4 (na média), 3 (abaixo da média), 6 e 5 (acima da média), para D.R. e 251 e 252 (acima da média), 249 (abaixo da média) e 250 (na média), para D.R.i. Quando se utilizaram dez impulsos, os valores médios para D.R. e D.R.i, foram 113 e 141 e as radiografias 1, 2, 3 e 4 ficaram muito próximas da média $(118,115$, 109, 112 e 137, 140, 146 e 143). Na faixa de um impulso, a média para a D.R. foi de 180 e os valores para as quatro radiografias, foram 181 e 183 (acima da média), 177 (abaixo da média) e 180 (na média). Para a D.R.i, a média foi 74 e os valores das radiografias 1, 2, 3 e 4, foram 73 e 72 (abaixo da média), 78 e 75 (acima da média). Na faixa de DBV, os valores médios para D.R. e D.R.i, foram 181 e 74 . Os valores das radiografias 1 e 2, ficaram acima da média (182); a radiografia 3 apresentou valor de 177, abaixo, e a 4 permaneceu dentro da média.

Os resultados encontrados na tabela 15, mostram os resultados para o grupo 4 , onde se utilizou a solução Kodak a $20^{\circ} \mathrm{C}$ por cinco minutos. A média para D.R. e D.R.i, na faixa de 300 impulsos, foi de 6 e 249. Os valores das radiografias 1 e 2, para D.R., foram 5 e 4, abaixo da média; a radiografia 3 apresentou valor 8 (acima) e a radiografia 4 permaneceu na média. Para a D.R.i, as radiografias 1 e 2 ficaram acima da média (250 e 251); a radiografia 3 ficou abaixo (247) e a 4 permaneceu na média. Na faixa de 60 impulsos, a média para D.R. foi 7; as radiografias 3 e 4 ficaram acima da média (10 e 8) e as radiografias 1 e 2 ficaram abaixo (6 e 4). A média da D.R.i foi 248 e os valores 249 e 251 (acima da média) e 245 e 247 (abaixo da média) foram encontrados para as radiografias 1, 2, 3 e 4, nesta ordem. Quando se utilizaram dez impulsos de exposição, as médias para D.R. e D.R.i, foram 125 e 130; as radiografias 3 e 4, na D.R., ficaram acima da média (127 e 128); a 1 ficou na média e a 2 ficou abaixo (122). Para a D.R.i, os valores foram 130 
(na média), 133 (acima da média), 129 e 127 (abaixo da média). Na faixa de um impulso, a média para a D.R. foi de 185 e as radiografias 3 e 4 ficaram acima da média (186); a radiografia 1 foi igual à média e a 2 abaixo (183). A média para a D.R.i foi 70 e os valores para as quatro radiografias foram 70 (na média), 72 (acima da média), 69 (abaixo da média). Na DBV, as médias para D.R. e D.R.i, foram 185 e 70; as radiografias 1 e 2, na D.R., foram abaixo da média (184 e 183); as radiografias 3 e 4 ficaram acima (187 e 186) e para a D.R.i, os valores das radiografias 1 e 2 foram acima da média (71 e 72) e as 3 e 4 mostraram os valores de 68 e 69 (abaixo da média).

Nos resultados do grupo 5, (tabela 16), onde utilizou-se a solução Kodak a $25^{\circ} \mathrm{C}$ por 2,5 minutos, observamos que a D.R. apresentou média de 5 na faixa de 300 impulsos de exposição e os valores 4 e 3 (abaixo da média), 7 (acima da média) e 5 (na média). Para a D.R.i, a média foi 250 e as radiografias 1, 2, 3 e 4, apresentaram, valores muito próximos (251, 252, 248 e 250). Na faixa de 60 impulsos, a média para D.R. foi de 5 e para a D.R.i foi 249; as radiografias 3 e 4, para D.R., ficaram acima da média (8 e 6); a radiografia 1 ficou na média e a 2, abaixo (3). Para D.R.i as radiografias 1 e 2 ficaram acima da média (250 e 252) e as radiografias 3 e 4 abaixo (247 e 248). Na faixa de dez impulsos, a média foi 122 para D.R. e 131 para a D.R.i e os valores das quatro radiografias foram, respectivamente, 126 (acima da média), 121 (abaixo da média), 123 e 125 (acima da média) para a D.R. e 129 (abaixo da média), 134 e 132 (acima da média) e 130 (abaixo da média) para D.R.i. Quando se utilizou um impulso, a média foi 184 para D.R. e 71 para D.R.i; as radiografias 1 e 2, para D.R., ficaram abaixo da média (183 e 182) e as radiografias 3 e 4 ficaram acima (185 e 186). Para D.R.i, as radiografias 1, 2, 3 e 4 apresentaram valores de 72 e 73 (acima da média) e 70 e 69 (abaixo da média). Na faixa da DBV, as médias para D.R. e D.R.i foram 182 e 72 e os valores 181 (abaixo da média), 178 (abaixo da média), 183 e 185 (acima da 
média) foram apresentados pelas radiografias 1, 2, 3 e 4, respectivamente, na D.R. e na D.R.i, os valores foram 74 e 75 (acima da média) e 71 e 70 (abaixo da média).

Na tabela 17 observamos os resultados alcançados no grupo 6, onde se utilizou a solução Kodak a $30^{\circ} \mathrm{C}$ por 1,25 minuto. As médias para D.R. e D.R.i foram 4 e 251 na faixa de 300 impulsos de exposição e os valores encontrados para as quatro radiografias na D.R. e D.R.i, ficaram muito próximos da média (3, 2, 6 e 5), para D.R e (252, 253, 249 e 250), para D.R.i.. $\mathrm{Na}$ faixa de 60 impulsos, as médias para D.R. e D.R.i foram 4 e 251 e as radiografias 1 e 2 ficaram abaixo da média ( 3 e 2); as radiografias 3 e 4 ficaram acima (6 e 5), para D.R. Na D.R.i, as radiografias 1 e 2 apresentaram os valores de 252 e 253 (acima da média) e as radiografias 3 e 4, os valores de 249 e 250 (abaixo da média). Quando se utilizaram dez impulsos, a média foi 116 para D.R. e 139 para D.R.i. As 4 radiografias apresentaram valores muito próximos: 115 e 112 (abaixo da média), 121 e 117 (acima da média) para a D.R. e 140 e 143 (acima da média) e 134 e 138 (abaixo da média) para D.R.i. Na faixa de um impulso, as médias foram de 180 e 74 para D.R. e D.R.i. As radiografias 1, 2, 3 e 4 apresentaram o valor de 179 (abaixo da média) e 183 e 182 (acima da média). Para D.R.i os valores encontrados foram 76 (acima da média), 72 e 73 (abaixo da média). Na DBV, os valores médios encontrados para D.R. e D.R.i foram 180 e 74. Para as radiografias 1 e 2 os resultados ficaram abaixo da média (179); as radiografias 3 e 4 ficaram acima (183 e 181), para D.R. e para a D.R.i, as radiografias 1 e 2 (76) ficaram acima da média, a radiografia 3 (72), abaixo e a 4 na média.

Pode-se observar que as médias obtidas pelo grupo 7, (tabela 18), onde se utilizou a solução Sillib a $20^{\circ} \mathrm{C}$ por dois minutos, foi na faixa de 300 impulsos, para D.R. e D.R.i, respectivamente 5 e 250. Na D.R., os valores encontrados para as radiografias foram muito semelhantes à média $(4,4,7 \mathrm{e}$ 
5) e na D.R.i apresentaram valores $251,252,249$ e 250. Na faixa de 60 impulsos, as médias foram 21 para D.R. e 234 para D.R.i. As radiografias 1, 2, 3 e 4 apresentaram os valores de 20 e 19 (abaixo da média), 24 (acima da média) e 21 (na média) para D.R. e 235 e 236 (acima da média), 231 (abaixo da média) e 234 (na média) para D.R.i. Na faixa de dez impulsos, os valores médios foram 162 para D.R. e 93 para a D.R.i. Os valores encontrados para D.R. nas radiografias 1 e 2, ficaram abaixo da média (161); a radiografia 3 ficou acima da média (164) e a 4, na média. Para D.R.i, os valores para as quatro radiografias foram 94 e 94 (acima da média), 91 (abaixo da média) e 94 (acima da média). Quando se utilizou um impulso, a média para D.R. foi de 201 e para D.R.i, 53. As radiografias 3 e 4 para D.R., ficaram acima da média (203 e 202); a radiografia 2 ficou na média e a 1 abaixo (200). Para D.R.i, os valores foram de 55 e 54 (acima da média), 52 (abaixo da média) e 53 (na média). Na faixa da DBV, as médias foram 202 e 53 para D.R. e D.R.i., para as quatro radiografias, os valores foram de 200 e 201 (abaixo da média) e 203 e 203 (acima da média), 54 e 54 (acima da média) e 52 e 52 (abaixo da média) para D.R. e D.R.i, respectivamente.

Os valores obtidos do grupo 8, onde se utilizou a solução Sillib a $25^{\circ} \mathrm{C}$ por um minuto, estão mostrados na tabela 19. Quando se analisa a faixa de 300 impulsos, observa-se que as médias para D.R. e D.R.i, foram 5 e 250. Os valores apresentados pelas radiografias 1 e 2 ficaram abaixo da média (4 e 2); a radiografia 3, ficou acima (8); a radiografia 4 apresentou valor igual à média. Para D.R.i, os valores de 251 e 252 ficaram acima da média e o valor de 247 (radiografia 3) ficou abaixo; a radiografia 4 permaneceu na média. $\mathrm{Na}$ faixa de 60 impulsos, os valores médios encontrados foram 18 para D.R. e 237 para D.R.i. Nas quatro radiografias analisadas, os valores foram muito próximos (16, 16, 22 e 17 para D.R. e 239, 239, 233 e 238 para D.R.i). A média na faixa de dez impulsos, para D.R., foi 160 e para D.R.i foi 95. As 
radiografias 1, 2 e 4 (159), ficaram abaixo da média e a radiografia 3, acima (162). Na D.R.i, as radiografias 1 e 4 ficaram acima da média (96), a radiografia 2 permaneceu na média e a 3 ficou abaixo (94). Quando se utilizou um impulso, os valores médios encontrados foram 201 e 54 para D.R. e D.R.i. Os valores para as quatro radiografias foram 200 e 200 (abaixo da média), 202 (acima da média), 201 (na média), 55 e 55 (acima da média), 53 (abaixo da média) e 54 (na média) para D.R e D.R.i, respectivamente. Na faixa de DBV, os valores foram idênticos aos da faixa anterior.

Analisando a tabela 20, observam-se os resultados do grupo 9, onde se utilizou a solução Sillib a $30^{\circ} \mathrm{C}$ por 0,5 minuto. Na faixa de 300 impulsos de exposição, as médias obtidas da D.R. e D.R.i, foram, respectivamente, 5 e 250. Os valores das radiografias 1 e 2 , foram 4 e 3 para D.R (abaixo da média); para as radiografias 3 e 4 os resultados foram 8 e 6 (acima da média) e para D.R.i, as radiografias 1 e 2 ficaram acima da média (251 e 252) e as 3 e 4 ficaram abaixo da média (247 e 249). Utilizando-se 60 impulsos, obteve-se uma média de 12 para D.R e 243 para D.R.i. As radiografias 1, 2, 3 e 4 apresentaram os valores de 11 e 9 (abaixo da média), 17 (acima da média) e 12 (na média) para D.R. e 244 e 246 (acima da média), 238 (abaixo da média) e 243 (na média) para D.R.i. Na faixa onde se utilizaram dez impulsos, observa-se que as médias da D.R. e D.R.i foram, respectivamente 155 e 100. Os valores para D.R. foram 155 e 155 (na média), 157 (acima da média) e 153 (abaixo da média) e os valores 100 e 100 (na média), 97 (abaixo da média) e 102 (acima da média) para a D.R.i. A faixa de um impulso apresentou média de 201 para D.R. e 54 para D.R.i. As radiografias 1 e 2 ficaram abaixo da média (200) e as 3 e 4 mostraram-se acima (202). Para a D.R.i, as radiografias 1 e 2 ficaram acima da média (55); as radiografias 3 e 4 apresentaram o valor de 53 (abaixo da média). Na área de DBV, os valores médios alcançados foram de 201 para D.R. e 54 para D.R.i. Para as radiografias 1, 2, 3 e 4 os 
valores encontrados foram 200 e 200 (abaixo da média), 203 e 202 (acima da média) para D.R e 55 e 55 (acima da média), 52 e 53 (abaixo da média) para D.R.i.

Após a descrição dos dados obtidos verificou-se que houve uma alta correlação entre os valores das médias das Densidades Radiográficas com os valores encontrados nas radiografias 1, 2, 3 e 4 individualmente, como também foi observado para os valores de Densidades Óticas. Assim, nota-se o alto controle na padronização do processamento radiográfico realizado neste estudo. 


\subsection{Densidades Óticas e Densidades Radiográficas}

Os dados apresentados na tabela 21, representam todos os valores obtidos de Densidade Ótica e Densidades Radiográficas nas quatro radiografias. Estes dados foram submetidos à análise estatística utilizando o Coeficiente de Correlação de Pearson. Na tabela 22 podemos observar os valores encontrados quando se aplicou o teste de correlações. Observa-se que em todos os grupos e entre todas as Densidades, houve uma correlação estatística significante, com índice de confiança de 95\%. Alta correlação estatística foi observada quando $\mathrm{p}<0,05$.

Em 1997, CHEN; $\mathrm{CHIANG}^{18}$, mostraram que imagens digitalizadas com o uso de um scanner apresentaram valores de pixels distribuídos similarmente aos valores de densidade ótica encontrados com o uso de um fotodensitômetro, em condições padronizadas de exposição e processamento.

Nossos resultados concordam com os achados de $\operatorname{COCLETE}^{21}$, 1999, que realizou um estudo a fim de analisar a utilização das Densidades Radiográficas como substituta da Densidade Ótica, utilizando tiras de filmes radiográficos extrabucais XK-1 expostos no sensitômetro MRA e processados em processadora automática em quatro diferentes temperaturas. Os resultados mostraram alta correlação entre a Densidade Ótica e Densidades Radiográficas, quando se aplicou a Correlação de Pearson. O autor concluiu que a substituição de um método pelo outro é viável além da obtenção dos dados ser mais rápida e objetiva.

Nossos resultados também estão de acordo com os de SILVA ${ }^{100}$, 1999, que em seu estudo se propôs a verificar a atividade da solução de processamento RP X-Omat da Kodak utilizando como parâmetro as Densidades Ótica e Radiográficas obtidas com filme radiográfico TMS-1, exposto no sensitômetro MRA e processado em processadora automática com diferentes temperaturas. Os resultados mostraram maior eficiência da solução 
de processamento nas temperaturas de $31^{\circ} \mathrm{C}$ e $34^{\circ} \mathrm{C}$. A análise estatística mostrou alta correlação entre os valores de Densidade Ótica e da Densidade Radiográfica, mostrando ser possível a substituição do método convencional, com o fotodensitômetro, pelo digital, quando se alcançam as Densidades Radiográficas com o programa de imagem Adobe Photoshop 4.0.

O trabalho de PAVAN $^{83}$, 1999, vem contribuir com nossos resultados uma vez que empregou uma metodologia semelhante à empregada nesta pesquisa. Utilizou filmes radiográficos periapicais Ultraspeed DF-58 da Kodak, processados manualmente em diferentes combinações de temperatura/tempo para comparar estatisticamente a validade deste método (Densidade Radiográfica) com o método convencional de leitura da Densidade Ótica com um fotodensitômetro. Um outro objetivo foi verificar uma possível variação na imagem radiográfica utilizando as temperaturas de $25^{\circ} \mathrm{C}, 30^{\circ} \mathrm{C}, 35^{\circ} \mathrm{C}$ e $40^{\circ} \mathrm{C}$ com diferentes tempos de processamento, comparados com $20^{\circ} \mathrm{C} / 5$ minutos. Concluiu este autor que o uso de imagens digitalizadas pode substituir a avaliação das imagens radiográficas realizadas com um fotodensitômetro, em filmes periapicais processados manualmente. As combinações $25^{\circ} \mathrm{C} / 3$ minutos e $35^{\circ} \mathrm{C} / 1$ minuto, quando comparadas com a padrão $\left(20^{\circ} \mathrm{C} / 5\right.$ minutos) apresentaram maiores valores de Densidade Ótica e Radiográficas em função de permanecerem tempo maior do que o necessário sob a ação dos agentes reveladores; as combinações $35^{\circ} \mathrm{C} / 15 \mathrm{~s}, 40^{\circ} \mathrm{C} / 15 \mathrm{~s}$ e $40^{\circ} \mathrm{C} / 10$ s de revelação apresentaram valores inferiores de Densidades Óticas e Radiográficas e baixa qualidade de imagem. O autor sugere que sejam realizados processamentos com as combinações de $35^{\circ} \mathrm{C} / 45 \mathrm{~s}$ e $40^{\circ} \mathrm{C} / 30 \mathrm{~s}$, quando utilizado o filme radiográfico DF-58 e a solução Kodak Dental para raios $\mathrm{X}$ da Kodak, pronta para uso.

IWAKI $^{57}, 2000$, analisou a atividade da solução de processamento RP X-Omat da Kodak, utilizando para exposição do filme aos raios X, o 
sensitômetro IDIM. Os filmes foram avaliados quanto à Densidade Ótica obtidas com leituras realizadas em um fotodensitômetro e quanto às Densidades Radiográficas, alcançadas com o uso de um programa de imagem, o Digora 2.0. Concluiu a autora que os dois métodos detectaram na mesma proporção a perda da atividade da solução de processamento. Os resultados mostraram alta correlação estatística entre os valores de Densidade Ótica e Radiográfica, sendo estes achados pertinentes aos nossos.

Segundo BROOKS; MILES ${ }^{12}$, a tecnologia vem colaborar cada vez mais na realização de pesquisas quanto a medidas realizadas para o controle de qualidade em Radiologia Odontológica, e de acordo com os resultados observados nas tabelas 21 e 22, podemos concordar com esta afirmação visto que obtivemos alta correlação estatística entre as Densidades Óticas e Densidades Radiográficas em todos os grupos analisados. 


\section{ConClusões}




\section{CONCLUSÕES}

Após a metodologia empregada nesta pesquisa concluiu-se que:

1) As diferentes combinações empregadas produziram no filme Agfa Dentus M2 "Comfort" propriedades sensitométricas com valores muito próximos;

- a solução Agfa Dentus nas três combinações utilizadas $\left(20^{\circ} \mathrm{C} / 5\right.$ minutos, $25^{\circ} \mathrm{C} / 2,5$ minutos e $30^{\circ} \mathrm{C} / 1,25$ minuto), produziu sensibilidade do grupo F para o filme Agfa Dentus M2 "Comfort", dentro das condições padronizadas para este experimento;

- as soluções Kodak e Sillib nas diferentes combinações de temperatura/tempo produziram no filme Agfa Dentus M2 "Comfort", sensibilidade do grupo E;

- o contraste radiográfico para todas as soluções e combinações, permaneceu dentro de uma faixa de normalidade, sendo que o menor contraste foi verificado quando se utilizou a solução Kodak na combinação de $30^{\circ} \mathrm{C} / 1,25$ minuto e o maior com a solução Sillib $25^{\circ} \mathrm{C} / 1$ minuto;

- as latitudes encontradas foram aceitáveis, e a solução Kodak $30^{\circ} \mathrm{C} / 1,25$ minuto, apresentou o maior valor. O menor valor foi observado quando se utilizou a solução Kodak $25^{\circ} \mathrm{C} / 2,5$ minutos;

- a solução Sillib nas três combinações de temperatura/tempo produziu no filme Agfa Dentus M2 "Comfort", propriedades sensitométricas aceitáveis, e por necessitar de um menor tempo de revelação, resulta em ganho de tempo para o profissional;

2) As Densidades Radiográficas apresentaram valores dentro da faixa normal de variação em todos os grupos estudados, assim como os valores de Densidade Ótica. A leitura das Densidades Radiográficas realizadas a partir do programa de imagem Adobe Photoshop 5.0 pode ser utilizada no 
controle de qualidade radiográfica para avaliar o filme radiográfico Agfa Dentus M2 "Comfort" e a atividade das soluções de processamento (Agfa Dentus, Kodak e Sillib), assim como a Densidade Ótica, visto que houve correlação estatística significante entre elas, com um nível de confiança de $95 \%$. 
REFERÊNCIAS BIBLIOGRÁFICAS 


\section{REFERÊNCIAS BIBLIOGRÁFICAS*}

1. ACHUTTI, N.L.A.; TAVANO, O.; ALVARES, L.C. Estudo comparativo das propriedades sensitométricas de dois reveladores para filmes radiográficos periapicais: rápido (Gecker) e convencional. Estomatol. Cult., v.11, n.1, p.47-59, jan./jun. 1977.

2. AKDENIZ, B.G.; LOMÇALI, G. Densitometric evaluation of four radiographic processing solutions. Dentomaxillofac. Radiol., v.27, n.2, p.102-6, Mar. 1998.

3. ALVARES, A.L.G.; ALVARES, L.C.; TAVANO, O. Estudo comparativo entre os filmes radiográficos dentais Agfa-Gevaert, Kodak Ultraspeed e Kodak Ektaspeed processados na solução Kodak. Estomatol. Cult., v.16, n.1, p.8-13, jan./jun. 1986.

4. ALVARES, L.C.; FREITAS, J.A.S. Da imprecisão dos marcadores de tempo de aparelhos de RX odontológicos. Rev. Fac. Odont. USP, v.5, n.3, p.275-84, jul./set. 1967.

5. ALVARES, L.C.; FREITAS, J.A.S.; ESTEVAM, E. Alguns reveladores para filmes radiográficos dentais, estudados através da curva característica. Arq. Cent. Est. Fac. Odont., v.6, n.2, p.20922, jul./dez. 1969.

\footnotetext{
* Normas recomendadas para uso no âmbito da Universidade de São Paulo, com base no documento "Referências Bibliográficas: exemplos", emanado do Conselho Supervisor do Sistema Integrado de Bibliotecas da USP, em reunião de 20 de setembro de 1990.
} 
6. AMERICAN ACADEMY OF DENTAL RADIOLOGY QUALITY ASSURANCE COMMITTEE. Recomendations for quality assurance in dental radiography. Oral Surg., v.55, n.4, p.421-6, Apr. 1983.

7. AMERICAN STANDARDS ASSOCIATION. American standard method for the sensitometry of medical X-ray films: PH 2.9 1964. New York, 1964. p.6-10.

8. BAAR, J.H.; STHEPENS, R.G. Image production with X-rays. In: . Dental radiology: pertinent basic concepts and their applications in clinical practice. Philadelphia, Saunders, 1980. p.53-65.

9. BARATIERI, N.M.M.; TAVANO, O.; NAGEM FILHO, H. Análise do processo de exaustão do revelador e reforçador rápido Kodak para raios X. Estomatol. Cult., v.14, n.1/2, p.61-7, jan./jun. 1984.

10. BORG, E.; GRÖNDAHL, H.G. On the dynamic range of different X ray photon detectors in intra-oral radiography. A comparison of image quality in film, charge-couple device and storage phosphor systems. Dentomaxillofac. Radiol., v.25, n.2, p.82-8, Apr. 1996.

11. BRIDGMAN, J.B.; CAMPBELL, D.J. An update on dental radiology: quality and safety. N. z. dent. J., v.91, n.403, p.16-21, Mar.1995. 
12. BROOKS, S.L.; MILES, D.A. Advances in diagnostic imaging in dentistry. Dent Clin. N. Amer., v.37, n.1, p.91-111, Jan. 1993.

13. BROWN JÚNIOR, C.E. et al. Degradation of dental radiographic processing solutions. J. Amer. dent. Ass., v.87, n.6, p.1200-5, Nov. 1973.

14. BRÜCKER, M.R.; TAVANO, O. Processamento radiográfico: comparação entre o processamento automático e manual. OdontoCienc., v.9, n.1, p.41-4, jul.1990.

15. BRÜCKER, M.R.; TAVANO, O.; COSTA, N.P. Análise do comportamento das soluções RPX-Omat da Kodak através do método sensitométrico. Odonto. Cienc., v.7, n.13, p.37-52, jan. 1992.

16. CARVALHO, I.F.; TAVANO, O. Estudo sensitométrico do reforçador Kodak usado como revelador rápido para filmes radiográficos dentais, em comparação com a solução reveladora convencional (Kodak). Estomat. Cult., v.12, n.1/2, p.67-74, jan./jun. 1982.

17. CASTElO, M.P.G.; TAVANO, O.; LOPES, E.S. Comparação sensitométrica de um revelador rápido (Rayonal) com um revelador convencional (Kodak) para filmes radiográficos periapicais. Estomat. Cult., v.13, n.1, p.12-19, jan./jun. 1983. 
18. CHEN, S.K.; CHIANG, T.C. Digitizing of radiographs with a rollertype CCD scanner. Oral Surg., v.83, n.6, p.719-24, June 1997.

19. CHESNEY, D.N.; CHESNEY, M.O. Sensitometry. In:

Radiographic imaging. Oxford, Blackwell, 1981. p.50-79.

20. CHONG, M.P.; DOCKING, A.R. The sensitometric properties of dental x ray films. Aust. dent. J., v.10, n.5, p.354-60, Oct. 1965.

21. COCLETE, G.A. Avaliação da solução Kodak RP X-OMAT quando utilizada na processadora $T 4$, da DUPONT, quanto às densidades ótica e radiográfica, analisadas pelo fotodensitômetro MRA e pelo sistema digital Digora. Bauru, 1999. 88p. Tese (Doutorado) - Faculdade de Odontologia de Bauru, Universidade de São Paulo.

22. CONOVER, G.L.; HILDEBOLT, C.F.; ANTHONY, D. A comparison of six intra-oral X-ray films. Dentomaxillofac. Radiol., v.24, n.3, p.169-72, Aug. 1995.

23. CONOVER, G.L.; HILDEBOLT, C.F.; ANTHONY, D. Objective and subjective evaluations of Kodak Ektaspeed Plus dental x-ray film. Oral Surg., v.70, n.2, p.246-50, Feb. 1995. 
24. DIHEL, R.; GRATT, B.M.; GOULD, R.G. Radiographic quality control measurements comparing D-speed film, E-speed film, and xeroradiograph. Oral Surg., v.61, n.6, p.635-40, June 1986.

25. DUNN, M.S; KANTOR, M.L. Digital radiology: facts and fictions. J. Amer. dent. Ass., v.124, n.2, p.39-47, Dec. 1993.

26. EASTMAN KODAK COMPANY. Sensitometric properties of $\mathbf{x}$-ray films. Rochester, New York, 1974. p.3-18.

27. ETTER, L.E. Radiation dose reduction by higher voltage dental roentgenography. J. Amer. dent. Ass., v.53, n.2, p.305-9, Sept. 1956.

28. FARMAN, A.G. et al. In vivo comparison of Visualix-2 and Ektaspeed Plus in the assessment of periradicular lesion dimensions. Oral Surg., v.85, n.2, p.203-9, Feb. 1998.

29. FARMAN, T.T.; FARMAN, A.G. Evaluation of a new F speed dental $\mathrm{X}$-ray film. The effect of processing solutions and a comparison with D and E speed films. Dentomaxillofac. Radiol., v.29, n.1, p.41-5, Jan. 2000.

30. FEJLLSTRÖM, C.A. et al. Optimal processing of ektaspeed dental film. Swed Dent. J., v.10, n.4, p.137-43, 1986. 
31. FERREIRA, R.A. Odontologia em imagens. Rev. Ass. paul. cirurg. Dent., v.50, n.3, p.218-28, maio/jun. 1996.

32. FLETCHER, J.C. A comparison of Ektaspeed and Ultra-speed films using manual and automatic processing solutions. Oral Surg., v.63, n.1, p.94-102, Jan. 1987.

33. FONTÃO, F.N.G.K. et al. Estudo sensitométrico de filme periapical, processado em soluções Kodak, à temperatura de $40^{\circ} \mathrm{C}$, com diferentes tempos de revelação. Salusvita, v.16, n.1, p.77-85, 1997.

34. FREDHOLM, V.; JULIN, P. Rapid developing of ektaspeed dental film by increase of temperature. Swed. Dent. J., v.11, n.2, p.121-6, 1987.

35. FREITAS, L. A imagem radiográfica. In: Radiologia bucal: técnicas e interpretação. São Paulo, Pancast, 1992. p.53-63.

36. FREITAS, L. Aparelhos e tubos de raios X. In: FREITAS, A.; ROSA, J.E.; SOUZA, I.F. Radiologia odontológica. 4.ed. São Paulo, Artes Médicas, 1998. p.27-37.

37. FROMMER, H.H.; JAIN, R.K. A comparative clinical study of group D and E dental film. Oral Surg., v.63, n.6, p.738-42, June 1987. 
38. FUCHS, A.W. X-ray film. In: Principles of radiographic exposure and processing. 2.ed. Springfield, Thomas, 1979. p.119.

39. FUJITA, M. et al. Digital image processing of dentomaxillofacial radiographs. Oral Surg., v.64, n.4, p.485-93, Oct. 1987.

40. FUJITA, M. et al. Digital image processing of periapical radiographs. Oral Surg., v.65, n.4, p.490-4, Apr. 1988.

41. GEIST, J.G.; GLEASON, M.J. Densitometric properties of rapid manual processing solutions: Abbreviated versus complete rapid processing. J. Endod., v.21, n.4, p.180-4, Apr. 1995.

42. GHILARDI NETO, T. et al. Características sensitométricas de filmes utilizados em radiologia odontológica. Odont. mod., v.15, n.2, p.6-12, mar. 1988.

43. GOAZ, P.W.; WHITE, S.C. Processing X-ray film. In: Oral radiology, principles and interpretation. 3.ed. St. Louis, Mosby, 1994. p.106-25.

44. GOULD, R.G.; GRATT, B. Technical aspects of a dedicated qualitycontrol system for dental radiology. Oral Surg., v.56, n.4, p.43744, Oct. 1983. 
45. GRATT, B.M.; BEIDEMAN, R.W. Quality assurance. In: GOAZ, P.W.; WHITE, S.C. Oral radiology: principles and interpretation. 2.ed. St. Louis, Mosby, 1987. p.142-60.

46. GRATT, B.M.; GOULD, R.G. Clinical trials of dental radiographic quality control system. Dentomaxillofac. Radiol., v.12, n.1, p.358, 1983.

47. HASHIMOTO, K.; THUNTHY, K.H.; WEINBERG, R. Automatic processing: effects of temperature and time change on sensitometric properties of Ultraspeed and Ektaspeed films. Oral Surg., v.71, n.1, p.120-4, Jan. 1991.

48. HAVUKAINEN, R.; SERVOMAA, A. Characterisitcs curves dental $\mathrm{x}$ ray film. Oral Surg., v.62, n.1, p.107-9, July 1986.

49. HINTZE, H.; CHRISTOFFERSEN, L.; WENZEL, A. In vitro comparison of Kodak Ultraspeed, Ektaspeed, and Ektaspeed Plus, and Agfa M2 Comfort dental x-ray films for the detection of caries. Oral Surg., v.81, n.2, p.240-4, Feb. 1996.

50. HINTZE, H.; WENZEL, A.; JONES, C. In vitro comparison of D and E speed film radiography, RVG, and Visualix digital radiography for the detection of enamel approximal and dentinal occlusal caries lesions. Caries Res., v.28, n.5, p.363-7, Sept./Oct. 1994. 
51. HORTON, P.S. et al. A clinical comparison of speed group D and E dental X-ray films. Oral Surg., v.58, n.1, p.104-8, July 1984.

52. HUDA, W. et al. Comparison of a photostimulable phosphor system with film for dental radiology. Oral Surg., v.83, n.6, p.725-31, June 1997.

53. HUNT, D. In the dark about. Those X ray processors? Dent. Econ., v.71, n.9, p.45-8. Sept. 1981.

54. HURTER, F.; DRIFFIELD, V.C. Photo-chemical investigations and a new method of determination of the sensitiveness of photographic plates. J. Soc. Chem. Industr., v.9, n.31, p.455-96, May 1890.

55. IUCIF, P.P. Análise da solução Agfa dentus D e F utilizada para processamento manual de filmes radiográficos periapicais. Bauru, 1994. 124p. Dissertação (Mestrado) - Faculdade de Odontologia de Bauru, Universidade de São Paulo.

56. IUCIF, P.P.; TAVANO, O. Avaliação da solução Agfa Dentus D e F quando utilizada no processamento manual do filme radiográfico periapical Agfa M2 "Comfort". Rev. Fac. Odont. Bauru, v.3, n.1/4, p.81-6, jan./dez. 1995. 
57. IWAKI, L.C.V. Estudo comparativo das densidades ótica e radiográficas de tiras sensitométricas obtidas no sensitômetro IDIM. Bauru, 2000. 95p. Dissertação (Mestrado) - Faculdade de Odontologia de Bauru, Universidade de São Paulo.

58. KAFFE, I. et al. Densitometric evaluation of three x-ray films with five different developing solutions. Oral Surg., v.57, n.2, p.207-11, Feb. 1984.

59. KAFFE, I. Objective and subjective analysis of the image quality of two E-speed dental X-ray films. Dentomaxillofac. Radiol., v.19, n.2, p.55-8, May 1990.

60. KAFFE, I.; GRATT, B.M. E-speed dental films processed with rapid chemistry: a comparison with D-speed film. Oral Surg., v.64, n.3, p.367-72, Sept. 1987.

61. KAFFE, I.; LITTNER, M.M.; KUSPET, M.E. Densitometric evaluation of intra oral $\mathrm{X}$ ray films: ektaspeed versus ultraspeed. Oral Surg., v.57, n.3, p.338-42, Mar. 1984.

62. KAFFE, I.; LITTNER, M.M.; TAMSE, A. Densitometric evaluation of three x-ray films with five different developing solutions. Oral Surg., v.2, n.57, p.207-11, Feb. 1984. 
63. KERBAUY, W.D.; MORAES, L.C. Processamento digital de imagens de radiografias periapicais subexpostas aos raios X. Rev. Odont. UNESP, v. 25, p.157-170, 1996. Número especial.

64. KLEIER, D.J.; BENNER, S.J.; AVERBACH, R.E. Two dental x-ray films compared for rater preference using endodontic views. Oral Surg., v.59, n.2, p.201-5, Feb. 1985.

65. KOGON, S. et al. The effects of processing variables on the contrast of type D and type E dental film. Dentomaxillofac. Radiol., v.14, n.1, p.65-8, Jan./June 1985.

66. KULLENDORFF, B.; PETERSSON, K.; ROHLIN, M. Direct digital radiography for the detection of periapical bone lesions: a clinical study. Endod. dent. Traumatol., v.13, n.3, p.183-9, Sept. 1997.

67. LANGLAND, O.E.; SIPPY, F.H.; LANGLAIS, R.P. Attenuation and recording the radiographic image. In: . Textbook of dental radiology. 3. ed. Illinois, Thomas, 1984. p.88-129.

68. LANGLAND, O.E.; SIPPY, F.H.; LANGLAIS, R.P. Diagnostic quality of dental radiographs. In: Textbook of dental radiology. 2.ed. Springfield, Thomas, 1984. p.130-52. 
69. LAURIS, J.R.P. SPIRO - Sistema para processamento de imagem radiográfica odontológica. Campinas, 1997. 72p. Dissertação (Mestrado) - Faculdade de Engenharia Elétrica e de Computação, Universidade Estadual de Campinas.

70. LILIENTHAL, B. Minimizing radiation exposure in dental radiology.Hazards and precautions. Aust. dent. J., v.19, n.5, p.302-12, Oct. 1974.

71. LOUZADA, M.J.Q. Avaliações de densidade óssea em imagens radiográficas: estudo em peças ósseas de cães. Rev. bras. Eng., v.14, n.1, p.47-64, jan./jun. 1998.

72. LOUZADA, M.J.Q. Metodologia para avaliação de densidade em imagem radiográfica. Rev. bras. Eng., v.14, n.2, p.37-47, jul./dez. 1998.

73. LOVESTEDT, S.A. O processamento de filmes radiográficos. In: - STAFNE, E.C.; GIBILISCO, J.A. Diagnóstico radiográfico bucal. Rio de Janeiro, Interamericana, 1982. p.431.

74. LUDLOW, J.B.; PLATIN, E.; HILL, C. Densitometric comparisons of Ultra-speed, Ektaspeed and Ektaspeed Plus intraoral films for two processing conditions. Oral Surg., v.79, n.1, p.105-13, Jan. 1995. 
75. LUDLOW, J.B. et al. The efficacy of caries detection using three intraoral films under different processing conditions. J. Amer. dent. Ass., v.128, n.10, p.1401-7, Oct. 1997.

76. MACDAVID, W.D.; TAYLOR, E.E. Quality assurance. In: LANGLAND, O.E.; SIPPY, F.H.; LANGLAIS, R.P. Textbook of dental radiology. 2.ed. Springfield, Thomas, 1984. p.352-66.

77. MADDALOZZO, D.; KNOEPPEL, R.O.; SCHOENFELD, C.M. Performance of seven rapid radiographic processing solutions. Oral Surg., v.69, n.3, p.382-7, Mar. 1990.

78. MANSON-HING, L.R.; MONNIER, P.Y. Radiographic densitometric evaluation of seven processing solutions. Oral Surg., v.39, n.3, p.493-501, Mar. 1975.

79. MANSON-HING, L.R.; PATEL, J.R. Densitometric evaluation of quick X ray developing solutions. Oral Surg., v.43, n.3, p.467-72, Mar. 1977.

80. MATTHEE, M.J.; BECKER, P.J.; SEELIGER, J.E. The effect of varying processing solution temperature on radiographic contrast and relative film speed of dental film. J. dent. Ass. S. Africa, v.45, n.12, p.525-8, Dec. 1990. 
81. MONTEBELO FILHO, A.; TAVANO, O. Degradação da solução Kodak dental em recipientes de plástico com tampas (protegidos) e em recipientes de vidro transparentes (desprotegidos). Rev. Odont. USP, v.7, n.1, p.55-62, jan./mar. 1993.

82. MOYSTAD, A. et al. Detection of approximal caries with a storage phosphor system. A comparison of enhanced digital images with dental X-ray film. Dentomaxillofac. Radiol., v.25, n.4, p.202-6, Sept. 1996.

83. PAVAN, A.J. Avaliação da solução Kodak quando utilizada para o processamento de filmes intrabucais DF-58, no que se refere às densidades ótica e radiográficas analisadas pelo fotodensitômetro MRA e pelo sistema digital Digora. Bauru, 1999. 95p. Tese (Doutorado) - Faculdade de Odontologia de Bauru, Universidade de São Paulo.

84. PESTRITTO, S.T.; ANDERSON, S.J.; BRASELTON, J.A. Comparison of diagnostic quality of dental radiographs produced by five rapid processing techniques. J. Amer. dent. Ass., v.89, n.2, p.353-5, Aug. 1974.

85. PINHO, M.B.; TAVANO, O.; LOPES, E.S. Análise das variações dos tempos de exposição e de revelação dos filmes periapicais Kodak (Ektaspeed) e Agfa Gevaert (Dentus M2). Rev. Odont. USP, v.1, n.1, p.21-30, jan./mar. 1987. 
86. PRICE, C. A method of determinig the sensitometric properties of emulsions and processing techniques in dental radiography. Oral Surg., v.50, n.1, p.94-8, July 1980.

87. PRICE, C. Sensitometric evaluation of a new E-speed dental radiographic film. Dentomaxillofac. Radiol., v.24, n.1, p.30-6, Feb. 1995.

88. PRICE, C. The effects of beam quality and optical density on image quality in dental radiography. Oral Surg., v.62, n.4, p.580-8, Nov. 1986.

89. RIBEIRO, A.; TAVANO, O.; PEREIRA, P.P.I. Avaliação do comportamento da solução Hexa, e de sua degradação, através do método sensitométrico. Rev. Odont. USP, v.2, n.2, p.68-73, maio/jun. 1994.

90. RIBEIRO, R.F.; TAVANO, O. Avaliação da exaustão da solução reveladora Ray em câmara escura portátil de processamento. Rev. Odont. USP, v.7, n.3, p.167-71, jul./set. 1993.

91. RICHARDS, A.G. Roentgen-rays doses in dental roentgenography. J. Amer. dent. Ass., v.56, n.1, p.351-68, Mar. 1958. 
92. RICHARDS, A.G.; COLQUITT, W.N. Reduction in dental x ray exposures over the past 60 years. J. Amer. dent. Ass., v.103, p.713-8, Nov. 1981.

93. RODRIGUES, C.B.F.; TAVANO, O. Avaliação sensitométrica de filmes radiográficos da Kodak processados na processadora automática Dupont Cronex T4, utilizando solução Kodak RPX OMat em diferentes temperaturas. Rev. Fac. Odont. Bauru, v.2, n.2, p.14-22, abr./jun. 1994.

94. ROUT, P.G.J. et al. A comparison of manual and automatic processing in general dental practice. Brit. dent. J., v.181, n.3, p.99-101, Aug. 1996.

95. RUSHTON, V.E.; HORNER, K. The impact of quality control on radiography in general dental practice. Brit. dent. J., v.179, n.7, p.254-61, Oct. 1995.

96. SÁ, M.S.H.; ALVARES, L.C.; TAVANO, O. Análise comparativa de variações de tempos de exposição e revelação no filme radiográfico periapical DF-58. Estomat. Cult., v.16, n.1, p.1-7, jan./mar. 1986.

97. SANDERINK, G.C.H. Imaging: new versus traditional technological. Int. dent. J., v.43, n.4, p.335-42, Aug. 1993. 
98. SILHA, R.E. Methods for reducing patient exposure combined with Kodak ektaspeed dental X ray film. Dent. Radiogr. Photogr., v.54, n.4, p.80-7, 1981.

99. SILHA, R.E. The new Kodak ektaspeed dental X ray film. Dent. Radiogr. Photogr., v.54, n.2, p.32-5, 1981.

100. SILVA, P.G. Comparação das Densidades Ópticas e Radiográficas analisadas pelo fotodensitômetro M.R.A. e pelo "software" Adobe Photoshop 4.0 dos filmes Kodak TMS-1 processados na solução Kodak RP X-OMAT, a diferentes temperaturas na processadora CRONEX T4. Bauru, 1999. 113p. Tese (Doutorado) - Faculdade de Odontologia de Bauru, Universidade de São Paulo.

101. SMITH, N.J.D. The sensitometric evaluation of dental radiographic film. Brit. dent. J., v.129, n.17, p.455-61, Nov. 1970.

102. SONODA, M. et al. Computed radiography utilizing scanning laser stimulated luminescence. Radiology, v.148, n.3, p.833-8, Sept. 1983.

103. SPOSTO, M.R.; TAVANO, O.; LOPES, E.S. Avaliação do comportamento de dois reveladores (Kodak e Sillib) utilizados para filmes radiográficos periapicais, através de estudo sensitométrico. Estomat. Cult., v.13, n.1, p.61-67, jan./jun. 1983. 
104. SULEIMAN, O.H. et al. Radiographic trends of dental officies and dental schools. J. Amer. dent. Ass., v.130, n.5, p. 1104-10, July 1999.

105. SVENSON, B.; PETERSSON, A. A comparison of Flow and Kodak dental X-ray films by means of perceptibility curves. Acta Odont. Scand., v.51, n.2, p.124-8, Apr. 1993.

106. SVENSON, B.; LINDVALL, A.M.; GRÖNDAHL, H.G.A comparison of a new dental X-ray film, Agfa Gevaert Dentus M4, with Kodak Ektaspeed and Ultraspeed dental X-ray films. Dentomaxillofac. Radiol., v.22, n.1, p.7-12, Feb. 1993.

107. SYRIOPOULOS, K. et al. Effects of developer exhaustion on the sensitometric properties of four dental films. Dentomaxillofac. Radiol., v.28, n.2, p.80-8, Mar. 1999.

108. SYRIOPOULOS, K. et al. Sensitometric evaluation of four dental x-ray films using five processing solutions. Dentomaxillofac. Radiol., v.28, n.2, p.73-9, Mar. 1999.

109. TAMBURÚS, J.R. Efeitos das variações da temperatura do revelador sobre o contraste e a densidade radiográfica. Rev. Ass. paul. Cirurg. Dent., v.41, n.4, p.218-21, jul./ago. 1987. 
110. TAVANO, O. Estudo do comportamento de filmes radiográficos periapicais (Rinn, Flow e Kodak) quando processados nos líquidos Continental Hexa, Sillib e Kodak. Determinação das mudanças de $\mathrm{pH}$ e cor e da exaustão destas soluções de processamento. Bauru, 1981. 139p. Tese (Livre Docência) Faculdade de Odontologia de Bauru, Universidade de São Paulo.

111. TAVANO, O. Filmes e métodos de processamento radiográfico. In: FREITAS, A.; ROSA, J.E.; SOUZA, I.F. Radiologia odontológica. 2.ed. São Paulo, Artes Médicas, 1988. p.39-60.

112. TAVANO, O.; ALVARES, L.C. Comparação das propriedades sensitométricas de dois reveladores rápidos (Gecker e Tiplimatic), com um convencional, para filmes radiográficos dentais. Ars curandi Odont., v.4, n.11, p.39-47, fev. 1978.

113. TAVANO, O.; BARATIERI, N.M.M. Processamento radiográfico utilizando a solução monobanho. Rev. gaúcha Odont., v.34, n.2, p.169-76, mar./abr. 1986.

114. TAVANO, O.; ESTEVAM, E. A imagem radiológica. In: ALVARES, L.C.; TAVANO, O. Curso de radiologia em odontologia. 4. ed. São Paulo, Editora Santos, 1998. p.17-43. 
115. TAVANO, O.; RAYMUNDO JÚNIOR, R. Avaliação das mudanças de pH, cor e da degradação da solução processadora Kodak (pó) para raios $\mathrm{X}$, por meio de método sensitométrico. Odont. mod., v.9, n.8, p.7-15, ago. 1982.

116. TAVANO, O.; SILVEIRA, M.M.F. Avaliação da solução Kodak para raios X (líquido concentrado), usada como revelador rápido. Enciclop. bras. Odont., v.2, n.4, p.245-61, 1984.

117. TAVANO, O.; CAPELOZZA, A.L.; FONTÃO, F.N.G.K. Análise sensitométrica de filmes periapicais, processados a temperatura de $35^{\circ} \mathrm{C}$ com diferentes tempos de revelação. Rev. Fac. Odont. Bauru, v.4, n.3/4, p.63-8, jul./dez. 1996.

118. THOROGOOD, D.; HORNER, K.; SMITH, N.J.D. Quality control in the processing of dental radiographs. A pratical guide to sensitometry. Brit. dent. J., v.164, n.9, p.282-7, May 1988.

119. THUNTHY, K.H.; WEINBERG, R. Effects of developer exhaustion on Kodak Ektaspeed Plus, Ektaspeed, and Ultra-speed dental films. Oral Surg., v.79, n.1, p.117-21, Jan. 1995.

120. THUNTHY, K.H.; WEINBERG, R. Sensitometric comparison of Kodak Ektaspeed Plus, Ektaspeed, and Ultra-speed dental films. Oral Surg., v.79, n.1, p.114-6, Jan. 1995. 
121. TJELMELAND, E.M. et al. A perceptibility curve comparison of Ultraspeed and Ektaspeed Plus films. Oral Surg., v.85, n.4, p.4858, Apr. 1998.

122. VAN AKEN, J. A study of some properties of twenty-three different dental x ray films. Oral Surg., v.15, n.11, p.1330-48, Nov. 1962.

123. VAN DER STELT, P.E. Modern radiographic methods in the diagnosis of periodontal disease. Adv. Dent. Res., v.7, n.2, p.158-62, Aug. 1993.

124. VAN DIS, M.L.; BECK, F.M.; MILES, D.A. Video enhancement of dental radiographic films. Oral Surg., v.68, n.2, p.226-31, Aug. 1989.

125. VANDRE, R.H.; WEBBER, R.L. Future trends in dental radiology. Oral Surg., v.80, n.4, p.471-8, Oct. 1995.

126. VILLANYI, A.A. Film sensitivity and kilovoltage in dental radiography. J. S. Calif. Dent. Ass., v.32, p.147-50, Apr. 1964.

127. WAINWRIGHT, W.W. Dental radiation dose: sensitometric method for determination of exposure development factors. Oral Surg., v.16, n.6, p.674-82. June 1963. 
128. WAKOH, M. et al. Comparing the sensitometric properties of dental Xray films. J. Amer. dent. Ass., v.126, n.3, p.341-4, Mar. 1995.

129. WELANDER, U. et al. Basic technical properties of a system for direct acquisition of digital intraoral radiographs. Oral Surg., v.75, n.4, p.506-16, Apr. 1993.

130. WENZEL, A. Current trends in radiographic caries imaging. Oral Surg., v.80, n.5, p.527-39, Feb. 1995.

131. WENZEL, A. Effect of image enhancement for detectability of bone lesions in digitized intraoral radiographs. Scand. J. dent. Res., v.96, p.149-60, 1988.

132. WENZEL, A. Effect of varying gray-scale resolution for detectability of bone lesions in intraoral radiographs digitized for teletransmission. Scand. J. dent. Res., v.95, p.483-92, 1987.

133. WENZEL, A.; GRÖNDAHL, H.G. Direct digital radiography in the dental office. Int. dent. J., v.45, n.1, p.27-34, Feb. 1995.

134. YACOVENCO, A. et al. Programa de garantia de qualidade em radiologia diagnóstica. Rev. bras. Eng., v.10, n.2, p.7-18, 1995. 
135. YACOVENCO, A. et al. Radiología diagnóstica y programa de garantía de calidad: evaluación crítica. Rev. bras. Eng., v.13, n.3, p.69-80, jul. 1997.

136. ZENÓBIO, E.G.; FERREIRA, A.F. Estudo das perdas ósseas periodontais através da imagem radiográfica digitalizada. Rev. gaúcha Odont., v.45, n.1, p.12-4, jan./fev. 1997.

137. ZUBERY, Y.; DOVE, S.B.; EBERSOLE, J. An in vitro study of the characteristics of a computer-aided radiographic evaluation (CARE) system for longitudinal assessment of density changes. $\mathbf{J}$. Periodont. Res., v.28, n.4, p.233-40, July 1993. 
AbStract 


\section{ABSTRACT}

Radiographic quality control is essential in Oral Radiology. Its employment is fairly justified in evaluating radiographic films and processing solutions activity, allowing for reaching a total control in clinic, in a regular basis. The present study has been aimed to the evaluation of the sensytometric properties of the radiographic film Agfa Dentus M2 "Comfort" (sensitivity, contrast and latitude) when processed in Agfa Dentus, Kodak and Sillib solutions, at different combinations: $20^{\circ} \mathrm{C} / 5$ minutes, $25^{\circ} \mathrm{C} / 2,5$ minutes and $30^{\circ} \mathrm{C} / 1,25$ minute for the former two solutions, and $20^{\circ} \mathrm{C} / 2$ minutes, $25^{\circ} \mathrm{C} / 1$ minute and $30^{\circ} \mathrm{C} / 0,5$ minute for the Sillib solution. In achieving these sensitometric properties, characteristic curves have been plotted from the average Optical Densities obtained in four radiographs exposed and processed in each group. The outcomes showed that the film Agfa Dentus M2 "Comfort" reached group F sensitivity when using Agfa Dentus solution in three different combinations, what has been observed in the analysis of the characteristic curves derived from groups 1, 2, and 3 (Agfa Dentus Solution). It has been noticed a leftward bias of the curve relative to the other six groups (Kodak and Sillib solutions). For the Kodak and Sillib solutions, at different combinations, the film reached group E sensitivity. The film has presented contrast within a normality band, ranging from 1,72 (Kodak $30^{\circ} \mathrm{C} / 1,25$ minute) to 2,21 (Sillib $25^{\circ} \mathrm{C} / 1$ minute), at all solutions and combinations taken into effect. The largest latitude has been observed when using Kodak solution at $30^{\circ} \mathrm{C}$ temperature and 1,25 minute development time. The smallest latitude has been observed when using Sillib solution at $25^{\circ} \mathrm{C}$ temperature and one minute development time. It has been concluded that the film Agfa Dentus M2 "Comfort" reached suitable sensytometric properties when processed in the three solutions and at different temperature/development time 
combinations. A second purpose of this work has been to confirm the observation that the Optical Densities measurements can be performed by digital methods, through the use of an image software. Its been concluded that Optical Density and Radiographic Densities can be employed in Oral clinics, in radiographic quality control for the assessment of the activity of processing solutions since that, under the conditions in which this study has been done, there has been a great statistic correlation among the values obtained, with a $95 \%$ confidence level for all the groups. 
Anexos 


\section{ANEXOS}

ANEXO 1 - Tabelas dos resultados das leituras das Densidades Óticas obtidas em dez pontos de cada uma das cinco faixas de exposição, com suas respectivas médias, realizadas no fotodensitômetro MRA, de filmes Agfa Dentus M2 "Comfort", processados na solução Agfa Dentus, na temperatura de $20^{\circ} \mathrm{C}$, por cinco minutos - Grupo 1 (radiografias 1, 2, 3 e 4, respectivamente)

\begin{tabular}{c|c|c|c|c|c|c|c|c|c|c|c}
\hline & 1 & 2 & 3 & 4 & 5 & 6 & 7 & 8 & 9 & 10 & Média \\
\hline $300-0$ & 4,70 & 4,71 & 4,63 & 4,74 & 4,78 & 4,75 & 4,73 & 4,75 & 4,73 & 4,73 & 4,69 \\
\hline $60-1$ & 2,39 & 2,49 & 2,55 & 2,58 & 2,61 & 2,65 & 2,67 & 2,65 & 2,58 & 2,53 & 2,57 \\
\hline $10-2$ & 0,37 & 0,38 & 0,41 & 0,42 & 0,43 & 0,43 & 0,42 & 0,42 & 0,40 & 0,40 & 0,41 \\
\hline $1-3$ & 0,07 & 0,07 & 0,07 & 0,07 & 0,07 & $\mathbf{0 , 0 7}$ & $\mathbf{0 , 0 7}$ & $\mathbf{0 , 0 7}$ & $\mathbf{0 , 0 7}$ & $\mathbf{0 , 0 7}$ & $\mathbf{0 , 0 7}$ \\
\hline DBV - 4 & $\mathbf{0 , 0 7}$ & $\mathbf{0 , 0 6}$ & $\mathbf{0 , 0 7}$ & $\mathbf{0 , 0 7}$ & $\mathbf{0 , 0 6}$ & $\mathbf{0 , 0 6}$ & $\mathbf{0 , 0 6}$ & $\mathbf{0 , 0 6}$ & $\mathbf{0 , 0 6}$ & $\mathbf{0 , 0 6}$ & $\mathbf{0 , 0 6}$ \\
\hline
\end{tabular}

\begin{tabular}{c|c|c|c|c|c|c|c|c|c|c|c}
\hline & 1 & 2 & 3 & 4 & 5 & 6 & 7 & 8 & 9 & 10 & Média \\
\hline $300-0$ & 4,82 & 4,78 & 4,67 & 4,76 & 4,71 & 4,64 & 4,46 & 4,71 & 4,46 & 4.70 & 4,67 \\
\hline $60-1$ & 2,63 & 2,69 & 2,70 & 2,69 & 2,69 & 2,72 & 2,71 & 2,69 & 2,68 & 2,63 & 2,68 \\
\hline $10-2$ & $\mathbf{0 , 4 3}$ & $\mathbf{0 , 4 4}$ & $\mathbf{0 , 4 6}$ & $\mathbf{0 , 4 6}$ & $\mathbf{0 , 4 5}$ & $\mathbf{0 , 4 5}$ & $\mathbf{0 , 4 5}$ & $\mathbf{0 , 4 5}$ & $\mathbf{0 , 4 6}$ & $\mathbf{0 , 4 5}$ & $\mathbf{0 , 4 5}$ \\
\hline $1-3$ & $\mathbf{0 , 0 7}$ & $\mathbf{0 , 0 7}$ & $\mathbf{0 , 0 7}$ & $\mathbf{0 , 0 7}$ & $\mathbf{0 , 0 7}$ & $\mathbf{0 , 0 7}$ & $\mathbf{0 , 0 8}$ & $\mathbf{0 , 0 8}$ & $\mathbf{0 , 0 8}$ & $\mathbf{0 , 0 9}$ & $\mathbf{0 , 0 7}$ \\
\hline DBV - 4 & $\mathbf{0 , 0 6}$ & $\mathbf{0 , 0 7}$ & $\mathbf{0 , 0 7}$ & $\mathbf{0 , 0 7}$ & $\mathbf{0 , 0 8}$ & $\mathbf{0 , 0 8}$ & $\mathbf{0 , 0 8}$ & $\mathbf{0 , 0 7}$ & $\mathbf{0 , 0 6}$ & $\mathbf{0 , 0 6}$ & $\mathbf{0 , 0 7}$ \\
\hline
\end{tabular}

\begin{tabular}{c|c|c|c|c|c|c|c|c|c|c|c}
\hline & 1 & 2 & 3 & 4 & 5 & 6 & 7 & 8 & 9 & 10 & Média \\
\hline $300-0$ & 5,05 & 4,81 & 4,72 & 5,10 & 4,89 & 4,68 & 5,05 & 4,97 & 5,05 & 5,00 & 4,93 \\
\hline $60-1$ & 2,36 & 2,45 & 2,55 & 2,59 & 2,57 & 2,63 & 2,61 & 2,56 & 2,52 & 2,62 & 2,56 \\
\hline $10-2$ & 0,40 & 0,43 & 0,44 & 0,44 & 0,45 & 0,44 & 0,44 & 0,43 & 0,43 & 0,41 & 0,43 \\
\hline $1-3$ & $\mathbf{0 , 0 7}$ & $\mathbf{0 , 0 8}$ & $\mathbf{0 , 0 8}$ & $\mathbf{0 , 0 8}$ & $\mathbf{0 , 0 8}$ & $\mathbf{0 , 0 8}$ & $\mathbf{0 , 0 8}$ & $\mathbf{0 , 0 8}$ & $\mathbf{0 , 0 8}$ & $\mathbf{0 , 0 8}$ & $\mathbf{0 , 0 8}$ \\
\hline DBV - 4 & $\mathbf{0 , 0 7}$ & $\mathbf{0 , 0 7}$ & $\mathbf{0 , 0 7}$ & $\mathbf{0 , 0 8}$ & $\mathbf{0 , 0 8}$ & $\mathbf{0 , 0 8}$ & $\mathbf{0 , 0 8}$ & $\mathbf{0 , 0 8}$ & $\mathbf{0 , 0 8}$ & $\mathbf{0 , 0 7}$ & $\mathbf{0 , 0 8}$ \\
\hline
\end{tabular}




\begin{tabular}{c|c|c|c|c|c|c|c|c|c|c|c}
\hline & 1 & 2 & 3 & 4 & 5 & 6 & 7 & 8 & 9 & 10 & Média \\
\hline $300-0$ & 4,83 & 4,83 & 4,83 & 4,55 & 4,90 & 4,92 & 4,68 & 4,46 & 4,61 & 4,49 & 4,71 \\
\hline $60-1$ & 2,56 & 2,66 & 2,67 & 2,67 & 2,66 & 2,69 & 2,70 & 2,66 & 2,66 & 2,69 & 2,65 \\
\hline $10-2$ & 0,43 & 0,45 & 0,46 & 0,46 & 0,46 & 0,47 & 0,46 & 0,45 & 0,46 & $\mathbf{0 , 4 3}$ & $\mathbf{0 , 4 5}$ \\
\hline $1-3$ & $\mathbf{0 , 0 8}$ & $\mathbf{0 , 0 8}$ & $\mathbf{0 , 0 8}$ & $\mathbf{0 , 0 8}$ & $\mathbf{0 , 0 8}$ & $\mathbf{0 , 0 9}$ & $\mathbf{0 , 0 9}$ & $\mathbf{0 , 0 9}$ & $\mathbf{0 , 0 9}$ & $\mathbf{0 , 1 0}$ & $\mathbf{0 , 0 9}$ \\
\hline DBV - 4 & $\mathbf{0 , 0 8}$ & $\mathbf{0 , 0 8}$ & $\mathbf{0 , 0 9}$ & $\mathbf{0 , 0 8}$ & $\mathbf{0 , 0 8}$ & $\mathbf{0 , 0 8}$ & $\mathbf{0 , 0 8}$ & $\mathbf{0 , 0 8}$ & $\mathbf{0 , 0 8}$ & $\mathbf{0 , 0 8}$ & $\mathbf{0 , 0 8}$ \\
\hline
\end{tabular}

ANEXO 2 - Tabelas dos resultados das leituras das Densidades Óticas obtidas em dez pontos de cada uma das cinco faixas de exposição, com suas respectivas médias, realizadas no fotodensitômetro MRA, de filmes Agfa Dentus M2 "Comfort", processados na solução Agfa Dentus, na temperatura de $25^{\circ} \mathrm{C}$, por 2,5 minutos - Grupo 2 (radiografias 1,2, 3 e 4, respectivamente)

\begin{tabular}{c|c|c|c|c|c|c|c|c|c|c|c}
\hline & 1 & 2 & 3 & 4 & 5 & 6 & 7 & 8 & 9 & 10 & Média \\
\hline $300-0$ & 4,53 & 4,60 & 4,69 & 4,65 & 5,06 & 4,82 & 4,58 & 4,75 & 4,64 & 4,71 & 4,70 \\
\hline $60-1$ & 2,93 & 3,06 & 3,12 & 3,16 & 3,18 & 3,14 & 3,12 & 3,02 & 3,01 & 3,02 & 3,07 \\
\hline $10-2$ & 0,54 & 0,58 & 0,59 & 0,62 & 0,62 & 0,63 & 0,61 & 0,59 & 0,57 & 0,57 & 0,59 \\
\hline $1-3$ & 0,13 & 0,14 & 0,14 & 0,15 & 0,14 & 0,14 & 0,13 & 0,13 & 0,13 & 0,13 & 0,14 \\
\hline DBV - 4 & $\mathbf{0 , 1 2}$ & $\mathbf{0 , 1 3}$ & $\mathbf{0 , 1 3}$ & $\mathbf{0 , 1 4}$ & $\mathbf{0 , 1 4}$ & $\mathbf{0 , 1 4}$ & $\mathbf{0 , 1 3}$ & $\mathbf{0 , 1 3}$ & $\mathbf{0 , 1 3}$ & $\mathbf{0 , 1 2}$ & $\mathbf{0 , 1 3}$ \\
\hline
\end{tabular}

\begin{tabular}{c|c|c|c|c|c|c|c|c|c|c|c}
\hline & 1 & 2 & 3 & 4 & 5 & 6 & 7 & 8 & 9 & 10 & Média \\
\hline $300-0$ & 4,40 & 4,46 & 4,36 & 4,45 & 4,50 & 4,90 & 4,52 & 4,67 & 4,51 & 4,37 & 4,51 \\
\hline $60-1$ & 2,87 & 2,95 & 3,01 & 3,03 & 3,06 & 3,05 & 3,05 & 3,02 & 3,00 & 2,98 & 3,00 \\
\hline $10-2$ & 0,50 & 0,50 & 0,54 & 0,57 & 0,58 & 0,55 & 0,55 & 0,55 & 0,54 & 0,54 & 0,54 \\
\hline $1-3$ & 0,11 & 0,11 & 0,11 & 0,11 & 0,12 & 0,12 & 0,12 & 0,12 & 0,11 & 0,11 & 0,11 \\
\hline DBV - 4 & $\mathbf{0 , 1 1}$ & $\mathbf{0 , 1 3}$ & $\mathbf{0 , 1 2}$ & $\mathbf{0 , 1 3}$ & $\mathbf{0 , 1 2}$ & $\mathbf{0 , 1 3}$ & $\mathbf{0 , 1 2}$ & $\mathbf{0 , 1 2}$ & $\mathbf{0 , 1 1}$ & $\mathbf{0 , 1 1}$ & $\mathbf{0 , 1 2}$ \\
\hline
\end{tabular}

\begin{tabular}{c|c|c|c|c|c|c|c|c|c|c|c}
\hline & 1 & 2 & 3 & 4 & 5 & 6 & 7 & 8 & 9 & 10 & Média \\
\hline $300-0$ & 4,48 & 4,67 & 4,62 & 4,54 & 4,70 & 4,40 & 4,58 & 4,61 & 4,34 & 4,37 & 4,53 \\
\hline $60-1$ & 3,02 & 3,11 & 3,16 & 3,18 & 3,18 & 3,19 & 3,19 & 3,17 & 3,18 & 3,18 & 3,16 \\
\hline $10-2$ & 0,56 & 0,58 & 0,60 & 0,69 & 0,60 & 0,60 & 0,59 & 0,58 & 0,58 & 0,60 & 0,59 \\
\hline $1-3$ & $\mathbf{0 , 1 2}$ & $\mathbf{0 , 1 2}$ & $\mathbf{0 , 1 2}$ & $\mathbf{0 , 1 2}$ & $\mathbf{0 , 1 2}$ & $\mathbf{0 , 1 2}$ & $\mathbf{0 , 1 2}$ & $\mathbf{0 , 1 2}$ & $\mathbf{0 , 1 3}$ & $\mathbf{0 , 1 3}$ & $\mathbf{0 , 1 2}$ \\
\hline DBV - 4 & $\mathbf{0 , 1 2}$ & $\mathbf{0 , 1 2}$ & $\mathbf{0 , 1 3}$ & $\mathbf{0 , 1 3}$ & $\mathbf{0 , 1 3}$ & $\mathbf{0 , 1 2}$ & $\mathbf{0 , 1 2}$ & $\mathbf{0 , 1 2}$ & $\mathbf{0 , 1 2}$ & $\mathbf{0 , 1 2}$ & $\mathbf{0 , 1 2}$ \\
\hline
\end{tabular}




\begin{tabular}{c|c|c|c|c|c|c|c|c|c|c|c}
\hline & 1 & 2 & 3 & 4 & 5 & 6 & 7 & 8 & 9 & 10 & Média \\
\hline $300-0$ & 4,43 & 4,38 & 4,70 & 4,33 & 4,61 & 4,74 & 4,51 & 4,54 & 4,74 & 4,42 & 4,54 \\
\hline $60-1$ & 3,17 & 3,29 & 3,33 & 3,30 & 3,35 & 3,27 & 3,27 & 3,15 & 3,24 & 3,13 & 3,25 \\
\hline $10-2$ & 0,59 & 0,64 & 0,65 & 0,67 & 0,67 & 0,64 & 0,63 & 0,60 & 0,58 & 0,59 & 0,63 \\
\hline $1-3$ & 0,13 & 0,14 & 0,14 & 0,15 & 0,15 & 0,14 & 0,14 & 0,13 & 0,13 & 0,13 & 0,14 \\
\hline DBV - 4 & $\mathbf{0 , 1 3}$ & $\mathbf{0 , 1 4}$ & $\mathbf{0 , 1 4}$ & $\mathbf{0 , 1 3}$ & $\mathbf{0 , 1 4}$ & $\mathbf{0 , 1 4}$ & $\mathbf{0 , 1 3}$ & $\mathbf{0 , 1 3}$ & $\mathbf{0 , 1 3}$ & $\mathbf{0 , 1 3}$ & $\mathbf{0 , 1 3}$ \\
\hline
\end{tabular}

ANEXO 3 - Tabelas dos resultados das leituras das Densidades Óticas obtidas em dez pontos de cada uma das cinco faixas de exposição, com suas respectivas médias, realizadas no fotodensitômetro MRA, de filmes Agfa Dentus M2 "Comfort", processados na solução Agfa Dentus, na temperatura de $30^{\circ} \mathrm{C}$, por 1,25 minuto - Grupo 3 (radiografias 1, 2, 3 e 4, respectivamente)

\begin{tabular}{c|c|c|c|c|c|c|c|c|c|c|c}
\hline & 1 & 2 & 3 & 4 & 5 & 6 & 7 & 8 & 9 & 10 & Média \\
\hline $300-0$ & 4,17 & 4,00 & 4,09 & 4,25 & 4,25 & 4,20 & 4,34 & 4,32 & 4,26 & 4,21 & 4,21 \\
\hline $60-1$ & 2,94 & 2,99 & 3,03 & 3,04 & 3,07 & 3,07 & 3,03 & 2,98 & 2,96 & 3,07 & 3,01 \\
\hline $10-2$ & 0,58 & 0,59 & 0,60 & 0,61 & 0,63 & 0,63 & 0,64 & 0,63 & 0,62 & 0,61 & 0,61 \\
\hline $1-3$ & 0,14 & 0,14 & 0,15 & 0,15 & 0,15 & 0,15 & 0,15 & 0,15 & 0,14 & 0,14 & 0,15 \\
\hline DBV - 4 & $\mathbf{0 , 1 3}$ & $\mathbf{0 , 1 4}$ & $\mathbf{0 , 1 5}$ & $\mathbf{0 , 1 5}$ & $\mathbf{0 , 1 5}$ & $\mathbf{0 , 1 5}$ & $\mathbf{0 , 1 5}$ & $\mathbf{0 , 1 4}$ & $\mathbf{0 , 1 3}$ & $\mathbf{0 , 1 3}$ & $\mathbf{0 , 1 4}$ \\
\hline
\end{tabular}

\begin{tabular}{c|c|c|c|c|c|c|c|c|c|c|c}
\hline & 1 & 2 & 3 & 4 & 5 & 6 & 7 & 8 & 9 & 10 & Média \\
\hline $300-0$ & 4,31 & 4,21 & 4,27 & 4,46 & 3,83 & 4,28 & 4,30 & 4,30 & 4,48 & 4,43 & 4,29 \\
\hline $60-1$ & 3,11 & 3,14 & 3,16 & 3,18 & 3,16 & 3,17 & 3,15 & 3,13 & 3,14 & 3,12 & 3,15 \\
\hline $10-2$ & 0,63 & 0,66 & 0,67 & 0,68 & 0,67 & 0,66 & 0,66 & 0,66 & 0,63 & 0,64 & 0,66 \\
\hline $1-3$ & $\mathbf{0 , 1 6}$ & $\mathbf{0 , 1 7}$ & $\mathbf{0 , 1 7}$ & $\mathbf{0 , 1 7}$ & $\mathbf{0 , 1 7}$ & $\mathbf{0 , 1 7}$ & $\mathbf{0 , 1 8}$ & $\mathbf{0 , 1 7}$ & $\mathbf{0 , 1 7}$ & $\mathbf{0 , 1 7}$ & $\mathbf{0 , 1 7}$ \\
\hline DBV - 4 & $\mathbf{0 , 1 6}$ & $\mathbf{0 , 1 7}$ & $\mathbf{0 , 1 8}$ & $\mathbf{0 , 1 6}$ & $\mathbf{0 , 1 7}$ & $\mathbf{0 , 1 8}$ & $\mathbf{0 , 1 8}$ & $\mathbf{0 , 1 7}$ & $\mathbf{0 , 1 6}$ & $\mathbf{0 , 1 5}$ & $\mathbf{0 , 1 7}$ \\
\hline
\end{tabular}

\begin{tabular}{c|c|c|c|c|c|c|c|c|c|c|c}
\hline & 1 & 2 & 3 & 4 & 5 & 6 & 7 & 8 & 9 & 10 & Média \\
\hline $300-0$ & 4,08 & 4,07 & 4,28 & 4,32 & 4,32 & 4,26 & 4,28 & 4,40 & 4,45 & 4,22 & 4,27 \\
\hline $60-1$ & 2,95 & 2,99 & 3,05 & 3,04 & 3,07 & 3,08 & 3,07 & 3,05 & 3,05 & 3,10 & 3,04 \\
\hline $10-2$ & 0,57 & 0,57 & 0,59 & 0,59 & 0,59 & 0,59 & 0,60 & 0,60 & 0,59 & 0,59 & 0,59 \\
\hline $1-3$ & $\mathbf{0 , 1 1}$ & $\mathbf{0 , 1 2}$ & $\mathbf{0 , 1 2}$ & $\mathbf{0 , 1 2}$ & $\mathbf{0 , 1 2}$ & $\mathbf{0 , 1 2}$ & $\mathbf{0 , 1 2}$ & $\mathbf{0 , 1 2}$ & $\mathbf{0 , 1 2}$ & $\mathbf{0 , 1 2}$ & $\mathbf{0 , 1 2}$ \\
\hline DBV - 4 & $\mathbf{0 , 1 3}$ & $\mathbf{0 , 1 3}$ & $\mathbf{0 , 1 3}$ & $\mathbf{0 , 1 3}$ & $\mathbf{0 , 1 4}$ & $\mathbf{0 , 1 3}$ & $\mathbf{0 , 1 3}$ & $\mathbf{0 , 1 2}$ & $\mathbf{0 , 1 2}$ & $\mathbf{0 , 1 3}$ & $\mathbf{0 , 1 3}$ \\
\hline
\end{tabular}




\begin{tabular}{c|c|c|c|c|c|c|c|c|c|c|c}
\hline & 1 & 2 & 3 & 4 & 5 & 6 & 7 & 8 & 9 & 10 & Média \\
\hline $300-0$ & 4,31 & 3,83 & 3,80 & 4,22 & 4,55 & 4,77 & 4,37 & 4,32 & 4,60 & 3,67 & 3,90 \\
\hline $60-1$ & 2,80 & 2,89 & 2,94 & 2,93 & 2,95 & 2,95 & 2,94 & 2,88 & 2,85 & 2,97 & 2,90 \\
\hline $10-2$ & 0,52 & 0,54 & 0,54 & 0,57 & 0,58 & 0,58 & 0,58 & 0,57 & 0,57 & 0,55 & 0,57 \\
\hline $1-3$ & $\mathbf{0 , 1 2}$ & $\mathbf{0 , 1 2}$ & $\mathbf{0 , 1 2}$ & $\mathbf{0 , 1 3}$ & $\mathbf{0 , 1 3}$ & $\mathbf{0 , 1 4}$ & $\mathbf{0 , 1 3}$ & $\mathbf{0 , 1 3}$ & $\mathbf{0 , 1 3}$ & $\mathbf{0 , 1 2}$ & $\mathbf{0 , 1 3}$ \\
\hline DBV - 4 & $\mathbf{0 , 1 2}$ & $\mathbf{0 , 1 3}$ & $\mathbf{0 , 1 3}$ & $\mathbf{0 , 1 4}$ & $\mathbf{0 , 1 3}$ & $\mathbf{0 , 1 3}$ & $\mathbf{0 , 1 4}$ & $\mathbf{0 , 1 3}$ & $\mathbf{0 , 1 3}$ & $\mathbf{0 , 1 2}$ & $\mathbf{0 , 1 4}$ \\
\hline
\end{tabular}

ANEXO 4 - Tabelas dos resultados das leituras das Densidades Óticas obtidas em dez pontos de cada uma das cinco faixas de exposição, com suas respectivas médias, realizadas no fotodensitômetro MRA, de filmes Agfa Dentus M2 "Comfort", processados na solução Kodak, na temperatura de $20^{\circ} \mathrm{C}$, por cinco minutos - Grupo 4 (radiografias 1, 2, 3 e 4, respectivamente)

\begin{tabular}{c|c|c|c|c|c|c|c|c|c|c|c}
\hline & 1 & 2 & 3 & 4 & 5 & 6 & 7 & 8 & 9 & 10 & Média \\
\hline $300-0$ & 4,01 & 4,04 & 3,99 & 4,19 & 4,28 & 4,14 & 3,93 & 4,12 & 4,18 & 4,22 & 4,11 \\
\hline $60-1$ & 2,71 & 2,72 & 2,73 & 2,73 & 2,74 & 2,74 & 2,76 & 2,77 & 2,77 & 2,75 & 2,74 \\
\hline $10-2$ & 0,53 & 0,54 & 0,54 & 0,54 & 0,54 & 0,54 & 0,53 & 0,53 & 0,52 & 0,51 & 0,53 \\
\hline $1-3$ & 0,13 & 0,13 & 0,12 & 0,12 & 0,12 & 0,12 & 0,12 & 0,12 & 0,12 & 0,13 & 0,12 \\
\hline DBV - 4 & $\mathbf{0 , 1 3}$ & $\mathbf{0 , 1 3}$ & $\mathbf{0 , 1 2}$ & $\mathbf{0 , 1 2}$ & $\mathbf{0 , 1 2}$ & $\mathbf{0 , 1 3}$ & $\mathbf{0 , 1 3}$ & $\mathbf{0 , 1 4}$ & $\mathbf{0 , 1 3}$ & $\mathbf{0 , 1 3}$ & $\mathbf{0 , 1 3}$ \\
\hline
\end{tabular}

\begin{tabular}{c|c|c|c|c|c|c|c|c|c|c|c}
\hline & 1 & 2 & 3 & 4 & 5 & 6 & 7 & 8 & 9 & 10 & Média \\
\hline $300-0$ & 4,12 & 4,16 & 4,16 & 4,09 & 4,22 & 4,24 & 3,95 & 4,15 & 4,13 & 4,07 & 4,13 \\
\hline $60-1$ & 2,54 & 2,60 & 2,63 & 2,68 & 2,71 & 2,68 & 2,68 & 2,70 & 2,70 & 2,68 & 2,66 \\
\hline $10-2$ & 0,49 & 0,50 & 0,51 & 0,52 & 0,52 & 0,53 & 0,53 & 0,53 & 0,53 & 0,53 & 0,52 \\
\hline $1-3$ & 0,11 & 0,11 & 0,12 & 0,12 & 0,12 & 0,13 & 0,12 & 0,12 & 0,12 & 0,12 & 0,12 \\
\hline DBV - 4 & $\mathbf{0 , 1 2}$ & $\mathbf{0 , 1 3}$ & $\mathbf{0 , 1 3}$ & $\mathbf{0 , 1 2}$ & $\mathbf{0 , 1 2}$ & $\mathbf{0 , 1 3}$ & $\mathbf{0 , 1 3}$ & $\mathbf{0 , 1 3}$ & $\mathbf{0 , 1 3}$ & $\mathbf{0 , 1 3}$ & $\mathbf{0 , 1 2}$ \\
\hline
\end{tabular}

\begin{tabular}{c|c|c|c|c|c|c|c|c|c|c|c}
\hline & 1 & 2 & 3 & 4 & 5 & 6 & 7 & 8 & 9 & 10 & Média \\
\hline $300-0$ & 3,92 & 4,35 & 4,40 & 4,49 & 4,40 & 4,66 & 4,16 & 4,26 & 4,30 & $\mathbf{3 , 9 0}$ & 4,28 \\
\hline $60-1$ & 2,54 & 2,56 & 2,59 & 2,64 & 2,66 & 2,69 & 2,71 & 2,70 & 2,68 & 2,67 & 2,66 \\
\hline $10-2$ & 0,51 & 0,52 & 0,52 & 0,53 & 0,54 & 0,53 & 0,54 & 0,53 & 0,53 & 0,52 & 0,53 \\
\hline $1-3$ & 0,13 & 0,13 & 0,13 & 0,13 & 0,13 & $\mathbf{0 , 1 4}$ & $\mathbf{0 , 1 3}$ & $\mathbf{0 , 1 3}$ & $\mathbf{0 , 1 3}$ & $\mathbf{0 , 1 3}$ & $\mathbf{0 , 1 3}$ \\
\hline DBV - 4 & $\mathbf{0 , 1 3}$ & $\mathbf{0 , 1 4}$ & $\mathbf{0 , 1 4}$ & $\mathbf{0 , 1 4}$ & $\mathbf{0 , 1 4}$ & $\mathbf{0 , 1 4}$ & $\mathbf{0 , 1 3}$ & $\mathbf{0 , 1 3}$ & $\mathbf{0 , 1 3}$ & $\mathbf{0 , 1 3}$ & $\mathbf{0 , 1 3}$ \\
\hline
\end{tabular}




\begin{tabular}{c|c|c|c|c|c|c|c|c|c|c|c}
\hline & 1 & 2 & 3 & 4 & 5 & 6 & 7 & 8 & 9 & 10 & Média \\
\hline $300-0$ & 3,27 & 4,17 & 4,28 & 4,22 & 4,18 & 4,25 & 4,32 & 4,22 & 4,36 & 4,16 & 4,14 \\
\hline $60-1$ & 2,55 & 2,56 & 2,57 & 2,59 & 2,61 & 2,61 & 2,59 & 2,57 & 2,57 & 2,53 & 2,57 \\
\hline $10-2$ & 0,50 & 0,50 & 0,51 & 0,51 & 0,51 & 0,51 & 0,50 & 0,50 & 0,50 & 0,50 & 0,50 \\
\hline $1-3$ & 0,13 & 0,13 & 0,13 & 0,13 & 0,13 & 0,13 & 0,12 & 0,13 & 0,13 & 0,13 & 0,13 \\
\hline DBV - 4 & 0,13 & 0,14 & 0,13 & 0,13 & 0,14 & 0,13 & 0,13 & 0,13 & 0,12 & 0,12 & 0,12 \\
\hline
\end{tabular}

ANEXO 5 - Tabelas dos resultados das leituras das Densidades Óticas obtidas em dez pontos de cada uma das cinco faixas de exposição, com suas respectivas médias, realizadas no fotodensitômetro MRA, de filmes Agfa Dentus M2 "Comfort", processados na solução Kodak, na temperatura de $25^{\circ} \mathrm{C}$, por 2,5 minutos - Grupo 5 (radiografias 1, 2, 3 e 4, respectivamente)

\begin{tabular}{c|c|c|c|c|c|c|c|c|c|c|c}
\hline & 1 & 2 & 3 & 4 & 5 & 6 & 7 & 8 & 9 & 10 & Média \\
\hline $300-0$ & 4,58 & 4,69 & 4,45 & 4,65 & 4,66 & 4,66 & 4,66 & 4,62 & 4,83 & 4,89 & 4,67 \\
\hline $60-1$ & 2,58 & 2,61 & 2,61 & 2,61 & 2,61 & 2,60 & 2,60 & 2,61 & 2,59 & 2,53 & 2,59 \\
\hline $10-2$ & 0,49 & 0,49 & 0,49 & 0,50 & 0,49 & 0,49 & 0,49 & 0,49 & 0,48 & 0,48 & 0,49 \\
\hline $1-3$ & $\mathbf{0 , 0 9}$ & $\mathbf{0 , 0 9}$ & $\mathbf{0 , 1 0}$ & $\mathbf{0 , 1 0}$ & $\mathbf{0 , 1 0}$ & $\mathbf{0 , 1 0}$ & $\mathbf{0 , 1 0}$ & $\mathbf{0 , 1 0}$ & $\mathbf{0 , 1 0}$ & $\mathbf{0 , 1 0}$ & $\mathbf{0 , 1 0}$ \\
\hline DBV - 4 & $\mathbf{0 , 1 0}$ & $\mathbf{0 , 1 0}$ & $\mathbf{0 , 1 0}$ & $\mathbf{0 , 1 0}$ & $\mathbf{0 , 1 1}$ & $\mathbf{0 , 1 0}$ & $\mathbf{0 , 1 1}$ & $\mathbf{0 , 1 0}$ & $\mathbf{0 , 1 0}$ & $\mathbf{0 , 0 9}$ & $\mathbf{0 , 1 0}$ \\
\hline
\end{tabular}

\begin{tabular}{c|c|c|c|c|c|c|c|c|c|c|c}
\hline & 1 & 2 & 3 & 4 & 5 & 6 & 7 & 8 & 9 & 10 & Média \\
\hline $300-0$ & 4,70 & 4,58 & 4,75 & 4,52 & 4,85 & 4,87 & 4,77 & 4,88 & 4,66 & 4,68 & 4,73 \\
\hline $60-1$ & 2,53 & 2,54 & 2,54 & 2,55 & 2,57 & 2,56 & 2,55 & 2,53 & 2,48 & 2,49 & 2,53 \\
\hline $10-2$ & 0,47 & 0,47 & 0,47 & 0,47 & 0,47 & 0,47 & 0,46 & 0,46 & 0,46 & 0,46 & 0,47 \\
\hline $1-3$ & $\mathbf{0 , 0 8}$ & $\mathbf{0 , 0 9}$ & $\mathbf{0 , 0 9}$ & $\mathbf{0 , 0 9}$ & $\mathbf{0 , 0 9}$ & $\mathbf{0 , 0 8}$ & $\mathbf{0 , 0 8}$ & $\mathbf{0 , 0 8}$ & $\mathbf{0 , 0 9}$ & $\mathbf{0 , 0 8}$ & $\mathbf{0 , 0 8}$ \\
\hline DBV - 4 & $\mathbf{0 , 1 1}$ & $\mathbf{0 , 1 1}$ & $\mathbf{0 , 1 1}$ & $\mathbf{0 , 1 0}$ & $\mathbf{0 , 1 0}$ & $\mathbf{0 , 0 9}$ & $\mathbf{0 , 1 0}$ & $\mathbf{0 , 1 0}$ & $\mathbf{0 , 1 0}$ & $\mathbf{0 , 1 0}$ & $\mathbf{0 , 0 9}$ \\
\hline
\end{tabular}

\begin{tabular}{c|c|c|c|c|c|c|c|c|c|c|c}
\hline & 1 & 2 & 3 & 4 & 5 & 6 & 7 & 8 & 9 & 10 & Média \\
\hline $300-0$ & 4,64 & 4,59 & 4,55 & 4,52 & 4,77 & 4,73 & 4,80 & 4,76 & 4,78 & 4,59 & 4,67 \\
\hline $60-1$ & 2,65 & 2,68 & 2,68 & 2,68 & 2,66 & 2,67 & 2,63 & 2,62 & 2,65 & 2,59 & 2,65 \\
\hline $10-2$ & 0,52 & 0,52 & 0,52 & 0,52 & 0,51 & 0,51 & 0,50 & 0,50 & 0,50 & 0,49 & 0,51 \\
\hline $1-3$ & $\mathbf{0 , 1 0}$ & $\mathbf{0 , 1 0}$ & $\mathbf{0 , 1 0}$ & $\mathbf{0 , 1 0}$ & $\mathbf{0 , 1 1}$ & $\mathbf{0 , 1 1}$ & $\mathbf{0 , 1 1}$ & $\mathbf{0 , 1 1}$ & $\mathbf{0 , 1 1}$ & $\mathbf{0 , 1 1}$ & $\mathbf{0 , 1 1}$ \\
\hline DBV - 4 & $\mathbf{0 , 1 1}$ & $\mathbf{0 , 1 1}$ & $\mathbf{0 , 1 1}$ & $\mathbf{0 , 1 1}$ & $\mathbf{0 , 1 1}$ & $\mathbf{0 , 1 0}$ & $\mathbf{0 , 1 0}$ & $\mathbf{0 , 1 1}$ & $\mathbf{0 , 1 0}$ & $\mathbf{0 , 1 0}$ & $\mathbf{0 , 1 1}$ \\
\hline
\end{tabular}




\begin{tabular}{c|c|c|c|c|c|c|c|c|c|c|c}
\hline & 1 & 2 & 3 & 4 & 5 & 6 & 7 & 8 & 9 & 10 & Média \\
\hline $300-0$ & 4,79 & 4,60 & 4,41 & 4,68 & 4,83 & 4,64 & 4,72 & 4,55 & 4,67 & 4,88 & 4,68 \\
\hline $60-1$ & 2,64 & 2,68 & 2,69 & 2,69 & 2,70 & 2,68 & 2,68 & 2,68 & 2,64 & 2,64 & 2,67 \\
\hline $10-2$ & 0,51 & 0,52 & 0,51 & 0,52 & 0,51 & 0,51 & 0,50 & 0,51 & 0,50 & 0,51 & 0,51 \\
\hline $1-3$ & 0,09 & 0,11 & 0,11 & 0,10 & 0,10 & 0,09 & 0,10 & 0,10 & 0,10 & $\mathbf{0 , 1 1}$ & $\mathbf{0 , 1 0}$ \\
\hline DBV - 4 & $\mathbf{0 , 1 0}$ & $\mathbf{0 , 1 0}$ & $\mathbf{0 , 0 9}$ & $\mathbf{0 , 0 9}$ & $\mathbf{0 , 0 9}$ & $\mathbf{0 , 0 9}$ & $\mathbf{0 , 0 9}$ & $\mathbf{0 , 0 9}$ & $\mathbf{0 , 0 9}$ & $\mathbf{0 , 1 0}$ & $\mathbf{0 , 0 9}$ \\
\hline
\end{tabular}

ANEXO 6 - Tabelas dos resultados das leituras das Densidades Óticas obtidas em dez pontos de cada uma das cinco faixas de exposição, com suas respectivas médias, realizadas no fotodensitômetro MRA, de filmes Agfa Dentus M2 "Comfort", processados na solução Kodak, na temperatura de $30^{\circ} \mathrm{C}$, por 1,25 minuto - Grupo 6 (radiografias 1, 2, 3 e 4, respectivamente)

\begin{tabular}{c|c|c|c|c|c|c|c|c|c|c|c}
\hline & 1 & 2 & 3 & 4 & 5 & 6 & 7 & 8 & 9 & 10 & Média \\
\hline $300-0$ & 4,52 & 4,52 & 4,62 & 4,64 & 4,62 & 4,60 & 4.56 & 4,57 & 4,58 & 4,60 & 4,59 \\
\hline $60-1$ & 2,83 & 2,85 & 2,88 & 2,91 & 2,91 & 292 & 2,93 & 2,93 & 2,94 & 2,92 & 2,90 \\
\hline $10-2$ & 0,56 & 0,56 & 0,57 & 0,57 & 0,57 & 0,58 & 0,58 & 0,59 & 0,59 & 0,59 & 0,58 \\
\hline $1-3$ & 0,14 & 0,14 & 0,14 & 0,13 & 0,13 & 0,14 & 0,13 & 0,14 & 0,14 & 0,14 & 0,14 \\
\hline DBV - 4 & $\mathbf{0 , 1 4}$ & $\mathbf{0 , 1 4}$ & $\mathbf{0 , 1 3}$ & $\mathbf{0 , 1 3}$ & $\mathbf{0 , 1 4}$ & $\mathbf{0 , 1 3}$ & $\mathbf{0 , 1 3}$ & $\mathbf{0 , 1 3}$ & $\mathbf{0 , 1 3}$ & $\mathbf{0 , 1 3}$ & $\mathbf{0 , 1 3}$ \\
\hline
\end{tabular}

\begin{tabular}{c|c|c|c|c|c|c|c|c|c|c|c}
\hline & 1 & 2 & 3 & 4 & 5 & 6 & 7 & 8 & 9 & 10 & Média \\
\hline $300-0$ & 4,58 & 4,62 & 4,66 & 4,64 & 4,62 & 4,87 & 4,39 & 4,65 & 4,72 & 4,72 & 4,65 \\
\hline $60-1$ & 2,56 & 2,46 & 2,69 & 2,75 & 2,78 & 2,80 & 2,82 & 2,81 & 2,84 & 2,85 & 2,74 \\
\hline $10-2$ & 0,55 & 0,54 & 0,54 & 0,54 & 0,54 & 0,55 & 0,55 & 0,56 & 0,56 & 0,56 & 0,55 \\
\hline $1-3$ & 0,13 & 0,13 & 0,13 & 0,13 & 0,13 & $\mathbf{0 , 1 3}$ & $\mathbf{0 , 1 4}$ & $\mathbf{0 , 1 4}$ & $\mathbf{0 , 1 4}$ & $\mathbf{0 , 1 4}$ & $\mathbf{0 , 1 3}$ \\
\hline DBV - 4 & $\mathbf{0 , 1 4}$ & $\mathbf{0 , 1 3}$ & $\mathbf{0 , 1 3}$ & $\mathbf{0 , 1 3}$ & $\mathbf{0 , 1 3}$ & $\mathbf{0 , 1 3}$ & $\mathbf{0 , 1 3}$ & $\mathbf{0 , 1 3}$ & $\mathbf{0 , 1 3}$ & $\mathbf{0 , 1 3}$ & $\mathbf{0 , 1 3}$ \\
\hline
\end{tabular}

\begin{tabular}{c|c|c|c|c|c|c|c|c|c|c|c}
\hline & 1 & 2 & 3 & 4 & 5 & 6 & 7 & 8 & 9 & 10 & Média \\
\hline $300-0$ & 4,52 & 4,52 & 4,50 & 3,97 & 4,48 & 4,60 & 4,68 & 4,48 & 4,74 & 4,52 & 4,50 \\
\hline $60-1$ & 2,87 & 2,86 & 2,86 & 2,88 & 2,89 & 2,89 & 2,90 & 2,92 & 2,93 & 2,91 & 2,89 \\
\hline $10-2$ & 0,58 & 0,57 & 0,57 & 0,57 & 0,57 & 0,57 & 0,57 & 0,57 & 0,58 & 0,57 & 0,57 \\
\hline $1-3$ & 0,13 & 0,14 & 0,14 & 0,14 & 0,14 & 0,14 & 0,14 & 0,14 & 0,14 & 0,13 & 0,14 \\
\hline DBV - 4 & $\mathbf{0 , 1 3}$ & $\mathbf{0 , 1 3}$ & $\mathbf{0 , 1 3}$ & $\mathbf{0 , 1 3}$ & $\mathbf{0 , 1 3}$ & $\mathbf{0 , 1 3}$ & $\mathbf{0 , 1 2}$ & $\mathbf{0 , 1 2}$ & $\mathbf{0 , 1 3}$ & $\mathbf{0 , 1 3}$ & $\mathbf{0 , 1 3}$ \\
\hline
\end{tabular}




\begin{tabular}{c|c|c|c|c|c|c|c|c|c|c|c}
\hline & 1 & 2 & 3 & 4 & 5 & 6 & 7 & 8 & 9 & 10 & Média \\
\hline $300-0$ & 4,38 & 4,48 & 4,63 & 4,56 & 4,63 & 4,91 & 4,50 & 4,72 & 4,88 & 4,90 & 4,66 \\
\hline $60-1$ & 2,99 & 3,00 & 3,02 & 3,02 & 3,05 & 3,07 & 3,07 & 3,07 & 3,08 & 3,06 & 3,04 \\
\hline $10-2$ & 0,59 & 0,60 & 0,60 & 0,60 & 0,61 & 0,61 & 0,61 & 0,61 & 0,60 & 0,60 & 0,60 \\
\hline $1-3$ & 0,13 & 0,13 & 0,13 & 0,13 & 0,14 & 0,14 & 0,13 & 0,13 & 0,13 & 0,13 & 0,13 \\
\hline DBV - 4 & $\mathbf{0 , 1 3}$ & $\mathbf{0 , 1 3}$ & $\mathbf{0 , 1 3}$ & $\mathbf{0 , 1 3}$ & $\mathbf{0 , 1 3}$ & $\mathbf{0 , 1 3}$ & $\mathbf{0 , 1 3}$ & $\mathbf{0 , 1 3}$ & $\mathbf{0 , 1 3}$ & $\mathbf{0 , 1 3}$ & $\mathbf{0 , 1 3}$ \\
\hline
\end{tabular}

ANEXO 7 - Tabelas dos resultados das leituras das Densidades Óticas obtidas em dez pontos de cada uma das cinco faixas de exposição, com suas respectivas médias, realizadas no fotodensitômetro MRA, de filmes Agfa Dentus M2 "Comfort", processados na solução Sillib, na temperatura de $20^{\circ} \mathrm{C}$, por dois minutos - Grupo 7 (radiografias 1, 2, 3 e 4, respectivamente)

\begin{tabular}{c|c|c|c|c|c|c|c|c|c|c|c}
\hline & 1 & 2 & 3 & 4 & 5 & 6 & 7 & 8 & 9 & 10 & Média \\
\hline $300-0$ & 4,57 & 4,58 & 4,52 & 4,58 & 4,51 & 4,62 & 4,50 & 4,41 & 4,53 & 4,45 & 4,53 \\
\hline $60-1$ & 1,65 & 1,71 & 1,72 & 1,75 & 1,72 & 1,74 & 1,74 & 1,74 & 1,75 & 1,74 & 1,73 \\
\hline $10-2$ & 0,25 & 0,26 & 0,26 & 0,26 & 0,26 & 0,27 & 0,26 & 0,26 & 0,26 & 0,27 & 0,25 \\
\hline $1-3$ & $\mathbf{0 , 0 3}$ & $\mathbf{0 , 0 2}$ & $\mathbf{0 , 0 3}$ & $\mathbf{0 , 0 3}$ & $\mathbf{0 , 0 3}$ & $\mathbf{0 , 0 3}$ & $\mathbf{0 , 0 3}$ & $\mathbf{0 , 0 3}$ & $\mathbf{0 , 0 3}$ & $\mathbf{0 , 0 3}$ & $\mathbf{0 , 0 3}$ \\
\hline DBV -4 & $\mathbf{0 , 0 3}$ & $\mathbf{0 , 0 2}$ & $\mathbf{0 , 0 2}$ & $\mathbf{0 , 0 2}$ & $\mathbf{0 , 0 3}$ & $\mathbf{0 , 0 2}$ & $\mathbf{0 , 0 2}$ & $\mathbf{0 , 0 3}$ & $\mathbf{0 , 0 3}$ & $\mathbf{0 , 0 3}$ & $\mathbf{0 , 0 2}$ \\
\hline
\end{tabular}

\begin{tabular}{c|c|c|c|c|c|c|c|c|c|c|c}
\hline & 1 & 2 & 3 & 4 & 5 & 6 & 7 & 8 & 9 & 10 & Média \\
\hline $300-0$ & 4,84 & 4,73 & 4,80 & 4,80 & 4,76 & 4,62 & 4,45 & 4,76 & 4,86 & 4,86 & 4,75 \\
\hline $60-1$ & 1,57 & 1,58 & 1,61 & 1,64 & 1,64 & 1,66 & 1,66 & 1,68 & 1,67 & 1,67 & 1,64 \\
\hline $10-2$ & 0,24 & 0,24 & 0,24 & 0,25 & 0.25 & 0,25 & 0,25 & 0,25 & 0,25 & 0,25 & 0,25 \\
\hline $1-3$ & $\mathbf{0 , 0 3}$ & $\mathbf{0 , 0 3}$ & $\mathbf{0 , 0 3}$ & $\mathbf{0 , 0 3}$ & $\mathbf{0 , 0 3}$ & $\mathbf{0 , 0 2}$ & $\mathbf{0 , 0 3}$ & $\mathbf{0 , 0 3}$ & $\mathbf{0 , 0 3}$ & $\mathbf{0 , 0 3}$ & $\mathbf{0 , 0 3}$ \\
\hline DBV - 4 & $\mathbf{0 , 0 2}$ & $\mathbf{0 , 0 2}$ & $\mathbf{0 , 0 2}$ & $\mathbf{0 , 0 2}$ & $\mathbf{0 , 0 2}$ & $\mathbf{0 , 0 2}$ & $\mathbf{0 , 0 2}$ & $\mathbf{0 , 0 3}$ & $\mathbf{0 , 0 3}$ & $\mathbf{0 , 0 3}$ & $\mathbf{0 , 0 2}$ \\
\hline
\end{tabular}

\begin{tabular}{c|c|c|c|c|c|c|c|c|c|c|c}
\hline & 1 & 2 & 3 & 4 & 5 & 6 & 7 & 8 & 9 & 10 & Média \\
\hline $300-0$ & 3,42 & 3,51 & 3,32 & 3,14 & 3,75 & 3,62 & 3,13 & 3,39 & 2,98 & 3,13 & 3,34 \\
\hline $60-1$ & 1,64 & 1,66 & 1,67 & 1,68 & 1,69 & 1,70 & 1,72 & 1,72 & 1,71 & 1,71 & 1,70 \\
\hline $10-2$ & 0,25 & 0,25 & 0,26 & 0,25 & 0,26 & 0,26 & 0,26 & 0,26 & 0,27 & 0,28 & 0,26 \\
\hline $1-3$ & $\mathbf{0 , 0 2}$ & $\mathbf{0 , 0 2}$ & $\mathbf{0 , 0 3}$ & $\mathbf{0 , 0 3}$ & $\mathbf{0 , 0 3}$ & $\mathbf{0 , 0 3}$ & $\mathbf{0 , 0 3}$ & $\mathbf{0 , 0 3}$ & $\mathbf{0 , 0 3}$ & $\mathbf{0 , 0 3}$ & $\mathbf{0 , 0 3}$ \\
\hline DBV - 4 & $\mathbf{0 , 0 2}$ & $\mathbf{0 , 0 2}$ & $\mathbf{0 , 0 2}$ & $\mathbf{0 , 0 2}$ & $\mathbf{0 , 0 2}$ & $\mathbf{0 , 0 3}$ & $\mathbf{0 , 0 3}$ & $\mathbf{0 , 0 3}$ & $\mathbf{0 , 0 2}$ & $\mathbf{0 , 0 2}$ & $\mathbf{0 , 0 2}$ \\
\hline
\end{tabular}




\begin{tabular}{c|c|c|c|c|c|c|c|c|c|c|c}
\hline & 1 & 2 & 3 & 4 & 5 & 6 & 7 & 8 & 9 & 10 & Média \\
\hline $300-0$ & 4,42 & 4,48 & 4,54 & 4,54 & 4,59 & 4,41 & 4,64 & 4,49 & 4,50 & 4,53 & 4,51 \\
\hline $60-1$ & 1,56 & 1,63 & 1,67 & 1,70 & 1,68 & 1,69 & 1,70 & 1,69 & 1,68 & 1,73 & 1,67 \\
\hline $10-2$ & 0,25 & 0,25 & 0,26 & 0,27 & 0,26 & 0,26 & 0,26 & 0,26 & 0,27 & 0,27 & 0,26 \\
\hline $1-3$ & $\mathbf{0 , 0 4}$ & $\mathbf{0 , 0 4}$ & $\mathbf{0 , 0 4}$ & $\mathbf{0 , 0 3}$ & $\mathbf{0 , 0 4}$ & $\mathbf{0 , 0 4}$ & $\mathbf{0 , 0 3}$ & $\mathbf{0 , 0 3}$ & $\mathbf{0 , 0 4}$ & $\mathbf{0 , 0 4}$ & $\mathbf{0 , 0 4}$ \\
\hline DBV - 4 & $\mathbf{0 , 0 3}$ & $\mathbf{0 , 0 3}$ & $\mathbf{0 , 0 3}$ & $\mathbf{0 , 0 3}$ & $\mathbf{0 , 0 2}$ & $\mathbf{0 , 0 2}$ & $\mathbf{0 , 0 3}$ & $\mathbf{0 , 0 3}$ & $\mathbf{0 , 0 3}$ & $\mathbf{0 , 0 3}$ & $\mathbf{0 , 0 3}$ \\
\hline
\end{tabular}

ANEXO 8 - Tabelas dos resultados das leituras das Densidades Óticas obtidas em dez pontos de cada uma das cinco faixas de exposição, com suas respectivas médias, realizadas no fotodensitômetro MRA, de filmes Agfa Dentus M2 "Comfort", processados na solução Sillib, na temperatura de $25^{\circ} \mathrm{C}$, por um minuto - Grupo 8 (radiografias 1, 2, 3 e 4, respectivamente)

\begin{tabular}{c|c|c|c|c|c|c|c|c|c|c|c}
\hline & 1 & 2 & 3 & 4 & 5 & 6 & 7 & 8 & 9 & 10 & Média \\
\hline $300-0$ & 4,58 & 4,54 & 4,42 & 4,51 & 4,52 & 4,52 & 4,42 & 4,70 & 4,49 & 4,51 & 4,52 \\
\hline $60-1$ & 1,80 & 1,83 & 1,84 & 1,84 & 1,84 & 1,84 & 1,85 & 1,84 & 1,84 & 1,84 & 1,83 \\
\hline $10-2$ & $\mathbf{0 , 2 8}$ & $\mathbf{0 , 2 8}$ & $\mathbf{0 , 2 8}$ & $\mathbf{0 , 2 8}$ & $\mathbf{0 , 2 8}$ & $\mathbf{0 , 2 8}$ & $\mathbf{0 , 2 8}$ & $\mathbf{0 , 2 8}$ & $\mathbf{0 , 2 8}$ & $\mathbf{0 , 2 8}$ & $\mathbf{0 , 2 8}$ \\
\hline $1-3$ & $\mathbf{0 , 0 4}$ & $\mathbf{0 , 0 4}$ & $\mathbf{0 , 0 4}$ & $\mathbf{0 , 0 4}$ & $\mathbf{0 , 0 3}$ & $\mathbf{0 , 0 3}$ & $\mathbf{0 , 0 4}$ & $\mathbf{0 , 0 4}$ & $\mathbf{0 , 0 4}$ & $\mathbf{0 , 0 4}$ & $\mathbf{0 , 0 4}$ \\
\hline DBV - 4 & $\mathbf{0 , 0 3}$ & $\mathbf{0 , 0 3}$ & $\mathbf{0 , 0 3}$ & $\mathbf{0 , 0 3}$ & $\mathbf{0 , 0 2}$ & $\mathbf{0 , 0 4}$ & $\mathbf{0 , 0 3}$ & $\mathbf{0 , 0 3}$ & $\mathbf{0 , 0 3}$ & $\mathbf{0 , 0 3}$ & $\mathbf{0 , 0 3}$ \\
\hline
\end{tabular}

\begin{tabular}{c|c|c|c|c|c|c|c|c|c|c|c}
\hline & 1 & 2 & 3 & 4 & 5 & 6 & 7 & 8 & 9 & 10 & Média \\
\hline $300-0$ & 4,47 & $\mathbf{4 , 5 3}$ & $\mathbf{4 , 4 6}$ & $\mathbf{4 , 4 7}$ & $\mathbf{4 , 4 5}$ & $\mathbf{4 , 6 2}$ & $\mathbf{4 , 5 0}$ & $\mathbf{4 , 5}$ & $\mathbf{4 , 4 8}$ & $\mathbf{4 , 4 3}$ & $\mathbf{4 , 5 0}$ \\
\hline $\mathbf{6 0}-\mathbf{1}$ & $\mathbf{1 , 6 7}$ & $\mathbf{1 , 6 9}$ & $\mathbf{1 , 7 5}$ & $\mathbf{1 , 7 6}$ & $\mathbf{1 , 7 6}$ & $\mathbf{1 , 7 7}$ & $\mathbf{1 , 7 5}$ & $\mathbf{1 , 7 5}$ & $\mathbf{1 , 7 4}$ & $\mathbf{1 , 7 4}$ & $\mathbf{1 , 7 4}$ \\
\hline $10-2$ & $\mathbf{0 , 2 6}$ & $\mathbf{0 , 2 6}$ & $\mathbf{0 , 2 6}$ & $\mathbf{0 , 2 7}$ & $\mathbf{0 , 2 7}$ & $\mathbf{0 , 2 7}$ & $\mathbf{0 , 2 7}$ & $\mathbf{0 , 2 7}$ & $\mathbf{0 , 2 7}$ & $\mathbf{0 , 2 8}$ & $\mathbf{0 , 2 7}$ \\
\hline $1-3$ & $\mathbf{0 , 0 4}$ & $\mathbf{0 , 0 4}$ & $\mathbf{0 , 0 4}$ & $\mathbf{0 , 0 5}$ & $\mathbf{0 , 0 4}$ & $\mathbf{0 , 0 4}$ & $\mathbf{0 , 0 5}$ & $\mathbf{0 , 0 4}$ & $\mathbf{0 , 0 4}$ & $\mathbf{0 , 0 4}$ & $\mathbf{0 , 0 4}$ \\
\hline DBV - 4 & $\mathbf{0 , 0 3}$ & $\mathbf{0 , 0 4}$ & $\mathbf{0 , 0 4}$ & $\mathbf{0 , 0 4}$ & $\mathbf{0 , 0 4}$ & $\mathbf{0 , 0 3}$ & $\mathbf{0 , 0 5}$ & $\mathbf{0 , 0 4}$ & $\mathbf{0 , 0 4}$ & $\mathbf{0 , 0 4}$ & $\mathbf{0 , 0 4}$ \\
\hline
\end{tabular}

\begin{tabular}{c|c|c|c|c|c|c|c|c|c|c|c}
\hline & 1 & 2 & 3 & 4 & 5 & 6 & 7 & 8 & 9 & 10 & Média \\
\hline $300-0$ & 4,59 & 4,58 & $\mathbf{4 , 5 2}$ & $\mathbf{4 , 5 8}$ & $\mathbf{4 , 5 9}$ & $\mathbf{4 , 7 4}$ & $\mathbf{4 , 5 9}$ & $\mathbf{4 , 5 1}$ & $\mathbf{4 , 6 3}$ & $\mathbf{4 , 4 3}$ & $\mathbf{4 , 5 8}$ \\
\hline $\mathbf{6 0}-\mathbf{1}$ & $\mathbf{1 , 7 8}$ & $\mathbf{1 , 8 2}$ & $\mathbf{1 , 8 2}$ & $\mathbf{1 , 8 4}$ & $\mathbf{1 , 8 4}$ & $\mathbf{1 , 8 4}$ & $\mathbf{1 , 8 4}$ & $\mathbf{1 , 8 5}$ & $\mathbf{1 , 8 4}$ & $\mathbf{1 , 8 4}$ & $\mathbf{1 , 8 3}$ \\
\hline $10-2$ & $\mathbf{0 , 2 8}$ & $\mathbf{0 , 2 8}$ & $\mathbf{0 , 2 8}$ & $\mathbf{0 , 2 9}$ & $\mathbf{0 , 2 9}$ & $\mathbf{0 , 2 9}$ & $\mathbf{0 , 2 8}$ & $\mathbf{0 , 2 9}$ & $\mathbf{0 , 2 8}$ & $\mathbf{0 , 2 9}$ & $\mathbf{0 , 2 8}$ \\
\hline $1-3$ & $\mathbf{0 , 0 5}$ & $\mathbf{0 , 0 4}$ & $\mathbf{0 , 0 4}$ & $\mathbf{0 , 0 5}$ & $\mathbf{0 , 0 5}$ & $\mathbf{0 , 0 5}$ & $\mathbf{0 , 0 4}$ & $\mathbf{0 , 0 4}$ & $\mathbf{0 , 0 4}$ & $\mathbf{0 , 0 4}$ & $\mathbf{0 , 0 4}$ \\
\hline DBV - 4 & $\mathbf{0 , 0 5}$ & $\mathbf{0 , 0 5}$ & $\mathbf{0 , 0 6}$ & $\mathbf{0 , 0 5}$ & $\mathbf{0 , 0 5}$ & $\mathbf{0 , 0 5}$ & $\mathbf{0 , 0 5}$ & $\mathbf{0 , 0 4}$ & $\mathbf{0 , 0 4}$ & $\mathbf{0 , 0 4}$ & $\mathbf{0 , 0 5}$ \\
\hline
\end{tabular}




\begin{tabular}{c|c|c|c|c|c|c|c|c|c|c|c}
\hline & 1 & 2 & 3 & 4 & 5 & 6 & 7 & 8 & 9 & 10 & Média \\
\hline $300-0$ & 4,27 & 4,40 & 4,43 & 4,52 & 4,59 & 4,66 & 4,68 & 4,49 & 4,53 & 4,43 & 4,50 \\
\hline $60-1$ & 1,71 & 1,74 & 1,75 & 1,74 & 1,75 & 1,78 & 1,78 & 1,78 & 1,79 & 1,81 & 1,75 \\
\hline $10-2$ & 0,27 & 0,27 & 0,27 & 0,28 & 0,27 & 0,28 & 0,28 & 0,28 & 0,28 & 0,29 & 0,28 \\
\hline $1-3$ & $\mathbf{0 , 0 4}$ & $\mathbf{0 , 0 4}$ & $\mathbf{0 , 0 5}$ & $\mathbf{0 , 0 5}$ & $\mathbf{0 , 0 4}$ & $\mathbf{0 , 0 4}$ & $\mathbf{0 , 0 4}$ & $\mathbf{0 , 0 4}$ & $\mathbf{0 , 0 4}$ & $\mathbf{0 , 0 4}$ & $\mathbf{0 , 0 4}$ \\
\hline DBV - 4 & $\mathbf{0 , 0 4}$ & $\mathbf{0 , 0 4}$ & $\mathbf{0 , 0 4}$ & $\mathbf{0 , 0 4}$ & $\mathbf{0 , 0 5}$ & $\mathbf{0 , 0 4}$ & $\mathbf{0 , 0 5}$ & $\mathbf{0 , 0 4}$ & $\mathbf{0 , 0 4}$ & $\mathbf{0 , 0 4}$ & $\mathbf{0 , 0 4}$ \\
\hline
\end{tabular}

ANEXO 9 - Tabelas dos resultados das leituras das Densidades Óticas obtidas em dez pontos de cada uma das cinco faixas de exposição, com suas respectivas médias, realizadas no fotodensitômetro MRA, de filmes Agfa Dentus M2 "Comfort", processados na solução Sillib, na temperatura de $30^{\circ} \mathrm{C}$, por 0,5 minuto - Grupo 9 (radiografias 1, 2, 3 e 4, respectivamente)

\begin{tabular}{c|c|c|c|c|c|c|c|c|c|c|c}
\hline & 1 & 2 & 3 & 4 & 5 & 6 & 7 & 8 & 9 & 10 & Média \\
\hline $300-0$ & 4,80 & 4,67 & 4,50 & 4,48 & 4,54 & 4,35 & 4,57 & 4,65 & 4,64 & 4,69 & 4,59 \\
\hline $60-1$ & 2,14 & 2,13 & 2,16 & 2,15 & 2,15 & 2,16 & 2,16 & 2,16 & 2,16 & 2,16 & 2,15 \\
\hline $10-2$ & 0,32 & 0,33 & 0,32 & 0,33 & 0,33 & 0,33 & 0,33 & 0,34 & 0,33 & 0,34 & 0,33 \\
\hline $1-3$ & $\mathbf{0 , 0 4}$ & $\mathbf{0 , 0 4}$ & $\mathbf{0 , 0 5}$ & $\mathbf{0 , 0 5}$ & $\mathbf{0 , 0 4}$ & $\mathbf{0 , 0 4}$ & $\mathbf{0 , 0 4}$ & $\mathbf{0 , 0 4}$ & $\mathbf{0 , 0 4}$ & $\mathbf{0 , 0 4}$ & $\mathbf{0 , 0 4}$ \\
\hline DBV - 4 & $\mathbf{0 , 0 5}$ & $\mathbf{0 , 0 4}$ & $\mathbf{0 , 0 4}$ & $\mathbf{0 , 0 5}$ & $\mathbf{0 , 0 4}$ & $\mathbf{0 , 0 4}$ & $\mathbf{0 , 0 5}$ & $\mathbf{0 , 0 4}$ & $\mathbf{0 , 0 4}$ & $\mathbf{0 , 0 4}$ & $\mathbf{0 , 0 4}$ \\
\hline
\end{tabular}

\begin{tabular}{c|c|c|c|c|c|c|c|c|c|c|c}
\hline & 1 & 2 & 3 & 4 & 5 & 6 & 7 & 8 & 9 & 10 & Média \\
\hline $300-0$ & 4,56 & 4,51 & 4,52 & 4,42 & 4,48 & 4,60 & 4,51 & 4,36 & 4,52 & 4,50 & 4,50 \\
\hline $60-1$ & 1,97 & 2,03 & 2,05 & 2,07 & 2,09 & 2,09 & 2,09 & 2,08 & 2,09 & 2,05 & $\mathbf{2 , 0 6}$ \\
\hline $10-2$ & $\mathbf{0 , 3 1}$ & $\mathbf{0 , 3 2}$ & $\mathbf{0 , 3 1}$ & $\mathbf{0 , 3 2}$ & $\mathbf{0 , 3 1}$ & $\mathbf{0 , 3 2}$ & $\mathbf{0 , 3 2}$ & $\mathbf{0 , 3 1}$ & $\mathbf{0 , 3 2}$ & $\mathbf{0 , 3 2}$ & $\mathbf{0 , 3 2}$ \\
\hline $1-3$ & $\mathbf{0 , 0 5}$ & $\mathbf{0 , 0 5}$ & $\mathbf{0 , 0 5}$ & $\mathbf{0 , 0 4}$ & $\mathbf{0 , 0 4}$ & $\mathbf{0 , 0 5}$ & $\mathbf{0 , 0 5}$ & $\mathbf{0 , 0 5}$ & $\mathbf{0 , 0 4}$ & $\mathbf{0 , 0 5}$ & $\mathbf{0 , 0 5}$ \\
\hline DBV - 4 & $\mathbf{0 , 0 5}$ & $\mathbf{0 , 0 5}$ & $\mathbf{0 , 0 5}$ & $\mathbf{0 , 0 4}$ & $\mathbf{0 , 0 4}$ & $\mathbf{0 , 0 5}$ & $\mathbf{0 , 0 5}$ & $\mathbf{0 , 0 5}$ & $\mathbf{0 , 0 5}$ & $\mathbf{0 , 0 5}$ & $\mathbf{0 , 0 5}$ \\
\hline
\end{tabular}

\begin{tabular}{c|c|c|c|c|c|c|c|c|c|c|c}
\hline & 1 & 2 & 3 & 4 & 5 & 6 & 7 & 8 & 9 & 10 & Média \\
\hline $300-0$ & 4,36 & 4,22 & 4,14 & 4,18 & $\mathbf{4 , 2 5}$ & $\mathbf{4 , 3 3}$ & $\mathbf{4 , 1 1}$ & $\mathbf{4 , 2 1}$ & $\mathbf{4 , 1 6}$ & $\mathbf{4 , 2 1}$ & $\mathbf{4 , 2 2}$ \\
\hline $\mathbf{6 0}-1$ & $\mathbf{1 , 9 4}$ & $\mathbf{1 , 9 6}$ & $\mathbf{1 , 9 6}$ & $\mathbf{1 , 9 6}$ & $\mathbf{1 , 9 6}$ & $\mathbf{1 , 9 7}$ & $\mathbf{1 , 9 9}$ & $\mathbf{2 , 0 0}$ & $\mathbf{2 , 0 3}$ & $\mathbf{1 , 9 8}$ & $\mathbf{1 , 9 7}$ \\
\hline $10-2$ & $\mathbf{0 , 3 0}$ & $\mathbf{0 , 3 0}$ & $\mathbf{0 , 3 1}$ & $\mathbf{0 , 3 1}$ & $\mathbf{0 , 3 1}$ & $\mathbf{0 , 3 2}$ & $\mathbf{0 , 3 2}$ & $\mathbf{0 , 3 0}$ & $\mathbf{0 , 3 0}$ & $\mathbf{0 , 3 0}$ & $\mathbf{0 , 3 1}$ \\
\hline $1-3$ & $\mathbf{0 , 0 4}$ & $\mathbf{0 , 0 5}$ & $\mathbf{0 , 0 5}$ & $\mathbf{0 , 0 5}$ & $\mathbf{0 , 0 5}$ & $\mathbf{0 , 0 5}$ & $\mathbf{0 , 0 5}$ & $\mathbf{0 , 0 5}$ & $\mathbf{0 , 0 5}$ & $\mathbf{0 , 0 5}$ & $\mathbf{0 , 0 5}$ \\
\hline DBV -4 & $\mathbf{0 , 0 5}$ & $\mathbf{0 , 0 5}$ & $\mathbf{0 , 0 5}$ & $\mathbf{0 , 0 4}$ & $\mathbf{0 , 0 4}$ & $\mathbf{0 , 0 4}$ & $\mathbf{0 , 0 4}$ & $\mathbf{0 , 0 4}$ & $\mathbf{0 , 0 4}$ & $\mathbf{0 , 0 4}$ & $\mathbf{0 , 0 4}$ \\
\hline
\end{tabular}




\begin{tabular}{c|c|c|c|c|c|c|c|c|c|c|c}
\hline & 1 & 2 & 3 & 4 & 5 & 6 & 7 & 8 & 9 & 10 & Média \\
\hline $300-0$ & 4,33 & 4,31 & 4,29 & 4,35 & 4,52 & 4,35 & 4,38 & 4,31 & 4,36 & 4,30 & 4,35 \\
\hline $60-1$ & 2,05 & 2,08 & 2,07 & 2,08 & 2,11 & 2,11 & 2,12 & 2,14 & 2,11 & 2,10 & 2,10 \\
\hline $10-2$ & 0,31 & 0,32 & 0,32 & 0,32 & 0,32 & 0,32 & 0,32 & 0,33 & 0,33 & 0,34 & 0,32 \\
\hline $1-3$ & $\mathbf{0 , 0 4}$ & $\mathbf{0 , 0 4}$ & $\mathbf{0 , 0 4}$ & $\mathbf{0 , 0 5}$ & $\mathbf{0 , 0 5}$ & $\mathbf{0 , 0 5}$ & $\mathbf{0 , 0 5}$ & $\mathbf{0 , 0 5}$ & $\mathbf{0 , 0 5}$ & $\mathbf{0 , 0 5}$ & $\mathbf{0 , 0 5}$ \\
\hline DBV - 4 & $\mathbf{0 , 0 5}$ & $\mathbf{0 , 0 6}$ & $\mathbf{0 , 0 5}$ & $\mathbf{0 , 0 5}$ & $\mathbf{0 , 0 4}$ & $\mathbf{0 , 0 4}$ & $\mathbf{0 , 0 4}$ & $\mathbf{0 , 0 4}$ & $\mathbf{0 , 0 5}$ & $\mathbf{0 , 0 5}$ & $\mathbf{0 , 0 5}$ \\
\hline
\end{tabular}


ANEXO 10 - Média das Densidades Radiográficas do filme Agfa Dentus M2 “Comfort”, nas cinco faixas de exposição, (impulsos) nas diferentes combinações de solução/ temperatura/tempo (nove grupos), obtidas com a leitura no programa de imagem Adobe Photoshop 5.0

\begin{tabular}{|c|c|c|c|c|c|c|c|c|c|c|c|c|c|c|c|c|c|c|}
\hline & \multicolumn{2}{|c|}{$\begin{array}{c}\text { Agfa } \\
20^{\circ} \mathrm{C} / 5 \mathrm{~min} . \\
\end{array}$} & \multicolumn{2}{|c|}{\begin{tabular}{|c|} 
Agfa \\
$25^{\circ} \mathrm{C} / 2,5$ min. \\
\end{tabular}} & \multicolumn{2}{|c|}{$\begin{array}{c}\text { Agfa } \\
30^{\circ} \mathrm{C} / 1,25 \min . \\
\end{array}$} & \multicolumn{2}{|c|}{$\begin{array}{c}\text { Kodak } \\
20^{\circ} \mathrm{C} / 5 \mathrm{~min} .\end{array}$} & \multicolumn{2}{|c|}{\begin{tabular}{|c|} 
Kodak \\
$25^{\circ} \mathrm{C} / 2,5$ min. \\
\end{tabular}} & \multicolumn{2}{|c|}{\begin{tabular}{|c|} 
Kodak \\
$30^{\circ} \mathrm{C} / \mathbf{1}, 25 \mathrm{~min}$. \\
\end{tabular}} & \multicolumn{2}{|c|}{$\begin{array}{c}\text { Sillib } \\
20^{\circ} \mathrm{C} / 2 \mathrm{~min} . \\
\end{array}$} & \multicolumn{2}{|c|}{$\begin{array}{c}\text { Sillib } \\
25^{\circ} \mathrm{C} / 1 \mathrm{~min} .\end{array}$} & \multicolumn{2}{|c|}{$\begin{array}{c}\text { Sillib } \\
\mathbf{3 0}^{\circ} \mathbf{C} / \mathbf{0 , 5} \text { min. } \\
\end{array}$} \\
\hline & D.R. & D.R.i & D.R. & D.R.i & D.R. & D.R.i & D.R. & D.R.i & D.R. & D.R.i & D.R & D.R.i & D.R. & D.R.i & D.R. & D.R.i & D.R. & D.R.i \\
\hline $300-0$ & 3 & 252 & 5 & 249 & 5 & 250 & 6 & 249 & 5 & 250 & 4 & 251 & 5 & 250 & 5 & 250 & 5 & 250 \\
\hline $60-1$ & 4 & 251 & 5 & 249 & 4 & 250 & 7 & 248 & 5 & 249 & 4 & 251 & 21 & 234 & 18 & 237 & 12 & 243 \\
\hline $10-2$ & 132 & 123 & 115 & 140 & 113 & 141 & 125 & 130 & 124 & 131 & 116 & 139 & 162 & 93 & 160 & 95 & 155 & 100 \\
\hline $1-3$ & 189 & 66 & 182 & 73 & 180 & 74 & 185 & 70 & 184 & 71 & 180 & 74 & 201 & 53 & 201 & 54 & 201 & 54 \\
\hline DBV - 4 & 190 & 65 & 184 & 71 & 181 & 74 & 185 & 70 & 182 & 72 & 180 & 74 & 202 & 53 & 201 & 54 & 201 & 54 \\
\hline
\end{tabular}


ANEXO 11 - Média das Densidades Óticas e Densidades Radiográficas do filme Agfa Dentus M2 “Comfort”, nas cinco faixas de exposição (impulsos), das diferentes combinações solução/temperatura/tempo (nove grupos).

\begin{tabular}{|c|c|c|c|c|c|c|c|c|c|c|c|c|c|c|c|c|c|c|c|c|c|c|c|c|c|c|c|}
\hline & \multicolumn{3}{|c|}{$\begin{array}{c}\text { Agfa } \\
20^{\circ} \mathrm{C} / 5 \mathrm{~min} .\end{array}$} & \multicolumn{3}{|c|}{$\begin{array}{c}\text { Agfa } \\
2^{\circ} \mathrm{C} / 2,5 \mathrm{~min} .\end{array}$} & \multicolumn{3}{|c|}{$\begin{array}{c}\text { Agfa } \\
30^{\circ} \mathrm{C} / 1,25 \mathrm{~min} .\end{array}$} & \multicolumn{3}{|c|}{$\begin{array}{c}\text { Kodak } \\
20^{\circ} \mathrm{C} / 5 \mathrm{~min} .\end{array}$} & \multicolumn{3}{|c|}{$\begin{array}{c}\text { Kodak } \\
2^{\circ} \mathrm{C} / 2,5 \mathrm{~min} .\end{array}$} & \multicolumn{3}{|c|}{$\begin{array}{c}\text { Kodak } \\
\mathbf{3 0}^{\circ} \mathrm{C} / \mathbf{1}, \mathbf{2 5 m i n} .\end{array}$} & \multicolumn{3}{|c|}{$\begin{array}{c}\text { Sillib } \\
20^{\circ} \mathrm{C} / 2 \mathrm{~min} .\end{array}$} & \multicolumn{3}{|c|}{$\begin{array}{c}\text { Sillib } \\
25^{\circ} \mathrm{C} / 1 \mathrm{~min} .\end{array}$} & \multicolumn{3}{|c|}{$\begin{array}{c}\text { Sillib } \\
\mathbf{3 0}^{\circ} \mathrm{C} / \mathbf{0 , 5} \mathrm{min} .\end{array}$} \\
\hline & D.O. & D.R. & D.R.i & D.O. & D.F & D.R.i & D.O. & D.R & D.R.i & D.O. & D.R. & D.R.i & D.O. & D.R. & D.R.i & D.O. & D.R. & D.R.i & D.O. & D.R. & D.R.i & D.O. & D.R. & D.R.i & D.O. & D.R. & D.R.i \\
\hline $300-0$ & 4,75 & 3 & 252 & 4,57 & 5 & 249 & 4,18 & 5 & 250 & 4,16 & 6 & 249 & 4,69 & 5 & 250 & 4,60 & 4 & 251 & 4,28 & 5 & 250 & 4,52 & 5 & 250 & 4,41 & 5 & 250 \\
\hline $60-1$ & 2,61 & 4 & 251 & 3,12 & 5 & 249 & 3,02 & 4 & 250 & 2,66 & 7 & 248 & 2,61 & 5 & 249 & 2,90 & 4 & 251 & 1,68 & 21 & 234 & 1,79 & 18 & 237 & 2,07 & 12 & 243 \\
\hline $10-2$ & 0,43 & 132 & 123 & 0,59 & 11 & 140 & 0,61 & 113 & 141 & 0,52 & 125 & 130 & 0,49 & 124 & 131 & 0,57 & 116 & 139 & 0,25 & 162 & 93 & 0,28 & 160 & 95 & 0,32 & 155 & 100 \\
\hline $1-3$ & 0,08 & 189 & 66 & 0,13 & 18 & 73 & 0,14 & 180 & 74 & 0,12 & 185 & 70 & 0,10 & 184 & 71 & 0,13 & 180 & 74 & 0,03 & 201 & 53 & 0,04 & 201 & 54 & 0,05 & 201 & 54 \\
\hline DBV - 4 & 0,07 & 190 & 65 & 0,12 & 18 & 71 & 0,14 & 18 & 74 & 0,12 & 185 & 70 & 0,10 & 182 & 72 & 0,13 & 180 & 74 & 0,02 & 202 & 53 & 0,04 & 201 & 54 & 0,04 & 201 & 54 \\
\hline Média & 1,59 & 104 & 151 & 1,71 & 98 & 157 & 1,62 & 97 & 158 & 1,52 & 102 & 153 & 1,60 & 100 & 155 & 1,67 & 97 & 158 & 1,25 & 118 & 137 & 1,33 & 117 & 138 & 1,38 & 115 & 140 \\
\hline
\end{tabular}

